\title{
PROJETO ESTRUTURAL DE VIGAS DE CONCRETO DE ALTO DESEMPENHO
}

JOÃO PAULO DE ANDRADE JÚNIOR

Dissertação apresentada à Escola de Engenharia de São Carlos, da Universidade de São Paulo, como parte dos requisitos para obtenção do Título de Mestre em Engenharia de Estruturas.

ORIENTADOR: Prof. Dr. Libânio Miranda Pinheiro

São Carlos

1999 


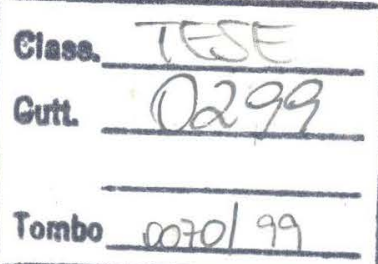

Ficha catalográfica preparada pela Seção de Tratamento da Informação do Serviço de Biblioteca - EESC/USP

A553p

Andrade Júnior, João Paulo de

Projeto estrutural de vigas de concreto de alto desempenho / João Paulo de Andrade Júnior. -- São Carlos, 1999.

Dissertação (Mestrado) -- Escola de Engenharia de São Carlos-Universidade de São Paulo, 1999.

Área: Engenharia de Estruturas.

orientador: Prof. Dr. Libânio Miranda Pinheiro.

1. Concreto de alto desempenho. 2. Vigas.

3. Dimensionamento. I. Título. 
Candidato: Engenheiro JOÃO PAULO DE ANDRADE JUNIOR

Dissertação defendida e aprovada em 10-02-1999

pela Comissão Julgadora:

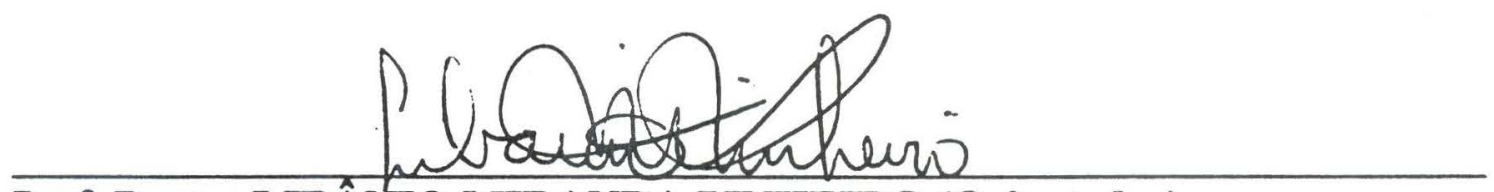

Prof. Doutor LIBÂNIO MIRANDA PINHEIRO (Orientador)

(Escola de Engenharia de São Carlos - Universidade de São Paulo)

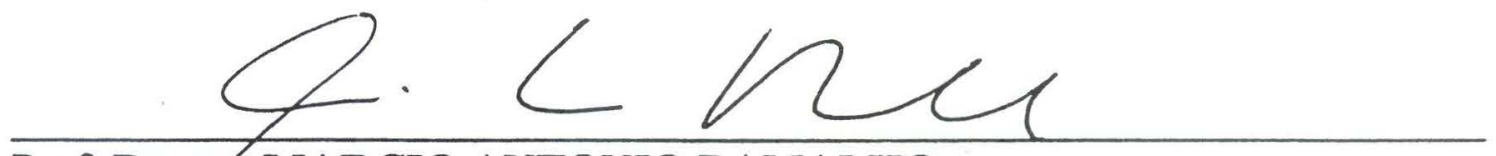

Prof. Doutor MARCIO ANTONIO RAMALHO

(Escola đe Engenharia de São Carlos - Universidade de São Paulo)

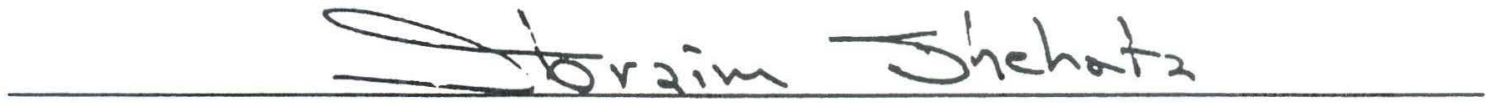

Prof. Doutor IBRAHIM ABD EL MALIK SHEHATA

(COPPE - UFRJ)

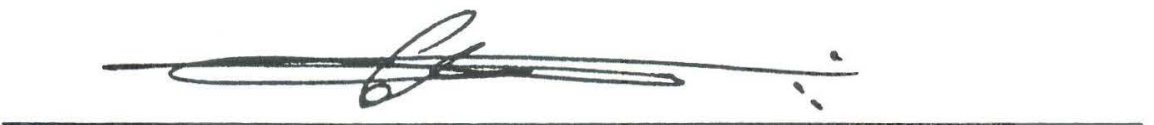

Prof. Titular CARLITO CALIL JUNIOR

Coordenador da Área de Engenharia de Estruturas

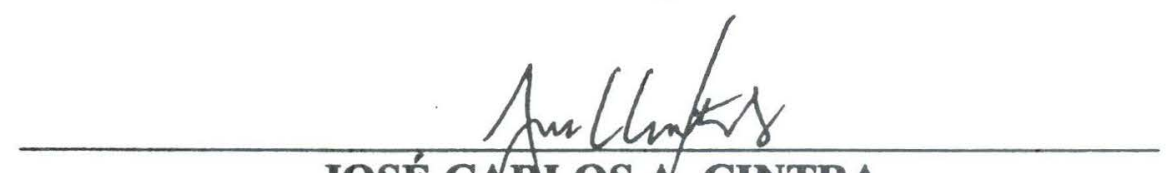

JOSÉ CARLOS A. CINTRA

Presidente da Comis_ão de Pós-Graduação da EESC 
Ao meu pai (in memoriam) e à minha mãe, aos quais tudo devo 


\section{AGRADECIMENTOS}

Ao Professor Libânio Miranda Pinheiro, pela dedicação, cuidadosa orientação e amizade ao longo destes dois anos.

A todos os amigos, inclusive os fisicamente distantes, pelo incentivo e pela presença.

Ao Prof. José Samuel Giongo, pelas suas primeiras palavras no Departamento de Engenharia de Estruturas, constante amizade e atenção.

Ao Eng. ${ }^{\circ}$ Hugo Alcântara Mota e ao professor Joaquim Eduardo Mota (Universidade Federal do Ceará - UFC), pelo incentivo.

Aos professores Mounir Kalil el Debs (EESC-USP) e Toshiaki Takeya (EESC-USP), pela atenção dispensada nas discussões informais.

À Maria Nadir Minatel e Eliana A. Bertin, pelo apoio como amigas e pela dedicação que ambas demonstraram no desempenho de suas atividades na biblioteca do departamento de Engenharia de Estruturas da EESC - USP.

À Coordenadoria de Aperfeiçoamento de Pessoal de Nível Superior (CAPES) e à Fundação de Amparo à Pesquisa do Estado de São Paulo (FAPESP), pelas bolsas de estudos no primeiro e segundo ano do curso, respectivamente.

Aos amigos Valério Silva Almeida, Vanessa Cristina de Castilho e Ângelo Vieira Mendonça, pela ajuda na impressão final dos exemplares.

A todos que direta ou indiretamente contribuíram para a realização deste trabalho. 


\section{SUMÁRIO}

LISTA DE SÍMBOLOS .................................................................. i

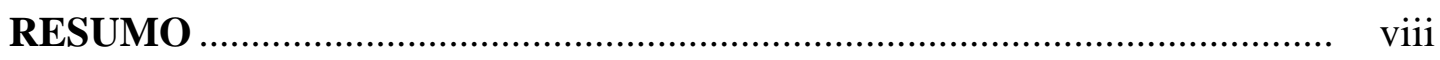

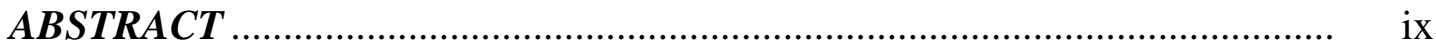

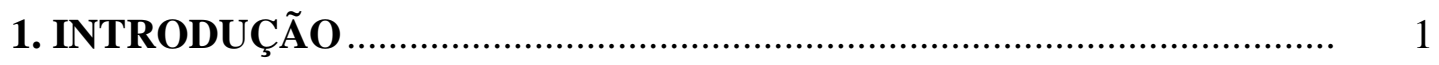

1.1 PRINCIPAIS APLICAÇÕES DO CAD ............................................. 2

1.2. APLICAÇÃO DO CAD EM ELEMENTOS FLETIDOS .................... 2

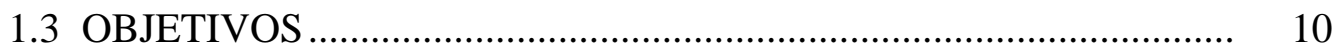

1.4 CONSIDERAÇÃO DA SEGURANÇA E NOTAÇÃO...................... 11

2. RETRAÇÃO E FLUÊNCIA …............................................................. 13

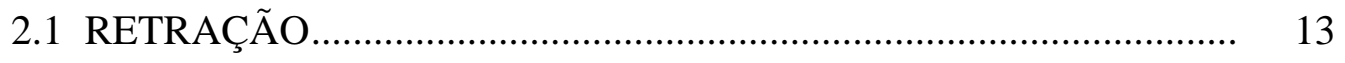

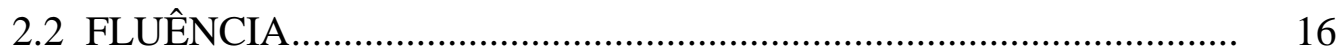

2.3 ASPECTOS DE NORMAS E CÁLCULO DA RETRAÇÃO E DA FLUÊNCIA.............................................................................. 20

2.4 EXEMPLO DE APLICAÇÃO …................................................. 26

3. DIMENSIONAMENTO À FLEXÃO .................................................... 33

3.1 RECOMENDAÇÕES DE NORMAS ............................................... 35

3.1.1 ACI 318 (1995) e CAN 3 (1994) .......................................... 35

3.1.2 NB-1 (1978) ................................................................ 37

3.1.3 Norma Norueguesa NS 3473 (1992).................................. 38

3.1.4 Norma Finlandesa Rak MK4 (1989) .................................... 41

3.1.5 Código Modelo CEB-FIP (1990)............................................ 42

3.2 DIAGRAMA RETANGULAR EQUIVALENTE PROPOSTO POR MacGREGOR E IBRAHIM (1997) .................................................. 43

3.3 LIMITES DOS DOMÍNIOS DE DEFORMAÇÃO PARA $\varepsilon_{c u}=3 \%$. 45 
3.4 DIMENSIONAMENTO ATRAVÉS DE TABELAS TIPO k ............ 48

3.4.1 Equações de equilíbrio...................................................... 49

3.4.2 Equações de compatibilidade das deformações ....................... 51

3.4.3 Tabelas para armadura simples .............................................. 51

3.4.4 Dimensionamento de seções de concreto protendido .............. 53

3.4.5 Tabelas para seções de concreto protendido e armado............ 54

3.5 ARMADURA MÍNIMA DE FLEXÃO............................................ 58

3.6 EXEMPLOS DE APLICAÇÃO ……............................................... 60

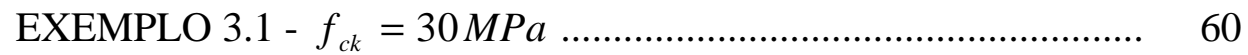

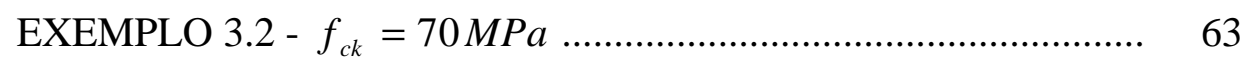

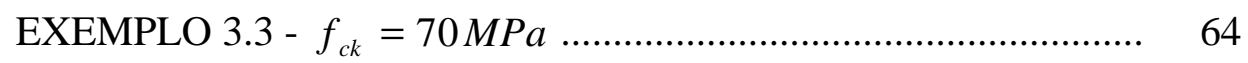

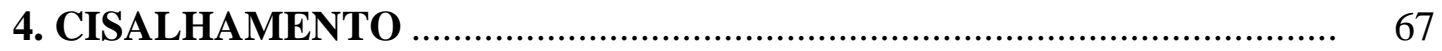

4.1 TRELIÇA CLÁSSICA DE RITTER-MÖRSCH............................... 67

4.2 MÉTODO PADRÃO............................................................... 71

4.3 ANALOGIA DA TRELIÇA COM DIAGONAIS DE

INCLINAÇÃO VARIÁVEL ............................................................ 74

4.4 DIMENSIONAMENTO AO CISALHAMENTO SEGUNDO A

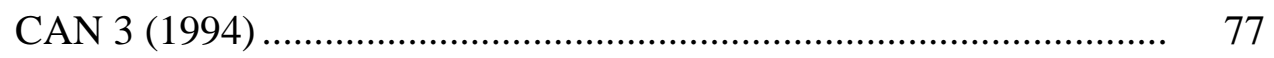

4.4.1 Resposta do concreto fissurado solicitado a cisalhamento ....... 78

4.4.2 Cálculo dos estribos ............................................................. 79

4.4.3 Cálculo da armadura longitudinal ........................................... 84

4.4.4 Seqüência de cálculo........................................................... 86

4.5 TAXAS MÍNIMAS DE ARMADURA DE CISALHAMENTO ........ 87

4.6 NORMA AUSTRALIANA AS-3600 (1988) ..................................... 92

4.6.1 Fissuração por flexão-cisalhamento.......................................... 95

4.6.2 Fissuração na alma por cisalhamento ..................................... 98

4.6.3 Resumo das recomendações da AS-3600 (1988).................... 100

4.7 CONCLUSÕES E RECOMENDAÇÕES DE PROJETO PARA

VIGAS DE CAD ....................................................................... 102

4.8 EXEMPLOS DE APLICAÇÃO _................................................. 104 


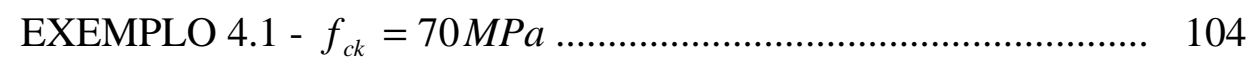

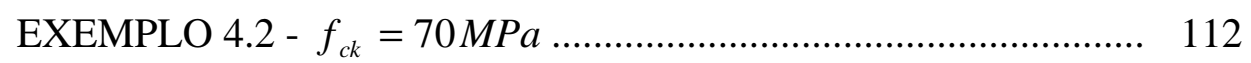

\section{DESLOCAMENTOS CAUSADOS POR AÇÕES DE CURTA E DE}

LONGA DURAÇÃO ........................................................................... 118

5.1 CÁlCULO DOS DESLOCAMENTOS SEGUNDO O ACI (1995) ... 118

5.1.1 Deslocamentos causados por ações de curta duração ............... 118

5.1.2 Deslocamentos causados por ações de longa duração .............. 123

5.2 MODELO BÁSICO DO CEB-FIP (1990) ...................................... 127

5.2.1 Influência do coeficiente de fluência $(\varphi)$............................... 133

5.2.2 Influência da resistência do concreto à tração $\left(f_{t}\right) \ldots \ldots \ldots \ldots \ldots . . . . . .133$

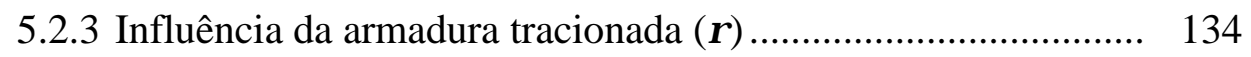

5.2.4 Influência da relação entre a armadura comprimida e a

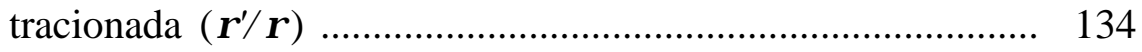

5.3 CÁLCULO SIMPLIFICADO - MÉTODO BILINEAR ..................... 135

5.4 CÁlCULO SIMPLIFICADO DOS DESLOCAMENTOS - MÉTODO DOS COEFICIENTES GLOBAIS ............................................... 136

5.5 MÉTODO DOS COEFICIENTES GLOBAIS APLICADO

AO CAD

5.6 EXEMPLOS DE APLICAÇÃO ................................................... 145

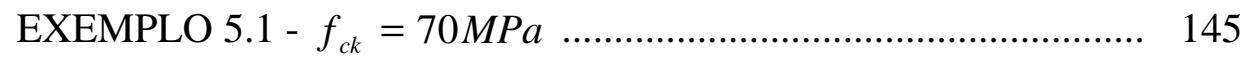

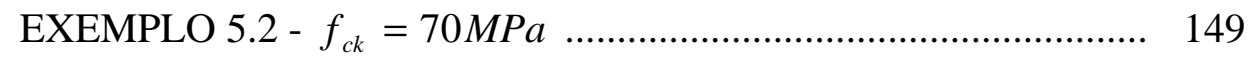

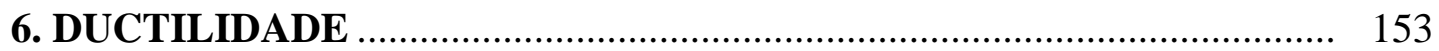

6.1 DUCTILIDADE NA FLEXÃO ....................................................... 153

6.2 CONCLUSÕES SOBRE DUCTILIDADE NA FLEXÃO ................ 158

6.3 DUCTILIDADE NO CISALHAMENTO ....................................... 159

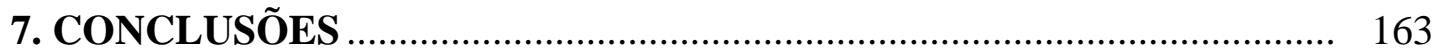

7.1 VIABILIDADE ECONÔMICA DA APLICAÇÃO DO CAD EM ELEMENTOS FLETIDOS ........................................................... 163 
7.2 RETRAÇÃO E FLUÊNCIA......................................................... 163

7.3 DIMENSIONAMENTO À FLEXÃO ............................................. 164

7.4 CISALHAMENTO .................................................................. 165

7.4.1 Método padrão .................................................................... 166

7.4.2 Norma australiana $A S-3600$ (1988)....................................... 166

7.5 DESLOCAMENTOS CAUSADOS POR AÇÕES DE CURTA E DE LONGA DURAÇÃO................................................................... 168

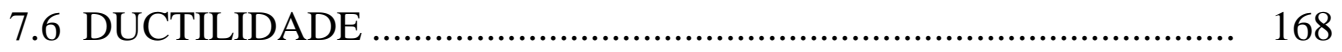

ANEXO A - TABELAS DE DIMENSIONAMENTO ............................... 170

Tabela A1 - CONCRETO PROTENDIDO ........................................ 171

Tabela A2 - CONCRETO ARMADO ............................................. 174

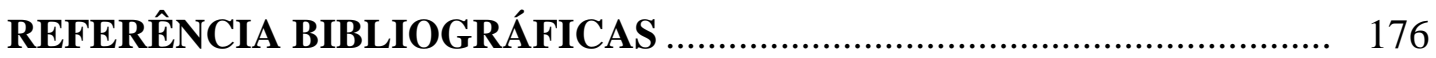




\section{LISTA DE SÍMBOLOS}

\section{LETRAS ROMANAS MAIÚSCULAS}

$A_{c} \quad$ área da seção transversal de concreto

$A_{p} \quad$ área da armadura longitudinal de protensão (cabos aderentes)

$A_{s} \quad$ área da armadura passiva longitudinal tracionada

$A_{s w} \quad$ área total (computados todos os ramos dos estribos) da armadura transversal na mesma seção

$E_{c} \quad$ módulo de deformação longitudinal do concreto

$E_{c i} \quad$ módulo de deformação longitudinal do concreto na transferência da protensão

$E_{c, 28} \quad$ módulo de deformação longitudinal do concreto aos 28 dias

$E_{p} \quad$ módulo de deformação longitudinal da armadura de protensão

$E_{s} \quad$ módulo de deformação longitudinal da armadura passiva

$I_{g} \quad$ momento de inércia da seção bruta de concreto em relação ao seu centro de gravidade, desprezando-se as armaduras

$I_{r} \quad$ momento de inércia da seção fissurada

Momento

$M_{d} \quad$ valor de cálculo do momento

$M_{e} \quad$ momento de inércia efetivo obtido a partir da expressão de Branson

$M_{P} \quad$ momento devido à força de protensão

$M_{n} \quad$ valor nominal do momento resistente da viga

$M_{r} \quad$ momento de fissuração

$M_{r, \text { red }} \quad$ momento de fissuração reduzido

$M_{0} \quad$ momento de descompressão

$M_{\max } \quad$ momento fletor máximo na viga

$M_{\text {tot }} \quad$ momento total que inclui o momento da protensão

$P \quad$ força de protensão 


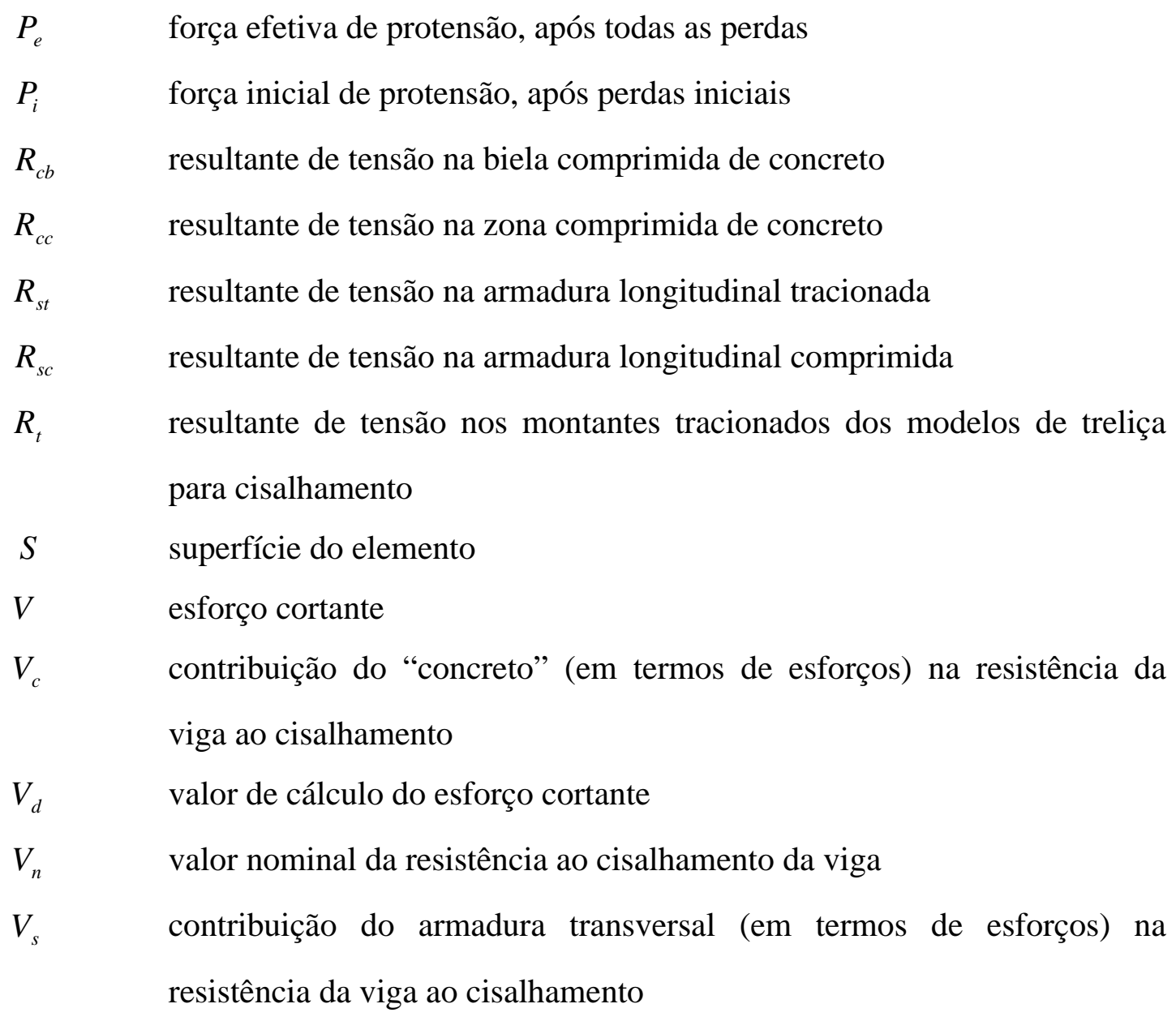

\section{LETRAS ROMANAS MINÚSCULAS}

$a$ vão de cisalhamento. Distância entre o ponto de aplicação da carga concentrada e a face do apoio da viga

$a_{c} \quad$ flecha elástica calculada com rigidez $E_{c} I_{c}$ da seção bruta (desprezando-

se

as armaduras)

$a_{i} \quad$ deslocamento causado por ações de curta duração

$a_{1}, a_{2}$ deslocamentos nos estádios 1 e 2 , respectivamente, para flexão simples

$a_{1 r}, a_{2 r} \quad$ deslocamentos $a_{1}$ e $a_{2}$ para o momento de fissuração $\left(M_{r d}\right)$

$a_{\text {add }} \quad$ deslocamento adicional causado por retração e fluência do concreto 


\begin{tabular}{|c|c|}
\hline$a_{\text {tot }}$ & imento total \\
\hline$b_{f}$ & largura do flange das vigas de seção " $\mathrm{T}$ " \\
\hline$b_{w}$ & $\begin{array}{l}\text { largura das vigas de seção retangular ou da nervura das vigas de seção } \\
\text { "T" }\end{array}$ \\
\hline$d_{0}$ & profundidade da camada mais baixa de armadura longitudinal de tração \\
\hline$d_{p}$ & $\begin{array}{l}\text { distância entre a fibra mais comprida de concreto e o C.G. da } \\
\text { armadura de protensão }\end{array}$ \\
\hline$d_{s}$ & $\begin{array}{l}\text { distância entre a fibra mais comprida de concreto e o C.G. da } \\
\text { armadura passiva longitudinal tracionada }\end{array}$ \\
\hline$e$ & excentricidade \\
\hline$e_{1}$ & $\begin{array}{l}\text { distância entre o C.G. da armadura de protensão e o C.G. da seção no } \\
\text { meio do vão }\end{array}$ \\
\hline$e_{2}$ & $\begin{array}{l}\text { distância entre o C.G. da armadura de protensão e o C.G. da seção da } \\
\text { viga sobre os apoios }\end{array}$ \\
\hline$f_{c}$ & resistência do concreto à compressão \\
\hline$f_{c}^{\prime}$ & resistência do concreto à compressão requerida em projeto \\
\hline$f_{c, 28}$ & resistência à compressão do concreto aos 28 dias \\
\hline$f_{c k}$ & valor característico da resistência do concreto à compressão \\
\hline$f_{c d}$ & valor de cálculo da resistência do concreto à compressão \\
\hline$f_{c m, t_{0}}$ & $\begin{array}{l}\text { resistência média do concreto à compressão em corpos } \\
\text { de prova cilíndricos na idade do carregamento }\left(t_{0}\right)\end{array}$ \\
\hline$f_{p}$ & tensão na armadura de protensão \\
\hline$f_{p e}$ & tensão efetiva na armadura de protensão, após todas as perdas \\
\hline$f_{p 0}$ & tensão na cordoalha onde o concreto em redor tem tensão nula \\
\hline$f_{p, 01, k}$ & $\begin{array}{l}\text { tensão no aço de protensão correspondente à deformação unitária residual } \\
\text { de } 1 \% 0\end{array}$ \\
\hline$f_{t}$ & resistência do concreto à tração \\
\hline$f_{t m}$ & valor médio de $f_{t}$ \\
\hline
\end{tabular}




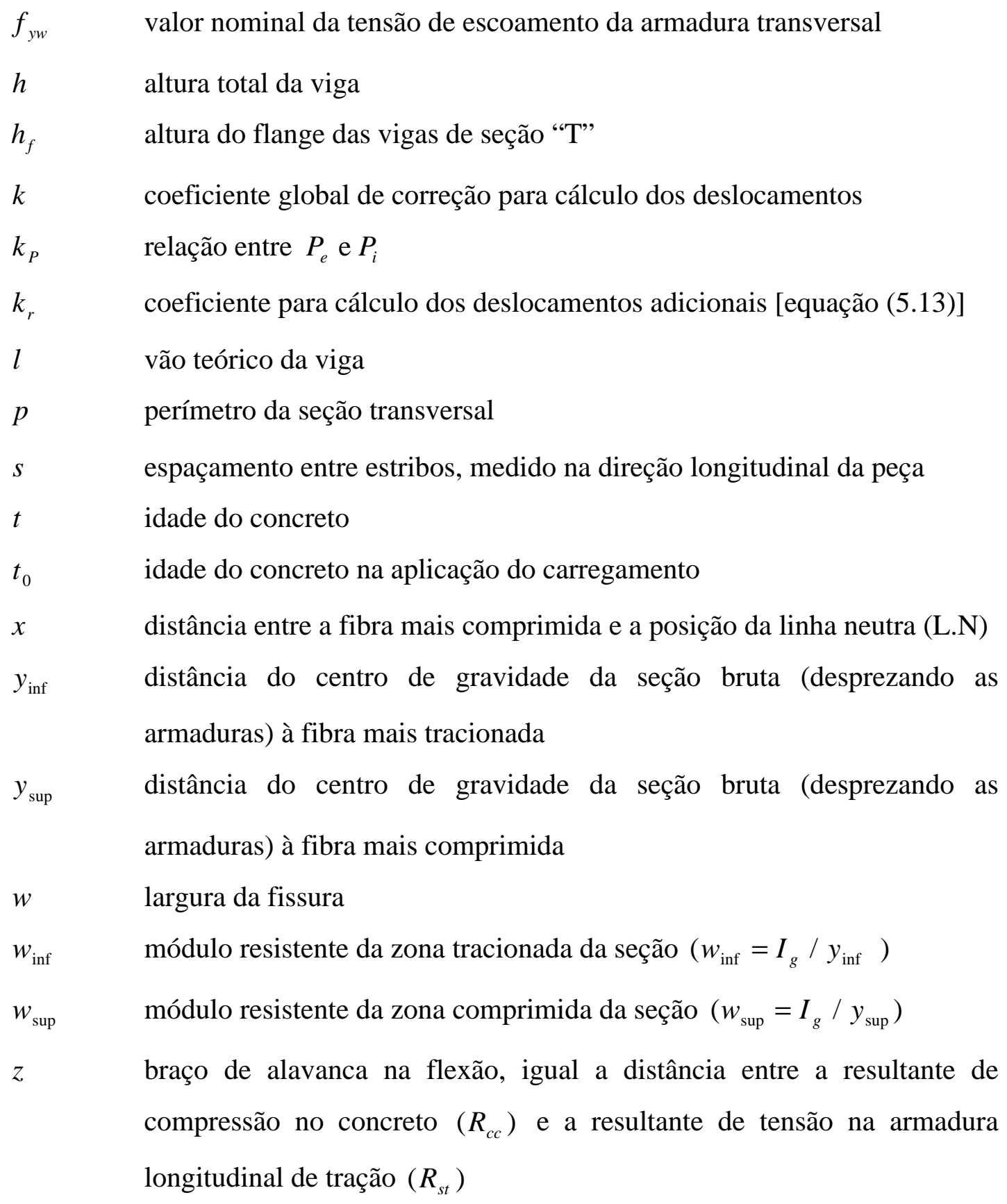

\section{LETRAS GREGAS}

$\alpha$ ângulo formado pela armadura de cisalhamento e a armadura longitudinal de tração

$\alpha_{1} \quad$ parâmetro para determinação do diagrama tensão-deformação proposto por IBRAHIM \& MacGREGOR (1997) [equação (3.13.)] 
$\alpha^{\prime} \quad$ coeficiente tomado igual a 0,5 [equação (2.2.)]

$\beta \quad$ coeficiente para cálculo do momento de fissuração reduzido do Modelo Básico do CEB-FIP (1990) para cálculo dos deslocamentos [equação (5.15)]

$\beta_{r} \quad$ coeficiente que indica a capacidade do concreto fissurado de transmitir cisalhamento

$\beta_{1} \quad$ parâmetro para determinação do diagrama tensão-deformação proposto por IBRAHIM \& MacGREGOR (1997) [equação (3.14.)]

$\beta_{2}$ fator da $A S$-3600 (1988) que leva em consideração a presença ou não de uma força axial $N_{d}$ para cálculo da contribuição do "concreto" no cisalhamento[equação (4.37)]

$\beta_{3} \quad$ coeficiente [equação (5.15)] que caracteriza a qualidade de aderência das barras da armadura. $\beta_{3}=1,0$ para barras de alta aderência; $\beta_{3}=0,5$ para barras lisas

$\beta_{4} \quad$ coeficiente [equação (5.15)] que representa o tipo de carregamento (duração da aplicação e repetição do carregamento). $\beta_{4}=0,8$ para o carregamento imediato ou para carregamentos de curta duração; $\beta_{4}=0,5$ para carregamentos de longa duração ou grande número de ciclos de carregamento

$\beta_{5} \quad$ coeficiente da $A S-3600$ (1988) que leva em consideração o efeito do tamanho para cálculo da contribuição do "concreto" no cisalhamento [equação (4.37)]

$\varepsilon_{1}$ deformação principal de tração no concreto fissurado

$\varepsilon_{c c} \quad$ deformação do concreto por fluência

$\varepsilon_{c u} \quad$ deformação de compressão máxima no concreto

$\varepsilon_{c i} \quad$ deformação elástica inicial do concreto

$\varepsilon_{c s}$ deformação do concreto por retração

$\varepsilon_{p d} \quad$ deformação total do aço de protensão no estado limite último

$\varepsilon_{c c u} \quad$ valor máximo de $\varepsilon_{c c}$ 


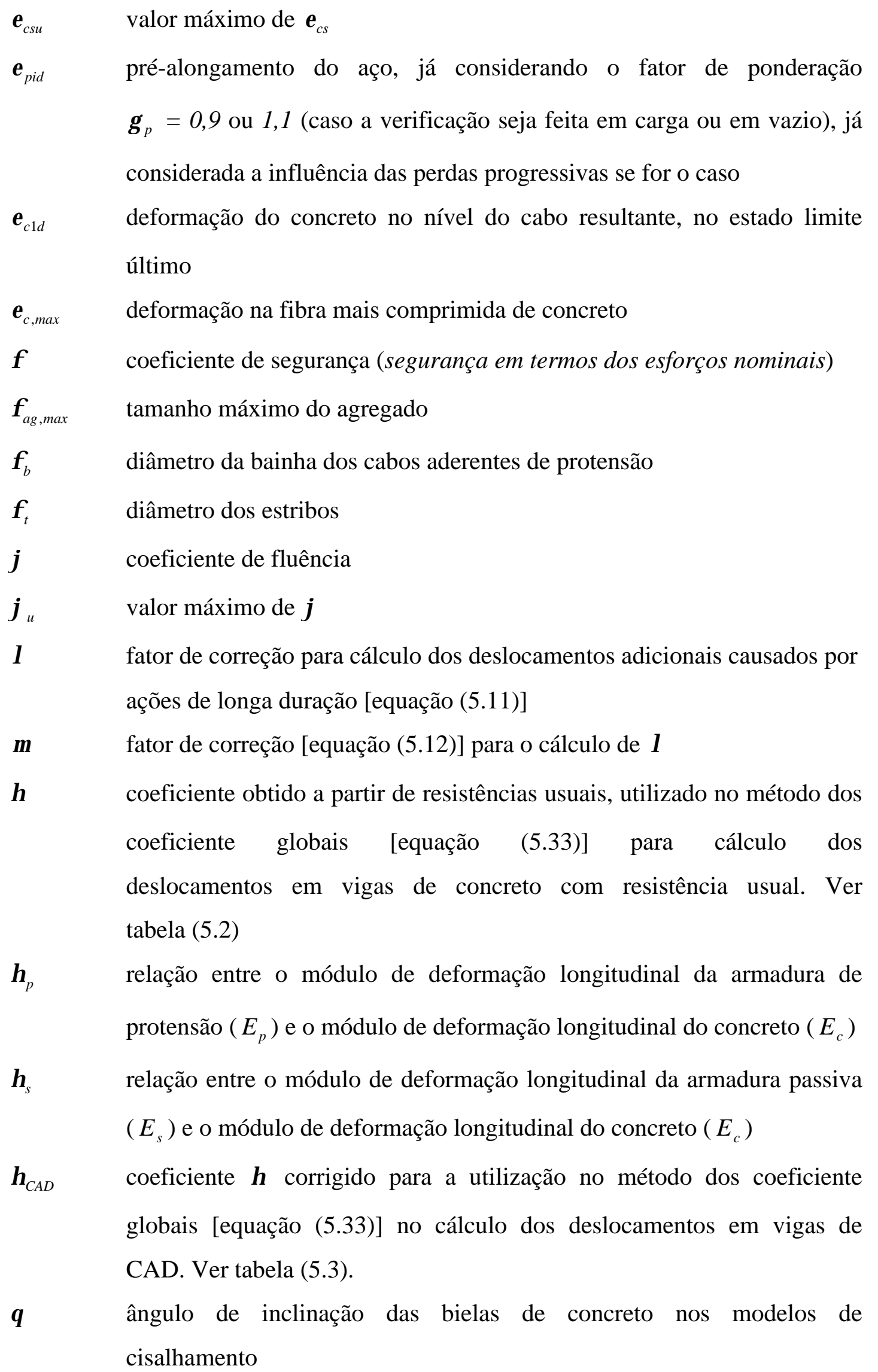




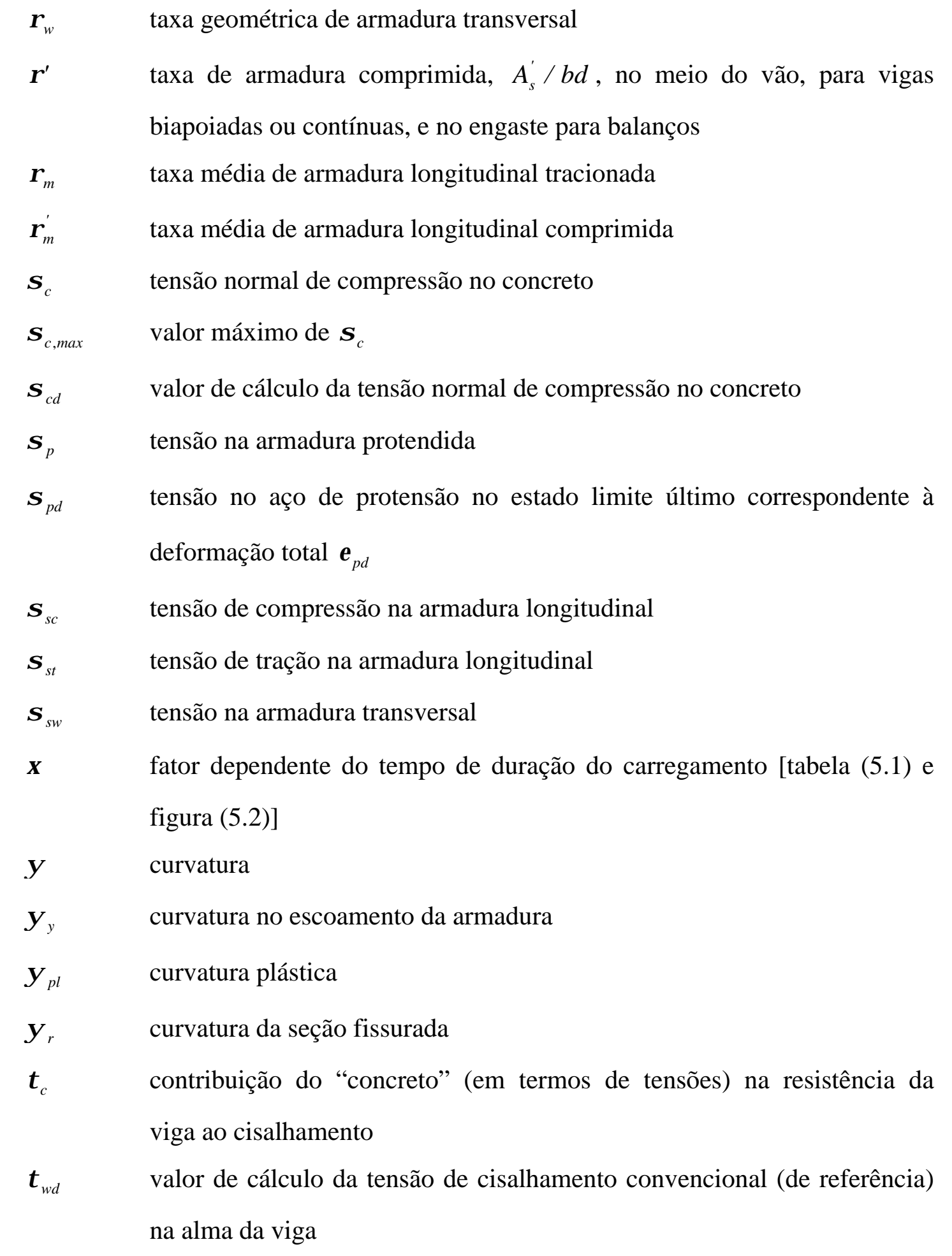




\section{RESUMO}

ANDRADE JR, J.P. (1999). Projeto estrutural de vigas de concreto de alto desempenho. São Carlos. 180p. Dissertação (mestrado) - Escola de Engenharia de São Carlos, Universidade de São Paulo.

Este trabalho fornece uma visão geral sobre a aplicação, o dimensionamento e o detalhamento de elementos fletidos de concreto de alto desempenho (CAD), armados ou protendidos, com particular atenção para estes últimos. Procurou-se, sempre que possível, realçar as situações nas quais os atuais procedimentos normalizados permanecem válidos, ou não, para o cálculo das vigas de CAD.

$\mathrm{Na}$ introdução, apresenta-se a viabilidade econômica da aplicação do concreto de alto desempenho nas vigas. No capítulo referente à retração e à fluência, abordamse procedimentos válidos para o CAD, os quais apresentam melhor correlação com os resultados experimentais que a obtida através do ACI 209 (1982) ou do CEB-FIP (1990).

No que se refere à flexão, apresenta-se um diagrama tensão-deformação retangular, e comparam-se os seus resultados para concretos usuais e de alto desempenho, com os obtidos pelo diagrama parábola-retângulo, em termos de consumo de armadura. No capítulo referente ao cisalhamento, apresentam-se recomendações para a utilização do Método Padrão e do Modelo de Treliças de Diagonais de Inclinação Variável para o cálculo da armadura transversal em vigas de CAD.

Para o cálculo dos deslocamentos causados por ações de curta duração, confirma-se a validade da metodologia de Branson para as vigas de CAD. Os deslocamentos adicionais causados por ações de longa duração também são considerados, incluindo-se metodologias para as vigas de concreto armado e para as pré-moldadas protendidas.

Exemplos de dimensionamento são feitos para todos os itens apresentados, considerando-se uma viga pré-moldada de $30 \mathrm{~m}$ de comprimento, seção "T", com pós-tensão e $f_{c k}=70 \mathrm{MPa}$.

Palavras-chave: Concreto de alto desempenho; Vigas; Dimensionamento. 


\section{ABSTRACT}

ANDRADE JR, J.P. (1999). Structural design of high performance concrete beams.

São Carlos. 184p. Dissertação (mestrado) - Escola de Engenharia de São Carlos, Universidade de São Paulo.

This work provides an overview of use and design of the high performance concrete (HPC) flexural members, reinforced or prestressed, with particular attention for the last ones. Cases in which procedures of the modern codes for calculation of HPC beams remain valid were enhanced.

In the introduction, the economic viability of high performance concrete beams is presented. In the chapter about shrinkage and creep, valid procedures for HPC are presented. These procedures have better correlation with the actual results than those relative to ACI 209 (1982) or CEB-FIP (1990).

A rectangular stress block is presented, and its results for usual and high performance concrete are compared with those from the parabolic-rectangular stress block, in terms of consume of steel. In the chapter about shear, recommendations for use of Standard Method and Variable Angle Truss Model for HPC beams are presented.

For the calculation of short term deflections, the validity of Branson's Method for high performance concrete beams is confirmed. Sustained load deflections are also considered, and including procedures for reinforced beams and for precast prestressed ones.

For all the considered topics, examples are presented for a $30 \mathrm{~m}$ span precast post-tensioned beam, "T" cross section and $f_{c k}=70 \mathrm{MPa}$.

Keywords: High performance concrete; Beam; Design. 


\section{INTRODUÇÃO}

Vários são os critérios que podem ser adotados para se classificar um concreto como sendo de alto desempenho. Dentre eles estão a durabilidade, a trabalhabilidade e a resistência.

Embora não haja ainda um consenso na literatura técnica, concretos com resistência característica à compressão superior a $40 M P a$ são normalmente considerados concretos de alto desempenho (CAD). Esta classificação está, portanto, intimamente relacionada à resistência. Isso é natural, tendo-se em vista que as principais propriedades do material (mecânicas e reológicas) melhoram com o aumento da resistência.

É importante ressaltar, porém, que a mudança nas propriedades do concreto são graduais com o aumento da resistência. O módulo de elasticidade e a resistência do concreto à tração, por exemplo, crescem continuamente (sem "saltos") à medida que se aumenta a resistência à compressão.

Portanto, o ideal é que os procedimentos de cálculo adotados retratem esta realidade física do material, evitando-se procedimentos diferentes para intervalos diferentes de resistência. Adotar para o dimensionamento à flexão um único diagrama retangular equivalente, válido para resistências entre $20 M P a$ e $100 \mathrm{MPa}$, por exemplo, é muito mais conveniente do que utilizar um diagrama retangular (ou parábola-retângulo) para concretos de até $40 \mathrm{MPa}$, e um diagrama triangular para concretos de resistência superior, ainda que esta resistência seja de 45MPa.

A denominação concreto de alto desempenho, deste ponto de vista, passa a ser uma simples referência. Neste trabalho, consideram-se concretos de alto desempenho aqueles que apresentam resistência à compressão maior ou igual a $40 M P a$ aos 28 dias. 
Por raciocínio análogo, os concretos com resistência à compressão inferior a $40 M P a$ são chamados, neste texto, concretos de resistência usual, ou simplesmente, concretos usuais.

\subsection{PRINCIPAIS APLICAÇÕES DO CAD}

O CAD tem sido utilizado principalmente em: infra e superestruturas de pontes, pilares de edifícios, plataformas marítimas, pisos industriais, elementos prémoldados e obras de recuperação.

Estas aplicações estão relacionadas às propriedades favoráveis do concreto de alto desempenho em relação aos concretos convencionais. A sua menor porosidade leva a uma maior proteção da armadura e conseqüente maior durabilidade da estrutura. O CAD, em função da sua alta resistência, possibilita redução das seções transversais, aumentando o espaço útil em edifícios, por exemplo, e diminuindo a carga nas fundações.

\subsection{APLICAÇÃO DO CAD EM ELEMENTOS FLETIDOS}

Muitas pesquisas têm sido desenvolvidas no Brasil no que se refere à aplicação do CAD em elementos onde a compressão é predominante (pilares). Essa é, provavelmente, a sua principal aplicação até o momento. Isso tem levado alguns a considerar, erroneamente, que a sua aplicação em elementos fletidos sempre é desvantajosa.

A título de ilustração da importância da utilização do CAD em elementos fletidos, mostra-se a seguir um estudo comparativo de custos para a superestrutura de uma ponte de $11 \mathrm{~m}$ de largura e $35 \mathrm{~m}$ de vão. 
Na figura 1.1, mostram-se as estruturas para a ponte, para as resistências de $40 \mathrm{MPa}$ e de 70MPa. As vigas são AASHTO-PCI Tipo IV, pré-tracionadas, com cordoalhas de $13 \mathrm{~mm}$ (baixa relaxação) em ambos os casos. Ambos os projetos utilizaram lajes com resistência de $28 M P a$.

Como se pode observar na tabela 1.1, apenas no item "tabuleiro" houve um aumento nos custos por metro linear de ponte ao se elevar a resistência do concreto. Devido ao aumento do espaçamento entre vigas, a espessura da laje teve que ser aumentada em $25 \mathrm{~mm}$ para o projeto com CAD.

TABELA 1.1 - Estudo Comparativo de Custos

FONTE : DURNING \& REAR (1993) (adaptada)

\begin{tabular}{|l|c|c|}
\hline \multicolumn{2}{|c|}{ Item da ponte } & \multicolumn{2}{c|}{ Custo por metro linear de ponte } \\
\cline { 2 - 3 } & $f_{c k}=\mathbf{4 0 M P a}$ & $f_{c k}=\mathbf{7 0 M P a}$ \\
\hline Tabuleiro $^{(1)}$ & $\mathrm{US} \$ 707,29$ & $\mathrm{US} \$ 895,20$ \\
\hline Cordoalhas de protensão $^{(2)}$ & $\mathrm{US} \$ 359,64$ & $\mathrm{US} \$ 309,33$ \\
\hline Concreto das vigas $^{*}$ & $\mathrm{US} \$ 243,36$ & $\mathrm{US} \$ 229,84$ \\
\hline Outros custos das vigas $^{(3)}$ & $\mathrm{US} \$ 1399,00$ & $\mathrm{US} \$ 622,40$ \\
\hline TOTAL POR METRO & $\mathrm{US} \$ \mathbf{2 7 0 9 , 2 9}$ & $\mathrm{US} \$ \mathbf{2 0 5 6}, \mathbf{7 7}$ \\
\hline
\end{tabular}

(1) Custos obtidos do Manual de Projeto de Pontes da Louisiana.

(2) Incluídos os custos com material, trabalhos de montagem e perdas e despesas gerais.

(3) Estes custos representam o trabalho e as despesas gerais de protensão, assim como os custos de transporte e de montagem.

Em todos os demais houve uma diminuição de custos, particularmente no item "outros custos das vigas", uma vez que, com o aumento da resistência, conseguiu-se uma sensível diminuição do número de vigas necessárias, o que se refletiu em uma drástica redução nos custos de protensão, transporte e montagem desses elementos. 
O projeto com $70 \mathrm{MPa}$ necessita de apenas quatro vigas e 232 cordoalhas no total, comparando-se com as nove vigas e um total de 270 cordoalhas para a resistência de $40 M P a$.

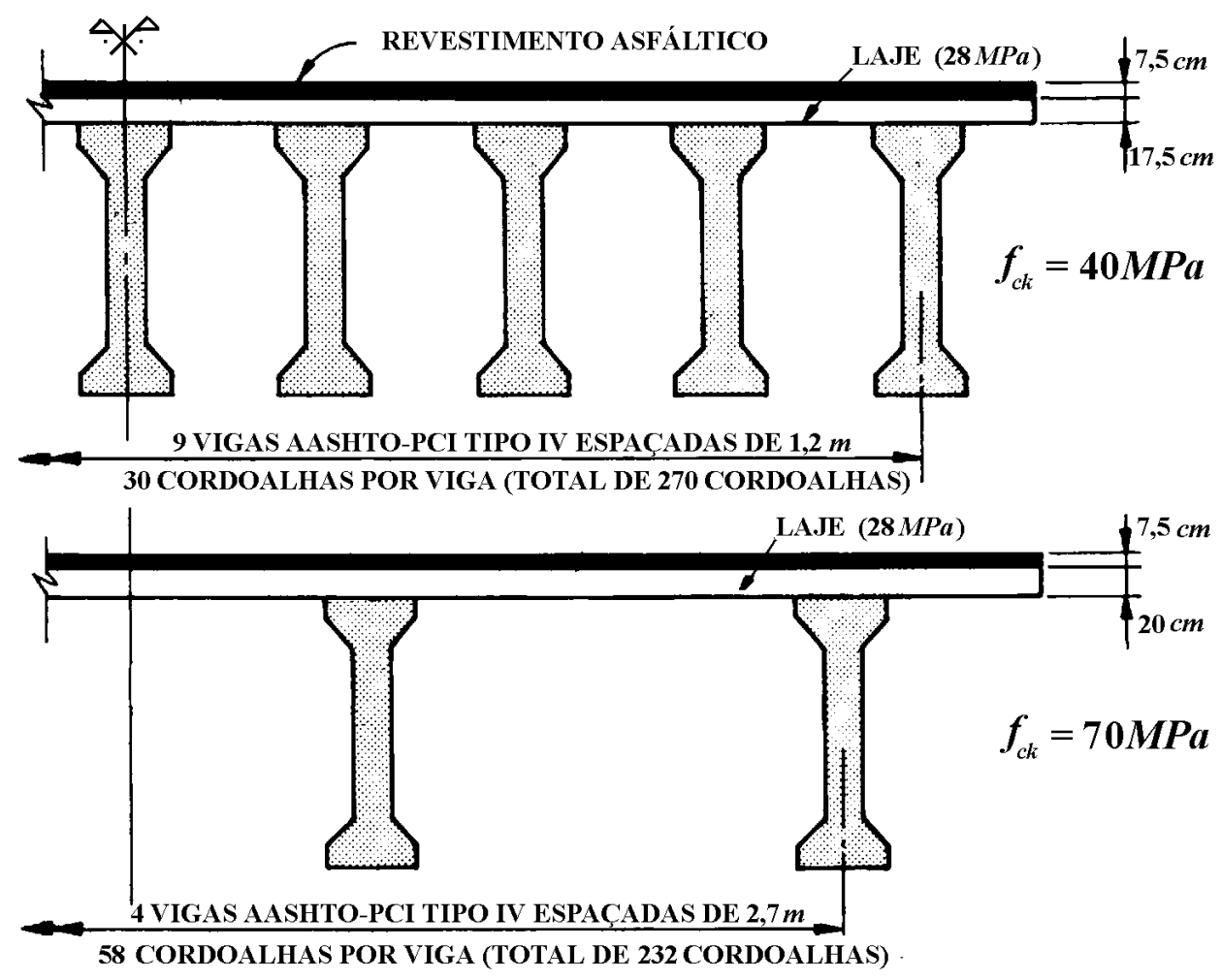

Figura 1.1 - Estruturas para a mesma ponte com $40 M P a$ e com $70 M P a$ FONTE : DURNING \& REAR (1993) (adaptada)

O aumento da resistência possibilitou a utilização de um número menor de vigas. Isto significa menor tempo de execução, maior facilidade de atendimento ao cronograma da obra e maior leveza arquitetônica à estrutura. Estes aspectos são importantes, já que muitas vezes as pontes ou os viadutos se localizam em centros urbanos com grande fluxo de veículos e sobrecarregados arquitetonicamente.

Como parte de um estudo realizado pela Universidade do Texas, resistências variando entre $40 \mathrm{MPa}$ e $103 \mathrm{MPa}$ foram examinadas para determinar o efeito no vão máximo e no espaçamento necessário para 12 diferentes tipos de seção transversal. 
Algumas das conclusões do estudo são apresentadas a seguir:

- Nenhuma simples avaliação de parâmetros de eficiência de uma seção parece refletir o efeito de todos os aspectos significativos da resistência. Portanto, comparar o aumento do momento resistente de uma seção com o aumento da resistência não tem grande significado de ordem prática. A comparação entre os resultados reais dos projetos com diferentes resistências é o melhor modo de se determinar a eficiência relativa dos diferentes tipos de seção (figura 1.2).

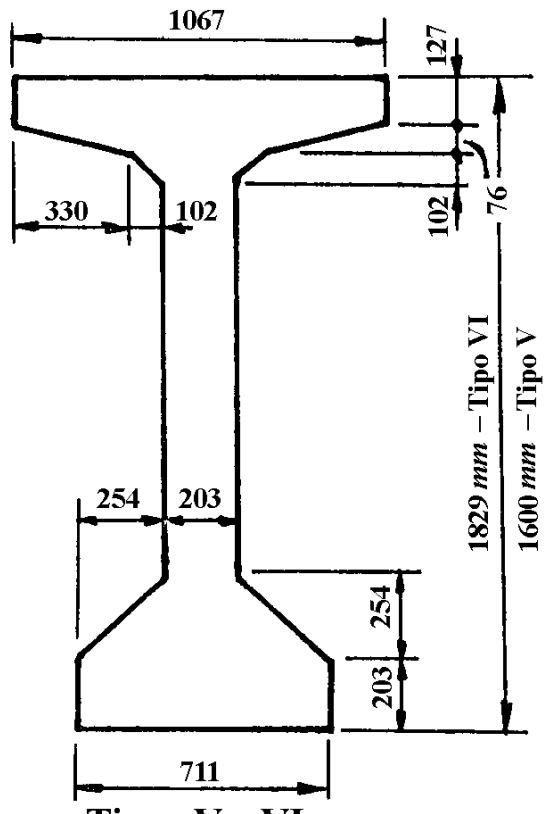

Tipos V e VI

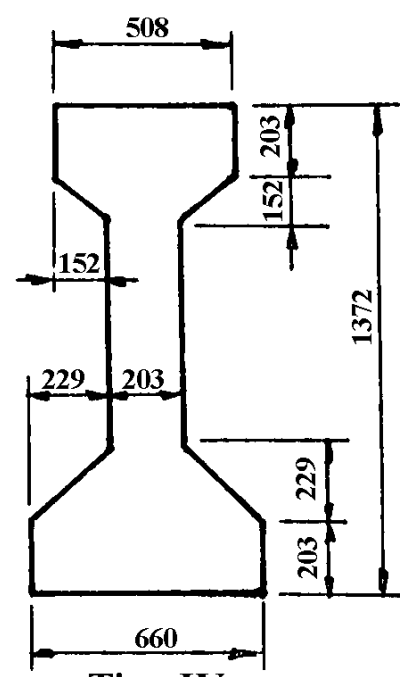

Tipo IV

Figura 1.2 - Vigas AASTHO-PCI tipos IV, V e VI

FONTE : DURNING \& REAR (1993) (adaptada)

- Um aumento na resistência do concreto permite um aumento entre $10 \%$ e 40\% no vão máximo para uma determinada seção, dependendo do espaçamento adotado (ver figura 1.3, na qual as vigas Tipo C (Texas) são vigas de seção transversal semelhante às vigas AASHTO-PCI Tipo IV, com altura de 1,01m). 
- Limites máximos de ordem prática devem ser considerados, como a capacidade dos berços de protensão (pré-tração) e a capacidade dos equipamentos de transporte e de montagem dos elementos pré-moldados.

- Um aumento na resistência pode permitir um aumento significativo no espaçamento entre vigas para um dado vão, permitindo assim a utilização de um número menor de vigas na estrutura. Em alguns casos, com a utilização do CAD, o espaçamento pode ser maior que o dobro do espaçamento necessário para vigas com concreto de resistência usual.

- Com base em número limitado de testes, o comprimento de transferência (pré-tração) da cordoalha no CAD é um pouco menor que o observado em concretos usuais.

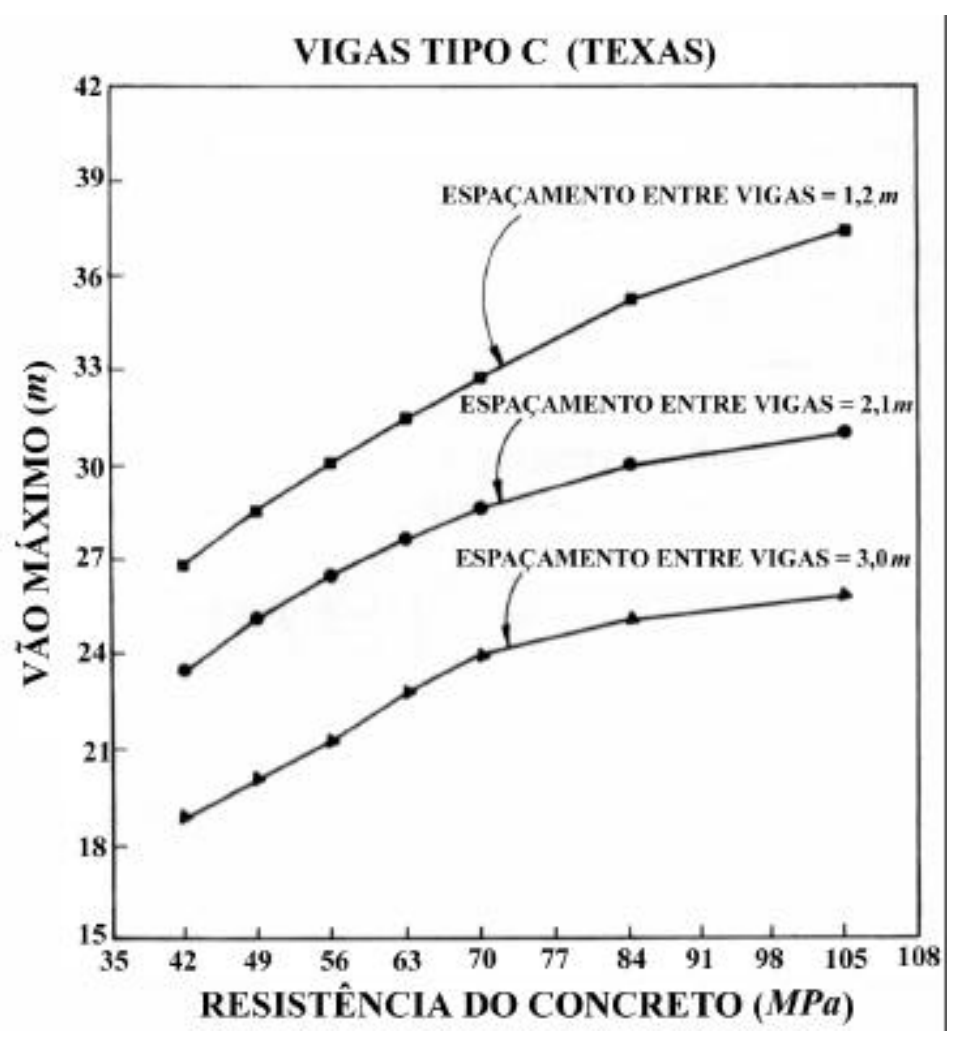

Figura 1.3- Relação entre vão máximo, espaçamento e resistência FONTE : DURNING \& REAR (1993) (adaptada) 
- Concretagem de elementos de CAD com seções estreitas e congestionadas é possível com a utilização de maiores quantidades de superplastificantes (redutores de água).

A figura 1.4 mostra o aumento no vão máximo para vigas espaçadas de $1,2 \mathrm{~m} \mathrm{e}$ 2,1 $\mathrm{m}$ para resistências entre $40 \mathrm{MPa}$ e $105 \mathrm{MPa}$. Esta figura mostra que um aumento na resistência de $40 \mathrm{MPa}$ para $70 \mathrm{MPa}$, associada a um aumento da armadura longitudinal e transversal, aumenta em mais de $20 \%$ o vão máximo.

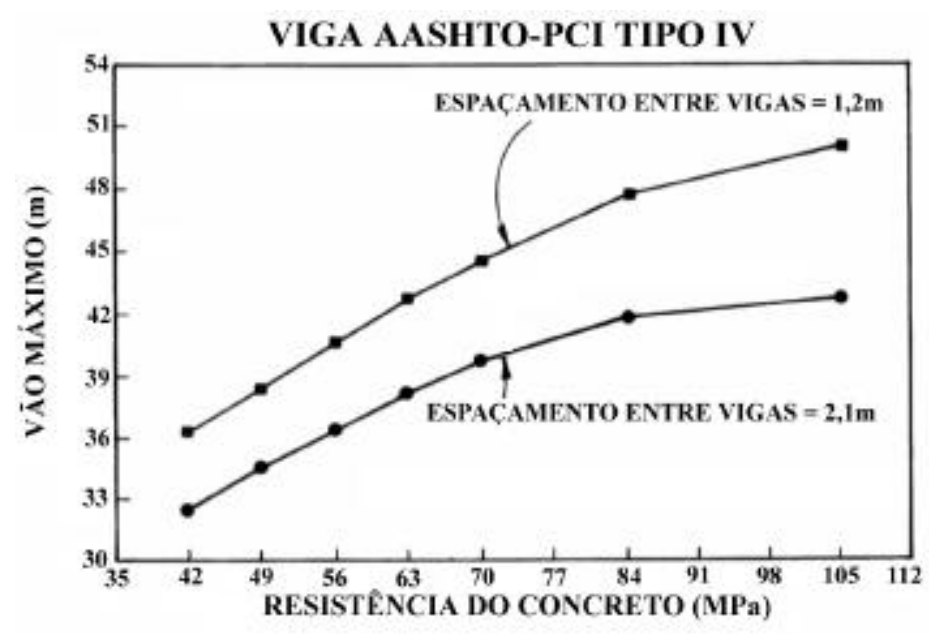

Figura 1.4- Relação entre vão máximo, espaçamento e resistência FONTE : DURNING \& REAR (1993) (adaptada)

A figura 1.5 mostra a variação no espaçamento permitido com o aumento da resistência para três diferentes vãos. Para um vão de $36 m$, estes dados mostram que, ao se aumentar a resistência do concreto de $40 \mathrm{MPa}$ para $70 \mathrm{MPa}$, o espaçamento entre vigas pode ser mais que dobrado (de $1,2 \mathrm{~m}$ para $2,7 \mathrm{~m}$ ).

Para se tirar proveito de resistência acima de 70MPa, cordoalhas de alta capacidade deveriam ser usadas. Isto é confirmado pela figura 1.6, a qual mostra que o uso de cordoalhas de $15 \mathrm{~mm}$ permite que se continue a aumentar a capacidade da viga para resistências acima de $70 M P a$. 


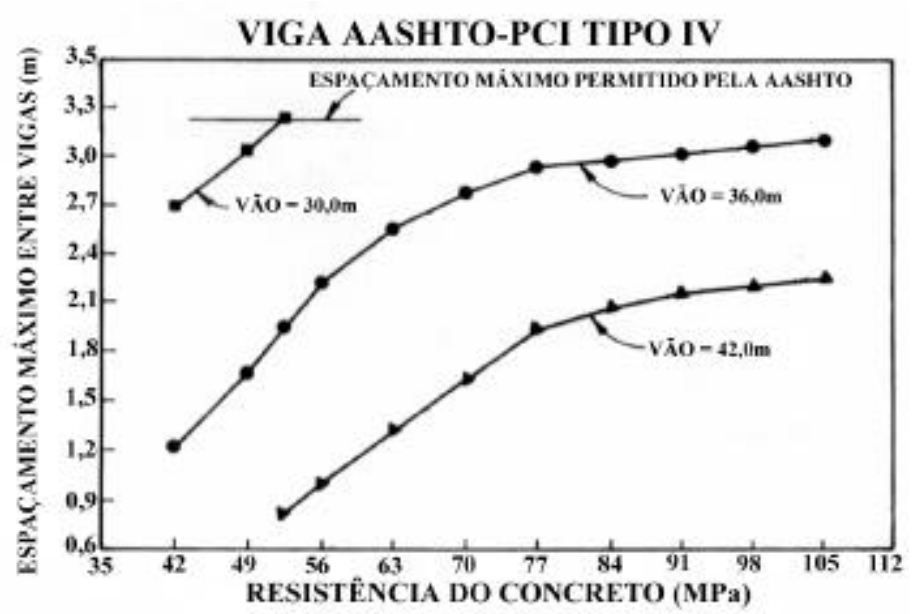

Figura 1.5- Relação entre vão máximo, espaçamento e resistência FONTE : DURNING \& REAR (1993) (adaptada)

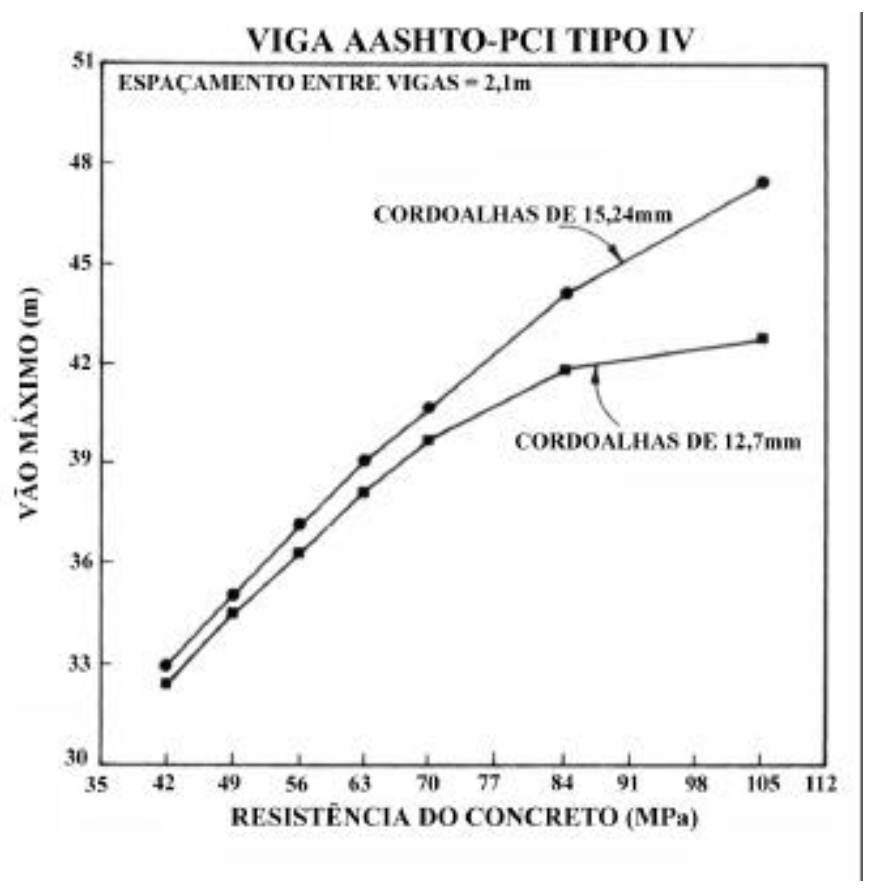

Figura 1.6- Relação entre vão máximo, tipos de cordoalhas e resistência FONTE : DURNING \& REAR (1993) (adaptada)

Este exemplo tem como objetivo mostrar o potencial econômico da aplicação do CAD em elementos fletidos. Não se deve esquecer, porém, que cada obra 
apresenta sua peculiaridades. Do mesmo modo que, para uma determinada estrutura, a utilização do aço pode ser mais indicada que a utilização do concreto, o CAD não se apresenta, sempre, como a melhor solução em relação aos concretos usuais.

Este trabalho é desenvolvido no âmbito do projeto de vigas de CAD, dada a importância da aplicação desse material em vigas de grandes vãos, em particular nas vigas de pontes.

O CAD tem grande aplicação na pré-moldagem, uma vez que esta permite a utilização de seções otimizadas do ponto de vista de comportamento mecânico. $\mathrm{O}$ emprego do $\mathrm{CAD}$ em vigas de seções retangulares pode significar um grande desperdício, uma vez que, na ruptura, despreza-se a contribuição do concreto no combate às tensões de tração. Esse é um dos fatores que dificultam a utilização do CAD em vigas usuais de concreto armado em edifícios. Outro aspecto a ser lembrado para o caso das vigas usuais de concreto armado, em edifícios, é que normalmente não há uma necessidade extra de resistência, e os concretos usuais são suficientes.

O aumento da resistência do concreto à compressão permite um maior aproveitamento da protensão, uma vez que aumenta também a sua resistência à tração, a qual se constitui muitas vezes em um fator limitante, especialmente nas fases onde não atuam todos os carregamentos do projeto. Além disso, a utilização do CAD em elementos protendidos diminui as perdas diferidas de protensão.

Assim, o grande campo para a aplicação do CAD em elementos fletidos são as vigas de grandes vãos (pontes e obras de vulto), protendidas e pré-moldadas.

O aumento da durabilidade é fator decisivo para a utilização do CAD em pontes e galpões industriais, uma vez que estas estruturas estão normalmente expostas a agentes agressivos. Os custos com manutenção são menores do que os que se apresentariam no caso da utilização de concretos de resistências usuais.

Novamente a parceria entre $\mathrm{CAD}$, protensão e pré-moldagem se mostra extremamente feliz, uma vez que as peças protendidas apresentam menor grau de fissuração e, na pré-moldagem, o controle de qualidade de execução é muito mais eficiente, aumentando-se assim a durabilidade da estrutura. 


\subsection{OBJETIVOS}

Observa-se ao longo do tempo um aumento da resistência dos concretos utilizados na Construção Civil. Concretos de resistência característica da ordem de $40 M P a$ ou superior são mais do que comuns em países como EUA, Noruega e Canadá. No Brasil, existe uma certa resistência por parte de muitos projetistas em relação ao seu uso em elementos fletidos. Alguns optam simplesmente por não utilizá-lo, enquanto que outros o utilizam seguindo as mesmas recomendações de norma para concretos de resistência usual.

Utilizar concretos de resistências inferiores em estruturas onde o concreto de alto desempenho se apresenta como melhor solução significa ir contra a tendência tecnológica natural da utilização de melhores materiais. Projetar e detalhar estruturas de CAD seguindo as mesmas recomendações de concretos usuais significa cometer erros ou de economia ou de segurança.

\section{O principal objetivo deste trabalho é ajudar a corrigir esta situação,} possibilitando o dimensionamento e detalhamento corretos das vigas de CAD.

As pesquisas realizadas nos últimos 20 anos confirmaram que, em alguns casos, os atuais procedimentos normalizados são aceitáveis. Em outros, porém, algumas diferenças têm sido descobertas, indicando que as expressões para projeto deveriam ser modificadas ou mesmo descartadas, partindo-se assim para novos procedimentos (SHAH \& AHMAD, 1994).

A Norma Brasileira em vigor (NB-1/1978) estabelece procedimentos de projeto (para elementos fletidos) considerados válidos, normalmente, para concretos de resistências características de até $50 M P a$. A rigor, a partir de $40 M P a$, já se justificam mudanças em alguns desses procedimentos, em função das diferentes propriedades mecânicas e reológicas do CAD.

Neste trabalho não serão abordados aspectos de produção (dosagem) do CAD, tampouco aspectos básicos do dimensionamento de elementos fletidos protendidos. 


\subsection{CONSIDERAÇÃO DA SEGURANÇA E NOTAÇÃO}

É importante lembrar que as diversas normas internacionais consideram a segurança de maneira diferente.

Existem basicamente duas formas de se considerar a segurança.

A primeira, neste texto referida como segurança em termos das tensões nos materiais, consiste em majorar os esforços solicitantes (como o faz a NB-1/1978, através do coeficiente $\gamma_{f}$ ) e em minorar as tensões na armadura e no concreto (como o faz a $N B-1 / 1978$, através dos coeficientes $\gamma_{s}$ e $\gamma_{c}$ ).

A segunda, que no presente texto é chamada segurança em termos dos esforços nominais, consiste em majorar os carregamentos atuantes na estrutura (e por conseguinte, os esforços solicitantes correspondentes) e em minorar os esforços resistentes nominais da seção. Estes últimos, por sua vez, são calculados com base nos valores (não minorados) da tensão nominal de escoamento do aço $\left(f_{y}\right)$ e da resistência do concreto à compressão $\left(f_{c}\right)$. É o caso, dentre outras, da norma americana ACI 318 (1995), da norma canadense CAN 3 (1994) e da norma australiana $A S$-3600 (1988).

Em algumas normas, o índice $u$ (ultimate) é acrescentado para indicar que os esforços solicitantes de cálculo foram obtidos majorando-se os carregamentos. Para os esforços resistentes nominais, normalmente acrescenta-se a letra $n$. Assim, $M_{u}$ seria o momento obtido em uma dada seção para os carregamentos majorados, e $M_{n}$ o momento resistente nominal da viga, calculado com base nos valores (não minorados) da tensão nominal de escoamento do aço $\left(f_{y}\right)$ e da resistência do concreto à compressão $\left(f_{c}\right)$. Assim, a segurança será garantida desde que:

$$
M_{u} \leq \phi M_{n}
$$


onde $\phi$ é um fator menor que a unidade que varia de norma para norma, de acordo com o tipo de solicitação estudada.

Infelizmente, a mesma notação pode ter diferentes significados de uma norma para outra, e diferentes normas adotam diferentes coeficientes de segurança.

No presente texto, uniformizou-se a notação e adotou-se, sempre que possível, a notação apresentada nas normas brasileiras. Tal recurso foi utilizado sempre que os conceitos eram idênticos, ou muito próximos, não causando perda de precisão nos resultados. Como exemplo, cita-se a resistência do concreto à compressão requerida $\left(f_{c}^{\prime}\right)$, muito comum em várias normas internacionais, que foi substituída pelo seu equivalente na $N B-1$ (1978), ou seja, pelo $f_{c k}$.

A segurança em termos dos esforços nominais é menos familiar aos projetistas brasileiros. Para os casos em que ela é abordada, adotou-se o índice $d$ (em lugar do índice $u$ e a exemplo do que se faz na NB-1/1978) para os esforços majorados (de cálculo), manteve-se o índice $n$ para os esforços resistentes nominais, e mantevese a letra $\phi$ para os fatores de redução da resistência nominal.

Portanto, a equação (1.1) passa a ser expressa por:

$$
M_{d} \leq \phi M_{n}
$$

Outro aspecto importante a se ressaltar é o cuidado que se deve ter ao se misturar procedimentos de normas diferentes. Não se aconselha tal mistura, a menos que o engenheiro saiba exatamente o que está fazendo, e se sinta suficientemente seguro do seu conhecimento sobre o assunto.

No presente trabalho foram apresentados e adotados diversos procedimentos, alguns normalizados e outros não, tomando-se sempre o cuidado de compatibilizálos para a sua correta aplicação nos exemplos. 


\section{RETRAÇÃO E FLUÊNCIA}

As deformações advindas da retração e da fluência são, ao lado da fissuração, objeto de grande atenção por parte dos pesquisadores, em razão das incertezas associadas ao seu cálculo.

O estudo da retração e da fluência é particularmente importante para o dimensionamento adequado dos elementos protendidos, uma vez que estes fenômenos estão diretamente relacionados com as perdas diferidas de protensão (perdas ao longo do tempo).

Há um consenso entre os pesquisadores de que o CAD é um material de qualidade superior aos concretos de resistência usual, particularmente no que se refere à fluência.

\subsection{RETRAÇÃO}

A retração é a diminuição do volume de concreto com o tempo. Esta diminuição é devida a mudanças físico-químicas dos materiais componentes do concreto, e ocorre mesmo que o elemento não esteja submetido a forças externas.

Estão dentre as muitas variáveis que influenciam a retração: a relação água/cimento, o tamanho do elemento, a taxa de armadura, as condições ambientais (umidade, vento e temperatura) e o tipo de cimento.

Não há muitas informações disponíveis na literatura técnica no que se refere à retração dos diferentes tipos de $\mathrm{CAD}$, e algumas são contraditórias.

Uma retração inicial relativamente alta há muito já havia sido observada por alguns pesquisadores, como PARROT (1969) e SWAMY \& ANAND (1973). Contudo, após 180 dias, esses autores observaram pouca diferença entre a retração do CAD e a do concreto usual feitos com dolomita ou calcário. Segundo PARROT (1969), reduzir o período de cura de 28 para 7 dias causou um aumento insignificante na retração. 
Autores como CORLEY et al. (1971), KAPLAN (1959) e NGAB et al. (1980) concluíram que a retração do $\mathrm{CAD}$ tem comportamento semelhante à do concreto usual. Isso não significa, contudo, que as metodologias disponíveis sejam totalmente adequadas para o cálculo das deformações por retração no CAD.

NAGATAKY \& YONEKURA (1978) relataram que a retração do CAD contendo elevada quantidade de redutores de água foi menor que a observada em concretos usuais.

Segundo MARIKUNTE (1996), o CAD com sílica ativa apresenta maior retração e menor fluência. Além disso, desenvolve fissuração significativamente mais rápido que o concreto usual, e as fissuras se apresentam, normalmente, com maiores aberturas. Os fatores responsáveis por essa maior fissuração são a maior retração, o maior módulo de deformação longitudinal e o menor engrenamento dos agregados.

Durante o processo de hidratação, a retração pode causar tensões que resultam em fissuração no concreto em idades jovens. A presença da fluência durante o período de hidratação, ou seja, em idades muito jovens (primeiras 24 horas), teria o efeito de reduzir essas tensões. A menor fluência no CAD contribuiria, portanto, para a maior fissuração observada.

Além dos fatores já citados, ATTIOGBE (1997) comenta que a microfissuração proveniente da autodissecação (comum em relações água/cimento menores que 0,35 ) pode também ser um fator importante da maior fissuração observada no CAD durante os primeiros dias. A autodissecação é a diminuição da quantidade de água nos poros do concreto, à medida que continua o processo de hidratação após a mistura.

COOK et al. (1997) realizaram pesquisas em concretos de $30 M P a, 70 M P a$ e $100 M P a$, todos com agregados calcários. Os concretos de resistência de 70MPa e $100 \mathrm{MPa}$ continham de $7 \%$ a $8 \%$ e de $8 \%$ a $9 \%$ de sílica ativa, respectivamente, e foram obtidos com a utilização de superplastificante à base de naftaleno. Em suas pesquisas, estes autores observaram que, ao se desmoldar os elementos de CAD em idades muito jovens, maiores deformações por retração eram obtidas à medida que se aumentava a resistência do concreto à compressão. 
A fissuração provocada pela retração pode causar não só problemas estéticos, mas pode, em casos extremos, prejudicar uma das principais qualidades do CAD, que é a durabilidade.

Por se tratar de um país de clima quente na maior parte do seu território, informações sobre o comportamento de elementos de CAD expostos a maiores temperaturas ambientes são interessantes para o Brasil. Nestas condições, há uma maior probabilidade de fissuração por retração plástica.

A retração plástica ocorre nas primeiras poucas horas depois da concretagem. Elementos com maiores superfícies como lajes, pavimentos rodoviários ou industriais, muros de contenção, ou mesmo grandes vigas protendidas, são mais facilmente afetados pela exposição às condições ambientais. Nestes casos, a umidade evapora-se rapidamente da superfície de concreto sendo substituída pela água que é exsudada das camadas inferiores da massa de concreto.

Em estudo realizado com painéis de concreto submetidos a diferentes condições de exposição ambiental, MIRZA et al. (1996) concluíram que:

- Concretos de resistência usual contendo uma grande quantidade de água de mistura apresentaram maiores taxas de evaporação; contudo, a sua fissuração foi muito menos severa que nos concretos de alto desempenho.

- A retração plástica é potencialmente maior no CAD com sílica ativa quando exposto a temperaturas ambientes mais elevadas.

- Quando ainda úmidos, concretos de resistência usual (23MPa e 40MPa) e de maior resistência $(60 \mathrm{MPa}$ e $84 \mathrm{MPa})$ apresentaram comportamentos diferentes em termos das características da retração plástica quando expostos a um ambiente aberto de clima quente. Devido a uma menor quantidade de água no CAD, tanto a perda de água como a taxa máxima de evaporação são menores.

- A presença de sílica ativa no concreto de $84 M P a$ torna a mistura consideravelmente impermeável, diminuindo a exsudação. Assim, mesmo em taxas de evaporação menores que o valor limite de $1,0 \mathrm{~kg} / \mathrm{m}^{2}-h$, as superfícies dos elementos de CAD apresentaram fissuração por retração plástica. 
- A presença de vento na superfície aumenta a perda total de umidade, aumenta a taxa máxima de evaporação e leva à fissuração tanto de elementos com concretos usuais como em elementos de CAD.

AÏTCIN et al. (1994) realizaram pesquisas com dois tipos de concreto. O primeiro com resistência à compressão de $98 M P a$ aos 91 dias, e o segundo com resistência de $80 M P a$. O primeiro continha sílica ativa, e o segundo não. Estes autores chegaram às seguintes conclusões:

- A retração do concreto de $98 M P a$ com uma relação água/(cimento+sílica ativa) de 0,22 foi menor que a observada no concreto de $80 M P a$ com uma relação água/cimento de 0,28 , para as diferentes condições de cura estudadas.

- A influência da duração da cura é mais pronunciada para o concreto com resistência de $80 M P a$ que para o de $98 M P a$. Para ambos, quanto maior o tempo de cura, menor a retração, a exemplo do que acontece com os concretos usuais.

- A relação retração/perda de massa para o CAD é quase linear, como no concreto usual.

\subsection{FLUÊNCIA}

Quando um elemento de concreto é submetido a tensão, sua deformação muda com o tempo. Este aumento das deformações dependente do tempo é chamada fluência.

Considera-se que a fluência tem duas parcelas: a fluência básica (basic creep) e a fluência seca (drying creep). A primeira é obtida de exemplares de laboratório, onde se obriga que a perda de umidade para o ambiente seja praticamente nula. A segunda (fluência seca) é calculada subtraindo-se as deformações da fluência básica e da retração, da deformação total de exemplares sob tensão constante, armazenados à uma determinada umidade relativa, de tal forma que os mesmos possam trocar umidade com o ambiente. 
De um modo geral, concretos que apresentam baixa retração também o fazem em relação à fluência. A recíproca não é necessariamente correta.

A exemplo do que acontece com os concretos usuais, a fluência no CAD é consideravelmente menor para carregamentos após os 28 dias, quando o aumento da resistência é pequeno.

PARROT (1969) relata que a deformação total observada em condições de perda de umidade quase nula, em elementos de CAD submetidos a carregamento prolongado e igual a 30\% da resistência última, foi a mesma verificada em concretos usuais quando expressa como um percentual da deformação inicial (imediata). Para cura ao ar livre, este percentual foi $25 \%$ menor que o observado nos concretos usuais.

Segundo NAGATAKY \& YONEKURA (1978), a fluência do CAD feito com elevadas quantidades de redutores é significativamente menor.

Pesquisas realizadas por CORLEY \& RUSSELL (1978) e NGAB et al. (1980) observaram que o coeficiente de fluência unitária $\left(\rho_{u}\right)$ máximo foi menor para o CAD que para concretos usuais carregados na mesma idade.

Seja o coeficiente de fluência $\varphi(t)$ definido por:

$$
\varphi(t)=\frac{\varepsilon_{c c}(t)}{\varepsilon_{c i}}
$$

onde:

$\varepsilon_{\mathrm{cc}}(t)$ deformação adicional devida à fluência

$\varepsilon_{c i} \quad$ deformação elástica inicial

Portanto, a deformação adicional (para uma determinada idade $t$ ) devida à fluência pode ser determinada em função da deformação elástica inicial.

Como se sabe, as deformações adicionais devidas à fluência tendem assintoticamente a um valor constante $\left(\varepsilon_{c c u}\right)$, chamado deformação adicional última (máxima) devida à fluência. 
O coeficiente de fluência último $\left(\varphi_{u}\right)$ será dado por:

$$
\varphi_{u}=\frac{\varepsilon_{c c u}}{\varepsilon_{c i}}
$$

Alguns valores típicos de $\varphi_{u}$ são apresentados na tabela 2.1

TABELA 2.1 - Valores de $\varphi_{u}$ Fonte: NILSON \& WINTER (1991) (adaptada)

\begin{tabular}{|c|c|}
\hline $\begin{array}{c}\text { Resistência à compressão } \\
\text { (MPa) }\end{array}$ & $\boldsymbol{\varphi}_{u}$ \\
\hline 20 & 3,10 \\
\hline 30 & 2,90 \\
\hline 35 & 2,65 \\
\hline 40 & 2,40 \\
\hline 50 & 2,20 \\
\hline 55 & 2,00 \\
\hline
\end{tabular}

Por estes valores, nota-se claramente a tendência de diminuição da fluência com o aumento da resistência.

O coeficiente de fluência unitária $\left(\rho_{u}\right)$ é definido como:

$$
\rho_{u}=\frac{\varepsilon_{c c u}}{\sigma_{c i}}
$$

onde:

$$
\begin{array}{ll}
\varepsilon_{c c u} & \text { deformação adicional devida à fluência } \\
\sigma_{c i} & \text { tensão no elemento estrutural correspondente à deformação inicial do } \\
& \text { concreto }\left(\varepsilon_{c i}\right)
\end{array}
$$


Um exemplo da diminuição da fluência com o aumento da resistência é dado na figura 2.1 .

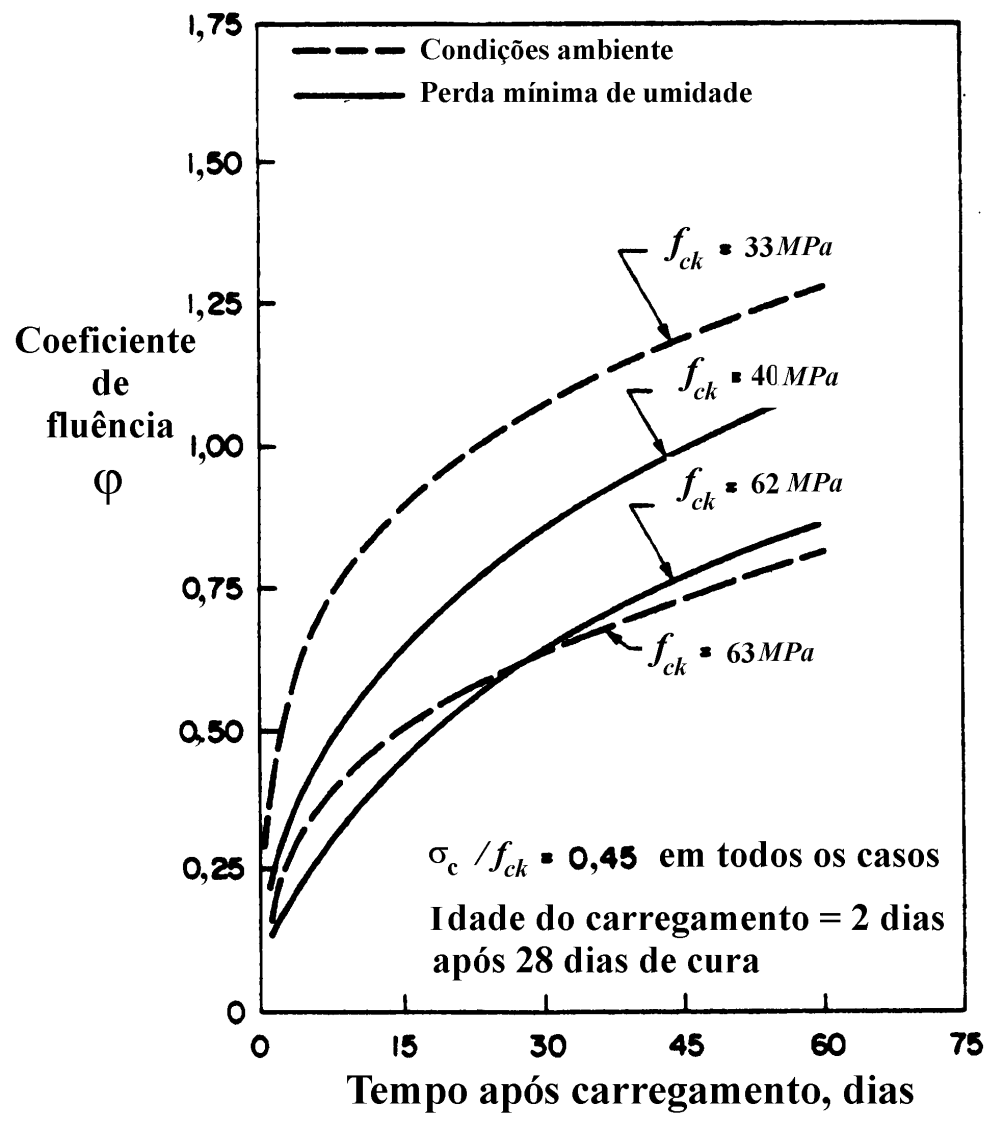

FIGURA 2.1 - Relação entre o coeficiente de fluência e o tempo FONTE: NGAB et al. (1980) (adaptada)

Contudo, os elementos feitos com CAD estão normalmente submetidos a níveis mais altos de tensão. Por isso, estes pesquisadores consideram que a fluência total será basicamente a mesma para qualquer resistência.

A exemplo do que ocorre nos concretos usuais, a fluência diminui quando aumenta a idade do concreto no carregamento, o coeficiente de fluência unitária $\left(\rho_{u}\right)$ aumenta quando aumenta a relação água/cimento, e há uma relação linear com a tensão aplicada. Esta linearidade se estende a uma relação tensão-deformação mais alta que para concretos usuais. 
O principal parâmetro que afeta a fluência é a intensidade do carregamento em função do tempo, ou seja, a tensão à qual está submetido o elemento. Contudo, a fluência também é influenciada pela composição do concreto, pelas condições do ambiente e pelo tamanho do elemento.

COOK et al. (1997) concluíram em suas pesquisas que:

- A fluência dos concretos de $100 M P a$ é muito mais sensível à idade do carregamento que concretos de resistência de $70 \mathrm{MPa}$ e de $30 \mathrm{MPa}$. Os concretos de $100 \mathrm{MPa}$ apresentaram deformações por fluência significativamente maiores para carregamentos em idades muito jovens. Contudo, isto pode ter sido causado pelo início tardio da pega em função da utilização de uma quantidade significativa de superplastificante à base de naftaleno. Este efeito não foi observado em casos onde o concreto foi carregado após ter atingido cerca de um terço da sua resistência aos 28 dias.

- A deformação total desenvolvida pelos concretos de $30 M P a$, com condições de cura onde é muito pequena a perda de água, estabilizou mais rapidamente que nos concretos de $70 M P a$ e de $100 M P a$.

- Para uma mesma idade de carregamento, a deformação por fluência diminui com o aumento da resistência.

\subsection{ASPECTOS DE NORMAS E CÁlCULO DA RETRAÇÃo E DA FLUÊNCIA}

Segundo Ä̈TCIN et al. (1994), a metodologia apresentada pelo ACI 209 (1992) para o cálculo da retração, a qual foi obtida a partir de concretos de resistência usual, não é válida para o $\mathrm{CAD}$, a menos que novos parâmetros sejam incluídos.

De acordo com COOK et al. (1997), o cálculo das deformações usando-se a metodologia do CEB-FIP (1990) concorda razoavelmente bem com as deformações por fluência, exceto para o caso dos concretos de $100 \mathrm{MPa}$ carregados em idades muito jovens. 
Trabalhos realizados por McDONALD \& ROPER (1993) e GARDNER \& ZHAO (1993) concluíram que as metodologias do CEB-FIP (1990) e do ACI 209 (1982) não são muito adequadas para o cálculo da fluência e da retração nos concretos de alto desempenho.

Segundo estes autores, o CEB-FIP (1990) subestima a retração em um fator de aproximadamente dois, e o ACI 209 (1982) mostra uma tendência sistemática de superestimar a retração nas idades iniciais e de subestimá-la nas idades avançadas.

Concluem ainda que o CEB-FIP (1990) apresenta uma correlação aceitável com as deformações experimentais por fluência, e o ACI 209 (1982) subestima a fluência.

Para as deformações totais, retração mais fluência sob uma tensão de $30 \%$ da resistência, as duas normas subestimam os resultados experimentais.

Se é necessário que o cálculo das deformações por retração e por fluência seja muito preciso, o comportamento para carregamentos de longa duração deve ser extrapolado a partir de testes de retração e de fluência realizados em protótipos de concreto, usando-se uma função de tempo adequada. Contudo, equações relativamente simples são necessárias para projeto quando apenas fatores conhecidos pelo projetista de estruturas são utilizados. Esse fatores são: resistência à compressão do concreto, idade do concreto no carregamento, provável umidade ambiente e relação volume/superfície do elemento.

No que se segue, descreve-se a proposta de GARDNER \& ZHAO (1993) para o cálculo da fluência e da retração no CAD.

O módulo de deformação longitudinal do concreto $\left(E_{c}\right)$ é estimado para propósitos de projeto por:

$$
E_{c}=3500+4300 \sqrt{f_{c m}^{\prime}}
$$

$f_{c m}^{\prime}$ é a resistência média à compressão do concreto em $M P a$.

Como o módulo de elasticidade é função da resistência do concreto, é necessário estimar, em situação de projeto, o desenvolvimento da resistência do 
concreto com o tempo e a temperatura (maturidade). Para se estimar a resistência do concreto nas idades iniciais, ZHAO (1991) sugere a seguinte expressão:

$$
f_{c m, t}^{\prime}=f_{c m, 28}^{\prime} \frac{t^{3 / 4}}{a+b t^{3 / 4}}
$$

onde:

$$
\begin{array}{ll}
f_{c m, t}^{\prime} & \text { resistência média do concreto na idade } t \\
f_{c m, 28}^{\prime} & \text { resistência média do concreto aos } 28 \text { dias } \\
t & \text { idade do concreto em dias }
\end{array}
$$

Os valores de $a$ e $b$ são dados na tabela 2.2.

TABELA 2.2 - Valores de $a$ e $b$

\begin{tabular}{|c|c|c|}
\hline TIPO DE CIMENTO & $\boldsymbol{a}$ & $\boldsymbol{b}$ \\
\hline I (CP) & 2,8 & 0,77 \\
\hline II (MRS) & 3,4 & 0,72 \\
\hline III (ARI) & 1,0 & 0,92 \\
\hline
\end{tabular}

A classificação dos cimentos em tipos I, II e III é referente às normas americanas.

O cimento tipo I é o cimento normal, usado em construções corriqueiras, onde não são necessárias propriedades especiais. Seria equivalente ao cimento brasileiro Portland comum (CP) (ver NBR-5732).

O cimento tipo II possui baixo calor de hidratação. É usado em situações onde existe moderada exposição ao ataque de sulfatos ou onde se deseja controlar o calor de hidratação. É equivalente ao cimento brasileiro Portland de moderada resistência a sulfatos e moderado calor de hidratação (MRS) (ver EB-903). 
O cimento tipo III apresenta alta resistência inicial e apresenta calor de hidratação consideravelmente maior que o cimento tipo I. É equivalente ao cimento brasileiro Portland de alta resistência inicial (ARI) (ver NBR-5733).

Vale ressaltar que não foi encontrado pelo autor do presente texto um estudo que correlacionasse propriedades específicas dos cimentos americanos com as dos brasileiros.

Além disso, sabe-se que dentro de um país, ou mesmo de uma região, até a simples mudança da marca de cimento (para um mesmo tipo de cimento) pode provocar mudanças no comportamento do concreto, tanto do ponto de vista de resistência como de propriedades dependentes do tempo. A correlação apresentada foi feita com base nas características principais dos cimentos americanos e brasileiros, como ganho de resistência com o tempo, resistência ao ataque de sulfatos e calor de hidratação.

Portanto, o paralelo feito aqui tem um objetivo prático, que se acredita não trazer maiores erros, em função de uma série de outras variáveis que influenciam no comportamento do concreto (como o tipo de agregado, por exemplo, que varia de região para região), que pela dificuldade de serem levadas em consideração, não são contempladas normalmente pelas normas.

A temperatura é uma variável normalmente considerada importante para cálculo da retração. A metodologia proposta por GARDNER \& ZHAO (1993) não leva em consideração este fato. Apesar disso, contudo, para o exemplo apresentado neste capítulo, leva a resultados bastante coerentes com a literatura atual, e próximos aos do ACI 209 (1992). Trata-se portanto de uma metodologia bastante útil, em particular por sua simplicidade e precisão de resultados.

A metodologia do ACI 209 (1992) é ampla e aborda os casos de cura úmida e de cura a vapor. Porém, necessita de dados nem sempre disponíveis em situações de projeto e é consideravelmente mais cansativa que a proposta por GARDNER \& ZHAO (1993).

O CAD apresenta uma taxa mais alta de ganho de resistência nas idades inicias quando comparado com os concretos usuais. Contudo, em idades posteriores, a diferença não é significativa. 
PARROT (1969) relatou relações entre as resistências aos 7 dias e aos 28 dias entre 0,7 e 0,75 para concretos usuais e entre 0,8 e 0,9 para CAD.

CARRASQUILO et. al (1982) encontraram relações entre as resistências aos 7 dias e aos 95 dias de 0,6 para concretos usuais e em torno de 0,73 para o CAD.

Um modo simples de se melhorar o cálculo das deformações é medir as resistências do concreto na idade do carregamento e aos 28 dias.

Usando-se a expressão em função do tempo proposta (2.6), a seguinte equação foi desenvolvida para o cálculo da retração, no tempo $t$, a partir da retração a uma umidade relativa de 40\%, com os fatores de correção para: (a) idade, (b) resistência à compressão, (c) duração do carregamento e (d) tamanho do elemento e umidade relativa.

$$
\begin{gathered}
\varepsilon_{c s}=\varepsilon_{c s u} \times \beta(h) \times \beta(t) \\
\varepsilon_{c s u}=900 \times K \times\left(\frac{f_{c m, 28}^{\prime}}{f_{c m, t_{c}}^{\prime}}\right)^{1 / 2} \times\left(\frac{25}{f_{c m, 28}^{\prime}}\right)^{1 / 2} \times 10^{-6}
\end{gathered}
$$

(a)

(b)

$$
\beta(t)=\left[\frac{7,27+\ln \left(t-t_{c}\right)}{17,18}\right] \times\left(\frac{t-t_{c}}{t-t_{c}+0,0125 \times(V / S)^{2}}\right)
$$

$$
\beta(h)=\left\{\begin{array}{l}
\left(1-h^{4}\right) \text { para } h<0,99 \\
-0,20 \text { para } h=1,00
\end{array}\right.
$$

onde:

$$
\begin{array}{ll}
h & \text { umidade expressa como um decimal } \\
t & \text { idade do concreto (dias) } \\
t_{c} & \text { idade de início da secagem (dias) } \\
K & K=1,00 \text { para cimento tipo I; } K=0,70 \text { para cimento tipo II; } K=1,33 \\
& \text { para cimento tipo III. }
\end{array}
$$


$(V / S)$ relação volume/superfície $(\mathrm{mm})$

$f_{c m, t}^{\prime} \quad$ resistência média do concreto no início secagem

$f_{c m, 28}^{\prime}$ resistência média do concreto aos 28 dias

$f_{c m, t_{0}}^{\prime} \quad$ resistência média do concreto na data do carregamento

Para concretos obtidos com cinza volante ou escória de alto forno granulada, as resistências medidas deveriam ser usadas para determinar qual dos valores da tabela 2.2 melhor representa o resultado dos testes para se determinar o valor adequado de $K$ a ser usado.

Para o cálculo da fluência, GARDNER \& ZHAO (1993) propuseram a seguinte expressão para o coeficiente de fluência $(\varphi)$ :

$$
\begin{aligned}
\varphi\left(t_{0}, t\right)= & {\left[1,57+2,98 \times\left(\frac{f_{c m, 28}^{\prime}}{f_{c m, t_{0}}^{\prime}}\right) \times\left(\frac{25}{f_{c m, 28}^{\prime}}\right)^{1 / 2} \times\left(1-h^{2}\right) \times\left(\frac{t-t_{0}}{t-t_{0}+0,1 \times(V / S)^{2}}\right)\right] \times } \\
& {\left[\frac{7,27+\ln \left(t-t_{0}\right)}{17,18}\right] }
\end{aligned}
$$

$t_{0}$ é a idade do concreto no carregamento (dias).

Note-se que não se assume uma deformação última por fluência. Portanto, teoricamente, a deformação cresce indefinidamente.

Todas as equações apresentadas até aqui usam a resistência média à compressão, a qual não é conhecida a priori pelo projetista. Assim, em situação de projeto, pode-se usar a expressão do CEB-FIP (1990) que relaciona a resistência média com a resistência característica aos 28 dias:

$$
f_{c m, 28}^{\prime}=f_{c k, 28}+8 \quad(M P a)
$$

onde: 
$f_{c m, 28}^{\prime}$ resistência média do concreto aos 28 dias

$f_{c k, 28}$ resistência à compressão característica ou especificada aos 28 dias

Para a resistência do concreto à tração $\left(f_{t}\right)$, pode-se adotar a expressão do CEB-FIP (1990):

$$
f_{t}=0,30 f_{c m}^{\cdot 2 / 3}(M P a)
$$

Vale ressaltar que o módulo de deformação longitudinal, a fluência e a retração são afetados pela rigidez do agregado, e que o único parâmetro usado nas expressões propostas são a resistência do concreto aos 28 dias e na idade do carregamento.

É comum a utilização de sílica ativa para obtenção de resistências mais altas.

De Larrard \& Le Roy (1992) concluiram que uma alta retração, responsável por fissuração em idades jovens, ocorre em concretos que apresentam simultaneamente baixa relação água/cimento e presença de sílica ativa.

Assim, nos casos onde esta fissuração é provável e prejudicial (como em reservatórios e usinas nucleares), é melhor não usar altos percentuais de sílica ativa, ou concretos com relações água/cimento muito baixas.

\subsection{EXEMPLO DE APLICAÇÃO}

Considere-se uma viga pré-moldada, com pós-tensão, biapoiada, apresentada na figura 2.2. Esta mesma viga será analisada nos exemplos dos capítulos posteriores.

\section{Propriedades geométricas da seção real:}

$$
\begin{aligned}
& A_{c}=0,66 \mathrm{~m}^{2} ; I_{g}=0,0815 \mathrm{~m}^{4} ; y_{\mathrm{inf}}=0,815 \mathrm{~m} ; y_{\text {sup }}=0,385 \mathrm{~m} \\
& w_{\mathrm{inf}}=I_{g} / y_{\mathrm{inf}}=0,100 \mathrm{~m}^{3} ; w_{\text {sup }}=I_{g} / y_{\text {sup }}=0,212 \mathrm{~m}^{3} ; p=5,217 \mathrm{~m}
\end{aligned}
$$


Propriedades geométricas da seção "T" equivalente:

$$
\begin{aligned}
& A_{c}=0,66 m^{2} ; I_{g}=0,0817 m^{4} ; y_{\text {inf }}=0,816 m ; y_{\text {sup }}=0,384 m \\
& w_{\text {inf }}=0,100 m^{3} ; w_{\text {sup }}=0,213 m^{3}
\end{aligned}
$$
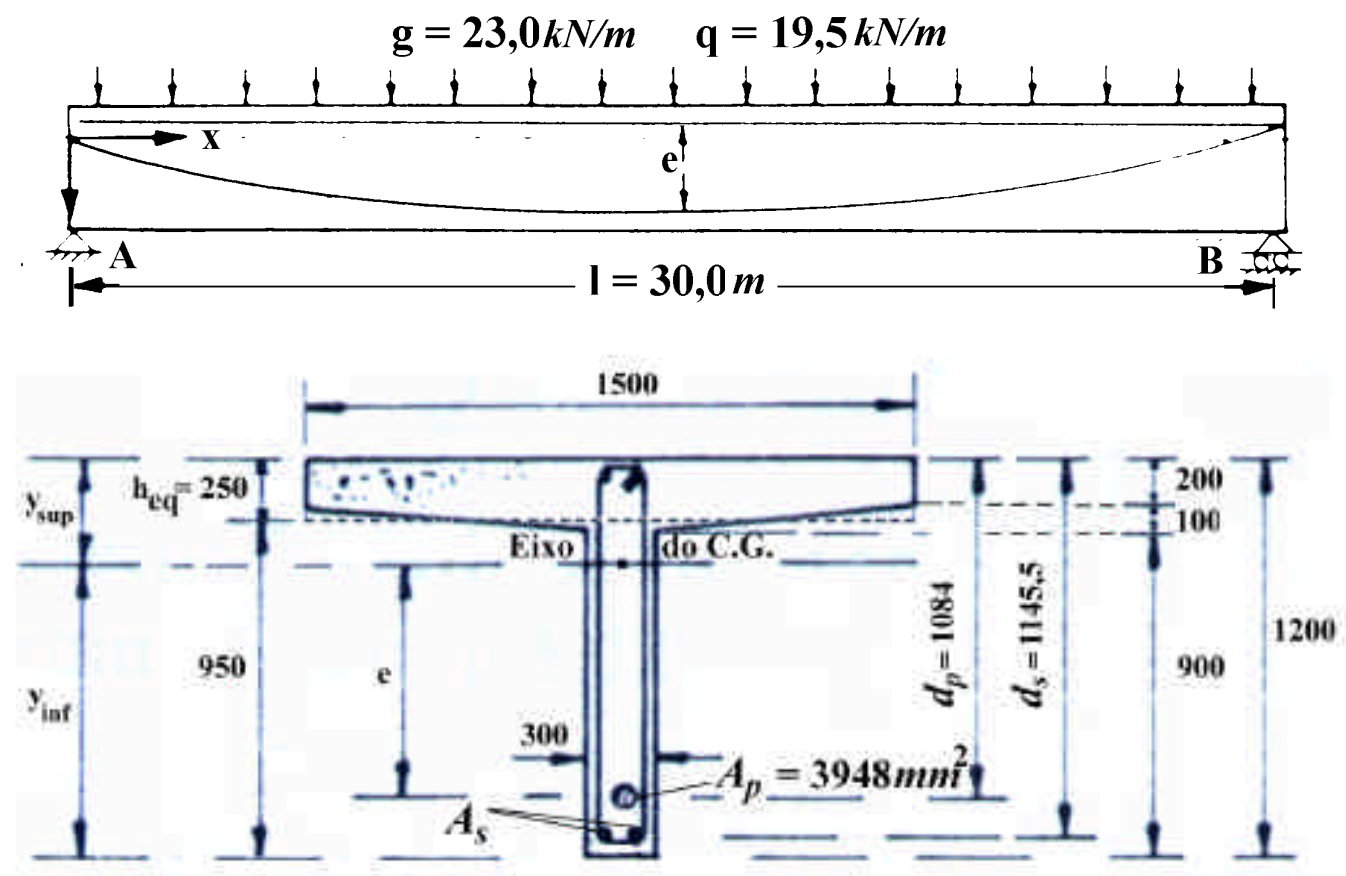

FIGURA 2.2 - Viga do item 2.4 e exemplos 3.3, 4.1 e 5.1.

Várias etapas do dimensionamento de uma viga protendida dependem da força efetiva de protensão $\left(P_{e}\right)$. Para o cálculo desta, faz-se necessário saber o valor das perdas iniciais e diferidas. Supondo-se conhecidas as perdas iniciais, será calculada a perda por fluência do concreto através da equação (2.11) válida para o CAD.

Será considerado um período de cinco anos, uma vez que, em termos práticos, a deformação por fluência já atingiu o seu valor máximo nesta idade. A protensão será aplicada aos 4 dias, e a umidade relativa do ar considerada igual a 50\%.

\section{$\underline{\text { Dados }}$}

$$
t=1825 \operatorname{dias}\left(5 \text { anos) } ; t_{0}=4 \text { dias; } h=50 \% ; E_{p}=195 G P a\right.
$$


Excentricidade do cabo no meio do vão: $e_{1}=0,7 \mathrm{~m}$

Força inicial de protensão, após perdas iniciais: $P_{i}=5330 \mathrm{kN}$

\section{Solução}

\section{$\rightarrow$ Perda por fluência}

\section{(a) Cálculos iniciais}

Relação volume/superfície:

$$
V / S=A_{c} l / p l=0,66 m^{2} / 5,217 m=126,5 m m
$$

Resistência média do concreto aos 28 dias:

$$
\begin{aligned}
& f_{c m, 28}^{\prime}=f_{c k, 28}+8 M P a \\
& f_{c m, 28}^{\prime}=78 M P a
\end{aligned}
$$

Resistência média na data da protensão:

$$
f_{c m, t}^{\prime}=f_{c m, 28}^{\prime} \frac{t^{3 / 4}}{a+b t^{3 / 4}}
$$

De acordo com a tabela 2.2, para o cimento ARI, tem-se: $a=1,00$ e $b=0,92$. Assim, para a resistência média com 4 dias, tem-se:

$$
\begin{aligned}
& f_{c m, 4}^{\prime}=78 \frac{4^{3 / 4}}{1+0,92 \times 4^{3 / 4}} \\
& f_{c m, 4}^{\prime}=61,25 \mathrm{MPa}
\end{aligned}
$$

Coeficiente de fluência: 


$$
\begin{aligned}
\varphi\left(t_{0}, \mathrm{t}\right) & =\left[1,57+2,98 \times\left(\frac{f_{c m, 28}^{\prime}}{f_{c m, t_{0}}^{\prime}}\right) \times\left(\frac{25}{f_{c m, 28}^{\prime}}\right)^{1 / 2} \times\left(1-h^{2}\right) \times\left(\frac{t-t_{0}}{t-t_{0}+0,1 \times(V / S)^{2}}\right)\right] \\
\times & {\left[\frac{7,27+\ln \left(t-t_{0}\right)}{17,18}\right] } \\
\varphi(4,1825) & =\left[1,57+2,98 \times\left(\frac{78}{61,25}\right) \times\left(\frac{25}{78}\right)^{1 / 2} \times\left(1-0,5^{2}\right) \times\left(\frac{1825-4}{1825-4+0,1 \times(126,5)^{2}}\right)\right] \\
& \times\left[\frac{7,27+\ln (1825-4)}{17,18}\right] \\
\varphi(4,1825) & =2,09
\end{aligned}
$$

Tensão inicial instalada no cabo de protensão (CP-190RB):

$$
\bar{\sigma}_{p 0}=P_{i} / A_{p}=5330 / 3948=1350 M P a
$$

Este valor é menor que o limite de $0,85 f_{p, 01, k}=1400 \mathrm{MPa}$ estabelecido pelo CEB-FIP (1990).

\section{(b) Cálculo da deformação no concreto por fluência}

Será feita uma estimativa aproximada e conservadora assumindo-se que a tensão no concreto ao nível do cabo $\left(\sigma_{c}\right)$ permanece constante e igual ao seu valor inicial (usualmente alto). Esta tensão $\left(\sigma_{c}\right)$ é a causada pela força inicial de protensão $\left(P_{i}\right)$ e pelo carregamento permanente $(g)$. Sob esta hipótese, a deformação por fluência $\left(\varepsilon_{c c}\right)$ em um tempo $t$ após a transferência (realizada em $t_{0}$ ) pode ser calculada por:

$$
\varepsilon_{c c}(t)=\frac{\sigma_{c}}{E_{c}} \varphi\left(t_{0}, t\right)
$$

A tensão no concreto no nível do cabo será calculada no meio do vão, para uma força de protensão inicial $\left(P_{i}\right)$ de $5330 \mathrm{kN}$.

Momento devido ao carregamento permanente: 


$$
M_{g}=\frac{23 \times 30^{2}}{8}=2588 \mathrm{kN} . \mathrm{m}
$$

Momento da protensão no meio do vão:

$$
M_{p}=P_{i} e_{1}=5330 \times 0,7=3731 \mathrm{kN} . \mathrm{m}
$$

Tensão na fibra extrema inferior:

$$
\begin{aligned}
& \sigma_{c, \text { inf }}=\frac{P_{i}}{A_{c}}+\frac{M_{p}}{w_{\mathrm{inf}}}-\frac{M_{g}}{w_{\mathrm{inf}}} \\
& \sigma_{c, \mathrm{inf}}=\frac{5330 \times 10^{3}}{0,66}+\frac{3731 \times 10^{3}}{0,1}-\frac{2588 \times 10^{3}}{0,1} \\
& \sigma_{c, \mathrm{inf}}=19,51 \mathrm{MPa}
\end{aligned}
$$

Tensão na fibra extrema superior:

$$
\begin{aligned}
\sigma_{c, \text { sup }} & =\frac{P_{i}}{A_{c}}-\frac{M_{p}}{w_{\text {inf }}}+\frac{M_{g}}{w_{\text {inf }}} \\
\sigma_{c, \text { sup }} & =\frac{5330 \times 10^{3}}{0,66}-\frac{3731 \times 10^{3}}{0,213}+\frac{2588 \times 10^{3}}{0,213} \\
\sigma_{c, \text { sup }} & =2,71 M P a
\end{aligned}
$$

A tensão no concreto no nível do cabo será de 17,89MPa, como mostra a figura 2.3:

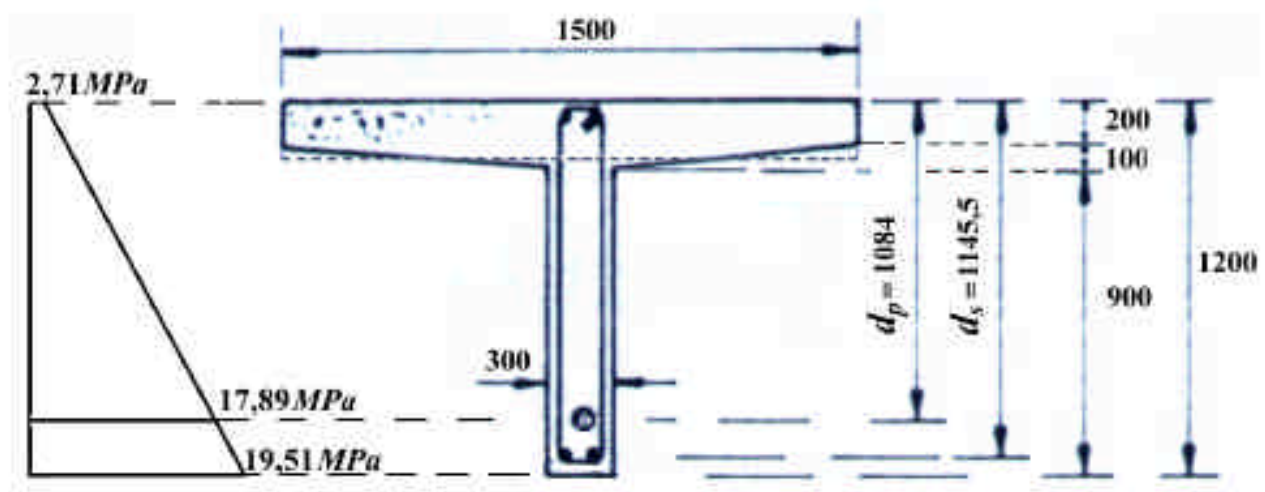

FIGURA 2.3 - Determinação da tensão no concreto no nível do cabo de protensão 
Módulo de deformação longitudinal:

$$
\begin{aligned}
& E_{c}=3500+4300 \sqrt{f_{c m}^{\prime}} \\
& E_{c}=3500+4300 \sqrt{78} \\
& E_{c}=41,47 G P a
\end{aligned}
$$

Deformação por fluência $\left(\varepsilon_{c c}\right)$ :

$$
\begin{aligned}
\varepsilon_{c c}(5 \text { anos }) & =\frac{\sigma_{c}}{E_{c}} \varphi\left(t_{0}, t\right) \\
\varepsilon_{c c}(5 \text { anos }) & =\frac{17,89 \times 10^{6}}{41,47 \times 10^{9}} \times 2,09 \\
\varepsilon_{c c}(5 \text { anos }) & =0,9 \%
\end{aligned}
$$

Portanto, haverá uma queda na tensão da armadura protendida devida à fluência do concreto, dada por:

$$
\begin{aligned}
\Delta \sigma_{p, c} & =\varepsilon_{c c}(5 \text { anos }) \times E_{p} \\
\Delta \sigma_{p, c} & =0,009 \times 195 \times 10^{9} \\
\Delta \sigma_{p, c} & =175,8 \mathrm{MPa}
\end{aligned}
$$

o que equivale a uma perda de $13 \%$ em relação à tensão inicial instalada de $1350 M P a$.

\section{$\rightarrow$ Perda por retração}

Parcela que leva em consideração a idade e a resistência à compressão:

$$
\begin{aligned}
& \varepsilon_{c s u}=900 \times K \times\left(\frac{f_{c m, 28}^{\prime}}{f_{c m, t_{c}}^{\prime}}\right)^{1 / 2} \times\left(\frac{25}{f_{c m, 28}^{\prime}}\right)^{1 / 2} \times 10^{-6} \\
& \varepsilon_{c s u}=900 \times 1,33 \times\left(\frac{78}{61,25}\right)^{1 / 2} \times\left(\frac{25}{78}\right)^{1 / 2} \times 10^{-6} \\
& \varepsilon_{c s u}=0,765 \% \mathrm{o}
\end{aligned}
$$

Parcela que leva em consideração a duração do carregamento e o tamanho do elemento: 


$$
\begin{aligned}
& \beta(t)=\left[\frac{7,27+\ln \left(t-t_{c}\right)}{17,18}\right] \times\left(\frac{t-t_{c}}{t-t_{c}+0,0125 \times(V / S)^{2}}\right) \\
& \beta(t)=\left[\frac{7,27+\ln (1825-4)}{17,18}\right] \times\left(\frac{1825-4}{1825-4+0,0125 \times(126,5)^{2}}\right) \\
& \beta(t)=0,775
\end{aligned}
$$

Parcela que considera a umidade relativa do ar:

$$
\begin{aligned}
& \beta(h)=\left(1-h^{4}\right) \\
& \beta(h)=\left(1-0,5^{4}\right) \\
& \beta(h)=0,9375
\end{aligned}
$$

Retração ao longo dos cinco anos:

$$
\begin{aligned}
\varepsilon_{c s} & =\varepsilon_{s h u} \times \beta(h) \times \beta(t) \\
\varepsilon_{c s} & =0,765 \times 10^{-3} \times 0,9375 \times 0,775 \\
\varepsilon_{c s} & =0,56 \% 0
\end{aligned}
$$

Portanto, haverá uma queda na tensão da armadura protendida devida à retração do concreto, dada por:

$$
\begin{aligned}
\Delta \sigma_{p, s} & =\varepsilon_{c s}(5 \text { anos }) \times E_{p} \\
\Delta \sigma_{p, s} & =0,56 \times 10^{-3} \times 195 \times 10^{9} \\
\Delta \sigma_{p, s} & =109 \mathrm{MPa}
\end{aligned}
$$

o que equivale a uma perda de $8,1 \%$. Assim, as perdas diferidas totais são de $21,1 \%$. 


\section{DIMENSIONAMENTO À FLEXÃO}

Para o correto dimensionamento das seções de concreto armado ou protendido, é necessário que se estabeleçam os diagramas tensão-deformação a serem adotados, de tal forma que eles representem o comportamento real dos materiais que as compõem. A partir dos diagramas, das equações de equilíbrio e de compatibilidade, são determinados os esforços resistentes da seção.

À medida que se aumenta a resistência do concreto, o diagrama tensãodeformação real vai mudando gradativamente, como visto na figura 3.1.

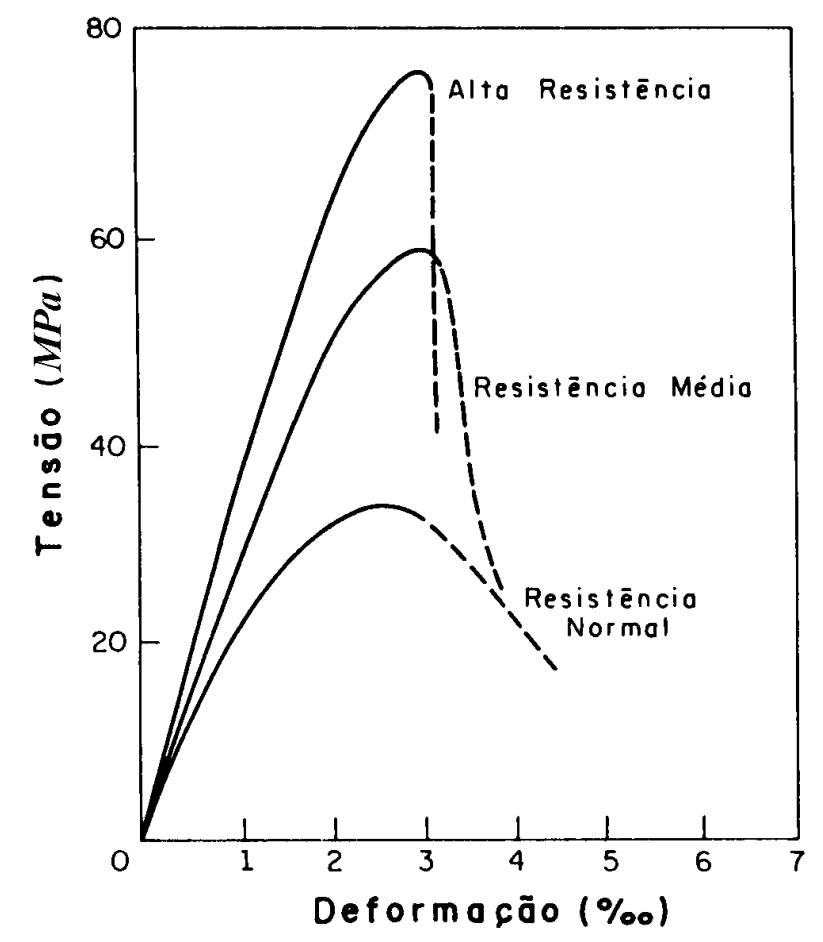

FIGURA 3.1 - Diagramas tensão-deformação típicos do concreto FONTE: NILSON (1985)

Como se pode observar, à medida que a resistência cresce, a deformação na tensão máxima tende a aumentar. Por outro lado, o trecho descendente 
(após a tensão máxima) torna-se mais íngreme, obtendo-se assim valores menores para a deformação última $\left(\varepsilon_{c u}\right)$.

Por comodidade de cálculo, é usual substituir-se o diagrama real por um diagrama simplificado (retangular), o qual deve fornecer resultados equivalentes ao real. Isso é permitido por normas como a NB-1 (1978), o CEB-FIP (1990) e o ACI 318 (1995), por exemplo, tanto para vigas como para pilares de concretos usuais. Vale ressaltar ser esse um recurso numérico, uma vez que a distribuição real de tensões na ruptura não é retangular.

O diagrama retangular das normas citadas anteriormente corresponde ao real com boa precisão no que se refere tanto à intensidade como à posição da resultante de compressão. Com a mudança gradual da forma do diagrama real à medida que se aumenta a resistência, é de se esperar que sejam necessárias mudanças, também graduais, no retangular equivalente.

Estudo realizado por GARCIA \& NILSON (1990), baseado nas curvas tensãodeformação de cilindros com carregamento centrado e tensão máxima igual a $0,85 f_{c}^{\prime}$, sugere que o diagrama retangular de tensão do ACI 318 (1995) é contra a segurança em até mais de $12 \%$ para o projeto de seções retangulares de CAD sujeitas a carregamentos axiais com pequenas excentricidades.

No $A C I 318, f_{c}^{\prime}$ é a resistência especificada à compressão, medida em testes de compressão em cilindros de $15 \mathrm{~cm}$ x $30 \mathrm{~cm}$ após os 28 dias de cura. É a resistência especificada no projeto e usada no dimensionamento. A formulação do ACI 318 (1995) estabelece a resistência média mínima necessária para se assegurar uma probabilidade não maior que $1 \%$ de que a média de três testes consecutivos de resistência estará abaixo da resistência especificada $\left(f_{c}^{\prime}\right)$. Visto de outra forma, ela assegura uma probabilidade não maior que $1 / 11$ de que algum teste resultará em um valor menor que $f_{c}^{\prime}$. Nestas definições, um teste é a média de dois resultados de ensaios de cilindros.

LESLIE et al. (1976) e GARCIA \& NILSON (1990) propuseram diagramas tensão-deformação não retangulares para o projeto de seções de CAD. SWARTZ et al. (1985) e LESLIE et al. (1976) sugerem que o valor de 3\%, adotado pelo 
ACI 318 para a deformação última de compressão no concreto $\left(\varepsilon_{c u}\right)$, é contra a segurança para o projeto de seções de CAD. Isso se torna ainda mais significativo no que se refere à $N B-1$ (1978), a qual adota $\varepsilon_{\mathrm{cu}}=3,5 \%$ o .

A norma norueguesa atual tem um diagrama tensão-deformação válido para CAD. Segundo IBRAHIM \& MacGREGOR (1997), este diagrama é a favor da segurança quando comparado ao do $A C I 318$, e a diferença entre os diagramas de interação gerados usando-se essas duas normas é significativa para a parte do diagrama onde o carregamento axial é alto (quando a seção está submetida a forças axiais com pequenas excentricidades).

\subsection{RECOMENDAÇÕES DE NORMAS}

No que se segue, serão revistas as principais recomendações das normas vigentes no que se refere aos diagramas tensão-deformação a serem adotados para o concreto. Espera-se assim, fornecer uma visão geral do atual estado de conhecimento do assunto, particularmente com relação ao CAD.

\subsubsection{ACI 318 (1995) e CAN 3 (1994)}

O ACI 318 e a norma canadense CAN 3 publicada pela CSA (Canadian Standard Association) têm considerações idênticas para o diagrama tensãodeformação. Ambos especificam a resistência do concreto à compressão $\left(f_{c}^{\prime}\right)$ usando cilindros de $15 \mathrm{~cm}$ x $30 \mathrm{~cm}$. No ACI 318 e na $C A N 3$, diagramas com forma retangular, trapezoidal, parabólica e outras podem ser assumidos, assegurando-se que a relação entre a distribuição de tensão de compressão e a resultante de deformação no concreto esteja de acordo com os testes experimentais. A figura 3.2c mostra os parâmetros do diagrama tensão-deformação obtidos experimentalmente: $k_{1}, k_{2}$ e $k_{3}$.

$k_{1}$ relação entre a tensão média de compressão e a tensão máxima de compressão 
$k_{2} \quad$ relação entre a distância da fibra mais comprimida até a resultante da tensão de compressão e a distância da fibra mais comprimida até a linha neutra

$k_{3}$ relação entre a tensão máxima de compressão no diagrama tensãodeformação na estrutura e a resistência do cilindro

O diagrama de tensão retangular equivalente é definido pelos parâmetros $\alpha_{1}$ e $\beta_{1}$, como mostrado na figura $3.2 \mathrm{~d}$.

$\alpha_{1}$ relação entre a tensão no diagrama retangular e a resistência do cilindro

$\beta_{1} \quad$ relação entre a altura do diagrama retangular e a posição da linha neutra

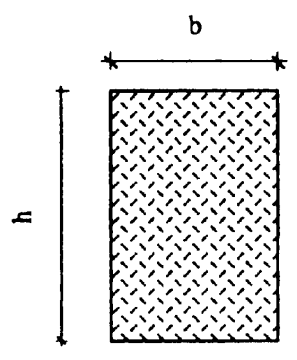

(a)

ZONA COMPRIMIDA

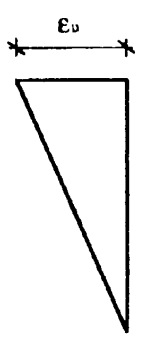

(b) DEFORMAÇ̃̃ES

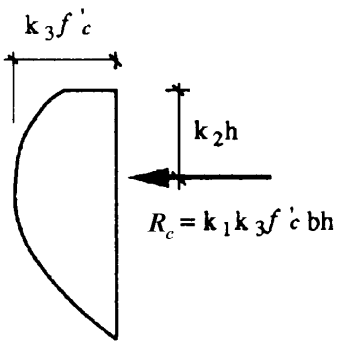

(c)

TENSÕES E PARÂMETROS GERAIS DOS DIAGRAMAS

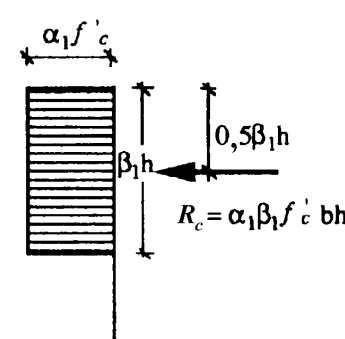

(d)

DIAGRAMA RETANGULAR

FIGURA 3.2 - Parâmetros do diagrama tensão-deformação para seções retangulares FONTE: IBRAHIM \& MacGREGOR (1997)

Fez-se uma distinção entre $k_{1}, k_{2}$ e $k_{3}$ obtidos experimentalmente e os parâmetros $\alpha_{1}$ e $\beta_{1}$ usados para definir o diagrama retangular, porque este utiliza apenas dois parâmetros para aproximar os efeitos dos três medidos nos testes.

No ACI 318 e na CAN 3 o parâmetro $\alpha_{1}$ é assumido como constante e igual a 0,85. O parâmetro $\beta_{1}$ é igual a 0,85 para concretos com resistências até $30 M P a$, sendo reduzido continuamente a uma razão de 0,08 para cada $10 M P a$ de resistência 
acima de 30MPa. O parâmetro $\beta_{1}$ não deve ser tomado menor que 0,65. A deformação máxima de compressão no concreto $\left(\varepsilon_{c u}\right)$ é assumida como tendo um valor constante igual a $3 \%$ o. O parâmetro $k_{2}$ é admitido como igual a $0,5 \beta_{1}$.

\subsubsection{NB-1 (1978)}

A $N B-1$ (1978) admite $\varepsilon_{c u}=3,5 \%$. Nas seções inteiramente comprimidas (domínio 5), admite que o encurtamento na borda mais comprimida varie de 3,5\%o a $2 \%$ na ocasião da ruptura, e que a deformação a 3/7 da altura total da seção, medida a partir da borda mais comprimida, mantém-se constante e igual a $2 \%$.

A distribuição das tensões do concreto na seção se faz de acordo com um diagrama parábola-retângulo (figura 3.3). Além disso, essa norma permite um procedimento semelhante ao do $A C I 318$, através da substituição do diagrama real por um diagrama retangular equivalente com altura de 0,8x (figura 3.3), com uma tensão uniforme dada por:

$0,85 f_{c d} \quad$ caso em que a largura da seção, medida paralelamente à linha neutra, não diminuir a partir desta para a borda mais comprimida

$0,80 f_{c d} \quad$ caso contrário

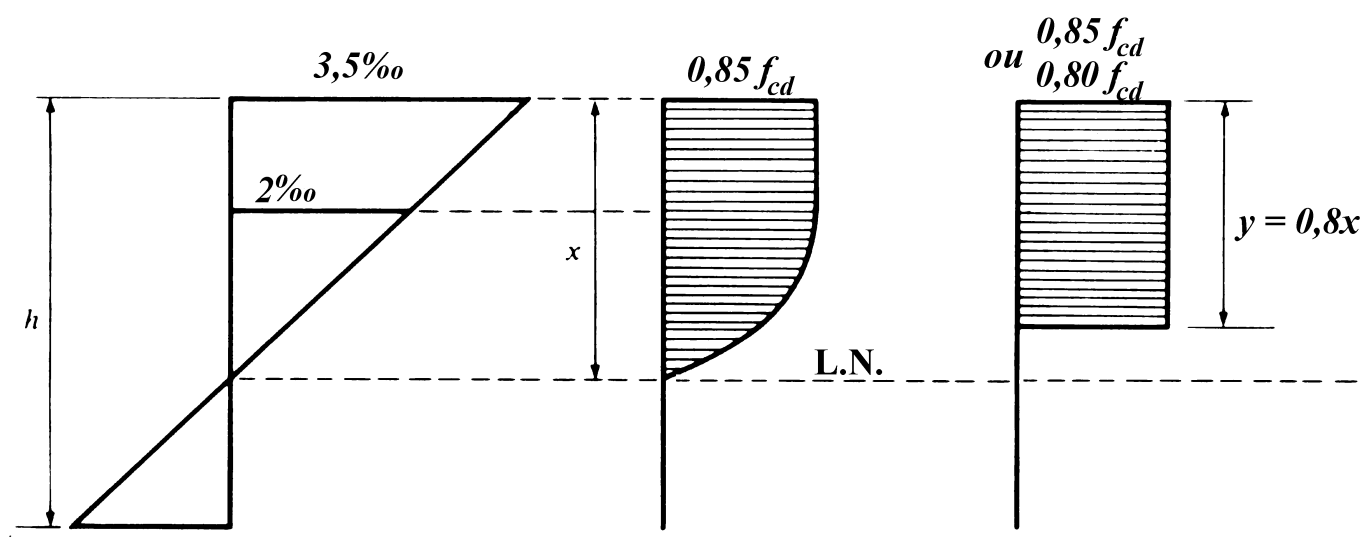

FIGURA 3.3 - Diagramas permitidos pela $N B-1$ (1978) 
O valor característico da resistência do concreto à compressão $\left(f_{c k}\right)$ é estabelecido em cilindros de $15 \mathrm{~cm}$ x $30 \mathrm{~cm}$, aos 28 dias. O valor de cálculo da resistência do concreto à compressão $\left(f_{c d}\right)$ é obtido minorando-se $f_{c k}$ através do coeficiente $\gamma_{\mathrm{c}}$ usualmente tomado igual a 1,4.

Portanto, fazendo-se um paralelo com o ACI 318, a NB-1 (1978) adota:

$\alpha_{1} \quad$ constante igual a 0,85 ou 0,8 , conforme os casos citados

$\beta_{1} \quad$ constante igual a 0,8

\subsubsection{Norma Norueguesa NS 3473 (1992)}

A resistência mais alta para concretos de densidade normal, baseada em corpos-de-prova cúbicos de $100 \mathrm{~mm}$ de aresta, é $105 \mathrm{MPa}$ (classe $\mathrm{C} 105$ ). O fator de conversão para o cilindro de $15 \mathrm{~cm} \times 30 \mathrm{~cm}$ é dado como 0,8 até C55 e a resistência do cubo menos 11MPa para classes mais altas (tabela 3.1).

TABELA 3.1 - Resistências da Norma Norueguesa $(M P a)$

\begin{tabular}{|l|c|c|c|c|c|c|c|c|c|c|}
\hline \multirow{2}{*}{$\begin{array}{l}\text { Valores } \\
\text { característicos para }\end{array}$} & \multicolumn{10}{|c|}{ Classes de resistência } \\
\cline { 2 - 13 } & LC15 & LC25 & C35 & C45 & C55 & C65 & C75 & C85 & C95 & C105 \\
\hline Resistência cúbica $f_{c c}$ & 15,0 & 25,0 & 35,0 & 45,0 & 55,0 & 65,0 & 75,0 & 85,0 & & \\
\hline Resistência cilíndrica $f_{c c k}$ & 12,0 & 20,0 & 28,0 & 36,0 & 44,0 & 54,0 & 64,0 & 74,0 & 84,0 & 94,0 \\
\hline Resistência "in situ" $f_{c n}$ & 11,2 & 16,8 & 22,4 & 28,0 & 33,6 & 39,2 & 44,8 & 50,4 & 56,0 & 61,6 \\
\hline Resistência à tração $f_{t k}$ & 1,55 & 2,1 & 2,55 & 2,95 & 3,3 & 3,65 & 4,0 & 4,3 & 4,6 & 4,9 \\
\hline $\begin{array}{l}\text { Resistência à tração } \\
\text { "in situ" } f_{t n}\end{array}$ & 1,0 & 1,4 & 1,7 & 2,0 & 2,25 & 2,5 & 2,6 & 2,7 & 2,7 & 2,7 \\
\hline
\end{tabular}

Tanto na figura 3.4 como nas expressões que se seguem, as deformações específicas devem ser tomadas com valores negativos.

Para concretos de densidade normal, a norma norueguesa admite as relações tensão-deformação dadas na figura 3.4, onde: 
Para $\varepsilon_{c u}<\varepsilon_{c} \leq \varepsilon_{c o}$, tem-se $\sigma_{c n}=-f_{c n}$

Para $\varepsilon_{c o}<\varepsilon_{c} \leq-0,6 \frac{f_{c n}}{E_{c n}}$, tem-se $\sigma_{c n}=E_{c n} \varepsilon_{c}+(m-1) f_{c n}\left[\frac{E_{c n} \varepsilon_{c}+0,6 f_{c n}}{(0,6-m) f_{c n}}\right]^{\frac{m-0,6}{m-1}}$

Para $-0,6 \frac{f_{c n}}{E_{c n}} \leq \varepsilon_{c}<0$, tem-se $\sigma_{c n}=E_{c n} \varepsilon_{c}$

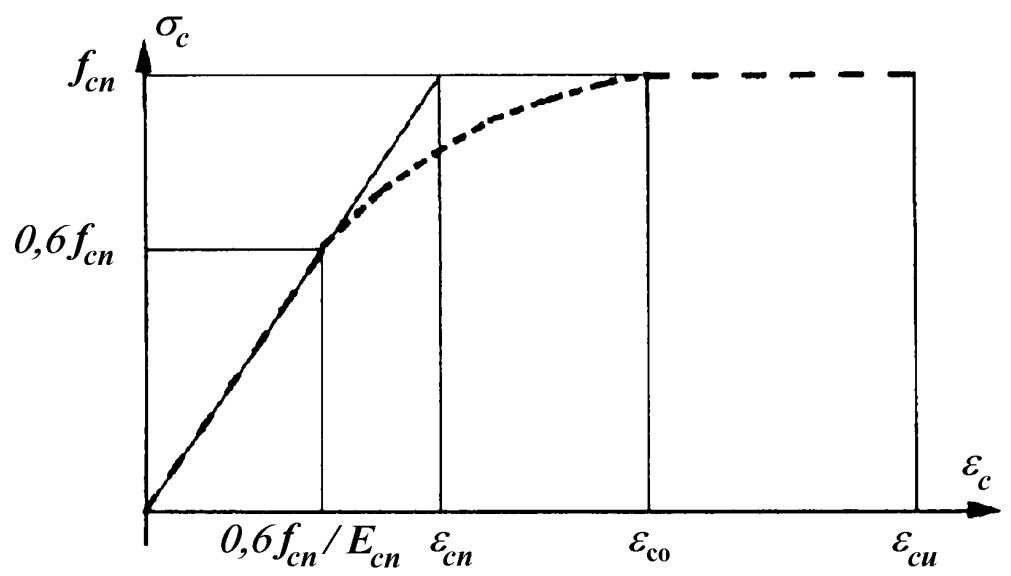

FIGURA 3.4 - Diagrama tensão-deformação do concreto - Norma Norueguesa

A deformação última no concreto $\left(\varepsilon_{c u}\right)$ é dada por:

$$
\begin{gathered}
\varepsilon_{c u}=(2,5 m-1,5) \varepsilon_{c n} \\
\varepsilon_{c n}=-f_{c n} / E_{c n} \\
m=\varepsilon_{c o} / \varepsilon_{c n}
\end{gathered}
$$

Para concretos de densidade normal com $f_{c c} \leq 85 \mathrm{MPa}$, pode-se admitir que:

$$
\begin{gathered}
E_{c n}=k_{E}\left(f_{c n}\right)^{0,3} \\
k_{E}=10000 \mathrm{MPa} \\
\varepsilon_{c o}=\varepsilon_{1}-k_{\varepsilon} f_{c n}
\end{gathered}
$$

onde: 


$$
\begin{gathered}
\varepsilon_{1}=-1,9 \% o \\
k_{\varepsilon}=4 \times 10^{-6}(\mathrm{MPa})
\end{gathered}
$$

Para concretos de resistência cúbica maior que $85 M P a$ e para todas as classes de concretos de agregados leves, os valores de $E_{c n}$ e $\varepsilon_{c 0}$ devem ser determinados por testes do concreto real a ser utilizado.

Variando-se a resistência cilíndrica $\left(f_{c c k}\right)$ entre $20 M P a$ e $94 M P a$, a deformação na tensão máxima $\left(\varepsilon_{c 0}\right)$ varia entre $-1,97 \%$ e $-2,15 \%$, e a deformação última $\left(\varepsilon_{c u}\right)$ varia entre $-3,84 \%$ e $-2,68 \%$. Tais valores refletem o aumento da deformação na tensão máxima, e a diminuição da deformação última, à medida que se aumenta a resistência. O símbolo $f_{c n}$ na figura 3.4 representa a resistência do concreto na estrutura.

Para concretos de densidade normal das classes C25 a C55 (resistências cilíndricas de $20 M P a$ a $44 M P a$ ), a tensão de compressão no concreto pode ser assumida como variando parabolicamente [equação (3.12)] entre $0 \mathrm{e}-f_{c d}$, enquanto a deformação $\left(\varepsilon_{c}\right)$ varia entre 0 e $-2,0 \%$.

$$
\sigma_{c}=-f_{c d} \frac{\varepsilon_{c}}{\varepsilon_{c o}}\left[2-\frac{\varepsilon_{c}}{\varepsilon_{c o}}\right]
$$

Para deformações entre $\varepsilon_{c o}=-2,0 \%$ e a deformação última $\varepsilon_{c u}=-3,5 \%$, a tensão de compressão pode ser assumida constante e igual a $-f_{c d}$, como na figura 3.5 . 


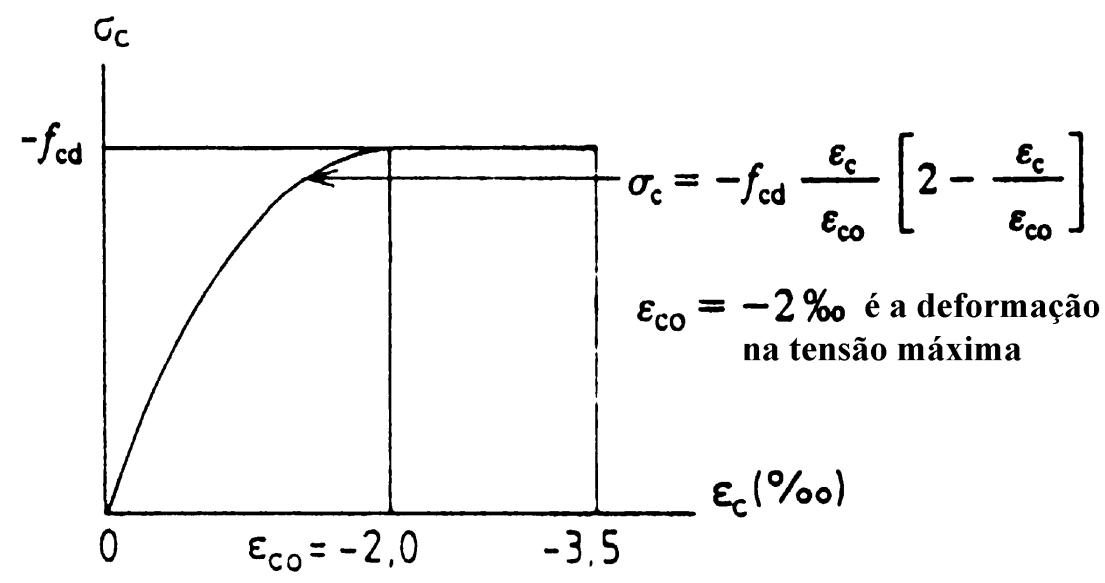

FIGURA 3.5 - Diagrama tensão-deformação para resistências usuais

\subsubsection{Norma Finlandesa Rak MK4 (1989)}

A resistência mais alta definida em testes de compressão de corpos-de-prova cúbicos de $15 \mathrm{~cm}$ de aresta é $100 \mathrm{MPa}$ (classe K100). O fator de conversão para o cilindro de $15 \mathrm{~cm}$ x $30 \mathrm{~cm}$ é igual à resistência do cubo menos $8 M P a$. A norma finlandesa assume um valor constante para $k_{3}$ igual a 0,7 .

A figura 3.6 mostra a relação tensão-deformação recomendada por essa norma. O símbolo $f_{c n}$ representa a resistência do concreto na estrutura.

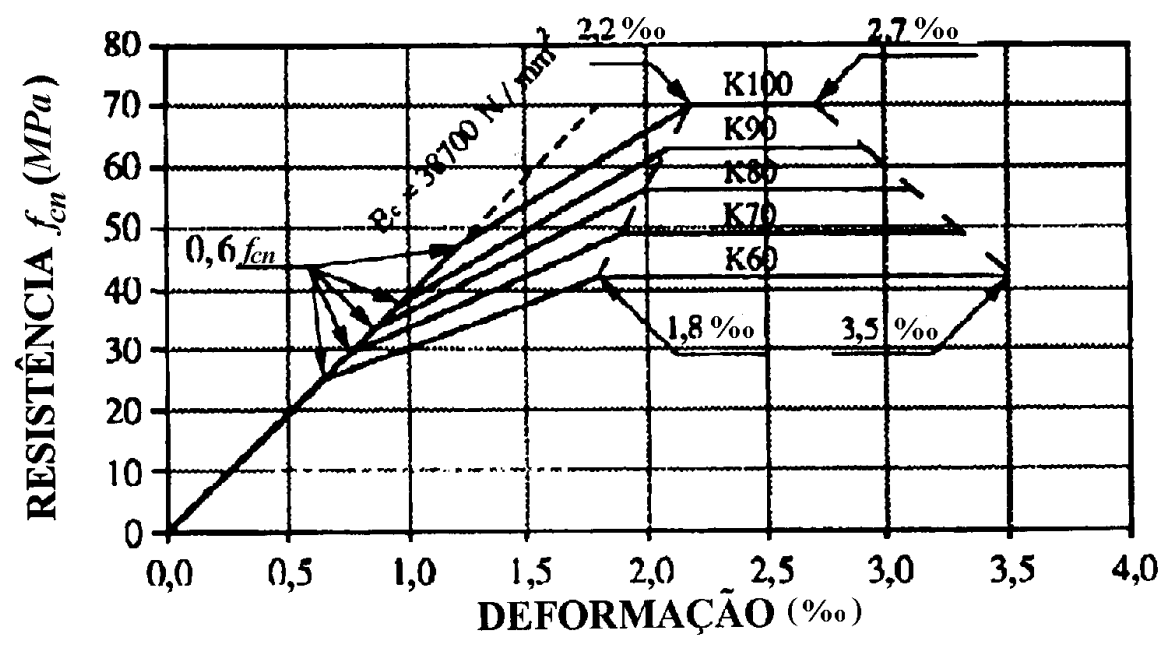

FIGURA 3.6 - Norma Finlandesa Rak MK4 (1989) 


\subsubsection{Código Modelo CEB-FIP (1990)}

A resistência mais alta para concretos de densidade normal baseada na compressão uniaxial de cilindros de $15 \mathrm{~cm}$ x $30 \mathrm{~cm}$ é de $80 M P a$. As formas dos diagramas tensão-deformação são mostradas esquematicamente na figura 3.7 para propósitos analíticos. O valor de $\varepsilon_{c 1}$ é admitido como 2,2\%o. Os valores de $E_{c}, E_{c 1}$ e $\varepsilon_{c u}$ variam com a resistência do concreto.

Para projeto, dois diagramas tensão-deformação são descritos. O primeiro (parábola-retângulo) consiste em uma parábola de segundo grau com uma tensão máxima de $0,85 f_{c k}$ na deformação de $2 \%$, seguida por um patamar de escoamento com uma tensão constante de $0,85 f_{c k}$ para deformações entre $2 \%$ e $3,5 \%$ o. O segundo, consiste em um diagrama retangular com $\alpha_{1}$ (função da resistência do concreto) decrescendo de 0,782, para $f_{c k}=20 M P a$, até 0,578 , para $f_{c k}=80 M P a$. $\beta_{1}$ é admitido constante e igual a 1 .

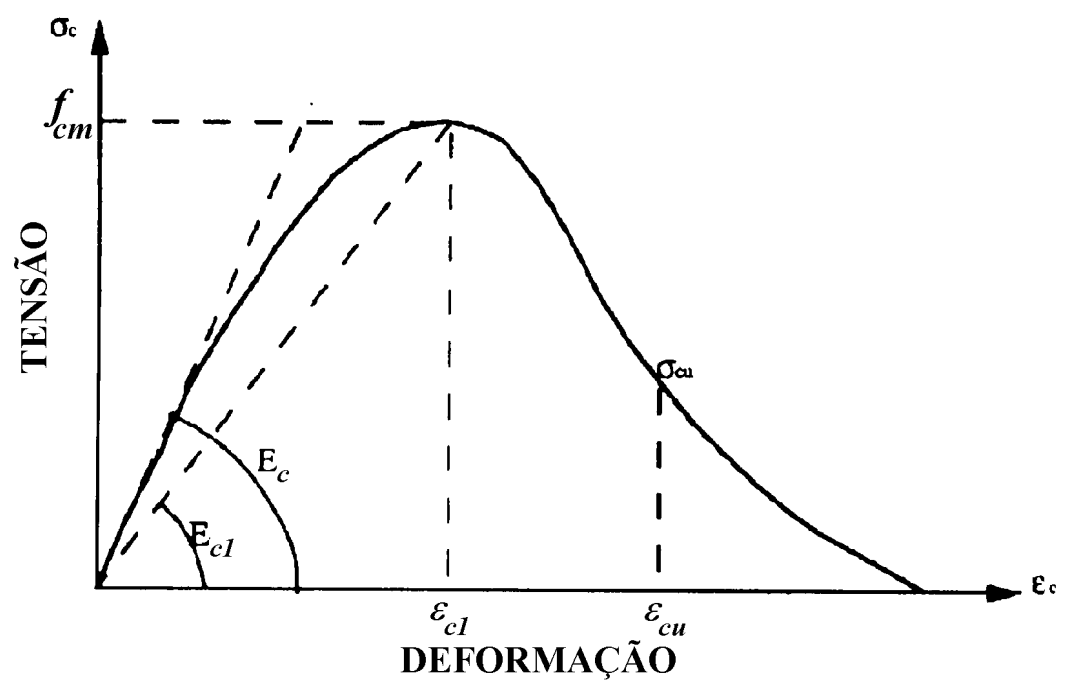

FIGURA 3.7 - Código Modelo CEB-FIP (1990) 


\subsection{DIAGRAMA RETANGULAR EQUIVALENTE PROPOSTO POR MacGREGOR E IBRAHIM (1997)}

Os diagramas retangulares propostos pela $N B-1$ (1978) e pelo ACI 318 (1995) não oferecem bons resultados à medida que crescem a resistência do concreto e a importância da força normal em relação à flexão (compressão com pequena excentricidade).

IBRAHIM \& MacGREGOR (1997) propuseram uma modificação para o diagrama retangular equivalente, de tal forma que houvesse melhor concordância com os resultados experimentais, e chegaram às seguintes conclusões:

- Os atuais parâmetros para o diagrama retangular do ACI 318 superestimam a capacidade de flexão para pilares de CAD que se rompem por compressão.

- Um diagrama retangular pode ser utilizado em projeto, com uma deformação limite de $3 \%$ e os parâmetros modificados $\alpha_{1}$ e $\beta_{1}$ como se segue:

$$
\begin{aligned}
& \alpha_{1}=0,85-\frac{f_{c k}}{800} \geq 0,725 \quad\left(f_{c k} \quad \text { em } M P a\right) \\
& \beta_{1}=0,95-\frac{f_{c k}}{400} \geq 0,70 \quad\left(\begin{array}{ll}
f_{c k} & \text { em } M P a
\end{array}\right)
\end{aligned}
$$

- Os parâmetros propostos dão forças resultantes mais altas para concretos de resistência usual e CAD que as equações do ACI 318 (aumentando a armadura necessária), e forças resultantes menores para concretos de resistência superior a $100 \mathrm{MPa}$. Visto de uma outra maneira, para uma mesma taxa de armadura, os esforços resistentes obtidos com a utilização dos parâmetros propostos são menores que os obtidos pelas equações do ACI 318.

Deste ponto em diante do texto, no que se refere ao dimensionamento à flexão, será adotado o diagrama retangular proposto por IBRAHIM \& MacGREGOR (1997) e suas recomendações, ressaltando-se que: 
- Para os concretos de alto desempenho, PINTO JR (1992) sugere um valor constante e aproximadamente igual 0,7 para $\alpha_{1}$. Esse valor é menor que o adotado pela NB-1 (1978) (constante e igual a 0,85), e já demonstra a necessidade de uma diminuição do valor de $\alpha_{1}$ à medida que cresce a resistência.

- Nos programas de dimensionamento, pode-se adotar uma formulação para o diagrama tensão-deformação real do concreto (através da entrada de uma função). A partir daí, todo o dimensionamento seria feito tendo o diagrama real como base, o que dispensaria simplificações como o diagrama retangular equivalente. Contudo, muitas são as normas que admitem simplificações pelas facilidades práticas a elas inerentes, o que realça a sua importância, particularmente no que se refere às seções não usuais, as quais necessitam de formulação e de programação mais elaboradas.

- Limita-se $\left(\varepsilon_{c u}\right)$ em 3\%o, o que reflete uma maior preocupação com a ductilidade. Esse valor é importante, em relação ao valor de 3,5\%o adotado pela $N B-1$ (1978), pois se reflete na mudança dos valores limites de $\beta_{x}$ para cada domínio de deformação. O domínio 4, por exemplo, passa a ter seu início em $\beta_{x}=0,592$ para o CA-50 (como se verá mais adiante), ao invés de $\beta_{x}=0,628$ obtido com o valor de $3,5 \%$, para o mesmo aço.

Além disso, mantidas idênticas a seção e a sua solicitação, a metodologia adotada por IBRAHIM \& MacGREGOR (1997) resulta em diferentes posições da linha neutra das que seriam obtidas com o diagrama parábola-retângulo, por exemplo. Um valor diferente para a posição da linha neutra influi não só na determinação da forma de ruptura do elemento (ductilidade), mas também na consideração da forma (retangular ou em “T”) da zona comprimida de uma seção.

Segundo SANTOS (1983), o valor de 3,5\%o é contra a segurança para as seções "T", nas quais o encurtamento de ruptura na borda mais comprimida é da ordem de $2 \%$. Neste caso, o cálculo com $\varepsilon_{c u}=3,5 \%$ o fica contra a segurança, principalmente por superestimar a tensão na armadura comprimida. Segundo o mesmo autor, isso não traz maiores conseqüências porque, na realidade, ao se levar em consideração a largura da mesa colaborante, tem-se em geral uma linha neutra alta, correspondente ao subdomínio 2a. Ao se adotar o valor de 3\%o, tira-se menos proveito deste fato, aumentando-se assim, teoricamente, a segurança da estrutura. Em edifícios, a 
consideração da mesa colaborante se deve à presença da laje. Porém, em elementos pré-moldados, por exemplo, esta seção pode ser conseguida sem a presença da laje, o que reforça a adoção de um valor mais conservador para $\left(\varepsilon_{c u}\right)$.

- O diagrama retangular equivalente proposto é válido tanto para concretos usuais como para CAD. Na flexão simples, apresenta os mesmos consumos de armadura de protensão para concretos usuais, independentemente do domínio (como se verá em capítulo posterior). Ainda na flexão simples, à medida que se aumenta a resistência do concreto e que se aproxima do domínio 4, resulta em consumos pouco maiores de armadura de protensão.

- Em relação aos diagramas retangulares propostos pela $N B-1$ (1978) e pelo ACI 318 (1995), o diagrama proposto por IBRAHIM \& MacGREGOR (1997) oferece resultados mais próximos dos experimentais à medida que crescem a resistência do concreto e a importância da força normal. É válido, portanto, para flexão simples e flexão composta, atendendo a uma tendência das normas que é a de uniformizar os procedimentos de cálculo. O objetivo último deste trabalho são as vigas protendidas pré-moldadas. Os casos de flexo-compressão são menos comuns nesses elementos que em pilares, por exemplo. Contudo, existem na prática. Os cabos de protensão superiores em vigas pré-moldadas biapoiadas são por vezes considerados como forças externas, caindo-se normalmente num caso de flexo-compressão com grande excentricidade. Tais cabos são utilizados para controle das tensões de tração antes da montagem final do elemento na estrutura (verificações em vazio).

\subsection{LIMITES DOS DOMÍNIOS DE DEFORMAÇÃO PARA $\varepsilon_{c u}=3 \% o$}

Os estados limites últimos de ruptura e de deformação plástica excessiva são caracterizados pelas deformações específicas últimas no concreto $\left(\varepsilon_{c u}\right)$ e na $\operatorname{armadura}\left(\varepsilon_{\mathrm{su}}\right)$.

Será adotado para a deformação específica última no concreto $\left(\varepsilon_{c u}\right)$ o valor de 3\%o sugerido por IBRAHIM \& MacGREGOR (1997). 
Admite-se, como valor convencional, que o alongamento específico último da armadura tracionada $\left(\varepsilon_{\mathrm{su}}\right)$, no caso de concreto armado, seja igual a $10 \%$.

O alongamento para as peças de concreto protendido também é limitado ao valor máximo de $10 \%$, e é contado a partir do estado de neutralização da seção transversal. Obtém-se o estado de neutralização anulando-se, em toda a seção transversal, as tensões no concreto decorrentes da aplicação isolada dos esforços de protensão.

A deformação plástica excessiva da armadura ocorre na Reta "a" e nos domínios 1 e 2. Nos domínios 3, 4, 4a, 5 e Reta "b", ocorre ruptura do concreto (figura 3.8).

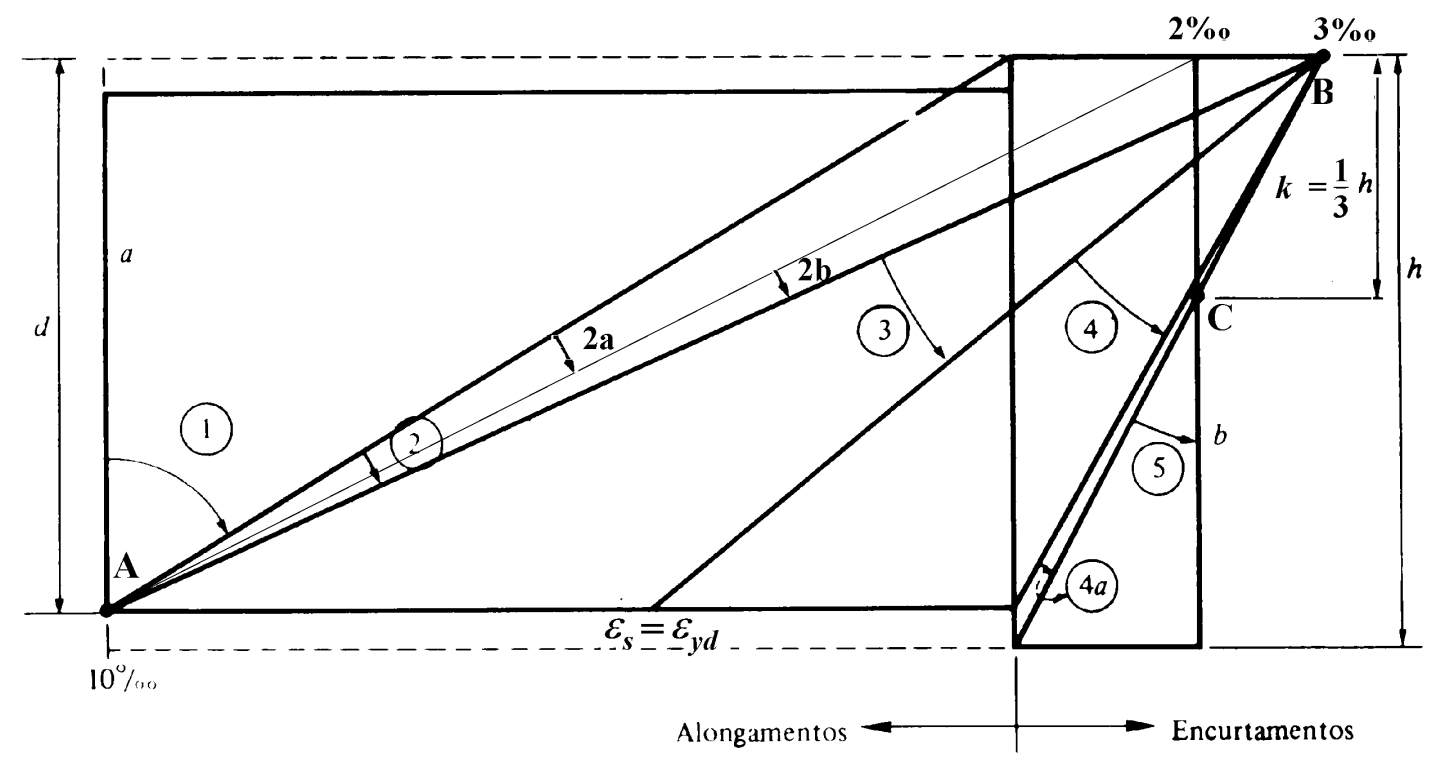

FIGURA 3.8 - Domínios de deformação $\left(\varepsilon_{c u}=3 \%\right.$ o

Nos domínios 1 e 2, os diagramas giram em torno do polo de rotação dado pelo ponto "A", ao passo que nos domínios 3, 4 e 4a o polo é o ponto "B". No domínio 5, o giro é em torno do ponto " $\mathrm{C}$ ".

Para $\varepsilon_{c u}=3 \%$ o, o ponto "C" passa a se situar a $1 / 3 h$, e não mais a $3 / 7 h$, como se pode observar da seguinte semelhança de triângulos (figura 3.8): 


$$
\begin{gathered}
\frac{k}{3 \% o-2 \% o}=\frac{h}{3 \% o} \\
k=\frac{1}{3} h
\end{gathered}
$$

Para que se possa determinar a resistência de cálculo de uma seção transversal, é necessário que se considere em qual dos domínios de deformação, definidos na figura 3.8, está situado o diagrama de deformações específicas da seção analisada.

Seja $\beta_{x}$ o coeficiente adimensional que relaciona a profundidade da linha neutra com a altura útil da peça:

$$
\beta_{x}=x / d
$$

Admitindo-se a validade de Lei de Bernoulli até o estado limite último e por semelhanças de triângulos, chega-se a:

$$
\beta_{x}=\frac{\varepsilon_{c}}{\varepsilon_{c}+\varepsilon_{s}}
$$

onde :

$$
\begin{array}{ll}
\varepsilon_{c} & \text { deformação no concreto } \\
\varepsilon_{s} & \text { deformação no aço tracionado }
\end{array}
$$

A figura 3.9 mostra a posição limite da linha neutra para cada um dos domínios considerados, adotando-se $\varepsilon_{c u}=3 \%$, indicando também a subdivisão do domínio 2 em domínio $2 \mathrm{a}\left(0<\varepsilon_{c}<2 \%\right.$ e domínio $2 \mathrm{~b}\left(2 \% o<\varepsilon_{c}<3 \%\right.$ ) 


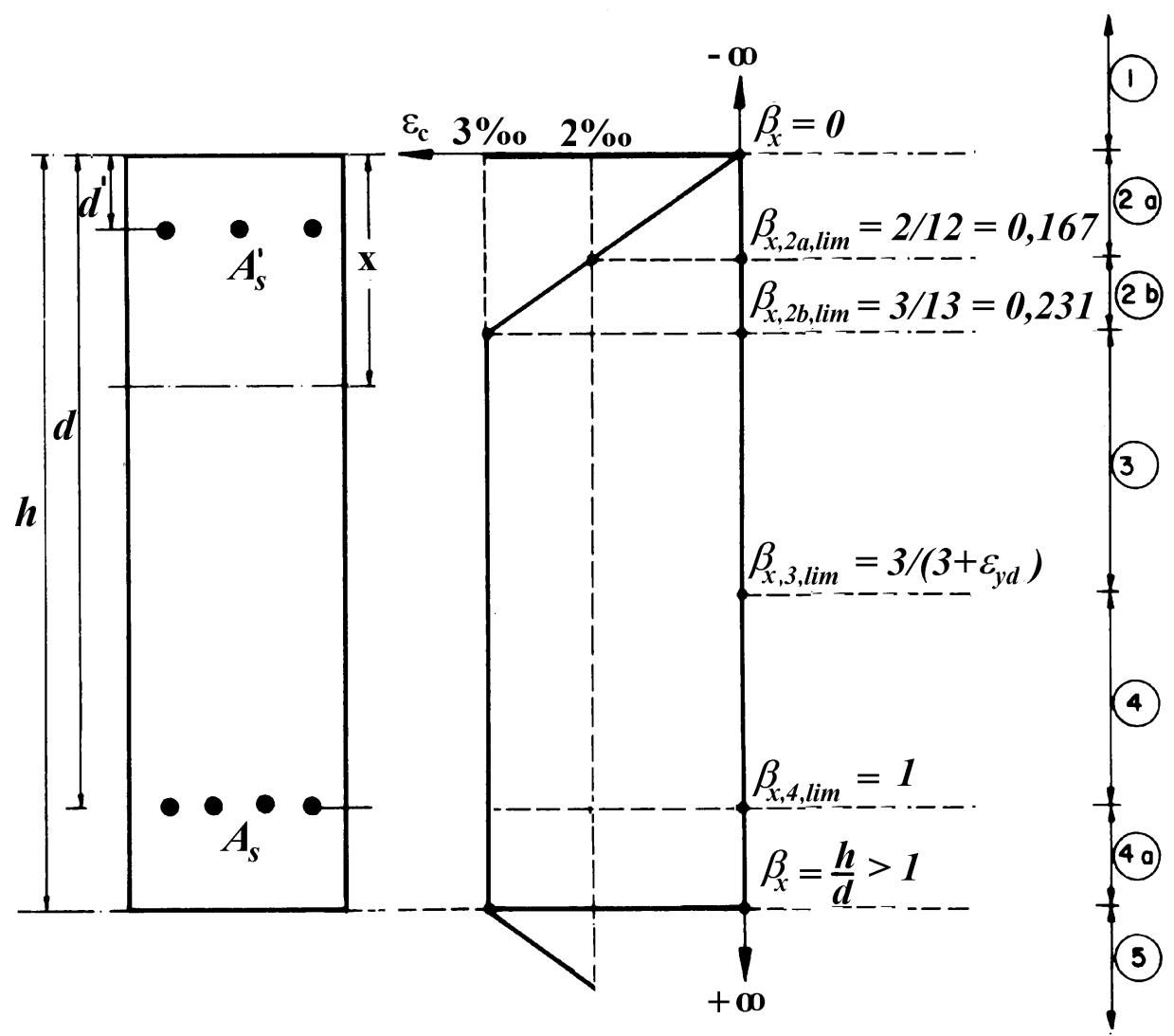

FIGURA 3.9 - Domínio de deformação - posições da linha neutra $\left(\varepsilon_{c u}=3 \% o\right)$ FONTE: FUSCO (1981) (adaptada)

\subsection{DIMENSIONAMENTO ATRAVÉS DE TABELAS TIPO k}

As tabelas conhecidas como "tabelas tipo k", correntemente empregadas no cálculo do concreto armado, têm seu formato com origem nas tabelas de Löser, as quais foram posteriormente rearranjadas para o cálculo no Estádio III por Burke e Gertsenchtein.

Nesta seção, serão elaboradas tabelas tipo k, apresentadas no final do capítulo, que permitem o dimensionamento rápido de seções retangulares de CAD armadas ou protendidas. 


\subsubsection{Equações de equilíbrio}

As expressões a seguir têm como base a figura 3.10d.

Pelo equilíbrio dos esforços horizontais na seção chega-se a:

$$
R_{c c}+R_{s c}-R_{s t}=0
$$
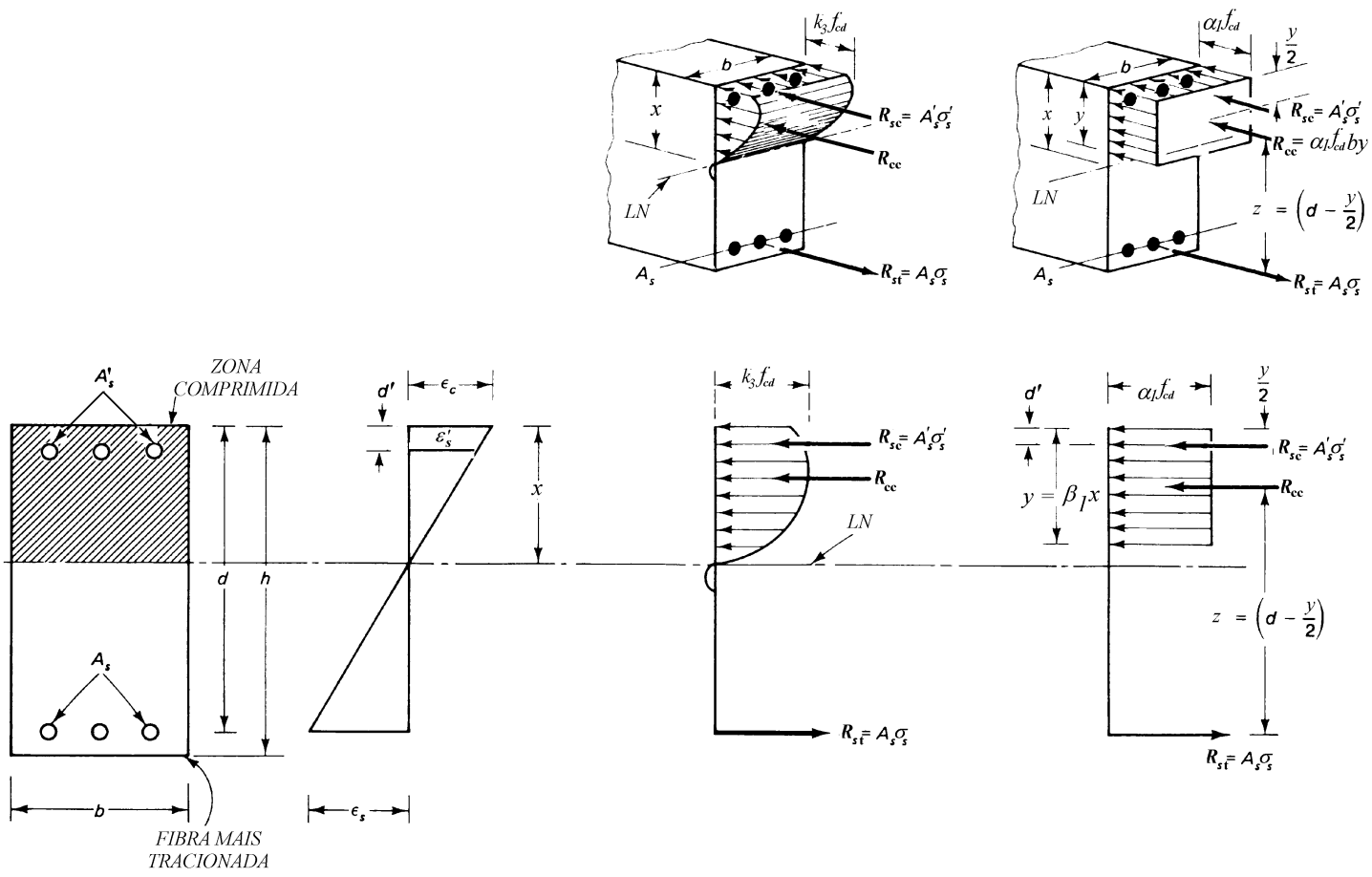

(a)

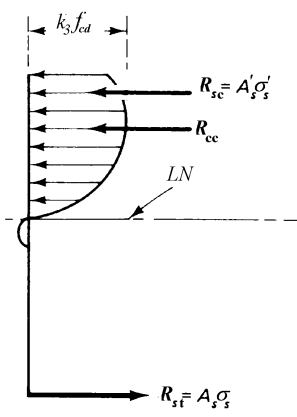

(c)

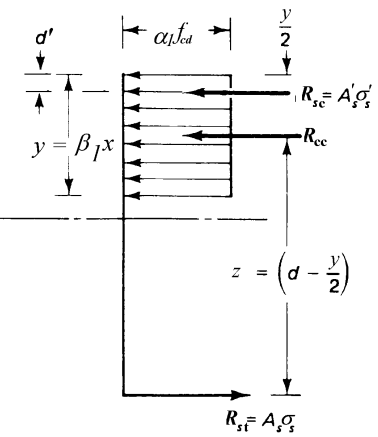

(d)

FIGURA 3.10 - Seção retangular com armadura dupla

FONTE: NAWY (1995) (adaptada)

Do equilíbrio de momentos em relação ao centro de gravidade da armadura tracionada:

$$
M_{d}=\gamma_{f} M_{k}=R_{c c}\left(d-\frac{y}{2}\right)+R_{s c}\left(d-d^{\prime}\right)
$$

A resultante de compressão no concreto $\left(R_{c c}\right)$ é dada por: 


$$
R_{c c}=b y \sigma_{c d}=b\left(\beta_{1} x\right)\left(\alpha_{1} f_{c d}\right) \frac{d}{d}
$$

$\sigma_{c d}$ é a tensão de compressão de cálculo no concreto.

Como $\beta_{x}=x / d$, vem:

$$
R_{c c}=b d \beta_{1} \beta_{x} \alpha_{1} f_{c d}
$$

O valor do braço de alavanca $\left(d-\frac{y}{2}\right)$ pode ser reescrito como:

$$
\left(d-\frac{y}{2}\right)=\left(d-\frac{\beta_{1} x}{2}\right) \frac{d}{d}=d\left(1-\frac{\beta_{1} \beta_{x}}{2}\right)
$$

A resultante de compressão e de tração no aço são dadas, respectivamente, por:

$$
\begin{aligned}
& R_{s c}=A_{s}^{\prime} \sigma_{s}^{\prime} \\
& R_{s t}=A_{s} \sigma_{s}
\end{aligned}
$$

Substituindo-se (3.19), (3.21) e (3.22) em (3.17) e (3.18), tem-se:

$$
\begin{gathered}
b d \beta_{1} \beta_{x} \alpha_{1} f_{c d}+A_{s}^{\prime} \sigma_{s}^{\prime}-A_{s} \sigma_{s}=0 \\
M_{d}=b d^{2} \beta_{1} \beta_{x} \alpha_{1} f_{c d}\left(1-\frac{\beta_{1} \beta_{x}}{2}\right)+A_{s}^{\prime} \sigma_{s}^{\prime}\left(d-d^{\prime}\right)
\end{gathered}
$$

Para o caso de armadura simples, tem-se $A_{s}^{\prime}=0$. Portanto: 


$$
\begin{gathered}
b d \beta_{1} \beta_{x} \alpha_{1} f_{c d}-A_{s} \sigma_{s}=0 \\
M_{d}=b d^{2} \beta_{1} \beta_{x} \alpha_{1} f_{c d}\left(1-\frac{\beta_{1} \beta_{x}}{2}\right)
\end{gathered}
$$

\subsubsection{Equações de compatibilidade das deformações}

Da figura $3.10 \mathrm{~b}$ chega-se a:

$$
\frac{\varepsilon_{c}}{x}=\frac{\varepsilon_{s}}{d-x}=\frac{\varepsilon_{s}^{\prime}}{x-d^{\prime}}
$$

Dividindo-se tudo por $d$, tem-se:

$$
\frac{\varepsilon_{c}}{\beta_{x}}=\frac{\varepsilon_{s}}{1-\beta_{x}}=\frac{\varepsilon_{s}^{\prime}}{\beta_{x}-\frac{d^{\prime}}{d}}
$$

Esta expressão leva a:

$$
\begin{aligned}
& \varepsilon_{s}=\varepsilon_{c} \frac{1-\beta_{x}}{\beta_{x}} \\
& \varepsilon^{\prime}=\frac{\beta \bar{d}}{\beta}
\end{aligned}
$$

\subsubsection{Tabelas para armadura simples}

$$
A_{s}^{\prime}=0 \text {, das equações de equilíbrio (3.25) e (3.26), tem-se: }
$$




$$
\begin{gathered}
b d \beta_{1} \beta_{x} \alpha_{1} f_{c d}=A_{s} \sigma_{s} \\
M_{d}=b d^{2} \beta_{1} \beta_{x} \alpha_{1} f_{c d}\left(1-\frac{\beta_{1} \beta_{x}}{2}\right) \\
M_{d}=A_{s} \sigma_{s} d\left(1-\frac{\beta_{1} \beta_{x}}{2}\right)
\end{gathered}
$$

O coeficiente $k_{c}$ é estabelecido a partir da equação (3.31):

$$
k_{c}=\frac{b d^{2}}{M_{d}}=\frac{1}{\beta_{1} \alpha_{1} \beta_{x} f_{c d}\left(1-\frac{\beta_{1} \beta_{x}}{2}\right)}
$$

onde:

$b \quad$ largura da zona de compressão

$M_{d} \quad$ momento de cálculo no estado limite último $=\gamma_{f} M_{k}\left(\operatorname{com} \gamma_{f}=1,4\right)$

$M_{k} \quad$ momento característico

O coeficiente $k_{s}$ é estabelecido a partir de equação (3.32):

$$
k_{s}=\frac{A_{s} d}{M_{d}}=\frac{1}{\sigma_{s}\left(1-\frac{\beta_{1} \beta_{x}}{2}\right)}
$$

A tensão na armadura $\left(\sigma_{s}\right)$ pode ser determinada a partir do diagrama tensão deformação estabelecido na NB-1 (1978), item 7.2. 


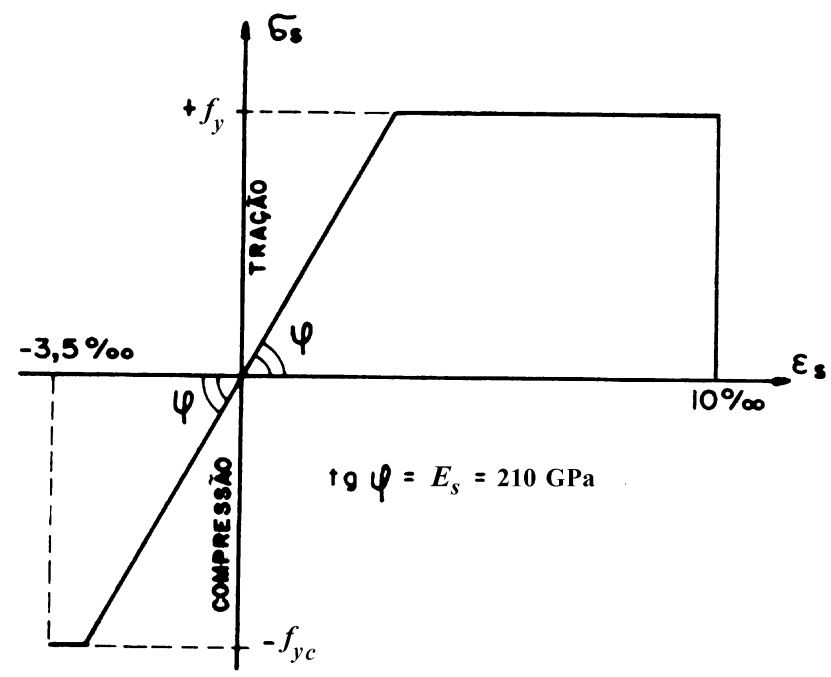

FIGURA 3.11 - Diagrama tensão-deformação do CA-50 da NB-1 (1978)

Para o CA-50, a relação tensão-deformação é linear até ${ }_{s}=f_{y d}$, ou ainda, até $\varepsilon_{s}=\varepsilon_{y d}$. Portanto:

$$
\begin{aligned}
& \text { Para } \varepsilon_{s} \leq \varepsilon_{y d}=2,07 \% \text {, tem-se } \sigma_{s}=E_{s} \varepsilon_{s} \\
& \text { Para } 2,07 \% o<\varepsilon_{s} \leq 10 \% \text {, tem-se } \sigma_{s}=f_{y d}
\end{aligned}
$$

A $N B-1$ (1978) adota $E_{s}=210$ GPa para o CA-50.

\subsubsection{Dimensionamento de seções de concreto protendido}

A diferença entre uma peça de concreto armado e uma peça idêntica (em materiais, dimensões e armaduras), porém com armadura protendida, é a existência do pré-alongamento.

Segundo VASCONCELOS (1980), a existência do pré-alongamento é pouco importante a menos que exista excesso de armadura, isto é, que a L.N. na ruptura ultrapasse o eixo baricêntrico da seção. 
O pré-alongamento é definido como o alongamento existente na armadura no estado de neutralização, isto é, no estado em que são nulas as tensões no concreto. Deve ser determinado na época em que se procura conhecer a eficiência da peça. No caso de verificação em vazio (pré-tração), o pré-alongamento é aquele que se aplica na armadura na pista de protensão. No caso de peças com armadura pós-tracionada, é aquele em que a armadura tracionada e presa em vínculos externos à peça provoca, na liberação desses vínculos, a protensão conhecida na peça.

Quando se trata de verificação em carga, escolhe-se normalmente uma idade bastante avançada da peça, em que praticamente já se cumpriram todas as perdas progressivas de protensão. Conhecida a porcentagem total de perdas para uma determinada idade, este pré-alongamento é equivalente ao pré-alongamento inicial reduzido na proporção das perdas.

Assim, em relação ao concreto armado, a única diferença é que, para determinação da tensão na armadura protendida no estado limite último $\left(\sigma_{\mathrm{pd}}\right)$, devese somar o valor do pré-alongamento $\left(\varepsilon_{\text {pid }}\right)$ ao valor da deformação do concreto no nível do cabo resultante no estado limite último $\left(\varepsilon_{\mathrm{cld}}\right)$.

\subsubsection{Tabelas para seções de concreto protendido e armado}

Neste item, segue-se o roteiro apresentado por VASCONCELOS (1980).

Elaborou-se a tabela A1 na qual, a partir do coeficiente $k_{c}$ (obtido do momento de cálculo $\left(M_{d}\right)$ e da escolha das dimensões da seção), chega-se à posição da linha neutra $\left(\beta_{x}\right)$ e aos valores de $\varepsilon_{c d}, \varepsilon_{c 1 d}$ e $\sigma_{p d}$ para diversas resistências à compressão do concreto e para os aços de protensão (CP 175 e CP 190).

$\mathrm{Na}$ elaboração da tabela A1 foram adotadas todas as recomendações de IBRAHIM \& MacGREGOR (1997), bem como os limites de $\left(\beta_{x}\right)$ para os domínios de deformação decorrentes da adoção de $\varepsilon_{c u}=3 \%$ (figura 3.9).

A tabela A1 pode ser usada tanto para seções de CAD como para concretos de resistência usual, como se observará através de exemplos. Além disso, podem ser 
aplicadas às seções tipo "T", considerando-as de forma adequada, em função da posição da L.N., como uma seção retangular (L.N. na mesa da seção “T”), ou como a soma de duas seções retangulares (L.N. abaixo da mesa).

Além das já estabelecidas, foram usadas as seguintes expressões:

$$
\beta_{z}=z / d
$$

onde:

$$
\begin{array}{ll}
z & \text { distância entre } R_{c c} \text { e } R_{s t} \\
d & \text { altura útil }
\end{array}
$$

Adotando-se o diagrama retangular (figura 3.10.d) sugerido por IBRAHIM \& MacGREGOR (1997), chega-se facilmente a:

$$
\beta_{z}=1-\frac{\beta_{1} \beta_{x}}{2}
$$

A deformação do concreto $\left(\varepsilon_{\mathrm{cd}}\right)$ na borda mais comprimida, no estado limite último, é dada por:

$$
\varepsilon_{c d}(\% \mathrm{o})=\frac{\beta_{x}}{1-\beta_{x}} 10 \% \text { o para } 0<\beta_{x} \leq 0,231 \text { (ou seja, até o domínio 2) }
$$

A deformação do concreto no nível do cabo resultante $\left(\varepsilon_{\mathrm{cld}}\right)$, no estado limite último, é dada por:

$$
\varepsilon_{c 1 d}(\% \mathrm{o})=\frac{1-\beta_{x}}{\beta_{x}} 3 \% \text { o para } \beta_{x}>0,231
$$

A deformação total do aço de protensão no estado limite último $\left(\varepsilon_{p d}\right)$ é dada por: 


$$
\varepsilon_{p d}=\varepsilon_{c 1 d}+\varepsilon_{p i d}+\varepsilon_{p 1}
$$

$\varepsilon_{\text {pid }}$ é o pré-alongamento do aço, já considerando o fator de ponderação $\gamma_{p}=0,9$ ou 1,1 (caso a verificação seja feita em carga ou em vazio), já considerada a influência das perdas progressivas se for o caso.

$\varepsilon_{p 1}$ é o alongamento unitário correspondente à variação de tensões entre a situação inicial e a descompressão do concreto ao nível da armadura de protensão. $\varepsilon_{p 1}$ tem valor pequeno quando comprado com $\varepsilon_{\text {pid }}$ e com $\varepsilon_{\text {cld }}$, podendo em geral ser desprezado.

Seja $\sigma_{p d}$ a tensão no aço de protensão (em $M P a$ ) no estado limite último correspondente à deformação total $\varepsilon_{p d}$.

A relação entre $\sigma_{p}$ e $\varepsilon_{p}$ foi determinada para um aço padrão, conforme indicação do $C E B$-FIP (1970), e corresponde aproximadamente ao diagrama médio dos aços fabricados pela Companhia Siderúrgica Belgo-Mineira (CSBM). O diagrama da figura 3.12 foi dividido em 4 trechos. Adotou-se o módulo de deformação longitudinal dos cabos encordoados $E_{p}=195 G P a$. Nas expressões seguintes, referentes à figura $3.12, \varepsilon_{p}$ deve ser inserido em valores por mil, estando $\sigma_{p}$ em $M P a$.

Na figura 3.12, para o CP 175, obtém-se os valores indicados na tabela 3.2.

TABELA 3.2 - Relações tensão-deformação para o CP 175

FONTE: VASCONCELOS (1980) (adaptada)

\begin{tabular}{|l|l|l|}
\hline Trecho AO & $0<\varepsilon_{p} \leq 5,47 \%$ o & $\sigma_{p}=195 \varepsilon_{p}$ \\
\hline Trecho AB & $5,47 \% \circ<\varepsilon_{p} \leq 7,7 \%$ o & $\sigma_{p} / f_{p t k}=-0,0198 \varepsilon_{p}^{2}+0,328 \varepsilon_{p}-0,592$ \\
\hline Trecho BC & $7,7 \% \circ<\varepsilon_{p} \leq 9,0 \%$ o & $\sigma_{p} / f_{p t k}=\left(\varepsilon_{p} / 65\right)+0,642$ \\
\hline Trecho CD & $9,0 \% \mathrm{o}<\varepsilon_{p} \leq 50,0 \% \mathrm{o}$ & $\sigma_{p} / f_{p t k}=\left(\varepsilon_{p} / 456\right)+0,76$ \\
\hline
\end{tabular}

Para o CP 190 obtém-se os valores da tabela 3.3. 
Seguindo-se procedimento semelhante, elaborou-se a tabela A2 para dimensionamento de seções retangulares de concreto armado, válida tanto para concretos usuais como para CAD.

TABELA 3.3 - Relações tensão-deformação para o CP 190

FONTE: VASCONCELOS (1980) (adaptada)

\begin{tabular}{|l|l|l|}
\hline Trecho AO & $0<\varepsilon_{p} \leq 5,94 \%$ o & $\sigma_{p}=195 \varepsilon_{p}$ \\
\hline Trecho AB & $5,94 \%$ o $<\varepsilon_{p} \leq 7,7 \%$ o & $\sigma_{p} / f_{p t k}=-0,0097 \varepsilon_{p}^{2}+0,218 \varepsilon_{p}-0,342$ \\
\hline Trecho BC & $7,7 \% \circ<\varepsilon_{p} \leq 9,0 \%$ o & $\sigma_{p} / f_{p t k}=\left(\varepsilon_{p} / 65\right)+0,642$ \\
\hline Trecho CD & $9,0 \%$ o $<\varepsilon_{p} \leq 50,0 \%$ o & $\sigma_{p} / f_{p t k}=\left(\varepsilon_{p} / 456\right)+0,76$ \\
\hline
\end{tabular}

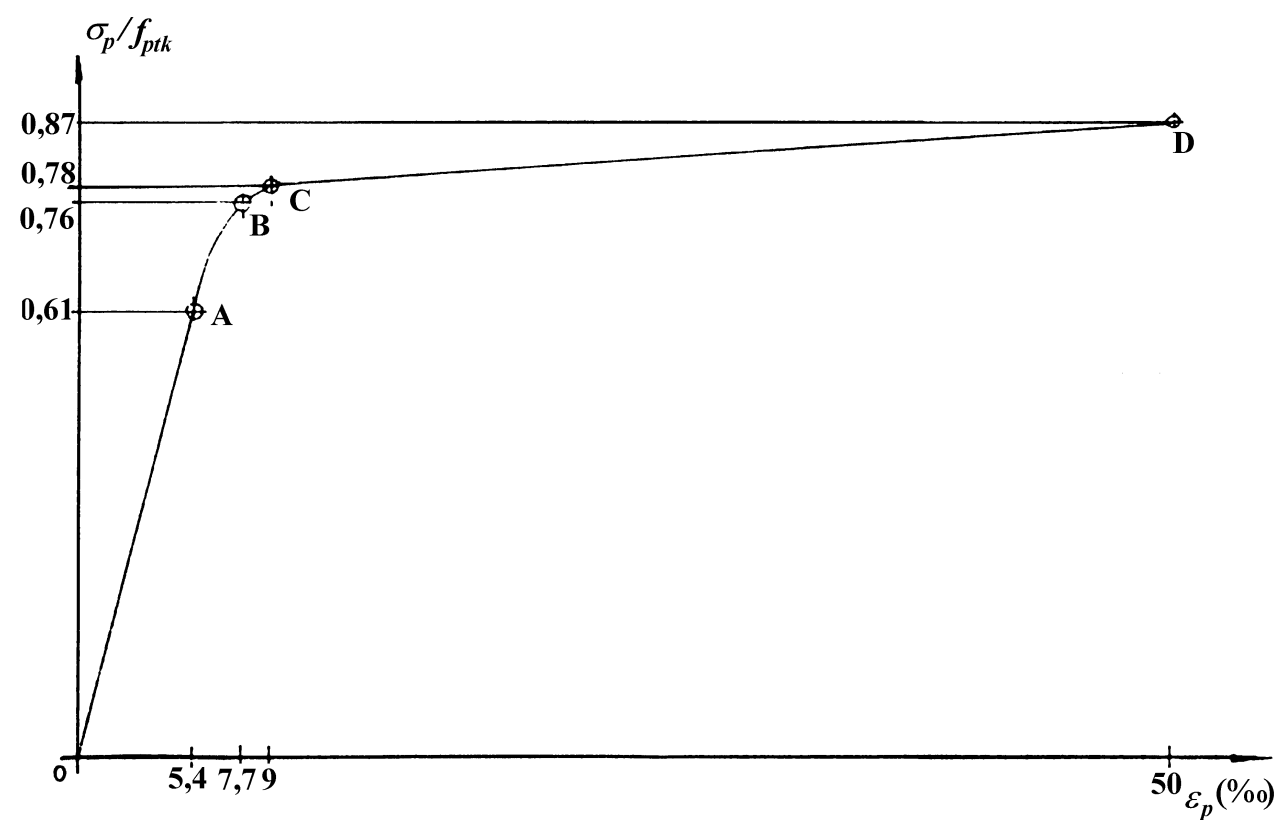

FIGURA 3.12 - Diagrama tensão-deformação simplificado dos aços de protensão FONTE: VASCONCELOS (1980)

Na tabela A2, observa-se que, para uma mesma posição da linha neutra, $k_{s}=A_{s} d / M_{d}$ diminui à medida que se aumenta a resistência. Tal variação é pequena, especialmente para os valores inferiores de $\beta_{x}$. Para $\beta_{x}=0,02$, por 
exemplo, tem-se $k_{s}=0,02320$ para $f_{c k}=30 M P a$, e $k_{s}=0,02316$ para $f_{c k}=100 \mathrm{MPa}$. À medida que se avança em relação ao domínio 4 (maiores valores de $\beta_{x}$ ) observa-se, para a mesma posição da linha neutra, uma variação de $k_{s}$ um pouco maior. Para $\beta_{x}=0,58$, por exemplo, tem-se $k_{s}=0,03082$ para $f_{c k}=30 M P a$, e $k_{s}=0,02886$ para $f_{c k}=100 M P a$.

Fica, portanto, a critério do engenheiro, optar ou não pela possibilidade de uma pequena redução de armadura passiva à medida que se aumenta a resistência, utilizando a tabela A2, ou simplesmente continuar usando as tabelas convencionais para o cálculo de $k_{s}$, as quais resultarão em armaduras passivas um pouco maiores.

As tabelas A1 e A2 podem ser utilizadas para o dimensionamento de seções “T” e "I", que apresentam zona de compressão retangular ou em "T", como se verá através de exemplos. Tais seções, como já ressaltado, são mais interessantes para a utilização em conjunto do CAD, protensão e pré-moldagem. Para a aplicação dessas tabelas para a verificação em vazio, isto é, no caso de carregamento em que atuam apenas a protensão inicial e o peso próprio, torna-se necessário que a zona de tração (por exemplo, fibras inferiores de uma viga biapoiada), previamente comprimida pela protensão, seja também retangular ou " $T$ ".

Essas tabelas também podem ser utilizadas para o dimensionamento de seções com armadura dupla.

\subsection{ARMADURA MÍNIMA DE FLEXÃO}

As armaduras mínimas são exigidas para que se garanta que o carregamento de ruína seja maior que o de fissuração. Assim, a ruína não ocorrerá sem aviso. Com o aumento da resistência, a fissuração deve iniciar-se em tensões mais altas e, assim, seriam necessárias maiores taxas de armadura mínima de flexão e de cisalhamento

Pesquisas realizadas por PINTO JR (1992) levantaram dúvidas sobre as taxas mínimas usuais de armadura longitudinal. Em suas conclusões, ele comenta que a taxa mínima, $\rho_{s, \min }=0,30\left(f_{t k} / f_{y k}\right)$, não é válida para as vigas de $\mathrm{CAD}$, e que são necessárias mais pesquisas nesta área. 
Por outro lado, os resultados dos seus ensaios mostraram que as vigas de concreto subarmadas apresentam comportamento dúctil.

O CEB-FIP (1990) estabelece uma taxa mínima de armadura longitudinal de flexão dada por:

$$
\begin{aligned}
& \rho_{l, \text { min }}=\frac{A_{s, \min }}{b_{t} d}=0,15 \% \text { para o S500 (ou CA-50) } \\
& \rho_{l, \text { min }}=\frac{A_{s, \min }}{b_{t} d}=0,25 \% \text { para o aço S220 (ou CA-25) }
\end{aligned}
$$

$b_{t}$ é a largura média da zona tracionada de concreto.

Fazendo-se a correlação entre as propriedades dos aços S500 e S220 do CEBFIP (1990) e as propriedades dos aços brasileiros, pode-se aplicar a equação (3.42) e (3.43) aos aços CA-50 e CA-25, respectivamente.

Para as vigas "T", se a linha neutra, no estado limite último, está localizada na mesa, a largura desta última não é levada em consideração para o cálculo de $b_{t}$.

O ACI 318 (1995) estabelece, para vigas com seção retangular ou com seção "T" (com a mesa comprimida), a seguinte expressão para a armadura mínima:

$$
A_{s, \min }=\frac{0,25 \sqrt{f_{c k}}}{f_{y}} b_{w} d \geq 1,379 \frac{b_{w} d}{f_{y}}
$$

Para as seções em "T" com a mesa tracionada, a armadura mínima $\left(A_{s, \text { min }}\right)$ a ser adotada deve ser maior ou igual ao menor dos valores dados por:

$$
A_{s, \min }=\frac{0,5 \sqrt{f_{c k}}}{f_{y}} b_{w} d
$$

ou pela expressão (3.44), na qual $b_{w}$ deve ser tomado igual à largura da mesa. 


\subsection{EXEMPLOS DE APLICAÇÃO}

Exemplifica-se a seguir a utilização da tabela A1, comparando-se os resultados com os apresentados em VASCONCELOS (1980), o qual segue o diagrama parábolaretângulo. Para efeito de comparação, tanto para o cálculo da tensão inicial máxima (o valor aqui adotado de 1615MPa é maior que o permitido pela NBR-7197/1987) como para o cálculo do pré-alongamento seguiu-se o apresentado pelo já citado autor.

EXEMPLO 3.1 $-f_{c k}=30 \mathrm{MPa}$

Uma viga biapoiada, de concreto protendido, com vão teórico de 20,0m, deve ser calculada para resistir a uma carga acidental sem impacto de $15 \mathrm{kN} / \mathrm{m}$. Os materiais disponíveis são:

Concreto: $f_{c k}=30 \mathrm{MPa}$; peso específico $=25 \mathrm{kN} / \mathrm{m}^{3}$.

Aço: CP $190 \mathrm{RB}\left(f_{p t k}=1900 M P a\right) ; E_{p}=200 G P a$

\section{Solução}

$$
\begin{array}{ll}
f_{p y k}=0,9 \times 1900=1710 \mathrm{MPa} & f_{c d}=30 / 1,4=21 \mathrm{MPa} \\
f_{p t d}=1900 / 1,15=1650 \mathrm{MPa} & f_{p y d}=0,9 \times 1650 \cong 1500 \mathrm{MPa}
\end{array}
$$

\section{Pré-dimensionamento}

A altura útil $(d)$ pode ser tomada aproximadamente como o vão sobre 20:

$$
d=l / 20=20 / 20=1,00 m
$$

A largura $(b)$ pode ser tomada entre $1 / 3$ e 1/4 da altura: $b=0,30 m$ 


\section{Esforços}

$$
\begin{aligned}
& A_{c}=1 \times 0,30=0,30 \mathrm{~m}^{2} \\
& g=25 \times 0,30=7,5 \mathrm{kN} / \mathrm{m} \\
& g+q=7,5+15=22,5 \mathrm{kN} / \mathrm{m} \\
& M_{g q}=\frac{22,5 \times 20^{2}}{8}=1125 \mathrm{kNm} \\
& M_{d}=1,4 \times 1125=1575 \mathrm{kNm}
\end{aligned}
$$

\section{$\rightarrow$ Situação em carga}

Tensão inicial máxima: $\sigma_{p i} \leq\left\{\begin{array}{l}0,85 f_{p t k}=0,85 \times 1900=1615 \mathrm{MPa} \rightarrow \text { valor adotado } \\ 0,95 f_{p y k}=0,95 \times 1710=1625 \mathrm{MPa}\end{array}\right.$

Segundo a NBR-7197/87: $\sigma_{p i} \leq\left\{\begin{array}{l}0,77 f_{p t k}=0,77 \times 1900=1463 \mathrm{MPa} \\ 0,86 f_{p y k}=0,86 \times 1710=1471 \mathrm{MPa}\end{array}\right.$

Valor com perdas estimadas de $20 \% \quad \rightarrow \quad 1615 \times 0,8=1292 \mathrm{MPa}$

Valor com o fator de ponderação $\gamma_{p}=0,9 \quad \rightarrow \quad 0,9 \times 1292=1163 \mathrm{MPa}$

\section{Cálculo de $\varepsilon_{c 1 d}$}

$$
k_{c}=\frac{b d^{2}}{M_{d}}=\frac{30 \times 100^{2}}{1,575 \times 10^{2}}=1,905 \mathrm{~cm}^{2} / \mathrm{kN}
$$

$\mathrm{Na}$ tabela $\mathrm{A} 1$, na coluna correspondente $f_{c k}=30 \mathrm{MPa}$, para $k_{c}=1,905$ (interpolando-se), chega-se a $\beta_{x}=0,423$ (domínio 3) e $\varepsilon_{c 1 d}=4,095 \%$. Para $f_{c k}=30 M P a$, tem-se $\beta_{1}=0,875$.

Cálculo de $\beta_{z}$ :

$$
\beta_{z}=1-0,5 \beta_{1} \beta_{x}=1-0,5 \times 0,875 \times 0,423=0,815
$$




\section{Pré-alongamento}

$$
\begin{aligned}
& \varepsilon_{p i, \infty d}=\frac{1163}{200}=5,82 \% o \\
& \varepsilon_{p d}=4,095+5,82=9,915 \% \circ \rightarrow \sigma_{p d}=1485 \mathrm{MPa}
\end{aligned}
$$

\section{Cálculo da área de protensão}

$$
A_{p}\left(\mathrm{~cm}^{2}\right)=\frac{M_{d}(M N / m)}{z(m) \sigma_{p d}(M P a)} 10^{4}
$$

Como $z=\beta_{z} d$, vem:

$$
A_{p}=\frac{1,575 \times 10^{4}}{0,815 \times 1,00 \times 1485}=13,01 \mathrm{~cm}^{2}
$$

Este é exatamente o mesmo valor apresentado em VASCONCELOS (1980), o qual segue o diagrama parábola-retângulo.

Na tabela 3.4 apresentam-se, para uma resistência de $30 M P a$, os resultados obtidos para armadura de protensão, a partir do diagrama retangular de IBRAHIM \& MacGREGOR (1997) e do diagrama parábola-retângulo, variando-se a posição da linha neutra. A posição da linha neutra foi variada aproveitando-se o exemplo anterior, mudando-se os valores de $M_{d}$, mantendo-se constantes as dimensões da seção $(b=0,30 m$ e $d=1,0 m)$.

Como se pode observar, não existe diferença significativa, para o dimensionamento de seções de concretos de resistências usuais submetidas a flexão simples, em se adotar um ou outro diagrama, no que se refere ao consumo de armadura. 
TABELA 3.4 - Comparação entre os dimensionamentos através dos diferentes diagramas tensão-deformação $\left(f_{c k}=30 \mathrm{MPa}\right)$

\begin{tabular}{|c|c|c|c|c|c|c|c|c|}
\cline { 4 - 10 } \multicolumn{2}{c|}{} & $\begin{array}{c}\text { IBRAHIM \& } \\
\text { MacGREGOR } \\
(1997)\end{array}$ & \multicolumn{2}{c|}{$\begin{array}{c}\text { Parábola- } \\
\text { retângulo }\end{array}$} & \multicolumn{2}{l|}{} \\
\hline $\begin{array}{c}f_{c k} \\
(M P a)\end{array}$ & $\begin{array}{c}M_{d} \\
(k \mathrm{~N} . \mathrm{m})\end{array}$ & DOM. & $\beta_{x}$ & $\begin{array}{c}A_{p} \\
\left(\mathrm{~cm}^{2}\right)\end{array}$ & $\beta_{x}$ & $\begin{array}{c}A_{p} \\
\left(\mathrm{~m}^{2}\right)\end{array}$ & $\begin{array}{c}\beta_{x} \\
D I F . \%\end{array}$ & $\begin{array}{c}A_{p} \\
D I F . \%\end{array}$ \\
\hline 30 & 437 & $2 \mathrm{a}$ & 0,100 & 3,03 & 0,142 & 3,05 & -42 & -1 \\
\hline 30 & 909 & $2 \mathrm{~b}$ & 0,220 & 6,66 & 0,236 & 6,66 & -7 & 0 \\
\hline 30 & 1575 & 3 & 0,423 & 13,01 & 0,440 & 13,00 & -4 & 0 \\
\hline 30 & 2005 & 3 & 0,592 & 18,66 & 0,600 & 18,34 & -1 & 2 \\
\hline 30 & 2377 & 4 & 0,800 & 28,68 & 0,816 & 28,05 & -2 & 2 \\
\hline
\end{tabular}

EXEMPLO $3.2-f_{c k}=70 M P a$

Idêntico ao exemplo 3.1, porém com concreto $f_{c k}=70 \mathrm{MPa}$. Os materiais disponíveis são:

Concreto: $f_{c k}=70 \mathrm{MPa}$; peso específico $=25 \mathrm{kN} / \mathrm{m}^{3}$.

Aço: CP $190 \mathrm{RB}\left(f_{p t k}=1900 \mathrm{MPa}\right) ; E_{p}=200 G P a$

Dimensões adotadas: $b=0,30 \mathrm{~m}$ e $d=1,0 \mathrm{~m}$

TABELA 3.5 - Comparação entre os dimensionamentos através dos diferentes diagramas tensão-deformação $\left(f_{c k}=70 M P a\right)$

\begin{tabular}{|c|c|c|c|c|c|c|c|c|}
\hline & \multirow{2}{*}{\multicolumn{2}{|c|}{$\begin{array}{c}\text { IBRAHIM \& } \\
\text { MacGREGOR } \\
(1997)\end{array}$}} & \multirow{2}{*}{\multicolumn{2}{|c|}{$\begin{array}{l}\text { Parábola- } \\
\text { retângulo }\end{array}$}} & \multirow{3}{*}{$\begin{array}{c} \\
\beta_{x} \\
D I F . \%\end{array}$} & \multirow[b]{3}{*}{$\begin{array}{c}A_{p} \\
\text { DIF. \% }\end{array}$} \\
\hline & & & & & & & & \\
\hline $\begin{array}{c}f_{c k} \\
(M P a)\end{array}$ & $\begin{array}{c}M_{d} \\
(k \mathrm{~N} . \mathrm{m})\end{array}$ & DOM. & $\overline{\beta_{x}}$ & $\begin{array}{c}A_{p} \\
\left(\mathrm{~cm}^{2}\right)\end{array}$ & $\overline{\beta_{x}}$ & $\begin{array}{c}A_{p} \\
\left(\mathrm{~cm}^{2}\right)\end{array}$ & & \\
\hline 70 & 852 & $2 a$ & 0,100 & 5,88 & 0,127 & 5,92 & -27 & -1 \\
\hline 70 & 1636 & $2 b$ & 0,200 & 11,75 & 0,193 & 11,72 & 4 & 0 \\
\hline 70 & 2997 & 3 & 0,400 & 23,85 & 0,338 & 23,29 & 16 & 2 \\
\hline 70 & 4043 & 3 & 0,592 & 36,16 & 0,493 & 34,27 & 17 & 5 \\
\hline 70 & 4894 & 4 & 0,800 & 55,63 & 0,65 & 46,91 & 19 & 16 \\
\hline
\end{tabular}


Como se pode observar, à medida que se aproxima do Domínio 4, para seções de $\mathrm{CAD}$, aumenta a diferença entre a armadura obtida a partir do diagrama parábolaretângulo e a obtida pela proposta de IBRAHIM \& MacGREGOR (1997).

EXEMPLO 3.3 $-f_{c k}=70 \mathrm{MPa}$

Considere-se a viga do item 2.4 .

\section{Dados adicionais:}

Vão: $l=30,0 m$

Cobrimento: $30 \mathrm{~mm}$

Excentricidade do cabo (aderente e parabólico) em relação ao C.G. da seção, em uma seção localizada $x(\mathrm{~m})$ à direita do apoio $\mathrm{A}$ :

$$
e=2,8\left[\frac{x}{30}-\left(\frac{x}{30}\right)^{2}\right]
$$

O diâmetro da bainha $\left(\phi_{b}\right)$ é de $120 \mathrm{~mm}$ e a excentricidade no meio do vão $\left(e_{1}\right)$ é de $700 \mathrm{~mm}$, e nos apoios é igual a zero.

A força de protensão em cada apoio é $4500 k N$, no meio do vão é $4200 k N$, e admite-se que varie linearmente $(20 \mathrm{kN} / \mathrm{m})$ ao longo da viga.

Admitindo-se que a armadura protendida necessária para atender aos estados limites de utilização tenha sido $A_{p}=3948 \mathrm{~mm}^{2}$ (12 cordoalhas de $12,7 \mathrm{~mm}$ ), desejase calcular a armadura passiva adicional necessária para atender ao estado limite último, com os coeficientes de segurança da norma brasileira (NB-1/1978). 


\section{Solução}

Momento de cálculo:

$$
M_{d}=1,4 \times \frac{(23+19,5) \times 30^{2}}{8}=6694 \mathrm{kN} . \mathrm{m}
$$

Momento absorvido por $A_{p}=3948 \mathrm{~mm}^{2}$ :

$$
M_{u 1}=\sigma_{p u 1} A_{p}\left(d_{p}-\frac{\beta_{1} x_{1}}{2}\right)
$$

onde, para $f_{c k}=70 \mathrm{MPa}$, tem-se $\beta_{1}=0,775$ (ver tabela A1). A posição da linha neutra $\left(x_{1}=0,1385 m\right)$ e a tensão na armadura de protensão $\left(\sigma_{p u 1}=1556 M P a\right)$ são obtidas a partir das equações de compatibilidade e de equilíbrio.

Assim, o momento absorvido pela armadura protendida na ruptura será:

$$
\begin{aligned}
& M_{u 1}=1556 \times 10^{6} \times 3948 \times 10^{-6} \times\left(1,084-\frac{0,775 \times 0,1385_{1}}{2}\right) \\
& M_{u 1}=6329,4 \mathrm{kN} . \mathrm{m}
\end{aligned}
$$

Como $M_{u 1}=6329,4 k N . m<M_{d}=6694 k N . m$, é necessária armadura passiva adicional para se atender ao estado limite último.

A armadura passiva $\left(A_{s}\right)$ para absorver o momento $\left(M_{d}-M_{u 1}\right)$ pode ser calculada pela seguinte expressão de equilíbrio:

$$
A_{s}=\frac{M_{d}-M_{u 1}}{f_{y d} z_{s}}
$$

onde $z_{s}$ é o braço de alavanca de flexão dado por:

$$
z_{s} \cong 0,9\left(d_{0}-\beta_{1} x_{1}\right) \cong 0,9(1,146-0,775 \times 0,1385) \cong 0,9348 m
$$

Portanto, para o aço CA-50, tem-se: 


$$
A_{s}=\frac{(6694-6329,4) \times 10^{3}}{\frac{500 \times 10^{6}}{1,15} \times 0,9348}=8,97 \times 10^{-4} \mathrm{~m}^{2}=8,97 \mathrm{~cm}^{2}
$$

Serão adotadas 2 barras de $25 \mathrm{~mm}\left(A_{s}=10,0 \mathrm{~cm}^{2}\right)$.

Tendo em vista o caráter aproximado da expressão para o cálculo de $z_{s}$, faz-se necessária uma verificação da capacidade da seção para as armaduras adotadas. $\mathrm{O}$ leitor poderá querer fazê-la e verificar que, para $A_{s}=10,0 \mathrm{~cm}^{2}$ e $A_{p}=3948 \mathrm{~mm}^{2}$, a capacidade da seção é de $6765,9 \mathrm{kN} . \mathrm{m}$, superior portanto a $M_{d}$. 


\section{CISALHAMENTO}

O dimensionamento das vigas normalmente é comandado pela flexão. Isto significa que, na maioria dos casos, ela determina as dimensões da peça. Feito isso, parte-se para o dimensionamento ao cisalhamento.

Em algumas situações, contudo, quando os vãos são pequenos ou é grande o carregamento aplicado (como nas vigas de transição), o cisalhamento cresce de importância, podendo liderar o dimensionamento.

Serão apresentadas aqui as seguintes propostas de dimensionamento ao cisalhamento, bem como a sua validade para o CAD: treliça clássica de RitterMörsch, método padrão, analogia de treliça com diagonais de inclinação variável, dimensionamento segundo a $A S-3600$ (1988) e segundo a CAN 3 (1994).

\subsection{TRELIÇA CLÁSSICA DE RITTER-MÖRSCH}

O modelo de treliça proposto por RITTER (1899) e mais tarde desenvolvido por MÖRSCH (1948) é fundamental para o entendimento dos que a ele se seguiram. Trata-se de uma analogia entre os esforços existentes em uma viga real de concreto armado (com alma cheia) e uma treliça.

Conhecido pelo nome de treliça clássica de Ritter-Mörsch, admite que a totalidade da força cortante é resistida pelos elementos da alma da viga de concreto: armadura transversal e diagonais de concreto (representados pelos tirantes e pelas bielas da treliça, respectivamente). Não se considera a contribuição do banzo comprimido de concreto.

Esse modelo (figuras 4.1 e 4.2 ) tem as seguintes características: 
- É formado por uma treliça isostática com um banzo comprimido (representando o concreto) e outro tracionado (representando a armadura longitudinal tracionada), admitidos paralelos.

- As diagonais comprimidas (bielas de concreto) têm inclinação $(\theta)$ de $45^{\circ}$.

- Os tirantes entre os banzos têm inclinação $(\alpha)$ que pode ser escolhida entre $45^{\circ}$ (para estribos inclinados, ou cavaletes) e $90^{\circ}$ (para estribos perpendiculares ao eixo longitudinal da peça).

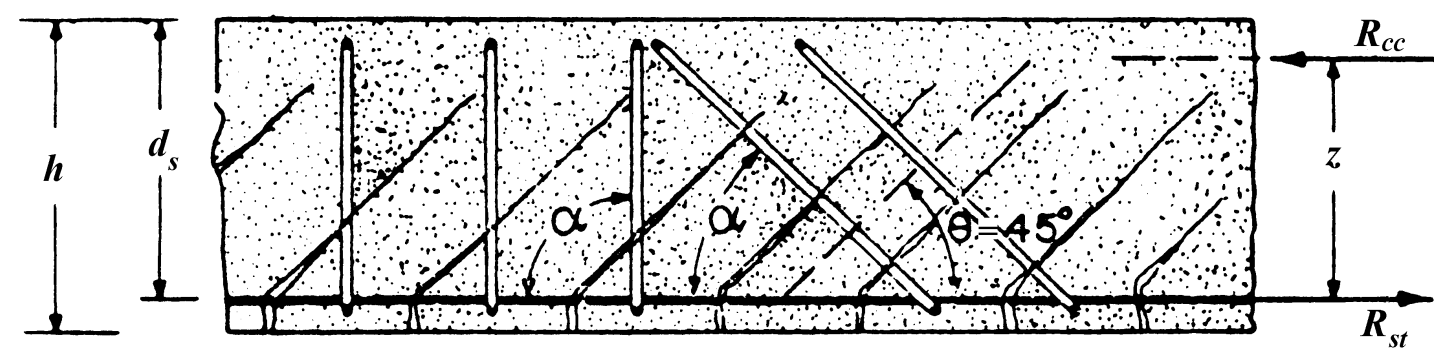

FIGURA 4.1 - Treliça clássica de Ritter-Mörsch

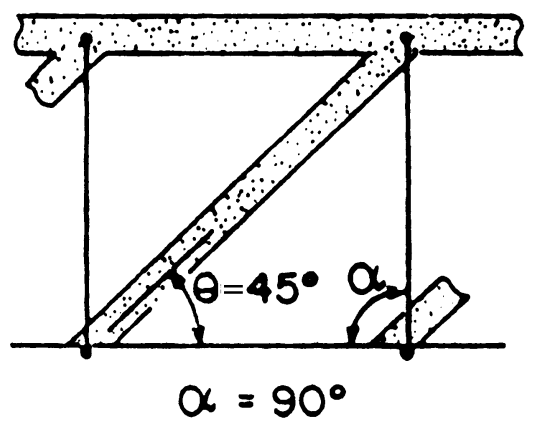

FIGURA 4.2- Treliça clássica de Ritter-Mörsch para estribos verticais

Analisando-se a figura (4.3), observa-se que no modelo de treliça os esforços de flexão não são exatamente iguais aos previstos para uma viga real de alma cheia. Nesta última, a resultante no banzo comprimido $\left(R_{c c}\right)$ e a resultante na armadura longitudinal de tração $\left(R_{s t}\right)$ que atuam em uma seção são proporcionais ao momento fletor que atua nesta mesma seção. Portanto, em uma viga real, $R_{c c}$ e $R_{s t}$ variam entre uma seção localizada em $x$ e outra localizada em $x+\Delta x$. 


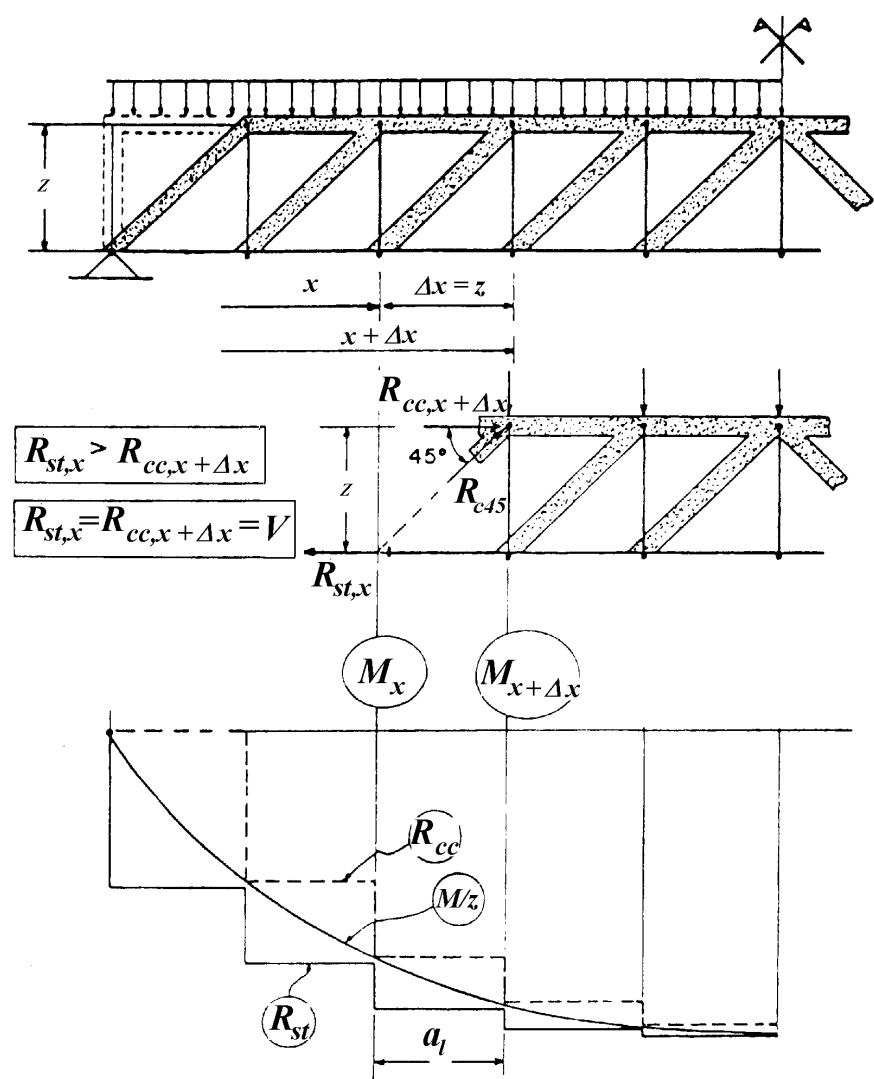

FIGURA 4.3 - Translação do diagrama de esforços na armadura de tração $\left(R_{s t}\right)$

FONTE: FUSCO (1981)

Na treliça, os esforços têm valores constantes entre dois nós que definem cada barra. Para uma seção de abscissa $x$, a resultante de tração na armadura longitudinal de tração $\left(R_{s t, x}\right)$ é determinada pelo momento fletor $M_{x+\Delta x}$ que age em uma seção adjacente afastada de $\Delta x=z$.

Para a determinação da resultante $R_{s t}$ tudo se passa como se houvesse uma translação $a_{l}$ do diagrama de momentos fletores (conhecida como decalagem do diagrama), aumentado-se a intensidade de $R_{s t}$. No banzo comprimido, a interação entre a força cortante e o momento fletor produz um efeito oposto ao observado no banzo tracionado, diminuindo a resultante de compressão no concreto $\left(R_{c c}\right)$.

A decalagem do diagrama permite, portanto, uma compatibilização entre o modelo de treliça e o comportamento real dos esforços na viga de alma cheia. 
Do equilíbrio de momentos (figura 4.4) em relação ao ponto de aplicação da resultante de compressão $\left(R_{c c}\right)$ tem-se:

$$
R_{s t, x}=\frac{M_{x+\Delta x}}{z}
$$

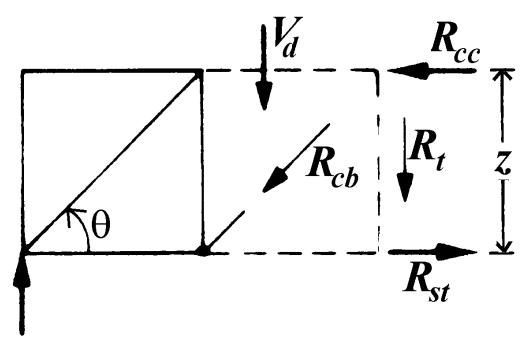

FIGURA 4.4 - Esforços nos elementos da treliça

Considerando-se o equilíbrio de momentos na seção de abscissa $x$, a resultante de compressão na biela de concreto é dada por:

$$
R_{c c, x+\Delta x}=\frac{M_{x}}{z}
$$

Montando-se a equação de equilíbrio das forças que agem na seção $x+\Delta x$, paralelas ao eixo da viga, resulta:

$$
R_{s t, x}=R_{c c, x+\Delta x}+R_{c b} \cos \theta
$$

A diferença entre as forças longitudinais que agem em duas seções afastadas de $\Delta x=z_{s}$ é igual à força cortante que age na seção:

$$
R_{s t, x}-R_{c c, x+\Delta x}=\frac{M_{x+\Delta x}-M_{x}}{z}=V
$$


Sendo $V_{d}$ a força cortante de cálculo que atua numa dada seção, a resultante das tensões de compressão nas bielas de concreto $\left(R_{c b}\right)$ é dada por (figura 4.4):

$$
R_{c b}=-\frac{V_{d}}{\operatorname{sen} \theta}
$$

A resultante das tensões de tração no montante tracionado $\left(R_{t}\right)$ é igual ao esforço cisalhante de cálculo:

$$
R_{t}=V_{d}
$$

Estudos experimentais realizados com concretos de resistência usual demonstram que a treliça clássica de Ritter-Mörsch leva a armaduras transversais maiores que as necessárias, errando portanto a favor da segurança. Na realidade, os valores de $\theta$ podem se apresentar menores que $45^{\circ}$. Como se verá mais adiante, essa e outras constatações experimentais levaram à formulação do modelo de treliça com diagonais de inclinações variáveis.

\subsection{MÉTODO PADRÃO}

A NB-1 (1978), a NBR-7197 (1989) e o CEB-FIP (1990) adotam o método padrão para o dimensionamento ao cisalhamento dos elementos fletidos.

Neste modelo, parte da resistência ao cisalhamento é atribuída ao banzo comprimido de concreto, por ser ele inclinado até atingir os apoios, e não totalmente horizontal como admitido pela treliça clássica de Ritter-Mörsch.

Assim, a resistência ao cisalhamento das vigas de concreto armado pode ser considerada como a soma das contribuições do concreto e da armadura transversal. Essa proposta conserva o modelo da analogia clássica, mas reduz a força cortante para cálculo da armadura transversal, atribuindo às partes comprimidas de concreto uma parcela de colaboração na resistência à força cortante. 
Em decorrência desse fato, a força cortante de cálculo $\left(V_{d}\right.$ pode ser representada por $V_{d}={ }_{c d} V_{s d}$, onde ${ }_{c d}$ e $V_{s d}$ "concreto" e da armadura de cisalhamento, respectivamente. Dessa forma, aplicandose a analogia da treliça clássica, uma armadura transversal é necessária para resistir $V_{s d}=V_{d}-V_{c d}$, diminuindo-se a armadura transversal a ser utilizada.

Embora a armadura transversal inclinada (estribos inclinados ou cavaletes) seja mais eficiente no combate ao cisalhamento, os estribos verticais são muito mais usados pela sua facilidade de execução.

No caso de armadura constituída apenas por estribos verticais, a correspondente taxa de armadura transversal será:

$$
\rho_{w}=\frac{V_{d}-V_{c d}}{b_{w} z \sigma_{s w}}
$$

onde:

$$
\begin{array}{ll}
b_{w} & \text { largura da alma da seção transversal } \\
z & \text { braço de alavanca interno da seção devido à flexão } \\
\sigma_{s w} & \text { tensão para cálculo da armadura transversal }
\end{array}
$$

Fazendo $\tau_{0 d}=V_{d} /\left(b_{w} z\right)$ e $\tau_{c d}=V_{c d} /\left(b_{w} z\right)$, a expressão (4.7) transforma-se em:

$$
\rho_{w}=\frac{\tau_{0 d}-\tau_{c d}}{\sigma_{s w}}
$$

Segundo o CEB-FIP (1990) e o EUROCODE (1992), pode-se admitir $d_{s} / z=1,11$ nessas relações. Segundo a NB-1 (1978), pode-se adotar a relação $d_{s} / z=1,15$.

A área da armadura transversal será obtida por: 


$$
A_{s w}=\rho_{w} s b_{w} \operatorname{sen} \alpha
$$

onde:

$A_{s w} \quad$ área da seção transversal dos ramos de estribos na mesma seção

$s \quad$ espaçamento entre os estribos

$\alpha \quad$ ângulo formado pela armadura longitudinal tracionada e os estribos, tomado no sentido horário. Para estribos verticais, $\alpha=90^{\circ}$

A contribuição do "concreto", expressa através da tensão $\left(\tau_{c}\right)$ ou do esforço $\left(V_{c}\right)$, é obtida experimentalmente e leva em consideração:

- A soma das contribuições do banzo comprimido de concreto.

- O engrenamento dos agregados ao longo das fissuras inclinadas.

- O efeito de pino da armadura longitudinal.

O engrenamento dos agregados é o efeito de fricção ao longo das fissuras (figura 4.5). O mecanismo de transferência de cisalhamento ao longo da interface concreto-concreto a qual está submetida simultaneamente a cisalhamento e esforço normal de compressão é chamado de fricção concreto-concreto e inclui o engrenamento dos agregados.

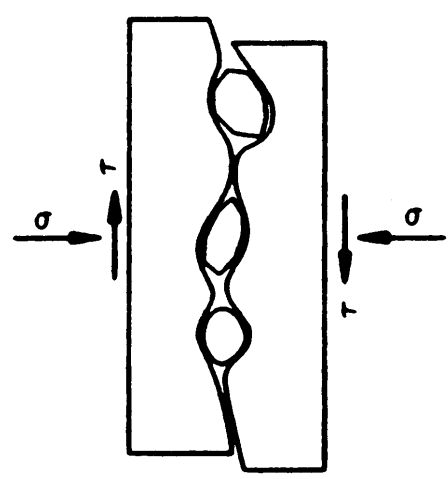

FIGURA 4.5 - Engrenamento dos agregados

FONTE: CEB-FIP (1990) 
Alguns pesquisadores admitem que a contribuição do "concreto" $\left(\tau_{c}\right)$ seja diretamente proporcional à resistência do concreto à compressão $\left(f_{c}\right)$. Outros admitem que esteja relacionado com a resistência do concreto à tração $\left(f_{t}\right)$, o que levaria a expressões em função de $\left(f_{c}\right)^{1 / 2}$ (como no $\left.A C I\right)$ ou $\left(f_{c}\right)^{1 / 3}$. Isso realça a importância da determinação de uma expressão confiável para o cálculo de $\tau_{c}$.

No $C E B-F I P(1990)$ a resistência máxima ao cisalhamento, obtida para $\theta=45^{\circ}$ em uma dada seção, é dada em função da resistência do concreto por:

$$
V_{R d, \max }=\frac{f_{c d 2}}{2} b_{w} z(1+\operatorname{cotg} \alpha)
$$

$f_{c d 2}$ é dado por:

$$
f_{c d 2}=0,6\left[1-\frac{f_{c k}}{250}\right] f_{c d}
$$

Segundo FERNANDES (1992), o método padrão pode ser adotado para as vigas de CAD, atribuindo-se ao concreto uma contribuição dada por:

$$
\tau_{c}=f_{c} / 20
$$

$f_{c}$ é a resistência do concreto à compressão determinada em cilindros com $10 \mathrm{~cm}$ de diâmetro e $20 \mathrm{~cm}$ de altura. FERNANDES (1992) ensaiou vigas de concreto com resistência à compressão em torno de 60MPa. A utilização da equação (4.12), para resistências maiores, deve ser feita com cuidado.

\subsection{ANALOGIA DA TRELIÇA COM DIAGONAIS DE INCLINAÇÃO VARIÁVEL}

Ensaios demonstraram que, dentro de certos limites, as diagonais comprimidas ajustarão sua inclinação até que seja atingido um estado de equilíbrio para o qual a 
armadura transversal existente seja eficaz. Quanto mais reduzida for a armadura para cisalhamento adotada, menores serão as inclinações $(\theta)$ assumidas pelas diagonais.

Em situação de projeto, o ângulo $\theta$ é arbitrado pelo projetista. Essa escolha determina o maior ou menor consumo de armadura transversal. Quanto menor o ângulo adotado, menor será o consumo de armadura e maior a tensão nas bielas comprimidas de concreto [equação (4.5)]. A quantidade de armadura será minimizada quando o menor ângulo $\theta$ puder ser adotado sem que haja esmagamento das diagonais com tensões de compressão $\sigma_{c d}$ ou o escoamento da armadura de cisalhamento. Assim, a armadura de cisalhamento é calculada para resistir à totalidade da força cortante $V_{d} \operatorname{com} \theta$ menor ou igual a $45^{\circ}$.

Segundo FERNANDES (1992), no estudo do cisalhamento, cresce a importância da forma da seção. LEONHARDT \& WALTHER (1961) ensaiaram, nos já conhecidos ensaios de Stuttgart, vigas de almas largas ou com pequena diferença entre a largura da mesa e a largura da alma. Nas seções $T$ ou $I$, mais adequadas ao $\mathrm{CAD}$, o banzo comprimido é muito inclinado e as diagonais comprimidas possuem inclinação bem menor que $45^{\circ}$, como admitido na treliça clássica de Mörsch. Isso diminui os esforços de tração na alma, resultando em menores armaduras transversais.

Considerando uma armadura transversal constituída somente por estribos verticais, a correspondente taxa de armadura será:

$$
\rho_{w}=\frac{V_{d}}{b_{w} z \sigma_{s w} \operatorname{cotg} \theta}
$$

Fazendo $\tau_{0 d}=V_{d} /\left(b_{w} z\right)$ a expressão (4.13) transforma-se em:

$$
\rho_{w}=\frac{\tau_{0 d}}{\sigma_{s w} \operatorname{cotg} \theta}
$$

No caso de armadura transversal constituída apenas por estribos verticais, esta armadura é obtida por $A_{s w}=\rho_{w} b_{w} s$, onde $A_{s w}$ a área da seção transversal de todos os ramos de estribos na mesma seção e $s$ é o espaçamento entre eles. 
A taxa de armadura de cisalhamento de acordo com a treliça clássica de RitterMörsch, a qual não considera a contribuição do "concreto", é dada por:

$$
\rho_{w, \mathrm{M}}=\frac{\tau_{0 d}}{\sigma_{s w}}
$$

O grau de armação ao cisalhamento é definido pela relação:

$$
\eta=\frac{\rho_{w}}{\rho_{w, M}}
$$

Assim, das equações (4.15) e (4.16) vem:

$$
\eta=\frac{1}{\operatorname{cotg} \theta}=\operatorname{tg} \theta
$$

Com a finalidade de se evitar a ruptura prematura do concreto e a deterioração do engrenamento dos agregados, deve-se limitar o ângulo $\theta$. Com base em investigações experimentais, GROB \& THÜRLIMANN (1976) estabeleceram o limite superior $\operatorname{cotg} \theta \leq 2$ (ou $\theta \geq 26,6^{\circ}$ ). Entretanto, para finalidade de projeto, aqueles autores recomendam o valor mais conservador $\operatorname{cotg} \theta \leq 5 / 3$ (ou $\theta \geq 31^{\circ}$ ).

O Código Modelo do CEB-FIP (1978) adotava o mesmo limite $\left(\theta \geq 31^{\circ}\right)$. O Código Modelo do CEB-FIP (1990) alterou esse limite para $\operatorname{cotg} \theta \leq 3$ (ou $\theta \geq 18,4^{\circ}$ ).

O EUROCODE 2 (1992) adota $0,4<\operatorname{cotg} \theta<2,5$ (ou $68,2^{\circ}>\theta>21,8^{\circ}$ ) para vigas com armadura longitudinal constante e $0,5<\operatorname{cotg} \theta<2$ (ou $63,4^{\circ}>\theta>26,6^{\circ}$ ) no caso de armadura longitudinal escalonada.

Segundo FERNANDES (1992), no caso das vigas de CAD, a interrupção de barras antes do apoio deve ser vista com maior cuidado, ou mesmo evitado, pelas seguintes razões: 
- Melhorar a ancoragem no apoio.

- Possibilitar apoio adequado para as bielas comprimidas.

Isso está de acordo com a proposta do EUROCODE 2 (1992) que adota um valor mais conservador para as vigas com armadura longitudinal escalonada.

Além disso, o deslocamento de $R_{s t}$ deve ser maior que os permitidos nos casos de vigas com concretos usuais (deve ser pelo menos igual a $d$ ).

LEVI \& MARRO (1989) concluíram em suas pesquisa que o modelo de treliça com diagonais de inclinação variável é válida para o CAD.

\subsection{DIMENSIONAMENTO AO CISALHAMENTO SEGUNDO A CAN 3 (1994)}

Como comentado anteriormente, pesquisas demostraram que o ângulo $\theta$, em geral, é diferente de $45^{\circ}$, e que as expressões estabelecidas pelo modelo de treliça com diagonais de inclinação variável fornecem uma metodologia mais realista para o cálculo do cisalhamento.

Além disso, testes realizados por COLLINS \& VECCHIO (1986) com painéis de concreto armado solicitados a cisalhamento puro aumentaram a compreensão das relações tensão-deformação do concreto com fissuras diagonais.

Essas relações permitiram o desenvolvimento de um modelo analítico, conhecido por teoria do campo de compressão modificado, que possibilitou uma previsão adequada do comportamento do concreto armado solicitado a cisalhamento.

Apresenta-se a seguir a metodologia proposta por COLLINS \& MITCHELL (1991), a qual foi adotada pelo Ontario Highway Bridge Design Code, Canadian Standards Association Design Code e pela AASHTO LRFD.

Em comparação com outras normas modernas, como o ACI 318 (1995) por exemplo, a proposta da CAN 3 (1994) representa uma significativa redução no número de equações. 
Além de ser válida para elementos de concreto armado ou protendido, apresentando boa correlação com os resultados experimentais, a metodologia da CAN 3 (1994) aqui proposta é válida para as vigas de CAD.

\subsubsection{Resposta do concreto fissurado solicitado a cisalhamento}

O modelo de fissuração do concreto é idealizado como uma série de fissuras paralelas com inclinação $\theta$ em relação à direção longitudinal. Em lugar de complexas variações de tensão, apenas um estado de tensão média e o estado de tensão em uma fissura são considerados (figuras $4.6 b$ e $4.6 \mathrm{c}$ ).

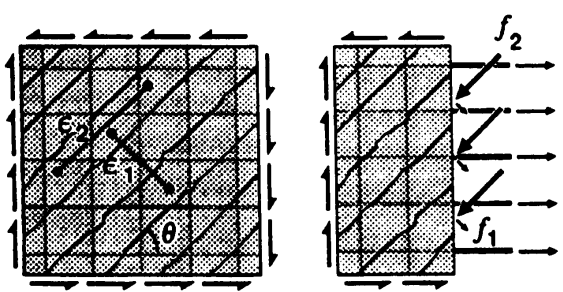

(a) Painel solicitado a cisalhamento

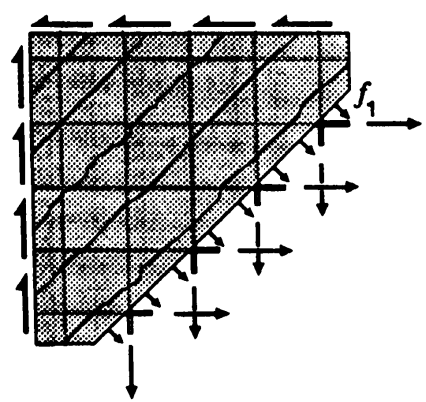

(b) Tensões médias calculadas

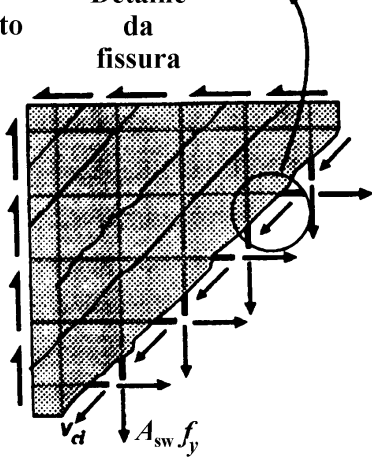

(c) Tensões locais na fissura

FIGURA 4.6 - Painéis de concreto armado solicitados a cisalhamento FONTE: ADEBAR et. al. (1996)

Como estes dois estados de tensão são estaticamente equivalentes, a perda de tensão de tração no concreto em uma fissura deve ser substituída por um aumento de tensão na armadura ou, após o escoamento de parte da armadura na fissura, pelas tensões de cisalhamento nas superfícies formadas pela fissura (ou seja, na interface da fissura). 
A tensão de cisalhamento que pode ser transmitida através da fissura será função da abertura da fissura. Note-se que a tensão de cisalhamento na fissura implica que a direção das tensões principais no concreto mudam no local da fissura.

\subsubsection{Cálculo dos estribos}

Ao se aplicar a teoria do campo de compressão modificado para o projeto de vigas, é apropriado que se façam algumas simplificações.

Como ilustrado na figura 4.7, as tensões de cisalhamento são assumidas como sendo uniformes ao longo de toda a área efetiva de cisalhamento $\left(b_{v} \mathrm{~d}_{\mathrm{v}}\right)$.

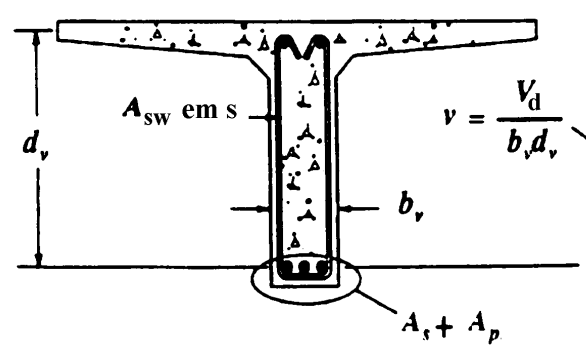

(a) Seção transversal

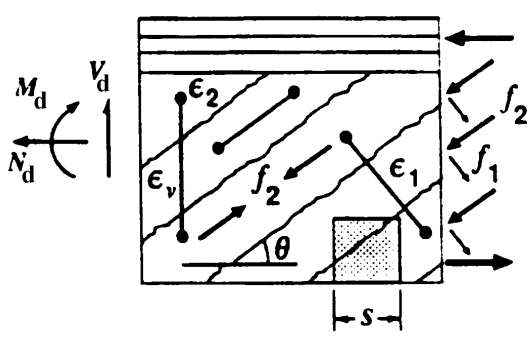

(d)

Deformações biaxiais na alma

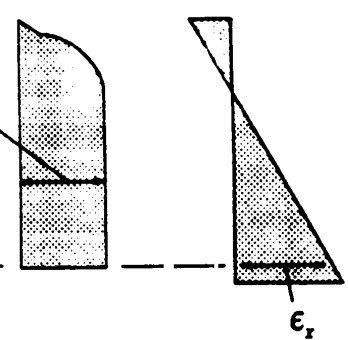

(c)

(b)

Tensão Deformação de cisalhamento longitudinal

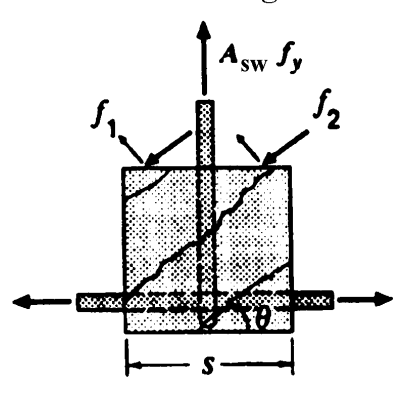

(e)

Tração nos estribos

FIGURA 4.7 - Vigas submetidas a cisalhamento, flexão e carregamento axial

FONTE: ADEBAR et. al. (1996)

A maior deformação longitudinal $\left(\varepsilon_{x}\right)$ que ocorre dentro da alma é usada para calcular a deformação principal de tração $\left(\varepsilon_{1}\right)$. Para projeto, $\varepsilon_{x}$ pode ser aproximada 
como a deformação na armadura longitudinal de tração. A determinação de $\varepsilon_{x}$ para uma viga não protendida é ilustrada na figura 4.8.

Para um elemento protendido, o concreto em redor da armadura permanecerá comprimido até que a tensão aplicada exceda a força de protensão $A_{p} f_{p o}$, onde $f_{p o}$ é a tensão na cordoalha onde o concreto em redor tem tensão nula. Em lugar de um cálculo mais acurado, $f_{p o}$ pode ser tomado como $1,1 f_{p e}$, onde $f_{p e}$ é a tensão efetiva na cordoalha de protensão depois de todas as perdas.

Portanto, para projeto:

$$
\varepsilon_{x}=\frac{\left[\left(M_{d} / d_{v}\right)+0,5 N_{d}+0,5 V_{d} \operatorname{cotg} \theta\right]-A_{p} f_{p o}}{E_{s} A_{s}+E_{p} A_{p}} \geq 0
$$

Assim, quando a deformação longitudinal $\left(\varepsilon_{x}\right)$ torna-se maior, a inclinação $\theta$ da tensão principal de compressão torna-se menor, evidenciando uma maior fissuração no concreto.
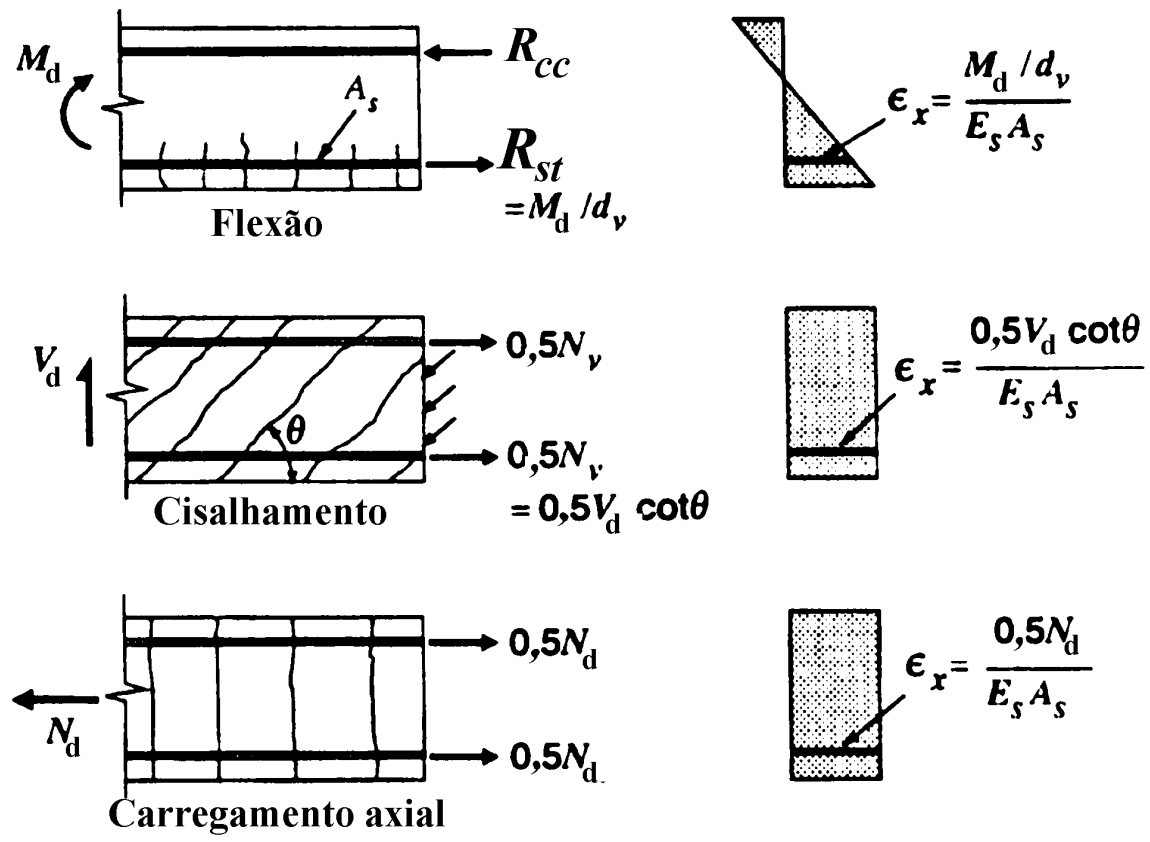

FIGURA 4.8 - Determinação da deformação $\varepsilon_{x}$ para vigas de concreto armado FONTE: ADEBAR et. al. (1996) 
A resistência nominal ao cisalhamento $\left(V_{n}\right)$ pode ser expressa pela soma das contribuições do concreto, da armadura passiva e da protensão:

$$
V_{n}=V_{c}+V_{s}+V_{p}
$$

Ou ainda, por:

$$
V_{n}=\beta_{r} \sqrt{f_{c k}} b_{v} d_{v}+\frac{A_{s w} f_{y w}}{s} d_{v} \operatorname{cotg} \theta+V_{p}
$$

onde:

$V_{p} \quad$ componente vertical da protensão $(\mathrm{kN})$

$A_{s w} \quad$ área de estribos verticais dentro de uma distância $s\left(\mathrm{~mm}^{2}\right)$

$f_{c k}, f_{y w}$ em $M P a$

$b_{v} \quad$ largura efetiva da alma, tomada como a menor largura da alma dentro da altura efetiva de cisalhamento $d_{v}(\mathrm{em} \mathrm{mm})$.

$d_{v} \quad$ altura efetiva de cisalhamento tomada como o braço de alavanca de flexão, não necessitando tomar-se valor menores que $0,9 d$. Para elementos protendidos, $d$ não precisa ser tomado menor que $0,8 h$ na determinação de $d_{v}$

d distância da fibra extrema mais comprimida ao centro de gravidade da armadura passiva longitudinal de tração

$\beta_{r} \quad$ fator que indica a capacidade do concreto fissurado de transmitir cisalhamento, dado por:

$$
\beta_{r}=\frac{0,33 \operatorname{cotg} \theta}{1+\sqrt{500 \varepsilon_{1}}} \leq \frac{0,18}{0,3+\frac{24 w}{\phi_{a g, \max }+16}}
$$

onde: 


$$
\begin{array}{ll}
\varepsilon_{1} & \text { deformação principal de tração no concreto fissurado } \\
\phi_{a g, \max } & \text { tamanho máximo do agregado } \\
w & \text { largura da fissura, tomada como o espaçamento das fissuras vezes } \varepsilon_{1}
\end{array}
$$

Para elementos com armadura transversal, os valores de $\theta$ e $\beta_{r}$ são apresentados na tabela 4.1 em função da deformação longitudinal $\left(\varepsilon_{\mathrm{x}}\right)$ e do nível de tensão de cisalhamento, ou seja, da relação $v / f_{c k}$, onde:

$$
v=\frac{V_{n}-V_{p}}{b_{v} d_{v}}
$$

Os valores da tabela 4.1 foram calculados assumindo-se um espaçamento de fissuração diagonal de $30,5 \mathrm{~cm}$ e um tamanho máximo do agregado de $19 \mathrm{~mm}$. ADEBAR et. al. (1996) consideram que estes valores são apropriados para todas as vigas com armadura transversal.

Tais valores foram escolhidos para se assegurar que a deformação nos estribos seja no máximo igual a $2 \%$ o, e de tal forma que, para membros submetidos a níveis de tensão mais elevados, a tensão principal de compressão não exceda a resistência de esmagamento do concreto.

Dentro do conjunto de valores de $\theta$ que satisfazem estas condições, os valores dados na tabela 4.1 resultarão em quantidades otimizadas de armadura de cisalhamento.

Pode-se interpolar linearmente os valores da tabela 4.1 mas, geralmente, o esforço não vale a pena.

Para uma dada seção de um elemento solicitado por $V_{d}, M_{d}$ e $N_{d}$, a resistência ao cisalhamento requerida $\left(V_{n}\right)$ é determinada por:

$$
V_{d} \leq \phi V_{n}
$$

onde: 
$\phi \quad$ fator de redução de resistência tomado igual a 0,85

$V_{d} \quad$ força de cisalhamento fatorada, tomada como positiva

A quantidade de estribos requerida na seção pode ser determinada a partir da equação (4.19). Assim:

$$
\mathrm{V}_{\mathrm{s}} \geq \frac{\mathrm{V}_{\mathrm{d}}}{\phi}-\mathrm{V}_{\mathrm{c}}-\mathrm{V}_{\mathrm{p}}
$$

TABELA 4.1 - Valores de $\theta$ e $\beta_{r}$ para elementos com armadura transversal

FONTE: ADEBAR et. al. (1996) (adaptada)

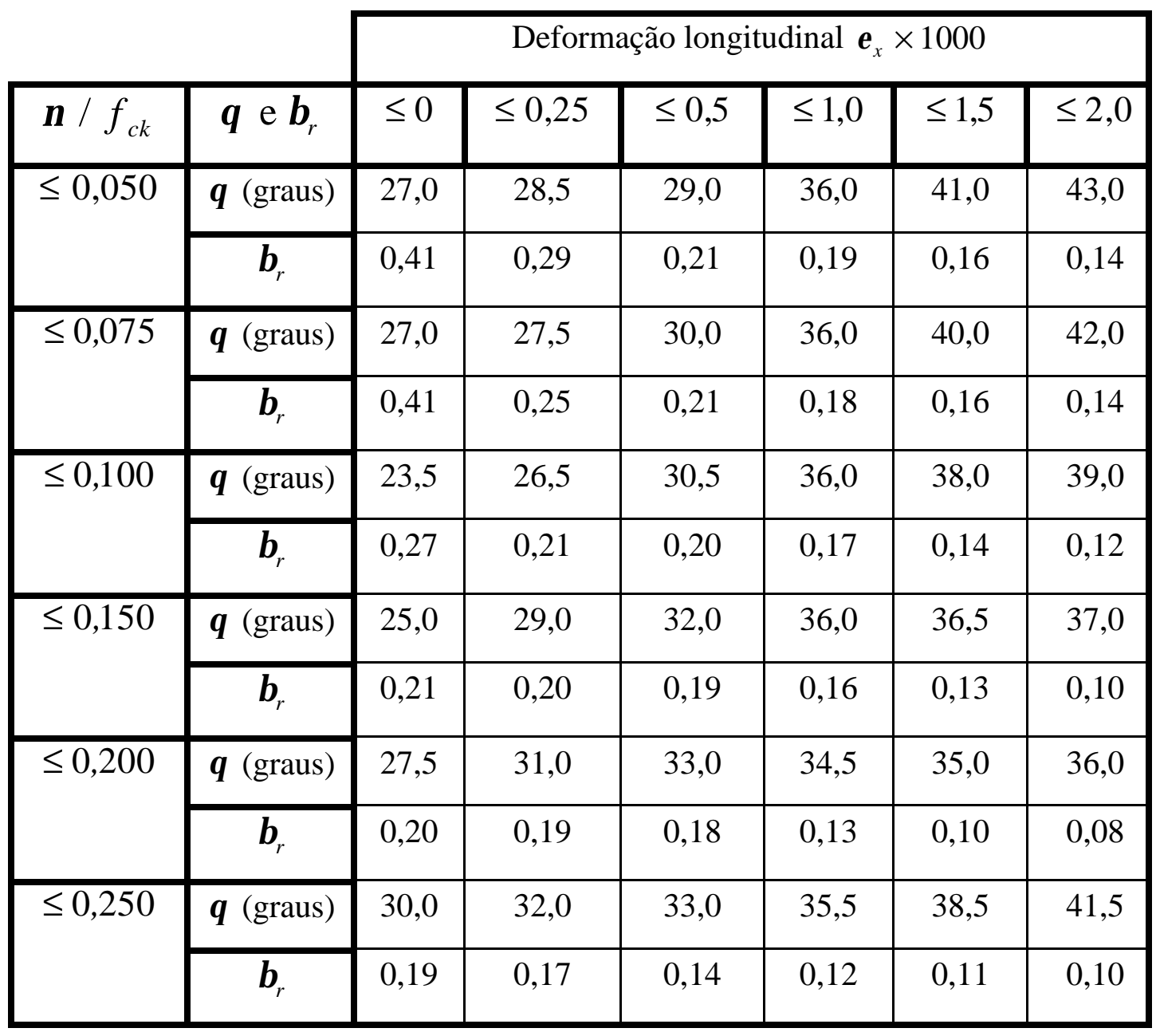

Embora estes cálculos sejam feitos para uma seção particular, uma ruína por cisalhamento causada pelo escoamento dos estribos envolve escoamento da armadura 
sobre um trecho da viga, cujo comprimento é igual a aproximadamente $d_{v} \operatorname{cotg} \theta$. Assim, os cálculos para uma seção podem ser tomados como representando um trecho de comprimento $d_{v} \operatorname{cotg} \theta$, com a seção calculada estando no meio deste comprimento. Assim, próximo ao apoio, a primeira seção a ser verificada é a seção a $0,5 d_{v} \operatorname{cotg} \theta$ a partir da face interna do apoio. Próximo a cargas concentradas, seções mais próximas que $0,5 d_{v} \operatorname{cotg} \theta$ precisam ser verificadas.

Como uma simplificação, ADEBAR et. al. (1996) sugerem que o termo $0,5 d_{v} \operatorname{cotg} \theta$ pode ser tomado igual a $d_{v}$.

A metodologia abrange também os elementos sem armadura transversal, com as devidas modificações dos valores de $\theta$ e $\beta_{r}$ que passam a ser dados em função da deformação longitudinal $\left(\varepsilon_{\mathrm{x}}\right)$ e do espaçamento das fissuras. Para maiores esclarecimentos para elementos sem armadura transversal, sugere-se a leitura de ADEBAR et. al. (1996).

\subsubsection{Cálculo da armadura longitudinal}

A figura 4.9 ilustra a influência do cisalhamento nas forças de tração na armadura longitudinal. Embora o momento seja nulo no apoio simples B, ainda assim é necessário que se considere a tração na armadura longitudinal próximo ao apoio.

A tração requerida na armadura inferior no apoio B pode ser determinada do diagrama de corpo livre na figura $4.9 \mathrm{~b}$, tomando-se os momentos sobre o ponto $\mathrm{C} \mathrm{e}$ assumindo-se que a força de engrenamento do agregado na fissura que contribui para $V_{c}$ tem um momento desprezível no ponto $\mathrm{C}$.

Para a viga de concreto armado da figura 4.9, a força de tração requerida na face interna do apoio é dada por:

$$
T=\left(\frac{V_{d}}{\phi}-0,5 V_{s}\right) \operatorname{cotg} \theta
$$




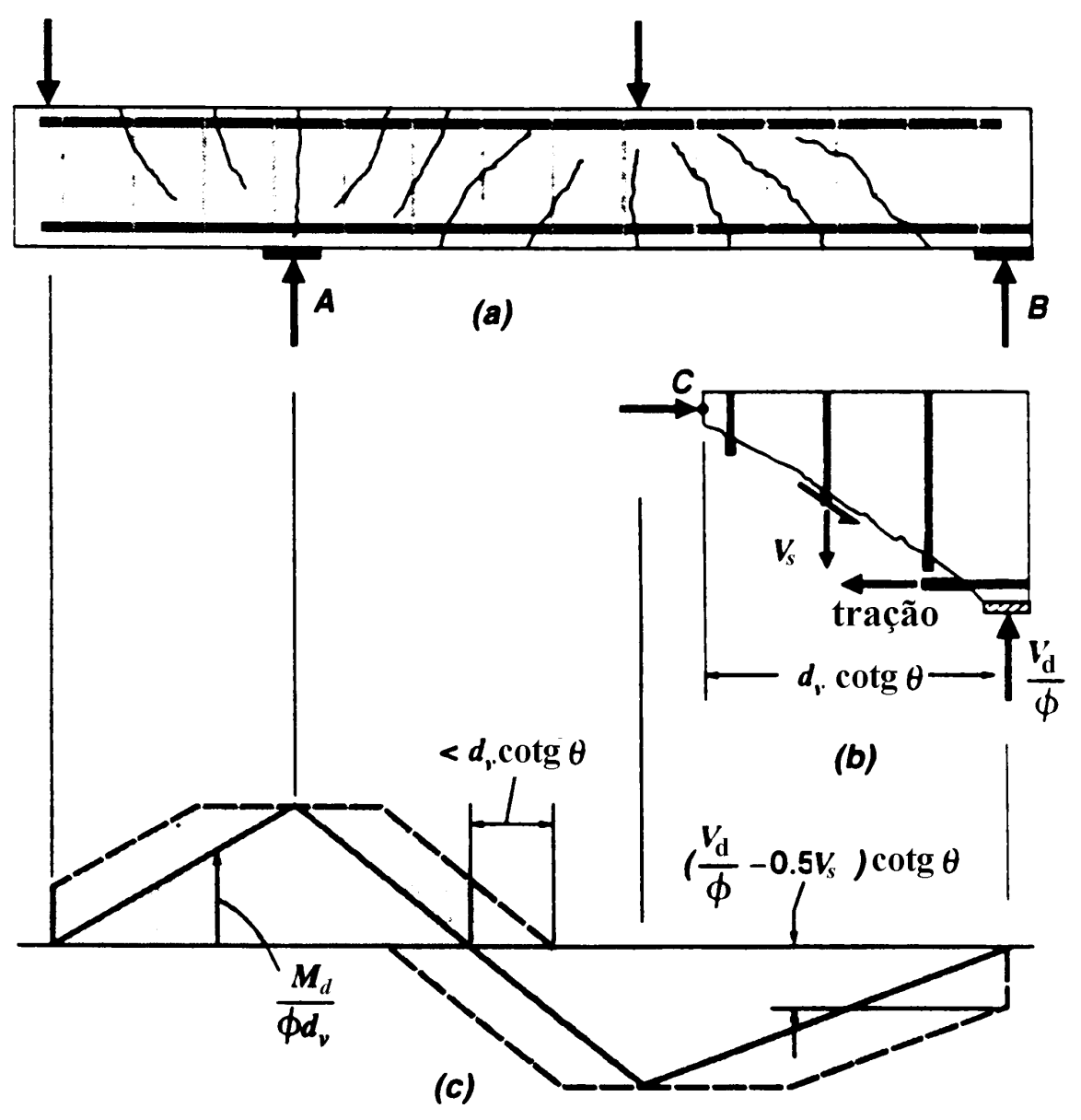

FIGURA 4.9 - Influência do cisalhamento nos esforços na armadura longitudinal FONTE: ADEBAR et. al. (1996)

A equação (4.24) dá o acréscimo de tensão que o cisalhamento provoca na armadura longitudinal de tração. Assim, em uma seção submetida a um esforço de cisalhamento $V_{d}$, ao momento $M_{d}$ e a uma força axial $N_{d}$, a armadura longitudinal de tração deve satisfazer:

$$
A_{s} f_{y}+A_{p} f_{p} \geq \frac{M_{d}}{\phi d_{v}}+0,5 \frac{N_{d}}{\phi}+\left(\frac{V_{d}}{\phi}-0,5 V_{s}-V_{p}\right) \operatorname{cotg} \theta
$$

onde:
$A_{s} \quad$ área de armadura longitudinal de tração
$f_{y} \quad$ tensão de escoamento do aço 
$A_{p} \quad$ área de armadura protendida no lado tracionado da peça

$f_{p} \quad$ tensão na armadura de protensão

$d_{v} \quad$ altura útil de cisalhamento tomada igual ao braço de alavanca da flexão, o qual não deve ser tomado menor que $0,9 d$. Para elementos protendidos, $d$ não deve ser tomado menor que $0,8 h$ ao se determinar $d_{v}$

\subsubsection{Seqüência de cálculo}

Para o dimensionamento de vigas ao cisalhamento, pelo campo de compressão modificado, como exposto neste capítulo, pode-se seguir os seguintes passos:

1. Na seção a ser calculada, obtém-se a tensão de cisalhamento (v) a partir da equação (4.21).

2. Calcula-se a deformação longitudinal $\left(\varepsilon_{\mathrm{x}}\right)$ a partir da equação (4.18).

3. Escolhe-se os valores de $\theta$ e $\beta$ na tabela 4.1.

4. A partir da equação (4.19) determina-se a área necessária de estribos $\left(A_{v}\right)$.

5. Compara-se a armadura calculada com a armadura mínima [equação (4.29)].

6. Verifica-se a capacidade da armadura longitudinal pela equação (4.25).

Segundo ADEBAR et. al. (1996), a metodologia da CAN 3 (1994) prevê as ruínas por cisalhamento de forma mais acurada que o ACI 318 (1995). Em algumas situações (por exemplo, elementos com grandes ou pequenas quantidades de armadura solicitados a níveis elevados de forças de compressão) o ACI 318 (1995) pode ser contra a segurança. Em outros casos (por exemplo, carregamentos uniformemente distribuídos, vigas com cordoalhas de protensão inclinadas e elementos solicitados a altas forças de tração axial) pode se apresentar extremamente contra a economia. 


\subsection{TAXAS MÍNIMAS DE ARMADURA DE CISALHAMENTO}

Com o advento dos concretos de alta resistência à compressão e com o correspondente aumento da resistência à tração, há uma preocupação em se verificar se as tradicionais taxas mínimas de armadura ao cisalhamento são suficientes para as vigas de $\mathrm{CAD}$.

A armadura mínima de cisalhamento deve prevenir a ruína frágil por cisalhamento na formação da primeira fissura diagonal e, além disso, deve controlar adequadamente as fissuras diagonais de tração nos carregamentos de serviço. Para prevenir uma ruína frágil, uma reserva adequada de resistência deve ser provida pela armadura de cisalhamento depois da fissuração diagonal das vigas de concreto armado.

Para controlar a abertura de fissuras nos carregamentos de serviço, não apenas uma quantidade mínima de armadura de cisalhamento deve ser provida, mas o espaçamento máximo entre os estribos deve ser limitado.

A adoção de uma armadura mínima de cisalhamento apropriada também ajuda no controle de fissuras de aderência que também poderiam levar a ruínas frágeis.

O ACI de 1989 (revisado em 1992) provê uma formulação para o cálculo da armadura mínima de cisalhamento em vigas de concretos de resistências maiores que $69 M P a$.

A CAN 3 (1994) introduziu uma nova equação para cálculo da armadura mínima como função da raiz quadrada de $f_{c k}$.

O ACI (1983) e a CAN 3 (1984) requeriam uma quantidade mínima de armadura de cisalhamento capaz de resistir uma tensão de cisalhamento de 0,33MPa (0,35 na CAN 3) se o esforço de cisalhamento excedesse metade da resistência ao cisalhamento provida pelo concreto. Nestes códigos, uma área mínima de armadura de cisalhamento $A_{s w}$ era dada por:

$$
A_{s w}=0,33 \frac{b_{w} s}{f_{y}} \quad \text { (unidades em } \quad N \text { e } \mathrm{mm} \text { ) }
$$


onde:
$A_{s w} \quad$ área de armadura de cisalhamento
$s \quad$ espaçamento entre estribos
$b_{w} \quad$ largura da alma

A contribuição do concreto no combate ao cisalhamento é dada por:

$$
V_{c}=0,166 \sqrt{f_{c k}} b_{w} d \quad \text { (unidades em } N \text { e } m m \text { ) }
$$

O ACI de 1989 (revisado em 1992) requer uma quantidade mínima de armadura de cisalhamento para elementos não protendidos, como dado na equação (4.26). Embora a equação (4.26) seja independente da resistência do concreto usado, se esta quantidade mínima de armadura é provida, então o código limita a raiz quadrada de $f_{c k}$ a $8,3 \mathrm{MPa}(8,3 \mathrm{MPa}=\sqrt{69} \mathrm{MPa})$ ao se calcular a contribuição do concreto $\left(V_{c}\right)$ na equação (4.27). Assim, este método não traz benefícios para concretos de resistência à compressão acima de $69 \mathrm{MPa}$ no cálculo de $V_{c}$. Para se tirar partido de concretos cujas resistências são superiores a 69MPa no cálculo de $V_{c}$, o ACI requer uma quantidade mínima de armadura de cisalhamento dada por:

$$
A_{s w}=\frac{f_{c k}}{35}\left(0,33 \frac{b_{w} s}{f_{y}}\right) \leq \frac{b_{w} s}{f_{y}} \quad \text { (unidades em } N \text { e } m m \text { ) }
$$

A contribuição do concreto $V_{c}$ é calculada pela equação (4.27).

A norma canadense CAN 3 (1994) sugere a seguinte expressão, a qual leva em consideração a variação da resistência do concreto, para o cálculo da armadura mínima:

$$
\left(A_{s w} / s\right)_{\min }=0,06 \sqrt{f_{c k}}\left(\frac{b_{v}}{f_{y w}}\right)
$$


onde $f_{c k}$ e $f_{y w}$ estão em MPa. Para $b_{v}$ em metro, $\left(A_{s w} / s\right)_{\min }$ será dada em $m^{2} / m$.

Como se pode observar, esta equação utiliza o valor nominal da tensão de escoamento da armadura transversal $\left(f_{y w}\right)$. Encontra-se, portanto, aferida para a segurança em termos dos esforços nominais. Para a segurança em termos das tensões nos materiais, $f_{y w}$ e $f_{c k}$ devem ser substituído por $f_{y d}$ e $f_{c d}$, respectivamente. Ao efetuar esta substituição na equação (4.29), o leitor verificará que o resultado permanece o mesmo.

A figura 4.10 mostra uma comparação entre as recomendações do $A C I$ e da CAN 3.

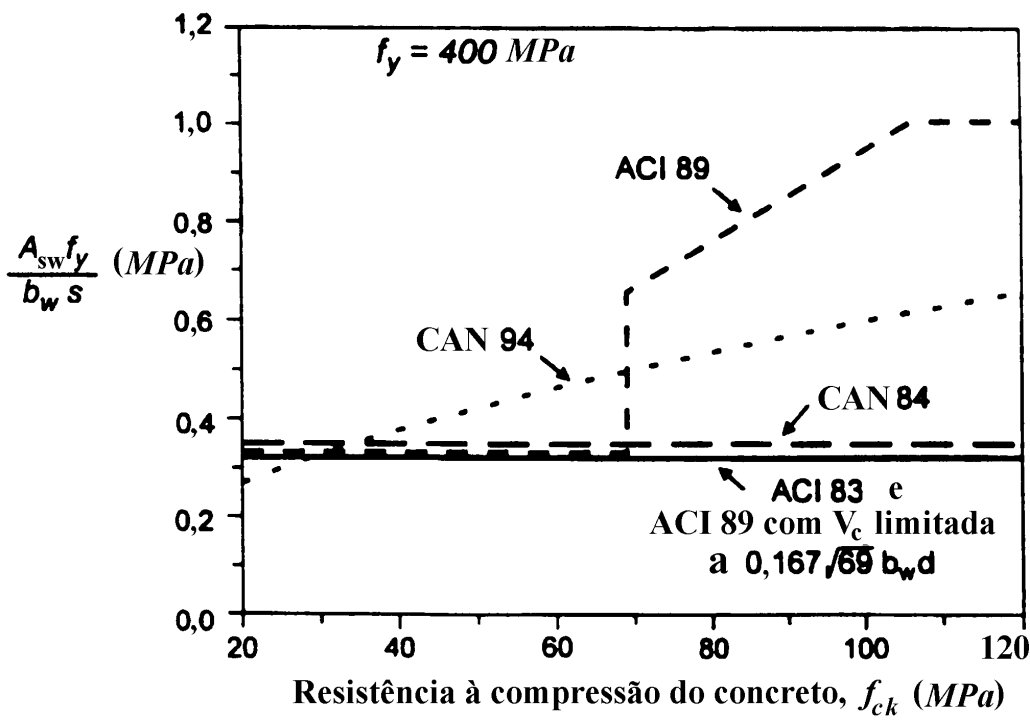

FIGURA 4.10 - Comparação entre as armaduras mínimas do $A C I$ e da CAN 3

FONTE: COOK et. al.(1996)

No $A C I$, para elementos sujeitos a níveis de tensões de cisalhamento relativamente baixos, o espaçamento entre estribos não deve exceder $d / 2 \mathrm{em}$ elementos não protendidos, ou 600mm. Para a mesma situação, a CAN 3 (1994) especifica espaçamento máximo de $0,7 d$ ou $600 \mathrm{~mm}$.

A CAN 3 (1994) estabelece a seguinte expressão para o cálculo da contribuição do concreto ao cisalhamento, válida para vigas com altura útil maior que $30 \mathrm{~cm}$ : 


$$
V_{c}=\left(\frac{220}{1000+d}\right) \sqrt{f_{c k}} b_{w} d \geq 0,0835 \sqrt{f_{c k}} b_{w} d \quad \text { (unidades em } N \text { e } m m \text { ) }
$$

A expressão simplificada da CAN 3 (1994) para determinação da contribuição do concreto ao cisalhamento $V_{c}$ equivale ao estabelecido pela equação (4.27) quando é feita a devida correlação entre as normas, em função dos seus diferentes coeficientes.

O CEB-FIP (1990) estabelece, através da tabela 4.2, taxas mínimas de armadura transversal em função da resistência do concreto e do tipo de aço:

Lembra-se que a taxa de armadura transversal $\left(\rho_{w}\right)$ do CEB-FIP (1990) pode ser obtida através da equação (4.9).

TABELA 4.2 - Taxas mínimas de armadura transversal $\left(\rho_{w}\right)$ em valores percentuais FONTE: $C E B-F I P(1990)$ (adaptada)

\begin{tabular}{|c|c|c|}
\cline { 2 - 3 } \multicolumn{1}{c|}{} & \multicolumn{2}{c|}{ AÇO } \\
\hline CONCRETO & S220 (CA-25) & S500 (CA-50) \\
\hline C12 & 0,15 & 0,06 \\
\hline C20 & 0,20 & 0,09 \\
\hline C30 & 0,26 & 0,12 \\
\hline C40 & 0,32 & 0,14 \\
\hline C50 & 0,37 & 0,16 \\
\hline C60 & 0,42 & 0,18 \\
\hline C70 & 0,46 & 0,20 \\
\hline C80 & 0,51 & 0,22 \\
\hline
\end{tabular}

Fazendo-se a correlação entre as propriedades dos aços S220 e S500 do CEBFIP (1990) e as propriedades dos aços brasileiros, pode-se aplicar a tabela 4.2 aos aços CA-25 e CA-50. 
COOK et. al.(1996) comparando o procedimento do ACI (1995) e o procedimento da CAN 3 (1994) concluíram que:

- A CAN 3 de 1994 provê uma expressão para a quantidade mínima de armadura de cisalhamento que é função da raiz quadrada da resistência à compressão. Assim, enquanto a resistência à compressão do concreto aumenta, a quantidade de armadura de cisalhamento requerida aumenta de uma maneira gradual. Os exemplares testados indicaram que essas exigências provêm uma reserva adequada de resistência após a fissuração.

- Para concretos com resistências acima de 69MPa, o ACI de 1989 requer uma quantidade mínima de armadura de cisalhamento que não é função da resistência do concreto (isto é, $A_{s w} f_{y} / b_{w} s=0,35 M P a$ ). Para resistências acima de $69 M P a$, um procedimento em dois níveis para se determinar a quantidade mínima de armadura de cisalhamento é provida, dependendo de se é feito ou não um cômputo total da resistência à compressão acima de $69 \mathrm{MPa}$. O uso de resistências à compressão mais altas requer um significativo aumento da armadura mínima de cisalhamento e resulta em respostas ao cisalhamento que têm significativa reserva de resistência após a fissuração por cisalhamento. Se a raiz quadrada de resistência à compressão é limitada a $\sqrt{\mathbf{6 9}} \mathrm{MPa}$ (isto é, 8,3MPa) no projeto, então o nível mais baixo de armadura de cisalhamento é permitido pelo ACI de 1989. Para concretos de alta resistência, esta quantidade de armadura mínima de cisalhamento pode não prover reserva adequada de resistência após a fissuração por cisalhamento.

A figura 4.11 mostra o comportamento dos procedimentos do ACI (1995) e da CAN 3 (1994). 


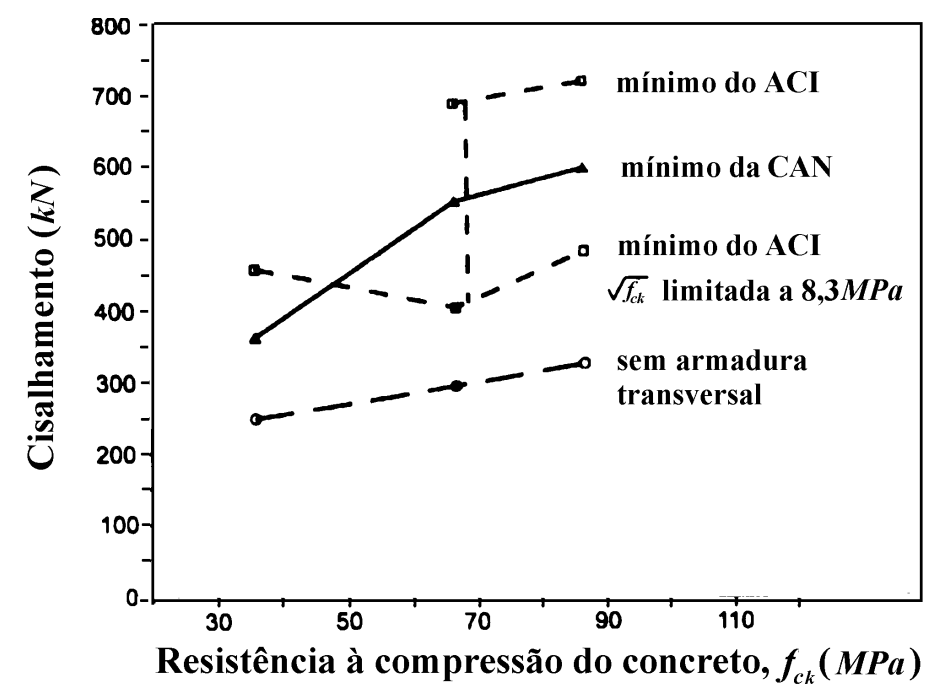

FIGURA 4.11 - Capacidade última ao cisalhamento em função de $f_{c k}$ FONTE: COOK et. al.(1996)

\subsection{NORMA AUSTRALIANA AS-3600 (1988)}

A norma australiana adota um modelo de treliça de diagonais de inclinação variável limitada, na qual o ângulo $\theta$ varia entre $30^{\circ}$ e $45^{\circ}$, dependendo do valor da força de cisalhamento de cálculo $V_{d}$. Sua metodologia analisa as diversas possibilidades de fissuração em uma viga protendida, como apresentado na figura 4.12.

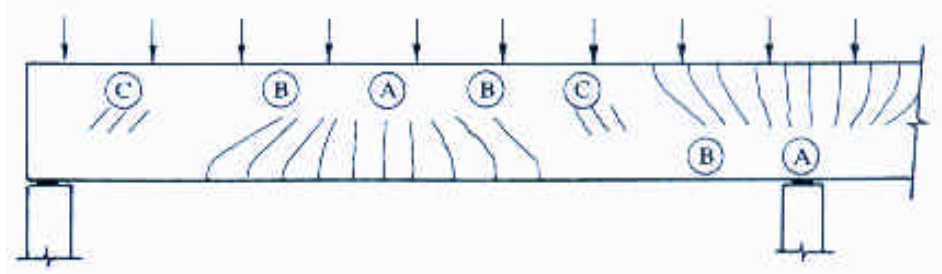

Região A - Fissuras por flexão $(M / V)$ é alto

Região B - Fissuras por flexão-cisalhamento $(M / V)$ é moderado

Região C - Fissuras por cisalhamento $(M / V)$ é baixo

FIGURA 4.12 - Tipos de fissuras em vigas protendidas

Fonte: GILBERT \& MICKLEBOROUGH (1990) 
Suas recomendações, como será visto adiante, são bem adequadas ao CAD. Exceção, contudo, é feita à sua recomendação de armadura mínima de cisalhamento.

No que se segue, a abordagem da norma australiana será seguida na sua íntegra, exceto no que se refere à armadura mínima, para a qual se adotará a recomendação de armadura mínima da norma canadense (CAN 3/1994).

A resistência nominal ao cisalhamento $\left(V_{n}\right)$ de uma viga é dada pela equações (4.31) e (4.32):

$$
V_{n}=V_{c}+V_{s}
$$

Onde a contribuição dos estribos verticais $\left(V_{s}\right)$ é dada por:

$$
V_{s}=\frac{A_{s w} f_{y w} d_{0} \operatorname{cotg} \theta}{s}
$$

$d_{0}$ é a profundidade da camada mais baixa de armadura longitudinal de tração.

Se a armadura de cisalhamento é inclinada de um ângulo $\alpha$ em relação à armadura longitudinal de tração (ou seja, $\alpha=90^{\circ}$ para estribos verticais), $V_{s}$ passa a ser dada por:

$$
V_{s}=\frac{A_{s w} f_{y w} d_{0} \operatorname{cotg} \theta}{s}(\operatorname{sen} \alpha \operatorname{cotg} \theta+\cos \alpha)
$$

O termo $V_{c}$ será apresentado mais à frente.

$\mathrm{Na}$ equação (4.32), $\theta$ pode ser assumido com variando linearmente entre $30^{\circ}$, quando $V_{d}=\phi V_{n, \min }$, e $45^{\circ}$, quando $V_{d}=\phi V_{n, \max }$, ou seja:

$$
\theta=30+\frac{15\left(V_{d}-\phi V_{n, \text { min }}\right)}{\phi V_{n, \text { max }}-\phi V_{n, \text { min }}}
$$


$V_{n, \min }$ é a resistência ao cisalhamento de uma viga com armadura mínima $\left(A_{s w}\right)_{\min }$ dada na $A S-3600(1988)$ por:

$$
\left(A_{s w} / \mathrm{s}\right)_{\min }=0,35 \frac{b_{v}}{f_{y w}}
$$

Observe-se que a expressão anterior é dada em função do valor nominal da tensão de escoamento da armadura transversal $\left(f_{y w}\right)$, uma vez que a $A S$-3600 (1988) tem seu conceito de segurança fundamentado nos esforços, e não nas tensões, como na $N B-1$ (1978).

Porém, tal recomendação passa a ser contra a segurança para resistências mais altas. Para o CAD, pode-se adotar para armadura mínima a recomendação da CAN 3 (1994) dada pela equação (4.29). Para $f_{c k}=35 M P a$, o mínimo da norma australiana coincide com o da norma canadense.

O termo $b_{v}$ é a largura efetiva ao cisalhamento e pode ser tomada como $b_{v}=b_{w}-0,5 \sum \phi_{b}$, onde $b_{w}$ é a largura da alma menos o diâmetro de algum ducto no seu interior no qual não houve injeção de nata de cimento e $\sum \phi_{b}$ é a soma dos diâmetros dos ductos com injeção de nata em um nível (plano horizontal) da seção. $\phi$ é o fator de segurança para o cisalhamento (tomado igual a 0,7 na norma australiana).

$V_{n, \min }$ pode ser obtido substituindo-se a equação (4.29) na equação (4.32) e incorporando-se a expressão resultante na equação (4.31). Assim:

$$
\begin{aligned}
& V_{n, \min }=V_{c}+\left(\frac{0,06 \sqrt{f_{c k}} b_{v} s}{f_{y w}}\right) f_{y w}\left(\frac{d_{0}}{s}\right) \operatorname{cotg} 30^{\circ} \\
& V_{n, \min }=V_{c}+0,10 \sqrt{f_{c k}} b_{v} d_{0} \\
& V_{n, \min }=V_{c}+\gamma b_{v} d_{0}
\end{aligned}
$$

onde 


$$
\gamma=0,10 \sqrt{f_{c k}} \geq 0,6
$$

$V_{n, \max }$ é a resistência máxima ao cisalhamento disponível em uma seção, limitada pelo esmagamento da diagonal comprimida, dada por:

$$
V_{n, \max }=0,2 f_{c k} b_{v} d_{0}+P_{v}
$$

$P_{v}$ é a componente vertical da força de protensão na seção considerada. $P_{v}$ também é incluída na equação (4.34) como parte da contribuição do "concreto" $\left(V_{c}\right)$, como indicado nas expressões (4.37) e (4.41).

Com $\theta$ limitado ao valor mínimo de $30^{\circ}$, as seguintes recomendações são feitas para o detalhamento da armadura longitudinal de tração. Em um apoio simples, a força a ser ancorada (com a armadura longitudinal sendo estendida além da face do apoio) é de $1,5 V_{d}$ na face do apoio. $V_{d}$ é o esforço cortante de cálculo a uma distância $d$ da face do apoio, e $d$ a altura útil da seção. Além disto, não menos que $50 \%$ da armadura positiva necessária no meio do vão deve ser estendida além da face do apoio simples de um comprimento igual a 12 diâmetros da barra ou uma ancoragem equivalente. Em um apoio onde a viga é contínua (ou engastada), não menos que $25 \%$ da armadura total positiva necessária no meio do vão deve passar a face mais próxima do apoio. A $A S$-3600 (1988) também requer que a armadura necessária à flexão em uma seção qualquer deve ser adotada e estendida até uma seção distante $d$ ao longo da viga, na direção na qual aumenta o esforço cortante.

\subsubsection{Fissuração por flexão-cisalhamento}

A força de cisalhamento necessária para produzir uma fissura inclinada de flexão-cisalhamento pode ser tomada como uma soma de três parcelas: 
- força de cisalhamento que existe quando a primeira fissura de flexão se desenvolve.

- força adicional necessária para produzir a porção inclinada da fissura (a qual se estende a uma distância de cerca de $d_{0}$ ao longo da viga na direção na qual o momento aumenta)

- componente vertical da força de protensão

A primeira e a terceira parcela desta soma são facilmente calculadas. A segunda é, normalmente, determinada usando-se expressões empíricas desenvolvidas a partir de dados obtidos em análises experimentais. A $A S$-3600 (1988) sugere que:

$$
V_{c}=V_{0}+\beta_{5} \beta_{2} b_{v} d_{0}\left(\frac{A_{p}+A_{s}}{b_{v} d_{0}} f_{c k}\right)^{1 / 3}+P_{v}
$$

$\beta_{5}=\left(1,4-d_{0} / 2000\right) \geq 1,1$ é o coeficiente que leva em consideração o efeito do tamanho $\left(d_{0}\right.$ em $\left.\mathrm{mm}\right)$.

$\beta_{2}$ é o fator que leva em consideração a presença ou não de uma força axial $N_{d}$ (externa) e:

$\beta_{2}=1$ se nenhuma força axial está presente

$\beta_{2}=1-\left(N_{d} / 3,5 A_{c}\right) \geq 0$ para tração axial

$\beta_{2}=1+\left(N_{d} / 14 A_{c}\right)$ para compressão axial

onde:

$N_{d} \quad$ valor absoluto da força axial externa

$A_{c} \quad$ a área da seção transversal de concreto

$A_{s}, A_{p}$ áreas de armadura longitudinal passiva e ativa, ancoradas adequadamente, e alojadas na zona tracionada da seção transversal sob consideração. 
$V_{0} \quad$ esforço cortante (em $N$ ) que existe na seção onde o momento atuante é igual ao momento de descompressão $\left(M_{0}\right)$

O momento de descompressão $\left(M_{0}\right)$ em uma seção é a soma dos momentos causados pelo peso próprio e demais carregamentos (exceto o de protensão) que levam à tensão nula a fibra extrema inicialmente comprimida pela protensão.

O momento de descompressão $\left(M_{0}\right)$ pode ser obtido a partir do momento de fissuração. Para uma viga protendida simplesmente apoiada, o momento de fissuração $\left(M_{r}\right)$ pode ser obtido por:

$$
\left(\frac{P}{A_{c}}-\frac{M_{P}}{w_{\mathrm{inf}}}\right)-\frac{M_{r}}{w_{\mathrm{inf}}}=f_{t}
$$

Ou ainda:

$$
M_{r}=P\left(e+\frac{w_{\mathrm{inf}}}{A_{c}}\right)+f_{t} w_{\mathrm{inf}}
$$

Fazendo-se $f_{t}=0$ em (4.38) chega-se ao momento de descompressão. Portanto:

$$
M_{0}=P\left(e+\frac{w_{\mathrm{inf}}}{A_{c}}\right)
$$

Se $M_{d}$ e $V_{d}$ são o momento e o esforço cortante de cálculo na seção, respectivamente, para estruturas estaticamente determinadas, $V_{0}$ pode ser tomado como:

$$
V_{0}=M_{0} \frac{V_{d}}{M_{d}}
$$


Para estruturas estaticamente indeterminadas, o esforço cortante e o momento causados pelos efeitos secundários da protensão devem ser tomados em consideração no cálculo de $M_{0}$ e $V_{0}$.

\subsubsection{Fissuração na alma por cisalhamento}

Se a seção transversal não está fissurada na flexão, o esforço cortante necessário para produzir uma fissura na alma por cisalhamento é dado por:

$$
V_{c}=V_{t}+P_{v}
$$

onde $V_{t}$ é o esforço cortante que, combinado com a tensão normal causada pela protensão e carregamentos externos, produziria uma tensão principal de tração de $0,33 \sqrt{f_{c k}}$ no mais crítico dos três níveis que se seguem:

- nível C.G. da seção

- nível da cordoalha

- interface da nervura com a mesa (se presente)

$V_{t}$ pode ser encontrado analiticamente substituindo-se $\sigma_{1}=0,33 \sqrt{f_{c k}}$ na equação (4.42):

$$
\sigma_{1}=\sqrt{\left(\frac{\sigma}{2}\right)^{2}+\tau^{2}}+\frac{\sigma}{2}
$$

A tensão normal $(\sigma)$ e a tensão tangencial $(\tau)$ são dadas por: 


$$
\sigma=\frac{-P_{e}}{A_{c}} \pm \frac{P_{e} e y}{I} \pm \frac{M y}{I} \quad \text { e } \quad \tau=\frac{Q V_{t}}{I b}
$$

onde as tensões de compressão são tomadas como negativas e as de tração como positivas e:

$b \quad$ valor adequado para a largura da alma, e igual a $b_{v}$ no nível da cordoalha e $b_{w}$ para pontos distantes.

Q momento estático, em relação ao C.G., da parte da área da seção transversal compreendida entre o nível analisado e a fibra extrema.

A presença do ducto na seção causa perturbações no campo de tensões tangenciais. Na região perturbada (no nível do ducto ou próximo a ele), as tensões tangenciais são maiores, e deve-se tomar $b=b_{v}$. Estas perturbações acabam a uma certa distância do ducto. A partir desta distância, pode se tomar $b=b_{w}$. Para se determinar a partir de que nível se pode usar $b_{w}$, existem duas possibilidades ilustradas na figura (4.13).

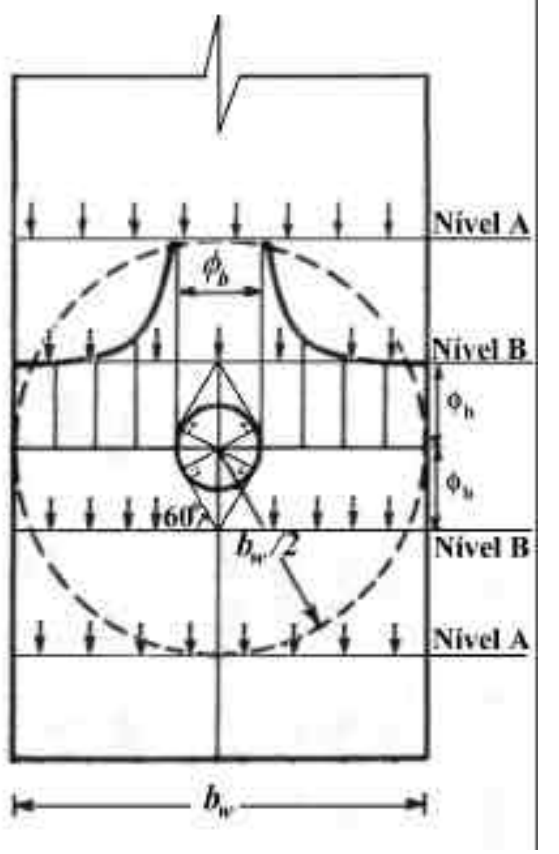

FIGURA 4.13 - Determinação do nível a partir do qual $b=b_{w}$ 
Pelo Princípio de Saint-Venant, se a largura da viga é grande em relação ao raio da bainha, pode-se considerar $b=b_{w}$ nos níveis $\mathrm{A}$, distantes $b_{w} / 2$ do centro da bainha. A segunda alternativa, menos conservadora, seria supor uma propagação de tensões como indicada na figura 4.13 (com um ângulo de $60^{\circ}$ com a horizontal), o que permitiria admitir $b=b_{w}$ nos níveis $\mathrm{B}$, distantes $\phi_{b}$ do centro da bainha.

\subsubsection{Resumo das recomendações da AS-3600 (1988)}

1- A resistência ao cisalhamento de cálculo de uma seção é $\phi V_{n}$, onde $V_{n}=V_{c}+V_{s}$ [equação (4.31)]

2- A contribuição do "concreto" $V_{c}$ é o menor dos valores obtidos das equações (4.37) e (4.41).

3- A contribuição da armadura ao cisalhamento $V_{s}$ é dada pela equação (4.32b):

$$
V_{s}=\frac{A_{s w} f_{y w} d_{0} \operatorname{cotg} \theta}{s}(\operatorname{sen} \alpha \operatorname{cotg} \theta+\cos \alpha)
$$

onde:

espaçamento de centro a centro da armadura de cisalhamento medido paralelamente ao eixo do elemento

$\theta$ é o ângulo da biela comprimida de concreto em relação à horizontal e pode ser conservadoramente tomado igual a $45^{\circ}$, ou admitido como variando linearmente de $30^{\circ}$, quando $V_{d}=\phi V_{n, \min }, \mathrm{a} 45^{\circ}$, quando $V_{d}=\phi V_{n, \max }$ [equação (4.33)].

$V_{d} \quad$ esforço cortante de cálculo

$V_{n, \min }$ e $V_{n, \max }$ definidos de acordo com as equações (4.34) e (4.36), respectivamente 
$\alpha$ ângulo entre a armadura de cisalhamento e a armadura longitudinal de flexão

4- Quando $V_{d}<0,5 \phi V_{c}$, não é necessária armadura de cisalhamento, exceto quando a altura total da seção exceder $750 \mathrm{~mm}$, caso em que se deve adotar armadura mínima. A armadura mínima é dada pela equação (4.34). Quando $0,5 \phi V_{c}<V_{d} \leq \phi V_{n, \min }$, deve-se adotar armadura mínima. Se a altura total da viga não excede o maior valor dentre $250 \mathrm{~mm}$ ou a metade da largura da alma, e se $V_{d} \leq \phi V_{c}$, nenhuma armadura de cisalhamento é necessária. Quando $V_{d}>\phi V_{n, \min }$, a armadura de cisalhamento necessária é maior que a mínima, e deve ser calculada segundo as equações (4.32a), para estribos verticais, ou (4.32b), para armadura inclinada de cisalhamento (cavaletes).

5- Em nenhum caso $V_{n}$ pode exceder $V_{n, \max }$, como definido na equação (4.36).

6- O espaçamento máximo entre estribos, medido na direção do eixo da viga, não deve exceder o menor valor dentre $0,5 \mathrm{~h}$ ou $300 \mathrm{~mm}$, exceto quando $V_{d} \leq \phi V_{n, \min }$, situação na qual o espaçamento pode ser aumentado para o menor valor dentre $0,75 \mathrm{~h}$ ou $500 \mathrm{~mm}$. O maior espaçamento transversal entre os ramos dos estribos verticais medido através da alma de uma viga não deve exceder o menor dentre os valores: $600 \mathrm{~mm}$ ou a altura total da seção $(h)$.

7- A quantidade de armadura transversal calculada como sendo necessária em uma seção deve ser adotada para uma distância $h$ da seção na direção para a qual o esforço cortante diminui.

8- Os estribos devem ser ancorados (preferencialmente na zona comprimida da viga) usando-se ganchos padrões dobrados em torno de $135^{\circ}$ envolvendo uma barra longitudinal de diâmetro maior.

Para as vigas de CAD, os casos onde a norma australiana permite a não utilização de armadura de cisalhamento, ou ainda, permite espaçamentos maiores que os máximos sugeridos $(0,5 \mathrm{~h}$ ou $300 \mathrm{~mm})$, devem ser vistos com maior cuidado. 
Assim, sugere-se que, nestes casos, adote-se a armadura mínima sugerida em (4.29) e os espaçamentos máximos $(0,5 h$ ou $300 \mathrm{~mm})$.

\subsection{CONCLUSÕES E RECOMENDAÇÕES DE PROJETO PARA VIGAS DE CAD}

FERNANDES (1992) e GOMIERO (1994) concluíram em suas pesquisas que:

- A evolução das tensões nos estribos nas vigas de CAD está em concordância com aquela que a literatura apresenta para o caso de concreto com resistência usual.

- Quando se analisam casos cuja armadura transversal necessária é maior que a mínima, a utilização de CAD permite taxas de armadura transversal ligeiramente menores que as obtidas com concreto de resistência usual.

- Tanto o método padrão como o da analogia de treliça com diagonais de inclinação variável podem ser aplicados às vigas de CAD.

- Quando se emprega o método padrão, a relação $\tau_{c}=f_{c} / 20$ representa um bom indicador da colaboração do concreto na resistência ao cisalhamento, pelo menos para resistências até 60MPa.

- No caso das vigas de CAD, a capacidade resistente à flexão pode ser mantida, mesmo com redução do grau de armação ao cisalhamento, desde que este não seja inferior a $60 \%$. Considerando que o grau de armação ao cisalhamento $\eta$ é o inverso da $\operatorname{cotg} \theta$ [equação (4.17)], conclui-se que, quando se emprega a analogia de treliça com diagonais de inclinação variável, para que a resistência à flexão das vigas de CAD seja mobilizada sem haver antes a ruína por força cortante, deve-se ter $\eta \leq 60 \%$, ou seja, $\theta_{\text {min }}=30,96^{\circ}(\operatorname{cotg} \theta \leq 5 / 3)$.

- Caso se admita $\theta=18,4^{\circ}(\operatorname{cotg} \theta=3)$ o concreto se apresenta bastante sacrificado, com fissuras em menor número, mal distribuídas e com aberturas grandes e prematuras. Apresentam-se ainda grandes flechas com ações de curta duração. Para $\theta<26,6^{\circ}$ os estados limites de serviço serão atingidos provavelmente 
antes do estado limite último. Para $\theta=26,6^{\circ}$ seria aconselhável a utilização de armadura de pele para controlar a fissuração.

- A ruptura das bielas de concreto antes do escoamento dos estribos só poderá ocorrer com taxas de armadura transversal extremamente altas e fora da realidade.

- O espaçamento máximo entre estribos dever ser o menor valor dentre: $d / 2$ ou $30 \mathrm{~cm}$.

$$
s_{\max } \leq\left\{\begin{array}{l}
d / 2 \\
30 \mathrm{~cm}
\end{array} \quad[\text { FERNANDES } \quad(1992)]\right.
$$

- A ancoragem nos apoios extremos deve ser prevista para um esforço maior que o esforço cortante. Talvez um valor seguro para o esforço a ser ancorado seria $1,35 V_{d}$.

A consideração ou não da componente vertical da força de protensão $\left(P_{v}\right)$, no cálculo da contribuição do concreto [equação (4.37)], pode resultar em diferenças significativas na armadura transversal calculada. A AS-3600 (1988) considera o valor integral da componente vertical, o ACI 318 (1995) não considera (desprezando totalmente a sua contribuição para o cisalhamento), e a NB-1 (1978) considera apenas uma parcela do seu valor.

A consideração ou não da contribuição da protensão através da sua componente vertical é uma decisão de engenharia. Considerá-la é razoável, desde que o engenheiro esteja seguro de que o traçado especificado para os cabos em projeto será realmente executado na viga. 


\subsection{EXEMPLOS DE APLICAÇÃO}

EXEMPLO 4.1 - $f_{c k}=70 M P a$

Seja a viga do item 2.4. Será calculada a armadura de cisalhamento segundo a metodologia e coeficientes de segurança da $A S$-3600 (1988).

\section{Solucão}

Combinação de carregamento:

$$
\begin{aligned}
& w_{d}=1,25 g+1,5 q=1,25 \times 23,0+1,5 \times 19,5 \\
& w_{d}=58,0 \mathrm{kN} / \mathrm{m}
\end{aligned}
$$

Esforço cortante de cálculo $\left(V_{d}\right)$ e momento de cálculo $\left(M_{d}\right)$ a $x$ metros à direita do apoio A:

$$
\begin{aligned}
& V_{d}=0,5(58 \times 30)-58 x=870-58 x(k N) \\
& M_{d}=870 x-29 x^{2}(k N . m)
\end{aligned}
$$

Excentricidade do cabo em relação ao C.G. da seção:

$$
e=2,8\left[\frac{x}{30}-\left(\frac{x}{30}\right)^{2}\right]
$$

Tangente ao cabo:

$$
\frac{d y}{d x}=y^{\prime}=\frac{2,8}{30}\left[1-\left(\frac{x}{15}\right)\right]
$$

Cálculo de $d_{0}$, admitindo-se estribos de $12 \mathrm{~mm}$ :

$$
\begin{aligned}
& d_{0}=h-c-\phi_{t}-\left(\phi_{b} / 2\right)=1200-30-12-12,5 \\
& d_{0}=1145,5 \mathrm{~mm}
\end{aligned}
$$


Seção crítica segundo a CAN 3 (1994):

$$
\begin{aligned}
& x=0,5 d_{v} \operatorname{cotg} \theta=0,5 \times(0,9 \times 1145,5) \times \operatorname{cotg} 45^{\circ} \\
& x=516 \mathrm{~mm}
\end{aligned}
$$

\section{Cálculo para uma seção distante $0,516 m$ do apoio $A$}

Das expressões anteriores, tem-se:

$$
\begin{aligned}
& V_{d}=840 \mathrm{kN} ; M_{d}=441 \mathrm{kN} . \mathrm{m} ; y^{\prime}=0,09012 \mathrm{rad} \\
& V_{d} / M_{d}=1,904 ; M_{d} / V_{d}=0,525 ; e=0,043 \mathrm{~m}
\end{aligned}
$$

Força efetiva de protensão:

$$
P_{e}=4500-0,516 \times 20=4490 k N
$$

Componente vertical da força de protensão:

$$
P_{v}=P_{e} y^{\prime}=4490 \times 0,09012=405 k N
$$

\section{$\rightarrow$ Fissuração por flexão-cisalhamento}

Momento de descompressão:

$$
\begin{aligned}
& M_{0}=P_{e}\left(e+\frac{w_{\mathrm{inf}}}{A_{c}}\right) \\
& M_{0}=4900 \times 10^{3} \times\left(0,043+\frac{0,1}{0,66}\right) \\
& M_{0}=873 \mathrm{kN} . \mathrm{m}
\end{aligned}
$$

Esforço cortante correspondente a $M_{0}$ :

$$
\begin{aligned}
V_{0} & =M_{0} \frac{V_{d}}{M_{d}} \\
V_{0} & =873 \times 1,9=1663 \mathrm{kN}
\end{aligned}
$$


Esforço cortante necessário para causar uma fissura de flexão-cisalhamento:

$$
\begin{aligned}
& V_{c}=V_{0}+\beta_{5} \beta_{2} b_{v} d_{0}\left(\frac{A_{p}+A_{s}}{b_{v} d_{0}} f_{c k}\right)^{1 / 3}+P_{v} \\
& V_{c}=1663+1,1 \times 1 \times 240 \times 1145,5 \times\left(\frac{3948+1000}{240 \times 1145,5} 70\right)^{1 / 3} \times 10^{-3}+405 \\
& V_{c}=1663+327+405=2395 \mathrm{kN}
\end{aligned}
$$

Como o momento de cálculo $\left(M_{d}\right)$ é menor que o momento de descompressão $\left(M_{0}\right)$ e, portanto, menor que o momento de fissuração $\left(M_{r}\right)$, a fissuração por cisalhamento na alma dever ser verificada em três níveis:

- nível do C.G. da seção

- nível da armadura de protensão

- na interface mesa-nervura

\section{$\rightarrow$ Fissuração por cisalhamento na alma}

$\rightarrow$ No nível do C. G. da seção:

Tensão normal:

$$
\begin{aligned}
& \sigma=\frac{-P_{e}}{A_{c}}-\frac{P_{e} \times e \times y}{I}+\frac{M \times y}{I} \\
& \sigma=\frac{-4490 \times 10^{-3}}{0,66} \\
& \sigma=-6,8 \mathrm{MPa}
\end{aligned}
$$

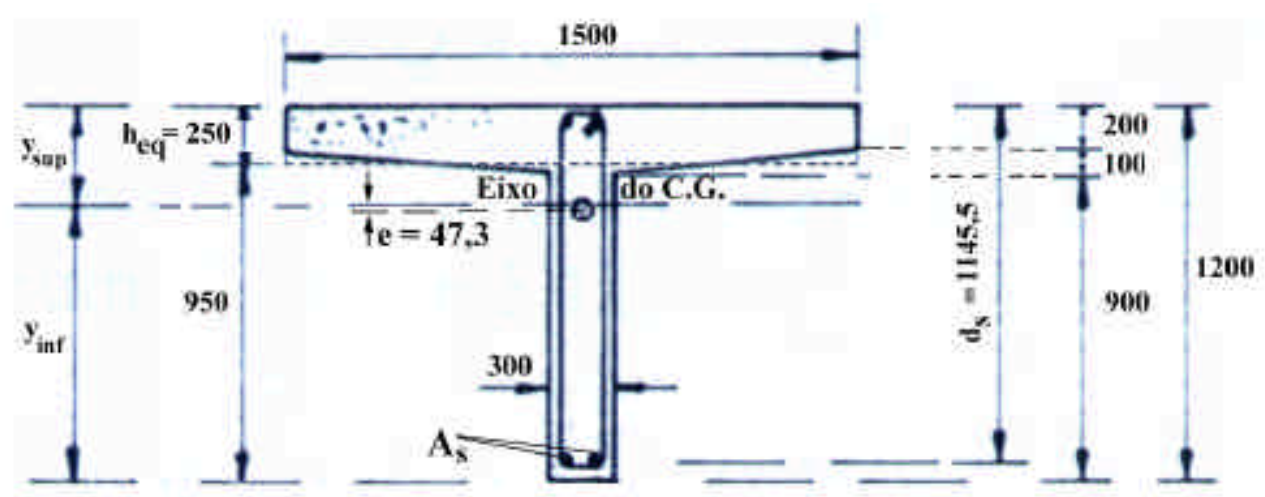

FIGURA 4.14 - Seção a 0,516m do apoio A 
Momento estático da área abaixo do C.G. da seção em relação ao C.G. da seção:

$$
Q=300 \times 0,816^{2} / 2=99,9 \times 10^{6} \mathrm{~mm}^{3}
$$

Largura efetiva de cisalhamento:

Como o nível do C.G. "atravessa" a bainha (ver figura 4.14), $b=b_{v}$.

$$
b_{v}=b_{w}-0,5 \sum \phi_{b}=300-0,5 \times 120=240 \mathrm{~mm}
$$

Tensão de cisalhamento:

$$
\begin{aligned}
\tau & =\frac{V_{t} Q}{I b} \\
\tau & =\frac{99,9 \times 10^{6} \times V_{t}}{81,7 \times 10^{9} \times 240} \\
\tau & =5,09 \times 10^{-6} V_{t}
\end{aligned}
$$

Tensão principal de tração:

$$
\begin{aligned}
& \sigma_{1}=0,33 \sqrt{f_{c k}} \\
& \sigma_{1}=0,33 \sqrt{70} \\
& \sigma_{1}=2,76 M P a
\end{aligned}
$$

Como $\sigma_{1}=\sqrt{\left(\frac{\sigma}{2}\right)^{2}+\tau^{2}}+\frac{\sigma}{2}$, tem-se:

$$
\begin{aligned}
& 2,76=\sqrt{\left(\frac{-6,8}{2}\right)^{2}+\left(5,09 \times 10^{-6} \times V_{t}\right)^{2}}+\frac{-6,8}{2} \\
& V_{t}=1009 \mathrm{kN}
\end{aligned}
$$

$\rightarrow$ No nível da cordoalha

Tensão normal: 


$$
\begin{aligned}
& \sigma=\frac{-P_{e}}{A_{c}}-\frac{P_{e} \times e \times y}{I}+\frac{M \times y}{I} \\
& \sigma=\frac{-4490 \times 10^{3}}{660 \times 10^{3}}-\frac{-4490 \times 10^{3} \times 43^{2}}{81,7 \times 10^{9}}+\frac{525 \times V_{t} \times 43}{81,7 \times 10^{9}} \\
& \sigma=-6,9+2,763 \times 10^{-7} V_{t}(M P a)
\end{aligned}
$$

Momento estático da área abaixo do nível da cordoalha em relação ao C.G. da seção:

$$
Q=300 \times 772,9 \times\left(\frac{772,9}{2}+43\right)=99,6 \times 10^{6} \mathrm{~mm}^{3}
$$

Largura efetiva de cisalhamento: $b=b_{v}=240 \mathrm{~mm}$.

Tensão de cisalhamento:

$$
\begin{aligned}
\tau & =\frac{V_{t} Q}{I b} \\
\tau & =\frac{99,6 \times 10^{6} \times V_{t}}{81,7 \times 10^{9} \times 240} \\
\tau & =5,08 \times 10^{-6} V_{t}
\end{aligned}
$$

Portanto, para $\sigma_{1}=2,76 M P a$, tem-se $V_{t}=1002 \mathrm{kN}$.

$\rightarrow$ Na interface mesa-nervura

Tensão normal:

$$
\begin{aligned}
& \sigma=\frac{-P_{e}}{A_{c}}-\frac{P_{e} \times e \times y}{I}+\frac{M \times y}{I} \\
& \sigma=\frac{-4490 \times 10^{-3}}{660 \times 10^{3}}-\frac{-4490 \times 10^{3} \times 43 \times 84,1}{81,7 \times 10^{9}}+\frac{525 \times V_{t} \times 84,1}{81,7 \times 10^{9}} \\
& \sigma=-6,6+5,4 \times 10^{-7} V_{t}
\end{aligned}
$$

Momento estático da área abaixo da interface em relação ao C.G. da seção:

$$
Q=300 \times 900\left(815,9-\frac{900}{2}\right)=98,8 \times 10^{3} \mathrm{~mm}^{3}
$$


Largura efetiva de cisalhamento:

Como a distância entre o C.G. da bainha e a interface $(127,1 \mathrm{~mm})$ é maior que $\phi_{\mathrm{b}}=120 \mathrm{~mm}, b=b_{w}=300 \mathrm{~mm}$.

Tensão de cisalhamento:

$$
\begin{aligned}
\tau & =\frac{V_{t} Q}{I b} \\
\tau & =\frac{98,8 \times 10^{6} \times V_{t}}{81,7 \times 10^{9} \times 300} \\
\tau & =4,03 \times 10^{-6} V_{t}
\end{aligned}
$$

Portanto, para $\sigma_{1}=2,76 M P a$, tem-se $V_{t}=1216 k N$.

O nível crítico, portanto, é o nível da cordoalha, com $V_{t}=1002 \mathrm{kN}$.

A força necessária para causar uma fissura por cisalhamento na alma será dada por:

$$
V_{c}=V_{t}+P_{v}=1002+405=1407 k N
$$

Este valor é menor que o obtido para flexão-cisalhamento $\left(V_{c}=2395 \mathrm{kN}\right)$.

Portanto, nesta seção (bem próxima ao apoio) as fissuras causadas por cisalhamento na nervura ocorrem para carregamentos bem inferiores aos das fissuras de flexão-cisalhamento.

Minoração dos esforços nominais resistentes:

$$
\phi V_{c}=0,7 \times 1407=985 k N>V_{d}=840 k N
$$

Isto indica que a seção poderá não necessitar de armadura transversal, ou ainda, necessitar apenas de armadura mínima.

Esforço resistente equivalente à armadura mínima: 


$$
\begin{aligned}
& V_{n, \text { min }}=V_{c}+\gamma b_{v} d_{0} \\
& V_{n, \text { min }}=1407 \times 10^{3}+0,8367 \times 10^{6} \times 0,24 \times 1,1455 \\
& V_{n, \text { min }}=1407 \times 10^{3}+230 \times 10^{3} \\
& V_{n, \text { min }}=1637 \mathrm{kN} \\
& \phi V_{n, \text { min }}=0,7 \times 1637=1146 \mathrm{kN}>V_{d}=840 \mathrm{kN}
\end{aligned}
$$

Verificação da necessidade de armadura mínima:

Como $0,5 \phi V_{c}<V_{d} \leq \phi V_{n \cdot \min }(493 k N<840 k N \leq 1146 k N)$ deve-se adotar armadura mínima.

Cálculo da armadura mínima (CA-25):

$$
\begin{aligned}
& \left(A_{s w} / s\right)_{\text {min }}=0,06 \sqrt{f_{c k}}\left(\frac{b_{v}}{f_{y}}\right) \\
& \left(A_{s w} / s\right)_{\text {min }}=0,06 \times \sqrt{70} \times \frac{0,240}{250} \\
& \left(A_{s w} / s\right)_{\text {min }}=4,8 \times 10^{-4} \mathrm{~m}^{2} / \mathrm{m} \\
& \left(A_{s w} / s\right)_{\text {min }}=4,8 \mathrm{~cm}^{2} / \mathrm{m}
\end{aligned}
$$

Espaçamento máximo:

$$
s_{\text {max }} \leq\left\{\begin{array}{l}
d / 2=114 / 2=57 \mathrm{~cm} \\
30 \mathrm{~cm} \rightarrow \text { valor limite adotado }
\end{array}\right.
$$

Portanto, pode-se adotar estribos de dois ramos (CA-25), com diâmetro de $10 \mathrm{~mm}$ espaçados de $30 \mathrm{~cm}$, com uma área total de $5,34 \mathrm{~cm}^{2} / \mathrm{m}$.

\section{Cálculo para uma seção distante $3,0 m$ do apoio $\mathrm{A}$}

Das expressões anteriores, tem-se:

$$
\begin{aligned}
& V_{d}=696 \mathrm{kN} ; M_{d}=2349 \mathrm{kN} . \mathrm{m} ; y^{\prime}=0,07467 \mathrm{rad} \\
& V_{d} / M_{d}=0,296 ; M_{d} / V_{d}=3,375 ; e=0,252 \mathrm{~m}
\end{aligned}
$$


Força efetiva de protensão:

$$
P_{e}=4500-3 \times 20=4440 k N
$$

Componente vertical da força de protensão:

$$
P_{v}=P_{e} y^{\prime}=4440 \times 0,07467=332 k N
$$

Momento de fissuração:

$$
\begin{aligned}
& M_{r}=M_{0}+f_{t} w_{\mathrm{inf}} \\
& M_{r}=1792+5,5 \times 0,1 \times 10^{-3} \\
& M_{r}=2342 \mathrm{kN} . \mathrm{m}
\end{aligned}
$$

Como o momento de cálculo $\left(M_{d}\right)$ é maior que o momento de fissuração $\left(M_{r}\right)$, a fissuração por cisalhamento na nervura não precisa ser verificada.

\section{$\rightarrow$ Fissuração por flexão-cisalhamento}

Momento de descompressão:

$$
\begin{aligned}
& M_{0}=P_{e}\left(e+\frac{w_{\mathrm{inf}}}{A_{c}}\right) \\
& M_{0}=4440 \times 10^{3} \times\left(0,252+\frac{0,1}{0,66}\right) \\
& M_{0}=1792 \mathrm{kN} . \mathrm{m}
\end{aligned}
$$

Esforço cortante correspondente a $M_{0}$ :

$$
\begin{aligned}
& V_{0}=M_{0} \frac{V_{d}}{M_{d}} \\
& V_{0}=1792 \times 0,296=531 \mathrm{kN}
\end{aligned}
$$

Esforço cortante necessário para causar uma fissura de flexão-cisalhamento: 


$$
\begin{aligned}
& V_{c}=\beta_{5} \beta_{2} b_{v} d_{0}\left(\frac{A_{p}+A_{s}}{b_{v} d_{0}} f_{c k}\right)^{1 / 3}+V_{0}+P_{v} \\
& V_{c}=1,1 \times 1 \times 240 \times 1145,5 \times\left(\frac{3948+1000}{240 \times 1145,5} 70\right)^{1 / 3} \times 10^{-3}+531+332 \\
& V_{c}=327+531+332=1190 \mathrm{kN} \\
& \phi V_{c}=0,7 \times 1190=833 \mathrm{kN}
\end{aligned}
$$

Como $\phi V_{c}=833 k N>V_{d}=696 k N$, a seção poderá não necessitar de armadura transversal, ou ainda, necessitar apenas de armadura mínima.

Esforço resistente equivalente à armadura mínima:

$$
\begin{aligned}
& V_{n, \text { min }}=V_{u c}+\gamma b_{v} d_{0} \\
& V_{n, \text { min }}=1190 \times 10^{3}+0,8367 \times 10^{6} \times 0,24 \times 1,1455 \\
& V_{n, \text { min }}=1190 \times 10^{3}+230 \times 10^{3} \\
& V_{n, \text { min }}=1420 \mathrm{kN} \\
& \phi V_{n, \text { min }}=0,7 \times 1420=994 \mathrm{kN}
\end{aligned}
$$

Verificação da necessidade de armadura mínima

Como $0,5 \phi V_{c}<V_{d} \leq \phi V_{n \cdot m i n}(416,5 k N<696 k N \leq 994 k N)$ deve-se adotar armadura mínima.

Pode-se adotar estribos de dois ramos (CA-25), com diâmetro de $10 \mathrm{~mm}$ espaçados de $30 \mathrm{~cm}$, com uma área total de $5,34 \mathrm{~cm}^{2} / \mathrm{m}$.

EXEMPLO 4.2 - $f_{c k}=70 M P a$

Idêntico ao anterior, porém com um carregamento maior $(g=33,31 k N ; q=28,24 k N)$, de tal forma que a armadura de cisalhamento necessária 
seja maior que a mínima. A armadura será calculada segundo a metodologia e coeficientes de segurança da $A S-3600$ (1988).

\section{Observação:}

A viga não foi verificada à flexão para este carregamento $(g=33,31 k N ; q=28,24 k N)$. Portanto, a armadura de flexão é insuficiente.

\section{Solução}

Combinação de carregamento:

$$
\begin{aligned}
& w_{d}=1,25 g+1,5 q=1,25 \times 33,31+1,5 \times 28,24 \\
& w_{d}=84,0 k N / m
\end{aligned}
$$

Esforço cortante de cálculo $\left(V_{d}\right)$ e momento de cálculo $\left(M_{d}\right)$ a $x$ metros à direita do apoio A:

$$
\begin{aligned}
& V_{d}=1260-84 x(k N) \\
& M_{d}=1260 x-42 x^{2}(k N . m)
\end{aligned}
$$

\section{Cálculo para uma seção distante $0,516 m$ do apoio A}

Das expressões anteriores, tem-se:

$$
\begin{aligned}
& V_{d}=1217 \mathrm{kN} ; M_{d}=639 \mathrm{kN} . \mathrm{m} ; y^{\prime}=0,09012 \mathrm{rad} \\
& V_{d} / M_{d}=1,904 ; M_{d} / V_{d}=0,525 ; e=0,043 \mathrm{~m}
\end{aligned}
$$

Componente vertical da força de protensão:

$$
P_{v}=P_{e} y^{\prime}=4490 \times 0,09012=405 k N
$$




\section{$\rightarrow$ Fissuração por flexão-cisalhamento}

Momento de descompressão:

$$
\begin{aligned}
& M_{0}=P_{e}\left(e+\frac{w_{\text {inf }}}{A_{c}}\right) \\
& M_{0}=4900 \times 10^{3} \times\left(0,043+\frac{0,1}{0,66}\right) \\
& M_{0}=873 \mathrm{kN} . \mathrm{m}
\end{aligned}
$$

Esforço cortante correspondente a $M_{0}$ :

$$
\begin{aligned}
V_{0} & =M_{0} \frac{V_{d}}{M_{d}} \\
V_{0} & =873 \times 1,9=1663 \mathrm{kN}
\end{aligned}
$$

Esforço cortante necessário para causar uma fissura de flexão-cisalhamento:

$$
\begin{aligned}
& V_{c}=\beta_{5} \beta_{2} b_{v} d_{0}\left(\frac{A_{p}+A_{s}}{b_{v} d_{0}} f_{c k}\right)^{1 / 3}+V_{0}+P_{v} \\
& V_{c}=1,1 \times 1 \times 240 \times 1145,5 \times\left(\frac{3948+1000}{240 \times 1145,5} 70\right)^{1 / 3} \times 10^{-3}+1663+405 \\
& V_{c}=327+1663+405=2395 \mathrm{kN}
\end{aligned}
$$

Como o momento de cálculo $\left(M_{d}\right)$ é menor que o momento de descompressão $\left(M_{0}\right)$ e, portanto, menor que o momento de fissuração $\left(M_{r}\right)$, a fissuração por cisalhamento na nervura dever ser verificada em três níveis:

- nível do C.G. da seção

- nível da armadura de protensão

- na interface mesa-nervura

\section{$\rightarrow$ Fissuração por cisalhamento na nervura}

Como a relação entre $g$ e $q$ foi mantida, os valores de $V_{t}$ permanecem os mesmos em todos os níveis (com o nível crítico sendo o da cordoalha), e $V_{c}=1407 k N$ e $\phi V_{c}=985 k N$ não mudam, indicando que as fissuras por cisalhamento 
na nervura ocorrem para carregamentos menores que os carregamentos que provocam fissuras de flexão-cisalhamento.

Porém, $\phi V_{n, \min }=1146 k N$ passa a ser menor que $V_{d}=1217 k N$, e a armadura necessária passa a ser maior que a mínima.

$$
\begin{aligned}
& V_{n, \text { max }}=0,2 f_{c k} b_{v} d_{0}+P_{v} \\
& V_{n, \text { max }}=0,2 \times 70 \times 10^{6} \times 0,24 \times 1,1455 \times+405 \times 10^{3} \\
& V_{n, \text { max }}=3849 \mathrm{kN}+405 \mathrm{kN} \\
& V_{n, \text { max }}=4254 \mathrm{kN} \rightarrow \phi V_{n, \text { max }}=0,7 \times 4254=2978 \mathrm{kN}
\end{aligned}
$$

Cálculo dos estribos verticais:

$$
\begin{aligned}
& \theta=30+\frac{15\left(V_{d}-\phi V_{n, \min }\right)}{\phi V_{n, \max }-\phi V_{n, \min }} \\
& \theta=30+\frac{15(1217-1146)}{2978-1146} \\
& \theta=30,58^{\circ}
\end{aligned}
$$

Para se garantir a segurança, deve-se ter $V_{d} \geq \phi V_{n}$. A partir de (4.31) e (4.32a) chega-se facilmente a:

$$
\begin{aligned}
\frac{A_{s w}}{s} & =\frac{V_{d}-\phi V_{c}}{\phi f_{y w} d_{0} \operatorname{cotg} \theta} \\
\frac{A_{s w}}{s} & =\frac{(1217-985) \times 10^{3}}{0,7 \times 250 \times 10^{6} \times 1,1455 \times \operatorname{cotg} 30,58^{0}} \\
\frac{A_{s w}}{s} & =6,84 \times 10^{-4} \mathrm{~m}^{2} / \mathrm{m}=6,84 \mathrm{~cm}^{2} / \mathrm{m}
\end{aligned}
$$

Portanto, pode-se adotar estribos de dois ramos (CA-25), com diâmetro de $10 \mathrm{~mm}$ espaçados de $23 \mathrm{~cm}$, com uma área total de $6,97 \mathrm{~cm}^{2} / \mathrm{m}$.

\section{Cálculo para uma seção distante $3,0 m$ do apoio $\mathrm{A}$}

Das expressões anteriores, tem-se:

$$
\begin{aligned}
& V_{d}=1008 \mathrm{kN} ; M_{d}=3402 \mathrm{kN} . \mathrm{m} ; y^{\prime}=0,07467 \mathrm{rad} \\
& V_{d} / M_{d}=0,296 ; M_{d} / V_{d}=3,375 ; e=0,252 \mathrm{~m}
\end{aligned}
$$


Força efetiva de protensão:

$$
P_{e}=4500-3 \times 20=4440 k N
$$

Componente vertical da força de protensão:

$$
P_{v}=P_{e} y^{\prime}=4440 \times 0,07467=332 k N
$$

Momento de fissuração:

$$
\begin{aligned}
& M_{r}=M_{0}+f_{t} w_{\mathrm{inf}} \\
& M_{r}=1792+5,5 \times 0,1 \times 10^{-3} \\
& M_{r}=2342 k N . m
\end{aligned}
$$

Como o momento de cálculo $\left(M_{d}\right)$ é maior que o momento de fissuração $\left(M_{r}\right)$, a fissuração por cisalhamento na nervura não precisa ser verificada.

\section{$\rightarrow$ Fissuração por flexão-cisalhamento}

Aumentando-se o carregamento, $\phi V_{c}=833 k N$ e $\phi V_{n, \min }=994 k N$ passam a ser menores que $V_{d}=1008 k N$, e a armadura necessária é maior que a mínima.

$$
\begin{aligned}
& V_{n, \text { max }}=0,2 f_{c k} b_{v} d_{0}+P_{v} \\
& V_{n, \text { max }}=0,2 \times 70 \times 10^{6} \times 0,24 \times 1,1455 \times+332 \times 10^{3} \\
& V_{n, \text { max }}=3849 k N+332 k N \\
& V_{n, \text { max }}=4181 k N \rightarrow \phi V_{n, \text { max }}=0,7 \times 4181=2927 k N
\end{aligned}
$$

Cálculo dos estribos:

$$
\begin{aligned}
& \theta=30+\frac{15\left(V_{d}-\phi V_{n, \min }\right)}{\phi V_{n, \max }-\phi V_{n, \min }} \\
& \theta=30+\frac{15(1008-994)}{2927-994} \\
& \theta=30,11^{0}
\end{aligned}
$$




$$
\begin{aligned}
\frac{A_{s w}}{s} & =\frac{V_{d}-\phi V_{c}}{\phi f_{y w} d_{0} \operatorname{cotg} \theta} \\
\frac{A_{s w}}{s} & =\frac{(1008-833) \times 10^{3}}{0,7 \times 250 \times 10^{6} \times 1,1455 \times \operatorname{cotg} 30,11^{0}} \\
\frac{A_{s w}}{s} & =5,06 \times 10^{-4} \mathrm{~m}^{2} / \mathrm{m}=5,06 \mathrm{~cm}^{2} / \mathrm{m}
\end{aligned}
$$

Para estribos de $10 \mathrm{~mm}$ de diâmetro o espaçamento passa ser limitado pelo limite de $30 \mathrm{~cm}$. Portanto, pode-se adotar estribos de dois ramos (CA-25), com diâmetro de $10 \mathrm{~mm}$ espaçados de $30 \mathrm{~cm}$, com uma área total de $5,34 \mathrm{~cm}^{2} / \mathrm{m}$. 


\section{DESLOCAMENTOS CAUSADOS POR AÇÕES DE CURTA E DE LONGA DURAÇÃO}

Embora a preocupação primeira dos projetistas seja, normalmente, atender aos critérios de segurança contra a ruína dos elementos (estado limite último), percebe-se nas normas modernas uma atenção cada vez maior dispensada aos estados limites de utilização. Dentre eles, está o estado limite de deformações excessivas. Um erro no cálculo dos deslocamentos dos elementos fletidos, e por conseqüência o não atendimento aos seus valores limites, pode causar não só desconforto visual, mas também sérios problemas nos elementos que neles se apoiam (alvenarias e caixilhos, por exemplo).

Dentre as diferenças existentes entre o projeto de uma viga de concreto de resistência usual e o de uma viga de $\mathrm{CAD}$, as que se referem ao cálculo dos deslocamentos causados por ações de longa duração estão entre as mais significativas.

Serão apresentadas aqui quatro abordagens para o cálculo dos deslocamentos: uma segundo o ACI (1995) e três segundo o CÓDIGO MODELO CEB-FIP (1990).

\subsection{CÁLCULO DOS DESLOCAMENTOS SEGUNDO O ACI (1995)}

Apresenta-se a seguir a metodologia inicial do ACI (1995) para cálculo dos deslocamentos, a qual foi posteriormente adaptada para o CAD.

\subsubsection{Deslocamentos causados por ações de curta duração}

Um dos problemas enfrentados pelos projetistas no cálculo dos deslocamentos é a avaliação da rigidez à flexão do elemento. Mesmo em serviço, os elementos 
fletidos em geral estão fissurados, o que reduz a sua inércia. Além disso, essa fissuração não é constante ao longo do vão, muito embora se procure fazer com que ela se apresente o mais uniforme possível, através de um detalhamento adequado das armaduras.

Para elementos de concreto armado, BRANSON (1965) apresentou uma solução prática para o problema, estabelecendo uma expressão para o momento de inércia a ser utilizado no cálculo dos deslocamentos, levando em consideração a fissuração, através do conceito do momento de inércia efetivo $\left(I_{e}\right)$ dado por:

$$
I_{e}=I_{r}+\left(\frac{M_{r}}{M_{\max }}\right)^{3}\left(I_{g}-I_{r}\right) \leq I_{g}
$$

onde:

$M_{r} \quad$ momento fletor de fissuração

$M_{\max }$ momento fletor máximo na peça para o qual o deslocamento é calculado

$I_{g} \quad$ momento de inércia da seção bruta de concreto em relação ao centro de gravidade, desprezando-se as armaduras

$I_{r} \quad$ momento de inércia da seção fissurada de concreto

O momento fletor de fissuração $\left(M_{r}\right)$ é dado por:

$$
M_{r}=\frac{f_{t} I_{g}}{y_{\mathrm{inf}}}
$$

onde:

$f_{t} \quad$ resistência do concreto à tração

$y_{\text {inf }}$ distância do centro de gravidade da seção bruta, desprezando as armaduras, à fibra tracionada mais externa 
A expressão de BRANSON (1965) é adotada pelo ACI 318 (1995).

HOVER et al. (1991), em estudo realizado com nove vigas de concreto armado com resistências variando entre $38 \mathrm{MPa}$ e $92 \mathrm{MPa}$, mediram os deslocamentos reais e compararam seus valores com os previstos pela equação de Branson.

Este estudo indica que os deslocamentos imediatos não dependem fortemente da resistência do concreto.

Os valores reais medidos para os deslocamentos imediatos foram em média $15 \%$ maiores que os previstos pela equação de Branson. Considerando-se a variação dos parâmetros usados no cálculo dos deslocamentos, pode-se adotar o procedimento do ACI 318 (1995) para o cálculo dos deslocamentos imediatos das vigas de CAD.

BRANSON (1974) também recomendou o uso de $I_{e}$ para vigas de concreto protendido com cabos aderentes. Neste caso, sugere-se que tanto o momento de fissuração $\left(M_{r}\right)$ como o momento máximo $\left(M_{\max }\right)$ sejam diminuídos de um valor igual ao momento de descompressão $\left(M_{0}\right)$.

Assim, a equação (5.1), para elementos protendidos, transforma-se em:

$$
I_{e}=I_{r}+\left(\frac{M_{r}-M_{0}}{M_{\max }-M_{0}}\right)^{3}\left(I_{g}-I_{r}\right) \leq I_{g}
$$

As equações (5.1) e (5.3) aplicam-se a vigas simplesmente apoiadas e a vigas contínuas, admitidas simplesmente apoiadas em seus pontos de inflexão. Para uma viga em balanço, o valor de $I_{e}$ deve ser tomado na face do apoio.

Com o objetivo de se calcular $I_{e}$, necessita-se do momento de inércia da seção fissurada $\left(I_{r}\right)$. Pode-se calcular o momento de inércia da seção fissurada através da relação momento-curvatura, assumindo-se que a distribuição de tensões ao longo da seção já tenha sido estabelecida previamente. Assim:

$$
\psi_{r}=\frac{\varepsilon_{c, \max }}{x}=\frac{M_{t o t}}{E_{c} I_{r}}
$$

onde: 
$\varepsilon_{c, \max }$ deformação na fibra mais comprimida de concreto

$M_{\text {tot }} \quad$ momento que inclui o momento da protensão

$x \quad$ distância entre a fibra mais comprimida e a posição da linha neutra

A equação (5.4) leva a:

$$
I_{r}=\frac{M_{t o t} x}{E_{c} \varepsilon_{c, \max }}=\frac{M_{t o t} x}{\sigma_{c, \max }}
$$

onde:

$\sigma_{c, \max }$ tensão na fibra mais comprimida de concreto

$M_{\text {tot }}$ momento para o qual $I_{c r}$ está sendo determinado, e que inclui o momento da força de protensão em relação ao C.G. da seção fissurada

A posição do C.G. da seção fissurada pode ser calculada por:

$$
\bar{y}=\frac{\left(b_{f}-b_{w}\right) h_{f}^{2} / 2+b_{w} x^{2} / 2+\eta_{p} A_{p} d_{p}+\eta_{s} A_{s} d_{s}}{\left(b_{f}-b_{w}\right) h_{f}+b_{w} x+\eta_{p} A_{p}+\eta_{s} A_{s}}
$$

onde:

$\eta_{p}=E_{p} / E_{c}$ e $\eta_{s}=E_{s} / E_{c}$

$d_{p} \quad$ distância entre a fibra mais comprida de concreto e o C.G. da armadura de protensão

$d_{s}$ distância entre a fibra mais comprida de concreto e o C.G. da armadura passiva longitudinal tracionada

$\bar{y}$ distância entre a fibra mais comprimida e o C.G. da seção homogeneizada

$x \quad$ distância entre a fibra mais comprimida e a posição da linha neutra da seção fissurada 
Elementos com protensão total não fissuram sob carregamentos de serviço e admite-se que tenham comportamento elástico linear. Seus deslocamentos podem ser determinados usando-se as expressões dadas na figura 5.1 para vários tipos de perfis de cabos de protensão e de carregamento.

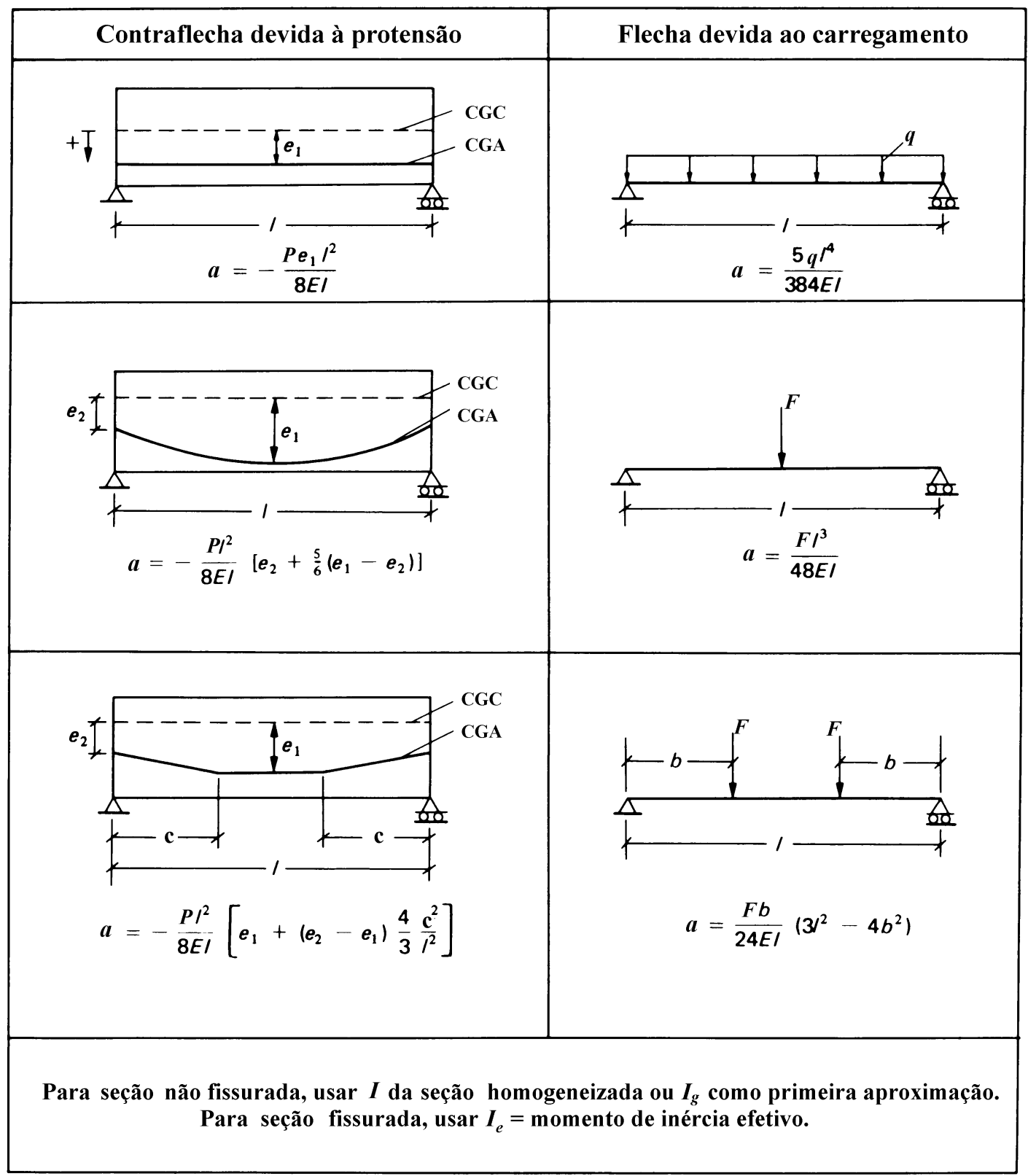

FIGURA 5.1 - Expressões para o cálculo de contraflechas e de flechas FONTE: NAAMAN (1982) 
Admite-se nas expressões da figura 5.1 que as vigas são simplesmente apoiadas com força de protensão constante e seções transversais com propriedades geométricas também constantes.

\subsubsection{Deslocamentos causados por ações de longa duração}

No ACI 318 (1995), os deslocamentos adicionais causados por ações de longa duração, devidos à fluência e à retração (em conjunto), em elementos de concreto armado, são calculados multiplicando-se os deslocamentos imediatos por um fator de correção $(\lambda)$ :

$$
\lambda=\frac{\xi}{1+50 \rho^{\prime}}
$$

onde:

$\rho^{\prime} \quad$ taxa de armadura comprimida, $A_{s}^{\prime} / b d$, no meio do vão, para vigas biapoiadas ou contínuas, e no engaste para balanços

$\xi$ fator dependente do tempo de duração do carregamento, conforme a tabela 5.1 e a figura 5.2

TABELA 5.1 - Valores de $\xi$

FONTE: ACI 318 (1995)

\begin{tabular}{|c|c|}
\hline PERÍODO & $\xi$ \\
\hline 5 anos ou mais & 2,0 \\
\hline 1 ano & 1,4 \\
\hline 6 meses & 1,2 \\
\hline 3 meses & 1,0 \\
\hline
\end{tabular}


Como a retração e a fluência (especialmente essa última) são menores no CAD, é de se esperar que o aumento dos deslocamentos com o tempo seja menor para elementos feitos com este material. Portanto, os fatores de correção para as vigas de CAD devem ser menores que os utilizados nas vigas de resistência usual.

Chamando-se de $a_{i}$ o deslocamento causado pelas ações de curta duração, o deslocamento total causado pelas ações de curta e de longa duração $\left(a_{t o t}\right)$ é dado por:

$$
a_{t o t}=(1+\lambda) a_{i}
$$

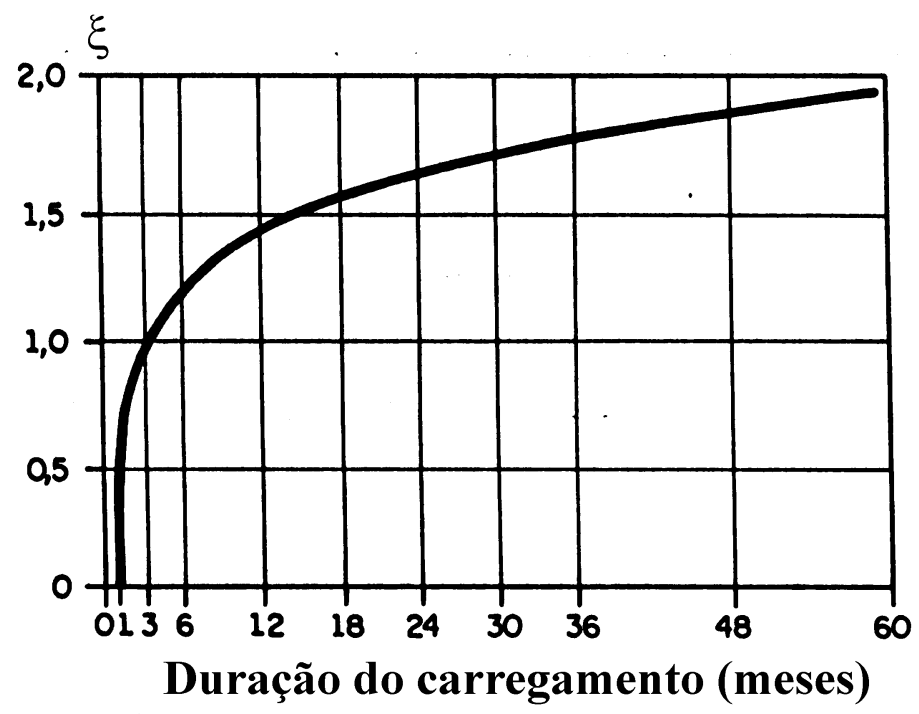

FIGURA 5.2 - Valores de $\xi$

FONTE: ACI 318 (1995).

HOVER et al. (1991) concluíram que a presença de armadura comprimida, nas vigas de $\mathrm{CAD}$, não desenvolve o mesmo efeito de minoração dos deslocamentos observado nas vigas de resistência usual. Nestas últimas, quando a armadura comprimida está presente, o aumento das deformações nas fibras comprimidas causado pela fluência provocará um acréscimo nas tensões na armadura comprimida. Isso permitirá a transferência de parte da força de compressão do concreto para a armadura comprimida. Como resultado, as deformações de compressão no concreto diminuem, resultando em deformações de fluência menores. Como a fluência no CAD é menor, esse mecanismo é menos eficiente. 
HOVER et al. (1991) sugerem uma correção para o valor de $\lambda$ como se segue:

$$
\lambda=\frac{\mu \xi}{1+50 \mu \rho^{\prime}}
$$

onde:

$$
\begin{gathered}
\mu=1,4-\left(f_{c k} / 70\right) \quad\left(f_{c k} \text { em } M P a\right) \\
0,4 \leq \mu \leq 1
\end{gathered}
$$

Como se observa, o fator $\lambda$ passa a ser dependente da resistência do concreto. A presença do fator $\mu$ no numerador e no denominador da equação (5.9) leva em consideração a diminuição dos deslocamentos devidos à retração e à fluência no CAD e a menor influência da presença da armadura comprimida para as resistências mais altas, respectivamente.

Os valores limites de 0,4 e 1 para $\mu$ correspondem às resistências de $70 M P a$ e $28 \mathrm{MPa}$, respectivamente. O limite inferior de 0,4 foi escolhido porque concorda razoavelmente bem com as vigas de $92 \mathrm{MPa}$ utilizadas na pesquisa, e que são aparentemente os únicos dados disponíveis para resistências acima de 70MPa. O limite superior de 1,0 foi escolhido porque o procedimento do ACI 318 (1995) é considerado adequado para vigas de até 28MPa. Nesses casos, a equação (5.9) dá os mesmos resultados obtidos com o já mencionado procedimento.

HOVER et al. (1991) concluíram ainda que:

- O método proposto por LUEBKEMAN et al. (1985), o qual é idêntico ao do ACI 318 (1995) para resistências de até $42 \mathrm{MPa}$, leva a resultados muito bons para vigas de CAD em geral. Este método é semelhante ao apresentado [equações (5.9) e (5.10)], diferindo na expressão e nos limites adotados para o coeficiente $\mu$. A expressão ora proposta [equação (5.10)] dá resultados ainda melhores para as vigas de CAD, e amplia a validade do procedimento, desde resistências usuais até 70MPa.

- Para vigas com resistência à compressão de cerca de $84 M P a$ submetidas a carregamento uniforme de longa duração, o coeficiente de fluência foi cerca de metade do estabelecido para resistências usuais. 
- A retração para o CAD foi cerca de $2 / 3$ da encontrada para a resistência mais baixa estudada.

- Para vigas com armadura tracionada apenas, o uso do CAD reduziu os deslocamentos para ações de longa duração em 30\% a 50\%.

- A armadura comprimida foi significativamente mais eficiente na redução dos deslocamentos por ações de longa duração para vigas de resistências usuais do que para vigas de CAD.

- Os deslocamentos provocados por ações de longa duração podem ser reduzidos significativamente através do uso de CAD ou de armadura comprimida, mas o uso de ambos é redundante.

- O coeficiente do ACI 318 (1995) [equação (5.7)], pelo qual os deslocamentos para ações de longa duração são calculados com base nos deslocamentos iniciais, dá bons resultados para vigas com resistências de até 35MPa. O seu uso, porém, superestima os deslocamentos para carregamentos de longa duração para vigas de CAD com resistências em torno de $90 M P a$.

Com base em extensiva avaliação dos parâmetros que influenciam os deslocamentos adicionais $\left(a_{\text {add }}\right)$ para elementos pré-moldados protendidos, MARTIN (1977) sugeriu a seguinte expressão:

$$
a_{\text {add }}=\lambda a_{i}=k_{p} \frac{E_{c i}}{E_{c}} k_{r} \varphi a_{i}
$$

onde:

$k_{p}=P_{e} / P_{i}$

$P_{e} \quad$ força de protensão efetiva após todas as perdas

$P_{i} \quad$ força de protensão imediatamente após a transferência

$k_{r}=\left(1+A_{s} / A_{p}\right)^{-1}$ quando $A_{s} / A_{p} \leq 2$

$\varphi \quad$ coeficiente de fluência 
$E_{c i} \quad$ módulo de deformação longitudinal do concreto na transferência da protensão

Os valores de $\lambda$ variam para vigas protendidas com seção simples ou composta. Para concretos de resistência usual, situam-se normalmente entre 1,85 e 3 . Para o CAD estes limites são menores, em função da menor fluência.

\subsection{MODELO BÁSICO DO CEB-FIP (1990)}

O CEB-FIP (1990) apresenta três metodologias para o cálculo dos deslocamentos. A primeira é o modelo básico, fundamentado na relação entre o momento e a curvatura com ou sem força normal, e que leva em consideração o efeito da armadura, o efeito global da fissuração, a retração e a fluência. Deste modelo, foram desenvolvidos dois outros métodos simplificados para cálculo dos deslocamentos: o método bilinear e o método dos coeficientes globais, que serão apresentados nos itens 5.3 e 5.4 respectivamente.

O CEB-FIP (1990) apresenta o conceito de enrijecimento de tração (tension stiffening) do concreto. Em uma seção transversal fissurada, considera-se que todos os esforços de tração são absorvidos somente pela armadura. Contudo, entre fissuras adjacentes, esforços de tração são transmitidos da armadura para o concreto que a envolve através de tensões de aderência. A contribuição do concreto pode ser considerada como que aumentando a rigidez da armadura de tração. Esse efeito é chamado de enrijecimento de tração.

O modelo básico fundamenta-se na relação momento-curvatura (figuras 5.3 e 5.4), da qual se concluiu que o efeito do enrijecimento de tração do concreto na curvatura de uma seção de um elemento submetido a flexão decresce com o aumento das ações além do nível correspondente ao momento de fissuração reduzido $\left(M_{r, \text { red }}\right)$. 
Para carregamentos de serviço, esta diminuição segue uma curva hiperbólica, que corresponde ao comportamento médio de uma seção transversal de uma estrutura de concreto, dada por:

$$
\Delta \psi_{t s}=\left(\psi_{2 r}-\psi_{1 r}\right) \beta \frac{M_{r}}{M} \text { para } M>M_{r, r e d}
$$

onde (figuras 5.3 e 5.4):

$\Delta \psi_{t s}$ redução na curvatura no estádio 2 devida ao enrijecimento de tração

$\psi_{1 r} \quad$ curvatura no estádio 1 para $M=M_{r}$ (seção não fissurada)

$\psi_{2 r} \quad$ curvatura no estádio 2 para $M=M_{r}$ (seção totalmente fissurada)

$M \quad$ momento fletor aplicado na seção

$M_{r, \text { red }}$ momento de fissuração reduzido, definido pela interseção do diagrama da curvatura média $\left(\psi_{m}\right)$ e a linha reta representando a curvatura no estádio 1. Para flexão simples (sem retração):

$$
M_{r, r e d}=\sqrt{\beta} M_{r}
$$

onde:

$\beta \quad \beta_{3} \times \beta_{4}$

$\beta_{3} \quad$ coeficiente que caracteriza a qualidade de aderência das barras da armadura. $\beta_{3}=1,0$ para barras de alta aderência; $\beta_{3}=0,5$ para barras lisas

$\beta_{4} \quad$ coeficiente que representa o tipo de carregamento (duração da aplicação e repetição do carregamento). $\beta_{4}=0,8$ para o carregamento imediato ou para carregamentos de curta duração; $\beta_{4}=0,5$ para carregamentos de longa duração ou grande número de ciclos de carregamento

$M_{r} \quad$ momento de fissuração 
No cálculo de $M_{r}$ para deslocamentos locais, pode-se usar $f_{t}=0,7 f_{t m} \cdot f_{t m}$ é a resistência média do concreto à tração. Para o cálculo dos deslocamentos globais, pode-se usar $f_{t}=f_{t m}$.

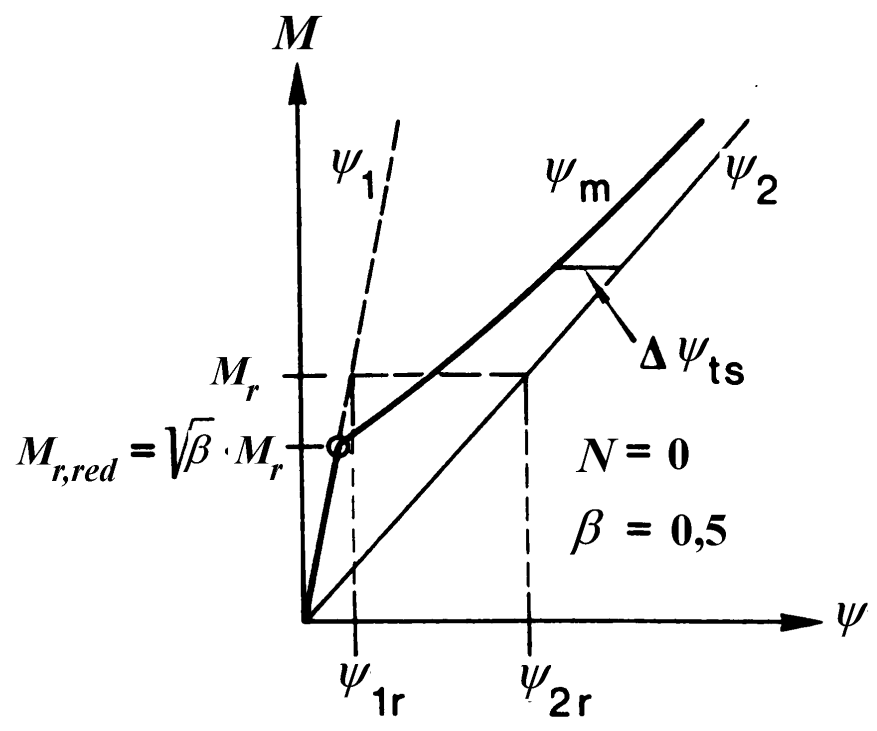

FIGURA 5.3 - Relação momento-curvatura do CEB-FIP (1990) (flexão simples) FONTE: CHARIF \& FAVRE (1994)

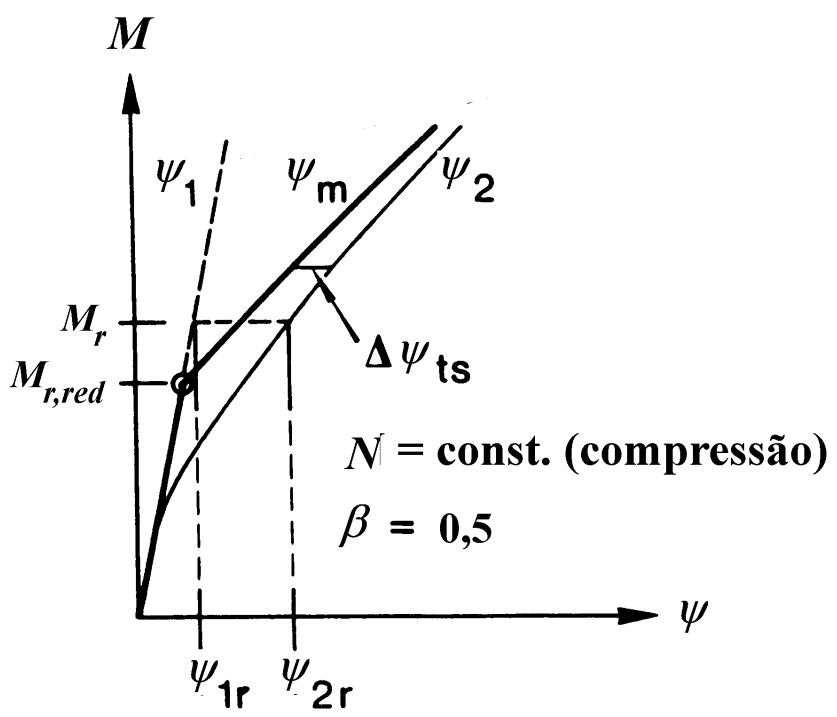

FIGURA 5.4 - Relação momento-curvatura do CEB-FIP (1990) (flexão composta) FONTE: CHARIF \& FAVRE (1994) 
Uma vez que a curvatura devida ao enrijecimento de tração $\Delta \psi_{t s}$ [equação (5.12)] é considerada como a diferença entre a curvatura média $\left(\psi_{\mathrm{m}}\right)$ e a curvatura no estádio $2\left(\psi_{2}\right)$, a curvatura média pode ser escrita como se segue:

$$
\begin{array}{ll}
\psi_{m}=\psi_{2}-\Delta \psi_{t s} & \\
\psi_{m}=\psi_{2}-\left(\psi_{2 r}-\psi_{1 r}\right) \beta \frac{M_{r}}{M} & \text { para } M>M_{r, \text { red }} \\
\psi_{m}=\psi_{1} & \text { para } M \leq M_{r, \text { red }}
\end{array}
$$

Considere-se o caso de flexão simples em uma seção não protendida (figuras 5.5 e 5.6).

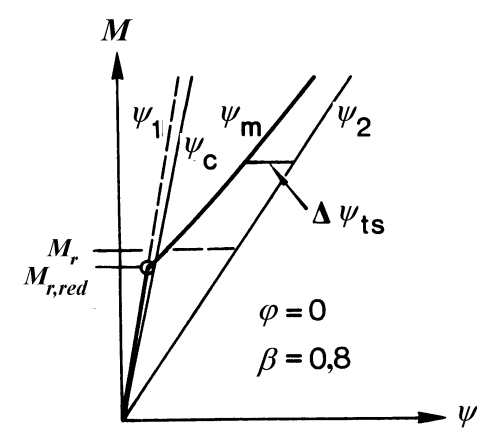

FIGURA 5.5 - Curvatura média imediata (flexão simples)

FONTE: CHARIF \& FAVRE (1994)

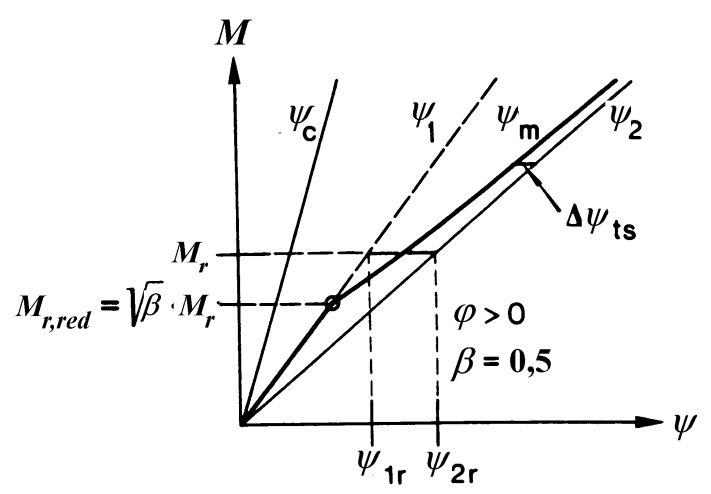

FIGURA 5.6 - Curvatura média para ações de longa duração (flexão simples) FONTE: CHARIF \& FAVRE (1994) 
As curvaturas $\psi_{1}$ e $\psi_{2}$ nos estádios 1 e 2 , respectivamente, são funções lineares do momento fletor $M$. Se são levados em consideração os efeitos da armadura comprimida, da retração e da fluência, as curvaturas resultantes podem ser consideradas como funções da curvatura básica $\left(\psi_{\mathrm{c}}\right)$ dada por:

$$
\psi_{c}=\frac{M}{(E I)_{c}}
$$

$(E I)_{\mathrm{c}}$ é a rigidez básica à flexão da seção (considerando-se apenas o concreto).

Isto permite a introdução de coeficientes de correção $k$, os quais são independentes das ações. As curvaturas $\psi_{1}$ e $\psi_{2}$, as quais representam os extremos (limites inferior e superior, respectivamente) da curvatura média $\left(\psi_{\mathrm{m}}\right)$, podem ser escritos como:

Efeito da armadura (curvatura instantânea):

$$
\psi_{1}=\psi_{c} k_{s 1} \quad \psi_{2}=\psi_{c} k_{s 2}
$$

Efeito da fluência ( $\varphi$ é o coeficiente de fluência):

$$
\psi_{1}=\psi_{c} k_{s 1} k_{\varphi 1} \varphi \quad \psi_{2}=\psi_{c} k_{s 2} k_{\varphi 2} \varphi
$$

Efeito da retração uniforme $\left(\varepsilon_{\mathrm{cs}}\right)$ :

$$
\psi_{1}=\left|\varepsilon_{c s}\right| \frac{k_{c s 1}}{d} \quad \psi_{2}=\left|\varepsilon_{c s}\right| \frac{k_{c s 2}}{d}
$$

onde:

d altura útil da seção

$\varepsilon_{c s}$ deformação média no concreto devida à retração esperada no elemento que não teve seus deslocamentos restringidos externamente 
A soma dos valores de $\psi_{1}$ e $\psi_{2}$, dados nas equação (5.16), (5.17) e (5.18), representa as curvaturas totais $\psi_{1}$ e $\psi_{2}$.

Note-se que no caso da proporcionalidade (flexão simples) entre $\psi_{1}, \psi_{2}$ e $\psi_{c}$, pode-se escrever a equação (5.14b) da seguinte forma:

$$
\psi_{1 r}=\psi_{1} \frac{M_{r}}{M} \quad \psi_{2 r}=\psi_{2} \frac{M_{r}}{M} \quad \psi_{m}=\psi_{2}-\left(\psi_{2}-\psi_{1}\right) \beta\left(\frac{M_{r}}{M}\right)^{2}
$$

Da condição de $\psi_{1}=\psi_{m}$ obtém-se o momento de fissuração reduzido $M_{r, \text { red }}=\sqrt{\beta} M_{r}$ (sem retração).

Os mesmos coeficientes de correção obtidos para o caso de flexão simples também são válidos para o caso de flexão composta, após algumas simplificações. A principal simplificação (figura 5.7) consiste em substituir a curvatura no estádio 2, a qual não é mais linear, por uma função bilinear.

A segunda metade desta função é paralela à curvatura no estádio 2 para flexão simples. $\psi_{m}$ pode novamente ser calculado usando-se a equação (5.14b), onde $M$ tem que ser substituído por $M-M_{0}$.

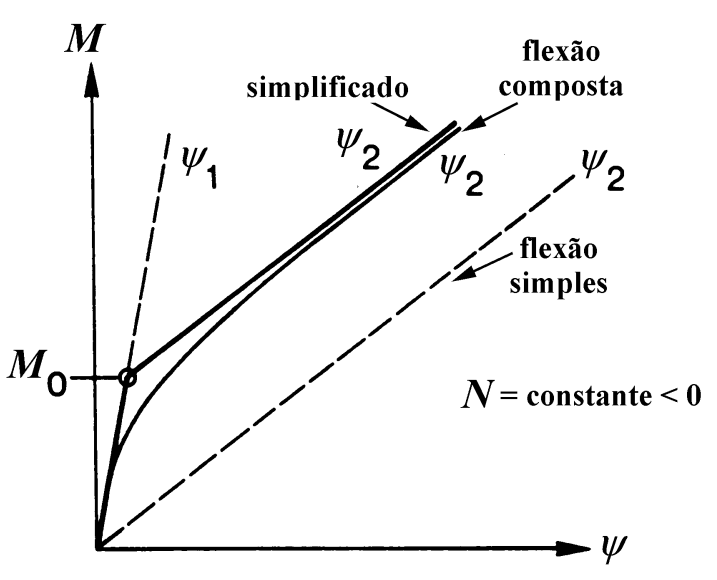

FIGURA 5.7 - Flexão composta: curvatura exata e simplificada no estádio $2\left(\psi_{2}\right)$

FONTE: CHARIF \& FAVRE (1994) 
CHARIF \& FAVRE (1994) realizaram um estudo paramétrico com o objetivo de avaliar a importância da fluência, da resistência do concreto à tração e das taxas de armaduras (de tração e compressão) nos deslocamentos das vigas submetidas a flexão simples. No estudo de cada parâmetro, os demais foram mantidos constantes. Os resultados são comentados a seguir.

\subsubsection{Influência do coeficiente de fluência $(\varphi)$}

Adotando-se o coeficiente de fluência $\varphi=2,5$ como valor de referência (100\%), pôde-se observar que:

- Reduzindo-se $\varphi$ de 2,5 para 1,5 (40\%) aumenta-se $\psi_{m}$ em aproximadamente $12 \%$.

- Aumentando-se $\varphi$ de 2,5 para 3,5 (40\%) aumenta-se $\psi_{m}$ em $12 \%$.

Portanto, $\varphi$ tem uma influência limitada na curvatura média na parte fissurada da estrutura.

\subsubsection{Influência da resistência do concreto à tração $\left(f_{t}\right)$}

Adotando-se uma resistência do concreto à tração $f_{t}=2,5 \mathrm{MPa}$ como um valor de referência (100\%), observou-se que o nível de carregamento tem grande influência na curvatura.

Para um momento fletor próximo ao momento de fissuração, pôde-se observar que:

- Aumentando-se $f_{t}$ de 2,5 para 3,5 (40\%), diminui-se $\psi_{m}$ em aproximadamente $33 \%$. 
- Reduzindo-se $f_{t}$ de 2,5 para 1,5 (40\%), aumenta-se $\psi_{m}$ em aproximadamente $22 \%$.

Contudo, para um nível mais alto de carregamento, uma variação de $\pm 40 \%$ em $f_{t}$ resulta em apenas $\pm 7 \%$ de variação em $\psi_{m}$.

Assim, $f_{t}$ tem uma grande influência na curvatura média apenas se o nível de carregamento está próximo ao momento de fissuração.

\subsubsection{Influência da armadura tracionada $(\rho)$}

Tomando-se a taxa de armadura tracionada $\rho=A_{s} / b d=0,5 \%$ como valor de referência (100\%), pôde-se observar que:

- Aumentado-se $\rho$ de 0,5\% para 0,75\% (50\%) diminui-se $\psi_{m}$ em $23 \%$.

- Diminuindo se $\rho$ de 0,5\% para 0,25\% (50\%) aumenta-se $\psi_{m}$ em 65\%.

Assim, $\rho$ tem uma significativa influência na curvatura média $\left(\psi_{m}\right)$.

\subsubsection{Influência da relação entre a armadura comprimida e a tracionada $\left(\rho^{\prime} / \rho\right)$}

Tomando-se a relação entre a armadura comprimida e a tracionada $\rho^{\prime} / \rho=0,5$ como valor de referência (100\%), pôde-se observar que:

- Reduzindo-se $\rho^{\prime} / \rho$ de 0,5 para $0,0(100 \%)$ aumenta-se $\psi_{m}$ em $6 \%$.

- Aumentando se $\rho^{\prime} / \rho$ de 0,5 para 1,0\% (100\%) diminui-se $\psi_{m}$ em 5\%.

Assim, $\rho^{\prime} / \rho$ tem uma menor influência na curvatura média $\left(\psi_{m}\right)$. 


\subsection{CÁLCULO SIMPLIFICADO - MÉTODO BILINEAR}

Pode-se desenvolver uma única expressão, baseada neste método, para uma estimativa rápida dos deslocamentos de um elemento.

Assumindo-se que o efeito de enrijecimento de tração de um elemento permanece constante além do momento de fissuração [figuras 5.8 (a) e (b)], então:

$$
a=a_{2}-\left(a_{2 r}-a_{1 r}\right) \beta
$$

onde:

$$
\begin{array}{ll}
a & \begin{array}{l}
\text { deslocamento estimado (provável) } \\
a_{1}, a_{2}
\end{array} \\
& \begin{array}{l}
\text { deslocamentos nos estádios } 1 \text { e } 2, \text { respectivamente, para flexão } \\
\text { simples }
\end{array} \\
a_{1 r}, a_{2 r} & \begin{array}{l}
\text { deslocamentos } a_{1} \text { e } a_{2} \text { para o momento de fissuração }\left(M_{r d}\right) \\
\beta
\end{array} \quad \begin{array}{l}
\text { coeficiente de redução do momento de fissuração }\left(\beta=\beta_{3} \beta_{4}\right)
\end{array}
\end{array}
$$

Note-se que a expressão $\left(a_{2 r}-a_{1 r}\right) \beta$ representa o efeito de enrijecimento de tração para o caso de flexão simples. Para flexão composta, $a_{2(\text { composta) }}$ é considerada paralela a $a_{2(\text { simples })}$. Assim, a compressão axial pode ser levada em consideração através do aumento do momento de fissuração do elemento.

Para flexão simples ou composta, pode-se escrever:

$$
a_{1 r}=a_{1} \frac{M_{r d}}{M_{d}} \quad a_{2 r}=a_{2} \frac{M_{r d}}{M_{d}}
$$

$M_{d}$ e $M_{r d}$ representam, respectivamente, o momento fletor atuante e o momento de fissuração na seção crítica do elemento, isto é, no meio do vão das vigas ou lajes, ou no extremo fixo de um balanço. Assim, das equações (5.20) e (5.21), a seguinte expressão é obtida: 


$$
a=a_{2}-\left(a_{2}-a_{1}\right) \beta \frac{M_{r d}}{M_{d}}
$$

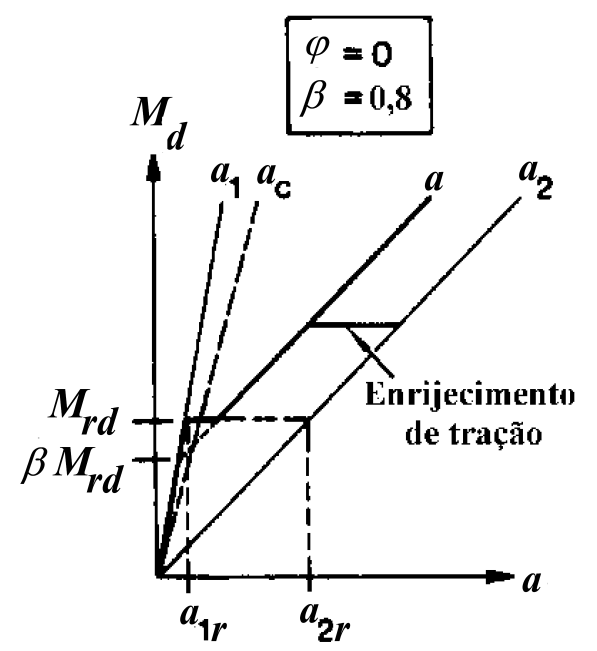

(a) Deslocamentos para cargas de curta duração

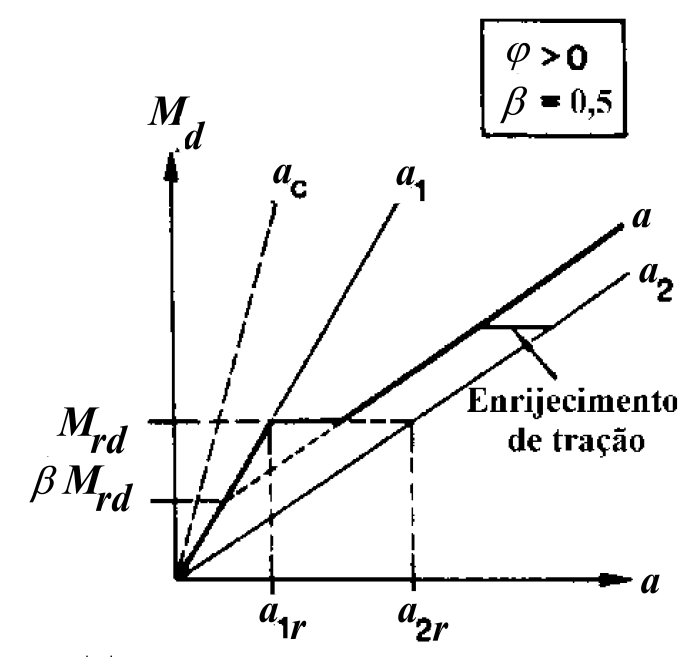

(b) Deslocamentos para cargas de longa duração (sem retração)

FIGURA 5.8 - Método bilinear

FONTE: CHARIF \& FAVRE (1994)

O cálculo dos deslocamentos extremos $a_{1}$ e $a_{2}$, assim como outras simplificações são dadas na próxima seção.

\subsection{CÁlCULO SIMPLIFICADO DOS DESLOCAMENTOS - MÉTODO DOS COEFICIENTES GLOBAIS}

A equação (5.22) pode ser muito simplificada se uma abordagem levemente diferente é adotada. Será adotada a seguinte notação [ver equações (5.16) e (5.17)]:

$$
k_{1}=k_{s 1}\left(1+k_{\varphi 1} \varphi\right) \quad k_{2}=k_{s 2}\left(1+k_{\varphi 2} \varphi\right)
$$


Levando-se em consideração a fluência e a armadura (uma estimativa para fluência será dada mais adiante), as curvaturas nos estádios 1 e 2 podem ser dadas por:

$$
\psi_{1}=\psi_{c} k_{1} \quad \psi_{2}=\psi_{c} k_{2}
$$

Assim, pelo princípio dos trabalhos virtuais, os deslocamentos máximos $a_{1}$ e $a_{2}$ podem ser expressos por:

$$
a_{1}=\int \psi_{c} k_{1} \bar{M} d x \quad a_{2}=\int \psi_{c} k_{2} \bar{M} d x
$$

$\bar{M}$ é o momento fletor devido a um carregamento vertical unitário aplicado onde o deslocamento é calculado.

Admitindo-se que os coeficientes de correção $k_{1}$ e $k_{2}$ são constantes ao longo do vão considerado, tem-se:

$$
a_{1}=k_{1} \int \psi_{c} \bar{M} d x=a_{c} k_{1} \quad a_{2}=k_{2} \int \psi_{c} \bar{M} d x=a_{c} k_{2}
$$

onde:

$$
a_{c}=\int \psi_{c} \bar{M} d x
$$

Os valores constantes escolhidos para os coeficientes de correção $k_{1}$ e $k_{2}$ podem ser os valores na seção crítica. Contudo, para coeficientes mais precisos e representativos, valores médios relativos ao comprimento total do elemento podem ser admitidos (como discutido posteriormente). $\mathrm{O}$ valor $a_{c}$ representa o deslocamento do elemento de concreto (a armadura é desprezada). De fato, este é um deslocamento dado por uma análise linear.

Agora, o provável deslocamento pode ser dado por [equação (5.22)]: 


$$
a=a_{c}\left[k_{2}-\left(k_{2}-k_{1}\right) \beta \frac{M_{r D}}{M_{D}}\right]=a_{c} k
$$

onde:

$$
k=k_{2}-\left(k_{2}-k_{1}\right) \beta \frac{M_{r d}}{M_{d}}
$$

O coeficiente $k$ é chamado de coeficiente global de correção. Ele depende de vários parâmetros: geométricos, mecânicos e do nível de carregamento. Tabelas de projeto são apresentadas pelo COMITÉ EURO-INTERNATIONAL DU BÉTON (1985).

CHARIF \& FAVRE (1994) realizaram um estudo paramétrico, considerando apenas o peso próprio, com o objetivo de estabelecer uma expressão simplificada para o coeficiente $k$. $\mathrm{O}$ estudo paramétrico revelou que os coeficientes $k_{1}$ e $k_{2}$ são essencialmente funções dos parâmetros que se seguem:

$d / h \quad$ relação entre a altura útil e a altura total do elemento

$\alpha \rho \quad$ onde $\alpha=E_{s} / E_{c}$ e $\rho$ é a taxa de armadura tracionada $\left(\rho=A_{s} / b d\right)$

$\rho^{\prime} / \rho$ relação entre as taxas das armaduras comprimida e tracionada

$\varphi \quad$ coeficiente de fluência

Os coeficientes $k_{1}$ e $k_{2}$ podem ser liberados da influência da armadura comprimida $\left(\rho^{\prime}\right)$ introduzindo-se o fator $\left(1-20 \rho^{\prime}\right)$. Assim:

$$
k=\left[k_{2}-\left(k_{2}-k_{1}\right) \beta \frac{M_{r d}}{M_{d}}\right]\left(1-20 \rho^{\prime}\right)
$$

A equação (5.30) torna $k_{1}$ e $k_{2}$ independentes de $\rho^{\prime}$ e muito mais fáceis de se estimar. 
O estudo paramétrico também mostra que o coeficiente global pode ser expresso por:

$$
k=(h / d)^{3} \eta\left(1-20 \rho^{\prime}\right)
$$

O fator $\eta$ é dado na figura 5.9.

A importância do fator $(h / d)^{3}$ é infeliz, uma vez que ele vai contra a boa prática de proteger a armadura com um generoso cobrimento. Para lajes em edifícios, este fator pode atingir o seguinte valor:

$$
(h / d)^{3}=(1,2)^{3}=1,73
$$

A equação (5.31) é válida desde que admitidas as seguintes simplificações:

- O parâmetro $\alpha=E_{s} / E_{c}=7$ (este é um valor usual para a relação entre os módulos de elasticidade do aço e concreto).

- Coeficiente de fluência $\varphi=2,5$. Para outros valores de $\varphi$, um único fator de correção pode ser usado, o qual será dado posteriormente.

- Coeficiente de amadurecimento $\chi=0,8$. Para maiores esclarecimentos sobre o coeficiente de envelhecimento, ver equação (5.8-3) do CEB-FIP (1990).

O fator de correção $\eta$ representa o efeito da fissuração como uma função do nível de carregamento $\left(M_{r d} / M_{d}\right)$ e da quantidade de armadura tracionada $(\rho)$. Se $\left(M_{r d} / M_{d}\right) \cong 0$, isto é, $M_{d}$ é muito maior que $M_{r d}$ ou $M_{r d} \cong 0$, $\eta$ é máximo. Por outro lado, se $\left(M_{r d} / M_{d}\right) \cong 1$, ou seja, imediatamente após a fissuração da estrutura, $\eta$ é mínimo.

$\rho^{\prime}$ na equação (5.31) representa o efeito benéfico da armadura comprimida. Contudo, para $\rho^{\prime} \leq 0,5 \%$, sua influência nos deslocamentos parece de pouca importância. Como já mencionado, a expressão (5.31) foi estabelecida para $\varphi=2,5$. 


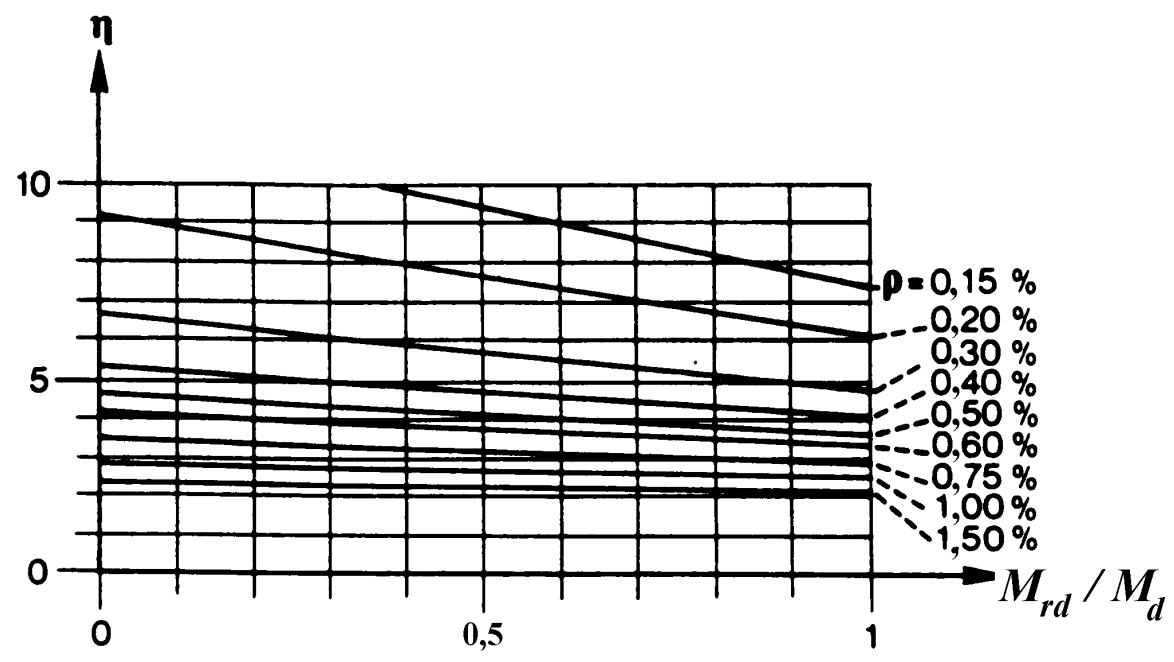

FIGURA 5.9 - Fator de correção $\eta$ contra $\boldsymbol{M}_{\boldsymbol{r d}} / \boldsymbol{M}_{\boldsymbol{d}}$

FONTE: CHARIF \& FAVRE (1994)

Pode-se observar na figura 5.9 que, para seções com normais ou altas taxas de armadura, o fator $\eta$ não depende muito da relação $\left(M_{r d} / M_{d}\right)$. Assim, como uma boa aproximação e uma grande simplificação do fator $\eta$, os valores de $\eta$ para $\left(M_{r d} / M_{d}\right)=0,5$ podem ser adotados para todas as seções ( $\eta$ passa a ser então, independente do carregamento). Estes valores têm sido adotados pelo CÓDIGO MODELO CEB-FIP (1990) e são apresentados na tabela 5.2.

TABELA 5.2 - Fator $\eta$ (concretos usuais) para estimativa dos deslocamentos pela equação (5.31)

FONTE: CÓDIGO MODELO CEB-FIP (1990)

\begin{tabular}{|c|c|c|c|c|c|c|c|}
\hline$\rho_{m}$ & $0,15 \%$ & $0,20 \%$ & $0,30 \%$ & $0,50 \%$ & $0,75 \%$ & $1,00 \%$ & $1,50 \%$ \\
\hline$\eta$ & 10 & 8 & 6 & 4 & 3 & 2,5 & 2 \\
\hline
\end{tabular}

Portanto, a estimativa do provável deslocamento se reduz ao seguinte (figura 5.10): 


$$
\begin{array}{ll}
a=a_{c}(1+\varphi) & \text { para } M_{d}<M_{r d} \\
a=a_{c}(h / d)^{3} \eta\left(1-20 \rho_{m}^{\prime}\right) & \text { para } M_{d}>M_{r d}
\end{array}
$$

onde:

$a_{c}$ flecha elástica calculada com rigidez $E_{c} I_{g}$ da seção bruta (desprezando-se as armaduras)

$\rho_{m}^{\prime} \quad$ taxa média de armadura longitudinal comprimida

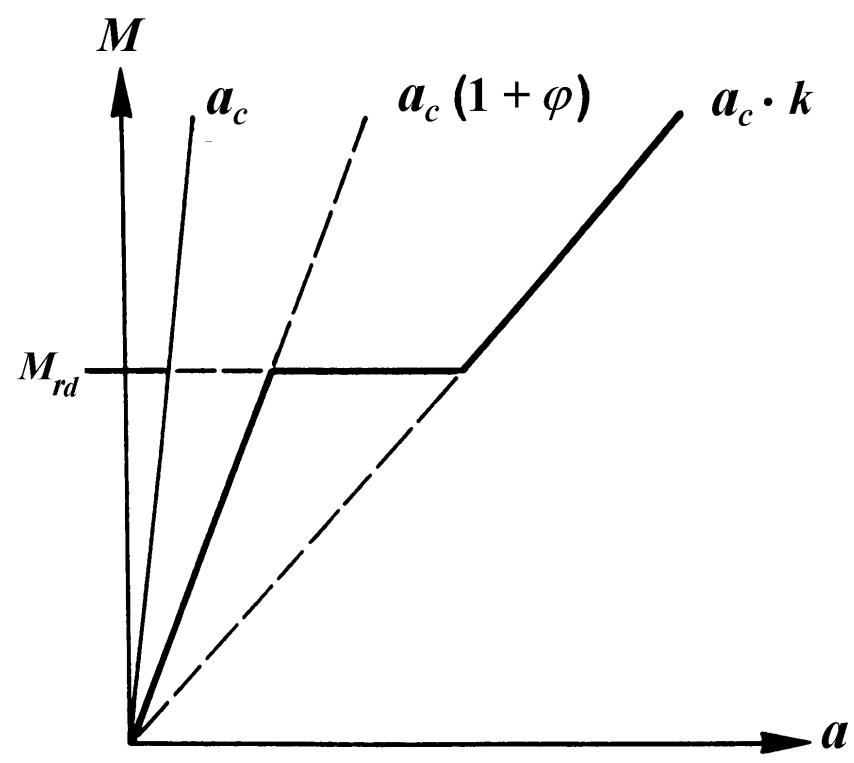

FIGURA 5.10 - Diagrama momento-deslocamento simplificado

FONTE: CHARIF \& FAVRE (1994)

Assumindo-se que se tem uma laje com $h=240 \mathrm{~mm}, d=20 \mathrm{~mm}, \rho_{m}=0,5 \%$ e $\rho_{m}^{\prime}=0$, pode-se calcular o fator de majoração da deformação elástica instantânea:

$$
a=a_{c}\left(\frac{240}{200}\right)^{3} \times 4 \times(1-0)=6,9 a_{c}
$$

Os efeitos da retração e da fluência nos deslocamentos podem ser calculados usando-se a figura 5.11 obtida a partir dos trabalhos de TELLENBACH (1985). 


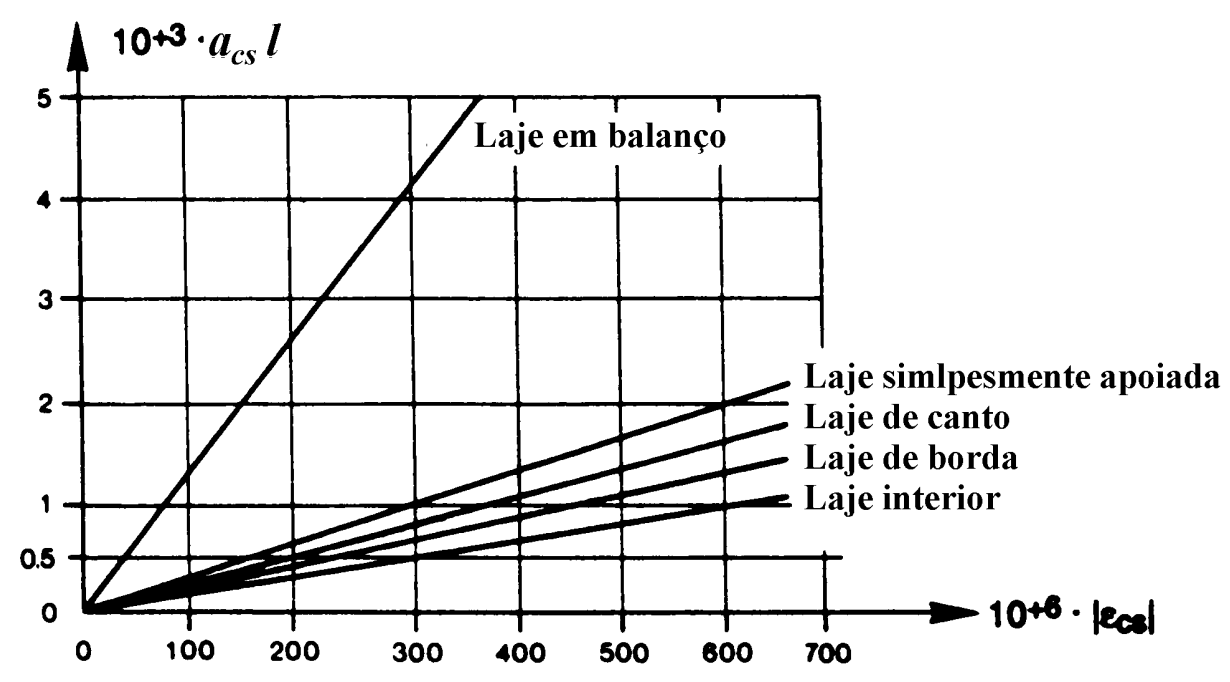

FIGURA 5.11 - Deslocamento de lajes devido apenas à retração

A figura 5.11 fornece o aumento do deslocamento devido à retração $\left(a_{c s}\right)$ a ser calculado diretamente como uma função da retração do concreto $\left(\varepsilon_{\mathrm{cs}}\right)$ e do comprimento do vão $(l)$.

O método simplificado dos coeficientes globais pode ser melhorado consideravelmente se os dois parâmetros seguintes são incorporados ao modelo: distribuição da armadura e evolução da fissuração.

Para se levar em consideração a distribuição da armadura, um valor médio de $\rho$ pode ser calculado em relação ao diagrama de momento fletor (figura 5.12).

Isto resulta em uma taxa média de armadura para o elemento $\rho_{m}$ :

$$
\rho_{m}=\rho_{a} \frac{l_{a}}{l}+\rho_{0} \frac{l_{0}}{l}+\rho_{b} \frac{l_{b}}{l}
$$

onde:

$\rho_{a}, \rho_{b} \quad$ armadura tracionada nos apoios (armadura superior)

$\rho_{0} \quad$ armadura tracionada no meio do vão (armadura inferior) 


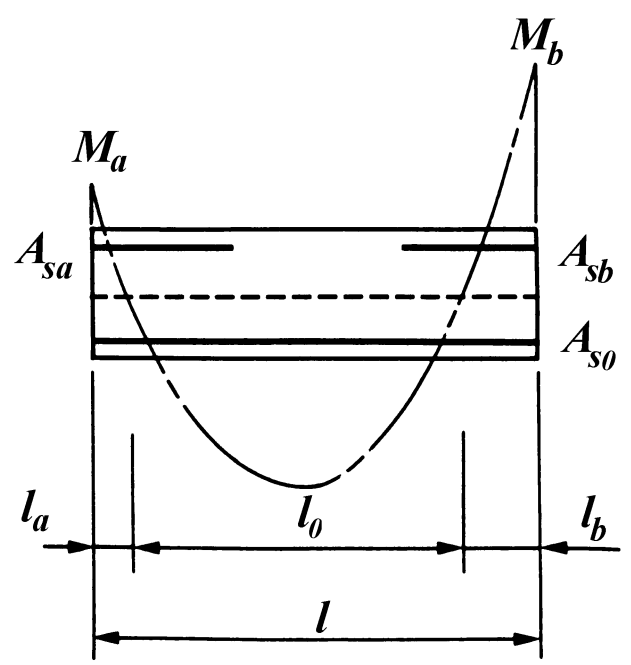

FIGURA 5.12 - Definição de $l_{a}, l_{b}$ e $l_{0}$ através do diagrama de momento fletor FONTE: $C E B-F I P(1990)$

Uma estimativa dos comprimentos $l_{a}$ e $l_{b}$ normalmente é suficiente. $\mathrm{O}$ mesmo cálculo também é válido para a taxa média de armadura de compressão $\rho_{m}^{\prime}$.

Para se levar em consideração a evolução da fissuração de um elemento (figuras 5.10 e 5.13), os dois níveis de carregamento $q_{r 1}$ e $q_{r 2}$ são calculados, onde:

$q_{r 1} \quad$ nível do carregamento que corresponde à formação da primeira fissura no elemento (normalmente sobre o apoio)

$q_{r 2} \quad$ nível do carregamento que corresponde à formação da primeira fissura na seção crítica

Os dois níveis de carregamento $q_{r 1}$ e $q_{r 2}$ definem o estado de fissuração das seções mencionadas anteriormente. Valores de deslocamentos entre esses dois níveis de carregamento podem ser determinados por interpolação linear. 


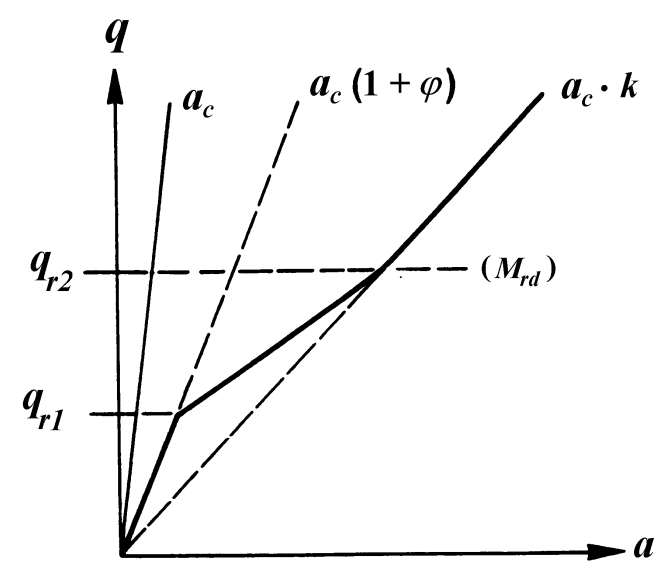

FIGURA 5.13 - Diagrama carregamento-deslocamento simplificado (trilinear)

FONTE: CHARIF \& FAVRE (1994)

\subsection{MÉTODO DOS COEFICIENTES GLOBAIS APLICADO AO CAD}

O método dos coeficientes globais foi desenvolvido e aferido para concretos usuais. Contudo, através de modificações do fator de correção $\eta$, pode-se aplicá-lo ao CAD.

O CEB-197 (1990) estabelece que os valores de $\eta$ dados na tabela 5.2 podem ser modificados, gerando novos fatores $\left(\eta_{C A D}\right)$, da seguinte forma:

$$
\eta_{C A D}(\varphi, \eta)=\frac{5+\varphi}{7,5} \eta
$$

$\eta_{C A D}$ será, portanto, o valor a ser utilizado no método dos coeficientes globais para estimativa dos deslocamentos em elementos de CAD.

TABELA 5.3 - Fator $\eta_{C A D}, \operatorname{com} \varphi=1,8$, para uso da equação (5.31)

\begin{tabular}{|c|c|c|c|c|c|c|c|}
\hline$\rho_{m}$ & $0,15 \%$ & $0,20 \%$ & $0,30 \%$ & $0,50 \%$ & $0,75 \%$ & $1,00 \%$ & $1,50 \%$ \\
\hline$\eta_{C A D}$ & 9,1 & 7,3 & 5,4 & 3,6 & 2,7 & 2,3 & 1,8 \\
\hline
\end{tabular}




\subsection{EXEMPLOS DE APLICAÇÃO}

EXEMPLO 5.1 $-f_{c k}=70 \mathrm{MPa}$

Considere-se a viga protendida apresentada no item 2.4 .

\section{Materiais:}

Concreto: densidade normal; cimento ARI

Armadura ativa: $E_{p}=195 G P a$

Armadura passiva: $E_{s}=210 G P a$

\section{Propriedades geométricas da seção real:}

$$
\begin{aligned}
& A_{c}=0,66 m^{2} ; I_{g}=0,0815 m^{4} ; y_{\text {inf }}=0,815 m ; y_{\text {sup }}=0,385 m \\
& w_{\text {inf }}=0,100 m^{4} ; w_{\text {sup }}=0,217 \mathrm{~m}^{4}
\end{aligned}
$$

\section{Dados:}

$$
\begin{aligned}
& l=30,0 \mathrm{~m} ; f_{c k}=70 \mathrm{MPa} ; A_{p}=3948 \mathrm{~mm}^{2} ; A_{s}=1000 \mathrm{~mm}^{2} \\
& g=23,0 \mathrm{kN} / \mathrm{m} ; q=19,5 \mathrm{kN} / \mathrm{m} \\
& \text { Excentricidade no apoio: } e_{2}=0 \\
& \text { Excentricidade em x }=15,0 \mathrm{~m}: e_{1}=551,2 \mathrm{~mm} \\
& \text { Em x }=15,0 \mathrm{~m}: P_{e}=4200 \mathrm{kN} ; P_{i}=5330 \mathrm{kN}
\end{aligned}
$$

Aplicação da protensão: 4 dias após a concretagem Aplicação da carga acidental (q): 28 dias

\section{Solução}

\section{(a) Cálculos iniciais}

Módulo de deformação longitudinal do concreto: 


$$
E_{c, t}=3500+4300 \sqrt{f_{c m, t}^{\prime}}
$$

Com base na resistência do concreto na data da protensão ( $t=4$ dias), pode-se calcular o módulo de deformação longitudinal do concreto:

$$
\begin{aligned}
& E_{c, 4}=3500+4300 \sqrt{61,25} \\
& E_{c, 4}=37,15 \times 10^{3} \mathrm{MPa} \\
& E_{c, 4}=37,15 \mathrm{GPa}
\end{aligned}
$$

Módulo de deformação longitudinal do concreto aos 28 dias:

$$
E_{c, 28}=41,47 G P a
$$

Assim, tem-se:

$$
\begin{aligned}
& \alpha_{p}=E_{p} / E_{c, 28}=4,702 \\
& \alpha_{s}=E_{s} / E_{c, 28}=5,064
\end{aligned}
$$

Para o estado limite de deformação excessiva, será adotada a combinação quase permanente de utilização da NBR 8681 (1984) :

$$
F_{d, q p}=23,0+0,2 \times 19,5=26,9 \mathrm{kN} / \mathrm{m}
$$

\section{$\rightarrow$ Na aplicação da protensão}

Admitindo-se que toda a carga permanente atue na aplicação da protensão, tem-se para o momento devido à carga permanente no meio do vão:

$$
M_{g}=\frac{23,0 \times 30^{2}}{8}=2588 \mathrm{kN} . \mathrm{m}
$$

Momento de fissuração no meio do vão na aplicação da protensão: 


$$
\begin{aligned}
& M_{r}=P_{i} \times\left(e+\frac{w_{\mathrm{inf}}}{A_{c}}\right)+f_{t} w_{\mathrm{inf}} \\
& M_{r}=5330 \times 10^{3} \times\left(0,7+\frac{0,1}{0,66}\right)+5,5 \times 10^{6} \times 0,1 \\
& M_{r}=5088 \mathrm{kN} . m
\end{aligned}
$$

Como o momento de fissuração $M_{r}=5088 \mathrm{kN} . \mathrm{m}$ é maior que $M_{g}=2588 \mathrm{kN} . m$, a viga não fissura na aplicação da protensão.

\section{$\rightarrow$ Em serviço}

Momento devido à carga acidental no meio do vão, para a combinação quase permanente:

$$
0,2 M_{q}=0,2 \times \frac{19,5 \times 30^{2}}{8}=439 k N . m
$$

Momento de fissuração no meio do vão em serviço:

$$
\begin{aligned}
& M_{r}=P_{e} \times\left(e+\frac{w_{\mathrm{inf}}}{A_{c}}\right)+f_{t} w_{\mathrm{inf}} \\
& M_{r}=4200 \times 10^{3} \times\left(0,7+\frac{0,1}{0,66}\right)+5,5 \times 10^{6} \times 0,1 \\
& M_{r}=4126 \mathrm{kN} . \mathrm{m}
\end{aligned}
$$

Como o momento de fissuração $M_{r}=4126 k N . m$ é maior que $0,2 M_{q}+M_{g}=3027 k N . m$, a viga não fissura em serviço.

(b) Viga não fissurada. Será calculado o deslocamento imediato na aplicação da protensão $\left(a_{\mathrm{i}}\right)$.

Para $\left(a_{\mathrm{i}}\right)$, serão considerados a força inicial de protensão $\left(P_{i}\right)$ e o módulo de deformação longitudinal do concreto para a idade de 4 dias, admitindo-se que as 
cargas permanentes $(g)$ atuam assim que a força de protensão é aplicada. Usando-se as equações da figura (5. 1) tem-se:

$$
\begin{aligned}
& a_{i}=\frac{-P_{i} l^{2}}{8 E_{c, 4 \text { dias }} I_{g}}\left[e_{2}+\frac{5}{6}\left(e_{1}-e_{2}\right)\right]+\frac{5 g l^{4}}{384 E_{c, 4 \text { dias }} I_{g}} \\
& a_{i}=\frac{-\left(5330 \times 10^{3}\right) \times 30,0^{2}}{8 \times\left(37,15 \times 10^{9}\right) \times 81,7 \times 10^{-3}}\left[\frac{5}{6} \times 0,7\right]+\frac{5 \times\left(23 \times 10^{3}\right) \times 30^{4}}{384 \times\left(37,15 \times 10^{9}\right) \times 81,7 \times 10^{-3}} \\
& a_{i}=-11,52 \times 10^{-2}+1,99 \times 10^{-2}=-3,53 \times 10^{-2} \mathrm{~m}
\end{aligned}
$$

Portanto, na aplicação da protensão, espera-se uma contraflecha de $3,53 \mathrm{~cm}$.

Para o deslocamento em serviço, serão utilizados os valores de $P_{e}$ e $E_{c}$. Os carregamento será:

$$
w_{g}+0,2 w_{q}=26,9 k N / m
$$

Logo,

$$
\begin{aligned}
& a_{i}=\frac{-P_{i} l^{2}}{8 E_{c} I_{g}}\left[e_{2}+\frac{5}{6}\left(e_{1}-e_{2}\right)\right]+\frac{5 g l^{4}}{384 E_{c} I_{g}} \\
& a_{i}=\frac{-\left(4200 \times 10^{3}\right) \times 30,0^{2}}{8 \times\left(41,47 \times 10^{9}\right) \times 81,7 \times 10^{-3}}\left[\frac{5}{6} \times 0,7\right]+\frac{5 \times\left(26,9 \times 10^{3}\right) \times 30^{4}}{384 \times\left(41,47 \times 10^{9}\right) \times 81,7 \times 10^{-3}} \\
& a_{i}=-8,1 \times 10^{-2}+8,37 \times 10^{-2}=2,4 \times 10^{-3} \mathrm{~m}
\end{aligned}
$$

Portanto, em serviço, espera-se uma flecha de $2,4 \mathrm{~mm}$.

(c) Deslocamentos adicionais. Uma vez que os deslocamentos adicionais (e totais) tendem assintoticamente a um valor máximo, que é atingido entre 2 e 3 anos, o deslocamento adicional será calculado para 2 anos através da equação (5.11).

Cálculos iniciais:

$$
\begin{aligned}
& k_{P}=P_{e} / P_{i}=0,83 ; E_{c i} / E_{c}=37,15 / 41,47=0,9 \\
& k_{r}=\left(1+A_{s} / A_{p}\right)^{-1}=0,373
\end{aligned}
$$


$V / S=A_{c} / p=0,3548 / 4,2672=83,1 \times 10^{-3} \mathrm{~m}=83,1 \mathrm{~mm}$

O coeficiente de fluência foi calculado no item 2.4 para um período de 5 $\operatorname{anos}(\varphi=2,09)$.

O deslocamento adicional ao final deste período será dado por (5.11):

$$
\begin{aligned}
a_{\text {add }} & =k_{p} \frac{E_{c i}}{E_{c}} k_{r} \varphi a_{i} \\
a_{\text {add }} & =0,788 \times 0,896 \times 0,798 \times 2,09 \times a_{i} \\
a_{\text {add }} & =1,178 \times 2,41 \\
a_{\text {add }} & =2,83 \mathrm{~mm}
\end{aligned}
$$

O deslocamento total em cinco anos será dado por:

$$
a_{\text {tot }}=a_{i}+a_{\text {add }}=2,4+2,83=5,2 \mathrm{~mm}
$$

EXEMPLO $5.2-f_{c k}=70 M P a$

Idêntico ao exemplo 5.1, porém com $P_{i}=3300 \mathrm{kN} . \mathrm{m}$ e $P_{e}=2600 \mathrm{kN} . \mathrm{m}$ (perdas diferidas mantidas iguais a 21\%). Através deste exemplo, será possível aplicar a metodologia para o caso de viga fissurada.

\section{Solução}

Momento de fissuração no meio do vão na aplicação da protensão:

$$
\begin{aligned}
& M_{r}=P_{i} \times\left(e+\frac{w_{\mathrm{inf}}}{A_{c}}\right)+f_{t} w_{\mathrm{inf}} \\
& M_{r}=3300 \times 10^{3} \times\left(0,7+\frac{0,1}{0,66}\right)+5,5 \times 10^{6} \times 0,1 \\
& M_{r}=3360 \mathrm{kN} . \mathrm{m}
\end{aligned}
$$

Como o momento de fissuração $M_{r}=3360 \mathrm{kN} . \mathrm{m}$ é maior $M_{g}=2588 \mathrm{kN} . \mathrm{m}$, a viga não fissura na aplicação da protensão, e a metodologia permanece a mesma. 


\section{$\rightarrow$ Em serviço}

Momento de fissuração no meio do vão em serviço:

$$
\begin{aligned}
& M_{r}=P_{e} \times\left(e+\frac{w_{\mathrm{inf}}}{A_{c}}\right)+f_{t} w_{\mathrm{inf}} \\
& M_{r}=2600 \times 10^{3} \times\left(0,7+\frac{0,1}{0,66}\right)+5,5 \times 10^{6} \times 0,1 \\
& M_{r}=2764 k N . m
\end{aligned}
$$

Como o momento de fissuração $M_{r}=2764 k N . m$ é menor que o momento para a combinação quase permanente $(3027 \mathrm{kN} . \mathrm{m})$, a viga fissura em serviço, e é necessário calcular-se o momento de inércia equivalente $\left(I_{e}\right)$.

\section{(a) Deslocamento inicial (viga fissurada)}

Para a combinação quase permanente das ações chega-se, a partir das equações de equilíbrio e compatibilidade, à posição da linha neutra $(x=0,462 m)$ e à correspondente tensão na fibra extrema mais comprimida $(11,38 M P a)$.

É necessário calcular o momento de inércia da seção fissurada $\left(I_{r}\right)$ para se chegar ao momento de inércia equivalente $\left(I_{e}\right)$. O momento de inércia da seção fissurada $\left(I_{r}\right)$ será calculado pela expressão (5.5) na qual o momento $M$ inclui a combinação quase permanente e o momento devido à força de protensão em relação ao C.G. da seção fissurada. A posição do C.G. da seção fissurada $(\bar{y})$ é dada pela equação (5.6). Assim, pode-se facilmente demonstrar que $\bar{y}=0,206 m$.

Momento da força de protensão:

$$
\begin{aligned}
& M_{P_{e}}=-P_{e}\left(d_{p}-\bar{y}\right) \\
& M_{P_{e}}=-2600 \times 10^{3} \times(1,084-0,206)=-2282,8 \mathrm{kN} . \mathrm{m}
\end{aligned}
$$

Momento total: 


$$
M_{\text {tot }}=3027-2282,8=744,2 \mathrm{kN} . \mathrm{m}
$$

Momento de inércia da seção fissurada:

$$
I_{r}=\frac{M_{t o t} x}{\sigma_{c, \max }}=\frac{744,2 \times 10^{3} \times 0,462}{11,38 \times 10^{6}}=0,0302 \mathrm{~m}^{4}
$$

Momento de descompressão:

$$
\begin{aligned}
& M_{r}=P_{e} \times\left(e+\frac{w_{\mathrm{inf}}}{A_{c}}\right) \\
& M_{r}=2600 \times 10^{3} \times\left(0,7+\frac{0,1}{0,66}\right)=2214 \mathrm{kN} . m
\end{aligned}
$$

Momento de inércia equivalente:

$$
\begin{aligned}
& I_{e}=I_{r}+\left(\frac{M_{r}-M_{0}}{M_{\max }-M_{0}}\right)^{3}\left(I_{g}-I_{r}\right) \\
& I_{e}=0,0302+\left(\frac{2214-2214}{3027-2214}\right)^{3}(0,0815-0,0302) \\
& I_{e}=0,0459 m^{4}
\end{aligned}
$$

Portanto, o momento de inércia equivalente $\left(I_{e}\right)$ é igual a $56 \%$ do momento de inércia da seção de concreto $\left(I_{g}=0,0817 m^{4}\right)$, e corresponde a $1,52 I_{r}$.

Deslocamento imediato no meio do vão, seção fissurada:

$$
\begin{aligned}
& a_{i}=\frac{-P_{e} l^{2}}{8 E_{c} I_{e}}\left[e_{2}+\frac{5}{6}\left(e_{1}-e_{2}\right)\right]+\frac{5 \times(0,2 q+g) \times l^{4}}{384 E_{c} I_{g}} \\
& a_{i}=\frac{-\left(2600 \times 10^{3}\right) \times 30,0^{2}}{8 \times\left(41,47 \times 10^{9}\right) \times 0,0459}\left[\frac{5}{6} \times 0,7\right]+\frac{5 \times\left(26,9 \times 10^{3}\right) \times 30^{4}}{384 \times\left(41,47 \times 10^{9}\right) \times 0,0459} \\
& a_{i}=-0,0896+0,149=5,94 \times 10^{-2} \mathrm{~m}
\end{aligned}
$$

Assim, espera-se uma flecha imediata de $5,94 \mathrm{~cm}$ para a combinação quase-permanente das ações. 
(b) Deslocamento adicional. Como no exercício anterior, o deslocamento adicional será calculado para 5 anos através da equação (5.11).

O deslocamento adicional ao final de 5 anos será dado por (5.11):

$$
\begin{aligned}
a_{\text {add }} & =k_{p} \frac{E_{c i}}{E_{c}} k_{r} \varphi a_{i} \\
a_{\text {add }} & =0,788 \times 0,896 \times 0,798 \times 2,09 \times a_{i} \\
a_{\text {add }} & =1,178 \times 5,94 \\
a_{\text {add }} & =6,99 \mathrm{~cm}
\end{aligned}
$$

O deslocamento total em cinco anos será dado por:

$$
a_{\text {tot }}=a_{i}+a_{\text {add }}=5,94+6,99 \cong 13 \mathrm{~cm}
$$

Como se pode observar, este deslocamento final é consideravelmente maior que o do exercício anterior, em função da fissuração da seção. 


\section{DUCTILIDADE}

O CAD é um material mais frágil que o concreto de resistência usual. Como resultado, surgiram dúvidas quanto à ductilidade de elementos fletidos feitos de CAD.

ATTARD \& MENDIS (1993) apontam as superfícies de ruptura lisas e a falta de engrenamento dos agregados como razões para a natureza frágil do CAD.

Neste capítulo serão abordadas a ductilidade na flexão e no cisalhamento das vigas de $\mathrm{CAD}$.

\subsection{DUCTILIDADE NA FLEXÃO}

A deformabilidade de elementos de concreto submetidos à flexão depende de um grande número de fatores, incluindo a taxa de armadura longitudinal tracionada, a quantidade de armadura longitudinal de compressão, a quantidade de armadura de pele e a resistência do concreto.

MENDIS et al. (1996) avaliaram a ductilidade de elementos fletidos de CAD através de alguns parâmetros, dentre eles: inclinações de relaxamento (softening slopes) e capacidade de rotação das rótulas plásticas. Estes parâmetros foram comparados com outros similares para concretos de resistência usual, como se verá ao longo deste capítulo.

O comportamento de elementos submetidos à flexão pode ser idealizado como um diagrama momento-curvatura trilinear, como mostrado na figura 6.1, constituído de um trecho elástico, outro plástico, e finalmente o trecho de relaxamento. 


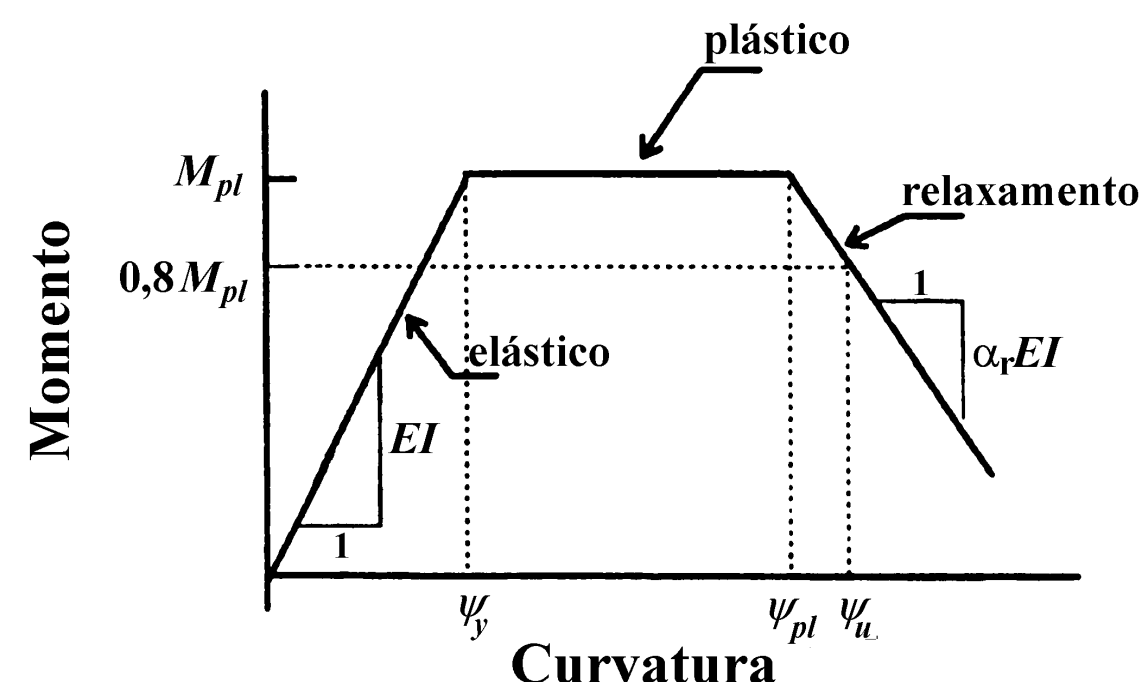

FIGURA 6.1 - Relação momento-curvatura trilinear

Fonte: MENDIS et al. (1996)

Como se pode observar na figura 6.1, quanto maior o parâmetro de inclinação de relaxamento $\left(\alpha_{r}\right)$, mais íngreme é o trecho de relaxamento.

A abordagem tradicional para a ductilidade na flexão tem sido desconsiderar o trecho de relaxamento da curva momento-curvatura $(M \times \psi)$. O trecho inelástico tem sido limitado apenas à parte plástica. Conseqüentemente, a ductilidade de um elemento submetido à flexão tem sido quantificada por:

$$
k_{\psi}=\frac{\psi_{p l}}{\psi_{y}}
$$

onde:

$$
\begin{array}{ll}
\psi_{p l} & \text { curvatura plástica } \\
\psi_{y} & \text { curvatura no escoamento }
\end{array}
$$

Tem sido mostrado que as estruturas podem continuar a absorver carregamentos adicionais, mesmo após algumas das rótulas plásticas nos elementos atingirem o trecho de relaxamento. A estrutura entra em colapso quando se forma um 
mecanismo. Para se computar o aumento da ductilidade devido ao relaxamento, a ductilidade de relaxamento foi redefinida como:

$$
k_{\psi}=\frac{\psi_{u}}{\psi_{y}}
$$

$\psi_{u}$ é a curvatura correspondente a um momento igual a $0,8 M_{p l}$.

GHOSH et al. (1989) sugerem que a ductilidade deveria ser considerada em deslocamentos correspondentes a $80 \%$ do carregamento último. Quando o relaxamento é desconsiderado, $\psi_{u}=\psi_{p l}$.

A ductilidade como definida na equação (6.1) pode ser chamada de ductilidade plástica de flexão, ou simplesmente ductilidade plástica. A ductilidade como definida pela equação (6.2) pode ser chamada de ductilidade de relaxamento de flexão, ou simplesmente, ductilidade de relaxamento. As considerações da ductilidade de relaxamento tornam-se importantes em projetos de estruturas submetidas a sismos e em projetos onde grandes deformações são esperadas. Em tais situações, algumas rótulas plásticas irão até o trecho de relaxamento, enquanto que outras ainda estarão em regime elastoplástico.

Extensivos testes têm sido feitos para investigar a ductilidade plástica e a de relaxamento em elementos de concreto de resistência usual, com a conclusão de que ductilidade de flexão adequada pode ser ativada através de uma cuidadosa distribuição proporcional de armaduras longitudinal e transversal.

A figura (6.2) mostra uma curva momento-curvatura típica de vigas de CAD. $\mathrm{Na}$ mesma figura, estão as curvas de vigas de resistências usuais, equivalentes àquelas.

A tabela (6.1) mostra uma comparação feita por MENDIS et al. (1996) entre os parâmetros de inclinação de relaxamento $\left(\alpha_{r}\right)$ para os concretos de alto desempenho e para os de resistências usuais. Como se pode observar na figura (6.2) e na tabela 6.1, elementos de CAD exibem inclinações de relaxamento mais íngremes, e as inclinações de relaxamento em elementos de CAD são comparáveis à inclinação crítica de relaxamento $\left(\alpha_{c r}\right)$ em estruturas. 


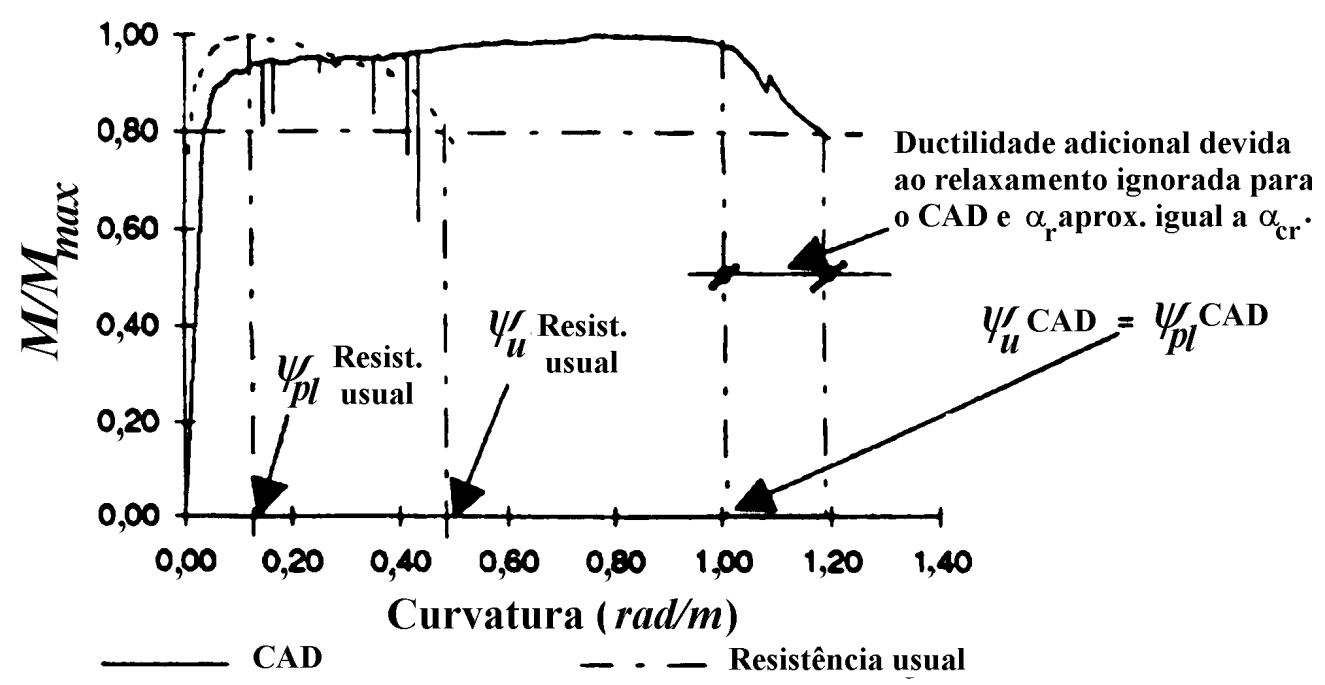

FIGURA 6.2 - Curvas momento-curvatura de vigas de CAD e de resistências usuais FONTE: MENDIS et al. (1996)

TABELA 6.1 -Inclinações de relaxamento: resistências usuais e CAD FONTE: MENDIS et al. (1996)

\begin{tabular}{|l|c|c|}
\cline { 2 - 3 } \multicolumn{1}{c|}{} & \multicolumn{2}{c|}{ Parâmetro de inclinação de relaxamento $\left(\alpha_{r}\right)$} \\
\hline Elemento & CAD & Resistência Usual \\
\hline A3-2/50 & $-0,02$ & + \\
\hline A3-2/75 & $-0,05$ & $-0,0035$ \\
\hline A4-2/50 & $-0,07$ & $-0,0084$ \\
\hline A4-2/75 & $-0,05$ & $-0,0095$ \\
\hline A4-2/150 & + & $-0,0181$ \\
\hline A4-3/150 & $-0,07$ & $-0,0092$ \\
\hline B4-2/75 & $-0,06$ & + \\
\hline A4-0/75 & $-0,01$ & + \\
\hline A4-2/30 & + & $-0,0043$ \\
\hline C4-2/75 & $-0,07$ & $-0,0026$ \\
\hline D4-2/75 & $-0,08$ & $-0,0052$ \\
\hline
\end{tabular}

${ }^{+}$Dado não disponível

A inclinação crítica de relaxamento em estruturas $\left(\alpha_{c r}\right)$ é definida como a rigidez negativa do ramo descendente do diagrama momento-curvatura, na qual a estrutura como um todo não pode mais sustentar um aumento de carregamento. 
Assim, o relaxamento não provê uma ductilidade adicional aos elementos de CAD como o faz para os elementos de resistência usual. Por isso, para membros feitos com CAD, $\psi_{u}=\psi_{p l}$ como mostrado na figura 6.2. MENDIS et al. (1996) observaram que:

- Aumentar o confinamento tende a diminuir a inclinação de relaxamento.

- Um aumento no valor da diferença percentual entre a armadura de tração e a armadura de compressão $\left(\rho_{\text {dif\% }}\right)$ provoca um aumento na inclinação de relaxamento.

Estas observações também são válidas para os concretos de resistência usual.

A diferença percentual entre a armadura de tração e a armadura de compressão $\left(\rho_{\text {dif\% }}\right)$ é dada por:

$$
\rho_{d i f}=\frac{A_{s}-A_{s}^{\prime}}{b d} \times 100
$$

A tabela 6.2 mostra uma comparação feita por MENDIS et al. (1996) entre as capacidades de rotação das rótulas plásticas. A comparação é feita com e sem a inclusão do relaxamento.

Na tabela 6.2 e na figura 6.2 pode-se observar que, embora as capacidades de rotação e índices de ductilidade sejam maiores para elementos de CAD, as capacidades totais de rotação e índices de ductilidade incluindo-se o relaxamento são comparáveis para concretos de alta resistência e para concretos de resistência usual.

Outras observações com relação à capacidade de rotação:

- Aumentando-se a quantidade de armadura de tração, diminui-se a capacidade de rotação dos elementos.

- Menor confinamento do núcleo de concreto diminui a capacidade de rotação do elemento. A ductilidade do CAD é menos sensível ao confinamento que nos concretos de resistência usual, em função da menor variação de volume exibida pelas estruturas de CAD. 
- Menores vãos de cisalhamento (a) ou maiores forças de cisalhamento diminuem a capacidade de rotação do elemento. $\mathrm{O}$ vão de cisalhamento é definido como a distância entre o ponto de aplicação da carga concentrada e a face do apoio.

- Diminuindo-se a inclinação de relaxamento aumenta-se a capacidade total de rotação do elemento.

TABELA 6.2 - Capacidades de rotações inelásticas e índices de ductilidade

FONTE: MENDIS (1996)

\begin{tabular}{|l|c|c|c|c|c|c|c|c|}
\cline { 2 - 10 } \multicolumn{1}{c|}{} & $\begin{array}{c}\text { Capacidade } \\
\text { de rotação } \\
\text { plástica } \\
\text { (radiano) }\end{array}$ & $\begin{array}{c}\text { Capacidade } \\
\text { de rotação de } \\
\text { relaxamento } \\
\text { (radiano) }\end{array}$ & \multicolumn{2}{c|}{$\begin{array}{c}\text { Índice de } \\
\text { ductilidade } \\
\text { plástica }\end{array}$} & \multicolumn{2}{c|}{$\begin{array}{c}\text { Índice de } \\
\text { ductilidade de } \\
\text { relaxamento }\end{array}$} \\
\hline Viga & CAD & $\begin{array}{c}\text { Resist. } \\
\text { usual }\end{array}$ & CAD & $\begin{array}{c}\text { Resist. } \\
\text { usual }\end{array}$ & CAD & $\begin{array}{c}\text { Resist. } \\
\text { usual }\end{array}$ & CAD & $\begin{array}{c}\text { Resist. } \\
\text { usual }\end{array}$ \\
\hline A3-2/50 & 0,07 & + & 0,09 & + & 33 & + & 39 & + \\
\hline A3-2/75 & 0,06 & 0,08 & 0,07 & 0,03 & 25 & 4 & 31 & 10 \\
\hline A4-2/50 & 0,03 & 0,09 & 0,04 & 0,04 & 12 & 4 & 14 & 13 \\
\hline A4-2/75 & 0,03 & 0,03 & 0,04 & 0,02 & 13 & 4 & 16 & 21 \\
\hline A4-2/150 & + & 0,09 & + & 0,03 & + & 3 & + & 8 \\
\hline A4-3/150 & 0,01 & 0,01 & 0,02 & 0,04 & 5 & 3 & 7 & 9 \\
\hline B4-2/75 & 0,02 & + & 0,03 & + & 7 & + & 10 & + \\
\hline A4-0/75 & 0,01 & + & 0,02 & + & 6 & + & 8 & + \\
\hline A4-2/30 & 0,09 & 0,01 & 0,011 & 0,07 & 32 & 4 & 41 & 18 \\
\hline C4-2/75 & 0,16 & 0,03 & 0,019 & 0,1 & 8 & 13 & 10 & 61 \\
\hline D4-2/75 & 0,15 & 0,004 & 0,017 & 0,09 & 17 & 2 & 20 & 19 \\
\hline
\end{tabular}

${ }^{+}$Dado não disponível

\subsection{CONCLUSÕES SOBRE DUCTILIDADE NA FLEXÃO}

O trabalho de MENDIS et al. (1996) conclui que elementos estruturais de CAD exibem tendências similares quando comparados aos de concreto de resistência usual, e que, a despeito de ser o CAD um material mais frágil, elementos de CAD exibem maior ductilidade.

Além disso, conclui que: 
- Embora elementos de CAD apresentem inclinações mais íngremes em testes de compressão, elementos de CAD submetidos à flexão apresentam uma maior ductilidade plástica quando comparados aos de concretos de resistência usual, mas podem exibir ductilidade comparável à destes últimos se o relaxamento é levado em consideração.

- A inclinação de relaxamento de elementos de CAD pode ser maior que a inclinação crítica de relaxamento em estruturas.

- Os resultados confirmam as conclusões de GHOSH et al. (1989) de que a ductilidade de elementos feitos de CAD não é menor.

- Dos testes de elementos de concretos de resistências usual e alta, pode-se concluir que a ductilidade tanto destes como daqueles mostram qualitativamente tendências similares no que se refere às quantidades relativas de armadura comprimida e tracionada, armadura de confinamento do núcleo de concreto e relação de vão de cisalhamento $(a)$.

Portanto, a exemplo do que acontece com as vigas de resistências usuais, o que determina a ductilidade na ruína das vigas de CAD é o detalhamento adequado da armadura.

\subsection{DUCTILIDADE NO CISALHAMENTO}

É bem reconhecido que a ruína por tração diagonal (cisalhamento) é brusca e de natureza frágil. Tem sido salientado por um grande número de pesquisadores que a metodologia de teste influencia o modo de ruína do concreto. Por exemplo, o modo de ruptura do concreto sob tensões de compressão muda de um tipo de ruína não controlada e frágil quando testado sob condições de carregamento controlado, para um tipo de ruína controlada quando testado sob condições de deformação controlada.

Segundo AHMAD et al. (1994), vigas que se rompem por cisalhamento exibem um estável e reprodutível ramo após a tensão máxima da curva de deslocamento do carregamento no meio do vão. 
Em vigas com ruína por cisalhamento, o estado de tensão é biaxial, combinando compressão diagonal na direção do ponto de carregamento para o apoio com tração diagonal na direção perpendicular àquela. Fissuras de tração diagonal formadas em vigas de CAD têm sido relatadas como apresentando superfícies relativamente lisas. Testes confirmam que o engrenamento dos agregados diminui com o aumento da resistência.

Deste modo, algumas formulações para cálculo da contribuição do "concreto" $\left(V_{c}\right)$ válidas para concretos usuais, como a proposta pelo ACI 318 (1995), por exemplo, podem superestimar o benefício do aumento da resistência, tornando-se contra a segurança no que se refere ao CAD.

A análise do modelo de treliça indica que um aumento em $f_{c k}$ aumentaria a resistência das diagonais de concreto. Para a formação do mecanismo da treliça, contudo, deve haver uma transferência adequada de forças na fissura diagonal. Em vigas de concretos de alto desempenho com pequenas quantidades de armadura transversal, em função da maior força de cisalhamento ser transferida no início da fissuração diagonal e da reduzida contribuição do engrenamento dos agregados, esta transferência de forças pode causar o escoamento e a ruptura dos estribos inicialmente solicitados. A ruptura da armadura transversal impediria uma possível futura redistribuição de forças e poderia resultar em uma diminuição da capacidade de reserva.

Segundo AHMAD et al. (1994), a armadura de cisalhamento aumenta o índice de ductilidade no cisalhamento tanto nas vigas de concreto armado de resistência usual como nas vigas de concreto de alta resistência. Vigas de CAD com $a / d=3$ exibem uma resposta plástica após a tensão máxima quando a armadura de cisalhamento adotada é cerca de duas vezes o mínimo recomendado pelo ACI (1992). Além disso, para vigas com armadura transversal, o índice de ductilidade no cisalhamento para vigas com $a / d=1$ diminui com um aumento na resistência do concreto, ao passo que para vigas com $a / d=2$ e $a / d=3$ há uma mudança insignificante no índice de ductilidade no cisalhamento, devida ao aumento na resistência do concreto. 
Os resultados indicaram que a armadura transversal aumenta a ductilidade de vigas que se rompem por cisalhamento tanto de concretos de resistência usual como alta e que a ductilidade no cisalhamento diminui com o aumento da resistência do concreto.

As pesquisas realizadas permitiram concluir que:

- Uma maneira de se quantificar a eficiência da armadura transversal em aumentar a capacidade de carregamento e as características de deformação após a tensão máxima é a taxa de absorção de energia. Para vigas com $a / d=3$, aumentar a taxa de armadura transversal de $0,51 \%$ para $0,65 \%$ quase dobra a taxa de absorção de energia. Além disso, aumentar a taxa de armadura transversal não tem um efeito significativo na taxa de absorção de energia.

- Vigas com concretos de resistência usual e de alta resistência, todas com $1 \leq a / d \leq 4$ e taxas de armadura transversal entre $0,49 \%$ e $0,78 \%$, apresentaram escoamento dos estribos no estágio de carregamento máximo.

- Aumentando-se a taxa de armadura transversal aumenta-se a capacidade de carregamento e diminui-se a inclinação do trecho após a tensão-máxima nas curvas de carregamento-deslocamento no meio do vão.

- As inclinações do trecho descentende das curvas de carregamentodeslocamento para concretos de alto desempenho são maiores que aquelas para vigas de concretos usuais.

- Do efeito da relação $a / d$ no deslocamento no meio do vão para vigas de concreto usual e de alta resistência com e sem armadura transversal, pode-se concluir que, para todas as vigas, a inclinação do trecho anterior à tensão máxima, assim como para o trecho posterior à mesma, é mais íngreme para $a / d=1$ comparando-se com

$a / d=2,3$ e 4 .

- Para vigas sem armadura transversal e $a / d$ igual a 1 e 2 , o índice de ductilidade diminui com o aumento da resistência do concreto, ao passo que para vigas com $a / d=3$, há uma mudança insignificante com o aumento da resistência do concreto. 
- Para vigas com armadura transversal e $a / d=1$, o índice de ductilidade no cisalhamento diminui com o aumento da resistência do concreto, ao passo que para vigas com $a / d=2$ e 3 , há uma insignificante mudança com o aumento na resistência do concreto.

- Para todas as vigas testadas, o índice de ductilidade no cisalhamento para vigas com $a / d=2$ é menor que para vigas com $a / d=1$ e 3 . A diferença é menor para vigas com estribos que para vigas sem estribos.

- Aumentar a taxa de armadura transversal para mais de $0,51 \%$ tem um efeito insignificante na ductilidade no cisalhamento de vigas com $a / d=1$ e 3 . Contudo, para vigas com $a / d=2$, o índice de ductilidade no cisalhamento aumenta. Para vigas com $a / d=3$, aumentando-se a taxa de armadura transversal de 0,51\% para $0,65 \%$ aumenta o índice de ductilidade em $43 \%$. Além disso, o aumento na taxa de armadura transversal não aumenta o índice de ductilidade no cisalhamento, uma vez que o trecho após a tensão máxima para uma viga com $0,65 \%$ de armadura transversal é essencialmente plástico.

- A eficiência da armadura de cisalhamento em aumentar a capacidade de carregamento último e as características de deformação após a tensão máxima aumenta com o aumento na relação $a / d$.

- Para vigas com $a / d=1$ e 3 , a eficiência dos estribos é similar em vigas de concreto de resistência usual e alta. Para vigas com $a / d=2$, a armadura transversal é mais eficiente para vigas de concreto de resistência usual do que para as de CAD. Para vigas com $a / d=3$, aumentar a taxa de armadura transversal de 0,49\% para 0,65\% quase dobra a taxa de absorção de energia; contudo, aumentar a taxa de armadura transversal além de $0,65 \%$ não resulta em significativa mudança na taxa de absorção de energia.

- Vigas de CAD com $a / d=3$ apresentam uma pequena resposta plástica após a tensão máxima quando a armadura transversal provida é cerca de duas vezes a quantidade mínima recomendada pelo ACI-318 (1989).

- As características de deformação após a tensão máxima expressas em termos do índice de ductilidade no cisalhamento indicam que as vigas com $a / d=2$ exibem valores menores quando comparados aos das vigas com $a / d=1$ e 3 . 


\section{CONCLUSÕES}

Neste capítulo, apresentam-se algumas conclusões e esclarecem-se alguns aspectos estudados neste trabalho.

\subsection{VIABILIDADE ECONÔMICA DA APLICAÇÃO DO CAD EM ELEMENTOS FLETIDOS}

Já são consagradas no meio técnico as vantagens do CAD em relação aos concretos usuais no que se refere à durabilidade e, portanto, à economia que a sua utilização representa a longo prazo com a diminuição dos custos de manutenção da estrutura.

Com o estudo realizado por DURNING \& REAR (1993), apresentado no capítulo introdutório, conclui-se que também a curto prazo o CAD pode se apresentar como uma solução melhor e mais econômica. Como se pôde observar na tabela 1.1, o aumento da resistência gerou uma economia de aproximadamente $25 \%$ no custo final por metro linear da ponte estudada.

\subsection{RETRAÇÃO E FLUÊNCIA}

Dos estudos apresentados no capítulo 2, montou-se a tabela 7.1, onde se pode ter uma visão geral da normalização atual no que se refere ao cálculo da retração $e$ da fluência do CAD.

A proposta de GARDNER \& ZHAO (1993) é mais adequada ao cálculo da retração e da fluência no CAD do que as apresentadas pelo CEB-FIP (1990) e 
pelo ACI 209 (1982), e os dados necessários para sua utilização são normalmente disponíveis na fase de projeto.

TABELA 7.1 - Comportamento de normas atuais em relação ao cálculo da retração e da fluência no CAD

\begin{tabular}{|c|c|c|c|c|}
\hline \multicolumn{2}{|c|}{ CEB-FIP (1990) } & \multicolumn{3}{c|}{ ACI 209 (1982) } \\
\hline RETRAÇÃO & FLUÊNCIA & \multicolumn{2}{|c|}{ RETRAÇÃO } & FLUÊNCIA \\
\cline { 3 - 5 } & & Idades jovens & Idades avançadas & \\
\hline Subestima & Aceitável & Superestima & Subestima & Subestima \\
\hline
\end{tabular}

\subsection{DIMENSIONAMENTO À FLEXÃO}

Demonstrou-se no exemplo 3.1 que, para resistências usuais, o procedimento sugerido por IBRAHIM \& MacGREGOR (1997) resulta em praticamente as mesmas armaduras que seriam obtidas pelo diagrama parábola-retângulo, para as seções submetidas à flexão simples, inclusive no domínio 4 (tabela 3.4). Não há, portanto, diferenças do ponto de vista da economia.

Para a resistência de $30 M P a$, a posição da linha neutra, obtida através dos dois procedimentos, difere pouco (diferença percentual menor que 5\%) para os domínios 3 e 4. Porém, apresenta-se maior no subdomínio $2 \mathrm{a}(-42 \%)$ e no subdomínio $2 \mathrm{~b}$ (-7\%). No exemplo 3.1, em todos os domínios, a posição da L.N. obtida pelo procedimento proposto por IBRAHIM \& MacGREGOR (1997) foi mais alta que a obtida pelo diagrama parábola-retângulo.

Demonstrou-se no exemplo 3.2 que, para o CAD, o procedimento sugerido por IBRAHIM \& MacGREGOR (1997) resulta em praticamente as mesmas armaduras que seriam obtidas pelo diagrama parábola-retângulo, para as seções submetidas à flexão simples, no domínio 2 (tabela 3.5). À medida que se avança nos domínios $3 \mathrm{e}$ 4, vai se acentuando a diferença entre os dois procedimentos. A armadura obtida pelo procedimento sugerido por IBRAHIM \& MacGREGOR (1997) é maior que a obtida 
pelo parábola-retângulo. Essa diferença chega a 5\% no domínio 3, e a $16 \%$ no domínio 4 (tabela 3.5).

Para a resistência de $70 \mathrm{MPa}$, a diferença percentual da posição da linha neutra, obtida através dos dois procedimentos, está entre $15 \%$ e $20 \%$ nos domínio 3 e 4 . No exemplo 3.2, em todos os domínios, exceto no subdomínio 2a, a posição da L.N. obtida pelo procedimento proposto por IBRAHIM \& MacGREGOR (1997) foi mais baixa que a obtida pelo diagrama parábola-retângulo.

Esses dados realçam que as diferenças entre os resultados obtidos através dos dois procedimentos aumentam, tanto no que se refere à armadura como à posição da L.N., à medida que se aumenta a resistência do concreto e se avança em direção ao domínio 4.

A resistência à flexão das vigas superarmadas é mais dependente da distribuição das tensões de compressão. A posição da resultante de compressão torna-se mais importante à medida que se aumenta a zona de compressão da viga (ou seja, caminhando-se em direção ao domínio 4). Assim, era de se esperar que essas diferenças ocorressem. Tais diferenças devem surgir também nas vigas com armadura dupla.

Embora vigas no domínio 4 sejam evitadas pelos projetistas (e até mesmo proibidas pelo $A C I$ ) por razões de ductilidade e de economia, a DIN 4227 admite o seu dimensionamento, adotando um coeficiente de segurança $\left(\gamma_{f}\right)$ de 2,1 [PFEIL (1984)].

Assim, a metodologia proposta é geral, sendo válida tanto para concretos de resistência usual com para os de alto desempenho, ao longo de todos os domínios de deformação.

\subsection{CISALHAMENTO}

Tanto o Método Padrão, familiar aos projetistas brasileiros, como a normas australiana e canadense podem ser utilizados para o dimensionamento ao cisalhamento das vigas de CAD. 


\subsubsection{Método padrão}

Segundo FERNANDES (1992), o método padrão pode ser adotado para as vigas de CAD, atribuindo-se ao concreto uma contribuição dada por (4.12).

Em situação de projeto, quando não se possui a resistência $f_{c}$, considera-se a resistência de cálculo $\left(f_{c d}\right)$ ou a resistência característica $\left(f_{c k}\right)$ com o coeficiente de redução $\left(\gamma_{c}\right)$ embutido em expressões empíricas que permitem calcular as parcelas $\left(\tau_{c}\right)$ ou $\left(V_{c}\right)$.

Assim, tem-se:

$$
\tau_{c d}=f_{c d} / 20
$$

$\operatorname{com} f_{c d}=f_{c k} / \gamma_{c}$, e $\gamma_{c}=1,4$ para os casos usuais.

\subsubsection{Norma australiana AS-3600 (1988)}

Para os elementos protendidos, a consideração do nível a partir do qual $b=b_{w}$ [figura (4.13)] é importante porque pode alterar consideravelmente a armadura transversal calculada. Considerar $b=b_{w}$ em níveis muito próximos ao ducto representa um erro de segurança. Considerar $b=b_{w}$ em níveis demasiadamente distantes representa um erro de economia.

A proposta de uma distribuição de tensões a $60^{\circ}$ com a horizontal (que leva à consideração de $b=b_{w}$ a partir dos níveis B) foi feita inspirada na prática corrente do cálculo de alvenaria estrutural onde, na presença de aberturas na alvenaria, admitemse ângulos de distribuição de tensões entre $30^{\circ}$ e $45^{\circ}$ graus em relação à horizontal. Estes ângulos, contudo, aproximariam demasiadamente os níveis $\mathrm{B}$ da borda do ducto. Pela prática corrente em projeto, o princípio de Saint-Venant levaria a considerações demasiadamente conservadoras. Optou-se portanto, por uma 
distribuição a $60^{\circ}$, que parece representar um equilíbrio entre esses extremos. Esta distribuição não foi verificada experimentalmente.

Segundo o $C E B-F I P(1990)$, a resistência à tração do concreto $\left(f_{t}\right)$ é dada por:

$$
f_{t}=0,3 \times\left(f_{c k}+8 M P a\right)^{2 / 3}
$$

Portanto, como se pode observar na tabela 7.2, fazer $\sigma_{1}=0,33 \sqrt{f_{c k}}$ significa limitar a tensão principal de tração a cerca da metade da resistência do concreto à tração.

TABELA 7.2 - Relação entre $\sigma_{1}=0,33 \sqrt{f_{c k}}$ e $f_{t}$ segundo o $C E B$-FIP (1990)

\begin{tabular}{|c|c|c|c|}
\hline $\begin{array}{c}f_{c k} \\
(M P a)\end{array}$ & $\begin{array}{c}\sigma_{1} \\
(M P a)\end{array}$ & $\begin{array}{c}f_{t}=0,3\left(f_{c k}+8 M P a\right)^{2 / 3} \\
(M P a)\end{array}$ & $\sigma_{1} / f_{t}$ \\
\hline 20 & 1,5 & 2,8 & 0,53 \\
\hline 25 & 1,7 & 3,1 & 0,53 \\
\hline 30 & 1,8 & 3,4 & 0,53 \\
\hline 35 & 2,0 & 3,7 & 0,53 \\
\hline 40 & 2,1 & 4,0 & 0,53 \\
\hline 45 & 2,2 & 4,2 & 0,52 \\
\hline 50 & 2,3 & 4,5 & 0,52 \\
\hline 55 & 2,4 & 4,7 & 0,52 \\
\hline 60 & 2,6 & 5,0 & 0,51 \\
\hline 65 & 2,7 & 5,2 & 0,51 \\
\hline 70 & 2,8 & 5,5 & 0,50 \\
\hline 75 & 2,9 & 5,7 & 0,50 \\
\hline 80 & 3,0 & 5,9 & 0,50 \\
\hline
\end{tabular}

De acordo com a $A S-3600$ (1988), em um apoio simples, a força a ser ancorada (com a armadura longitudinal sendo estendida além da face do apoio) é de $1,5 V_{d}$ na face do apoio. Este valor é maior que o sugerido por FERNANDES (1992), que é de $1,35 V_{d}$. 


\subsection{DESLOCAMENTOS CAUSADOS POR AÇÕES DE CURTA E DE LONGA DURAÇÃO}

Os deslocamentos imediatos não dependem fortemente da resistência do concreto. Portanto, a proposta de Branson [equações (5.1) e (5.3)] permanece válida para o CAD e resulta, provavelmente, em valores ligeiramente menores que os reais.

Em função da menor fluência, os deslocamentos adicionais nas vigas de CAD, causados por ações de longa duração, são menores que os observados nas vigas de concreto usual. Pode-se tirar proveito do aumento da resistência na diminuição dos deslocamentos adicionais, para vigas protendidas, através da utilização da equação (5.11), com um coeficiente de fluência $(\varphi)$ adequado, ou ainda, para vigas não protendidas, através da equação (5.9).

\subsection{DUCTILIDADE}

Pelo exposto no capítulo 6, percebe-se que não há razão para preocupações exacerbadas com a ductilidade das vigas de CAD.

Para se garantir ductilidade na ruptura por cisalhamento de elementos fletidos de CAD com pequenas taxas de armadura transversal, a armadura de cisalhamento mínima proposta pela CAN 3 (1994) [equação (4.29)] foi incorporada na metodologia da $A S-3600$ (1988).

O ACI 318 (1995), numa preocupação clara de aumentar a ductilidade de elementos fletidos à medida que se aumenta a resistência, apresenta expressões para cálculo das armaduras mínimas longitudinais tracionadas em função da resistência do concreto à compressão [equações (3.44) e (3.45)], que resultam (para $f_{c k} \geq 30 M P a$ ) em taxas consideravelmente maiores que as propostas pela sua versão anterior, a qual não levava em consideração a resistência do concreto à compressão. A NB-1 (1978), neste aspecto, encontra-se desatualizada, uma vez que não leva em consideração a resistência à compressão no cálculo da armadura mínima de flexão. 
Portanto, a exemplo do que acontece com as vigas de resistências usuais, o que determina a ductilidade na ruína das vigas de $\mathrm{CAD}$, quer na flexão, quer no cisalhamento, é o detalhamento adequado da armadura.

Embora as recomendações normalizadas para fadiga da armadura sejam mais que satisfatórias para elementos fletidos que se utilizam de concretos com resistências usuais, a sua validade para vigas de CAD não foi apresentada neste trabalho e o assunto parece merecer maiores pesquisas experimentais.

Conclui-se finalmente que é possível projetar uma viga de CAD de forma adequada, através dos procedimentos apresentados, e que não se justifica a utilização de procedimentos desatualizados, os quais provocariam erros desnecessários.

Fica, portanto, cumprido o objetivo inicial do trabalho. 
ANEXO A - TABELAS DE DIMENSIONAMENTO 
TABELA A1 - DIMENSIONAMENTO DE SEÇÕES RETANGULARES DE CONCRETO PROTENDIDO

$$
k_{c}=b d^{2} / M_{d}\left(\mathrm{~cm}^{2} / \mathrm{kN}\right)
$$

Unidades de entrada: $b, d: c m ; M_{d}: k N . c m$

$\alpha_{1}=0,85-\left(f_{c k} / 800\right) \geq 0,725\left(f_{c k}\right.$ em MPa $)$

$$
\varepsilon_{c d}=\frac{\beta_{x}}{1-\beta_{x}} 10 \% \quad\left(\text { para } \beta_{x}<0,231\right)
$$

$\varepsilon_{c u}=3 \%$

$\beta_{z}=z / d=\left(1-0,5 \beta_{1} \beta_{x}\right)$

$\beta_{1}=0,95-\left(f_{c k} / 400\right) \geq 0,700\left(f_{c k}\right.$ em $\left.M P a\right)$

$\varepsilon_{c 1 d}=\varepsilon_{p d}=\frac{1-\beta_{x}}{\beta_{x}} 3 \%_{o}\left(\right.$ para $\left.\beta_{x} \geq 0,231\right)$

$k_{c}=b d^{2} / M_{d}=\beta_{1} \alpha_{1} \beta_{x} f_{c d}\left(1-\frac{\beta_{1} \beta_{x}}{2}\right)^{-1}$

$A_{p}\left(\mathrm{~cm}^{2}\right)=\frac{M_{d}(M N / m)}{z(m) \sigma_{p d}(M P a)} 10^{4}$

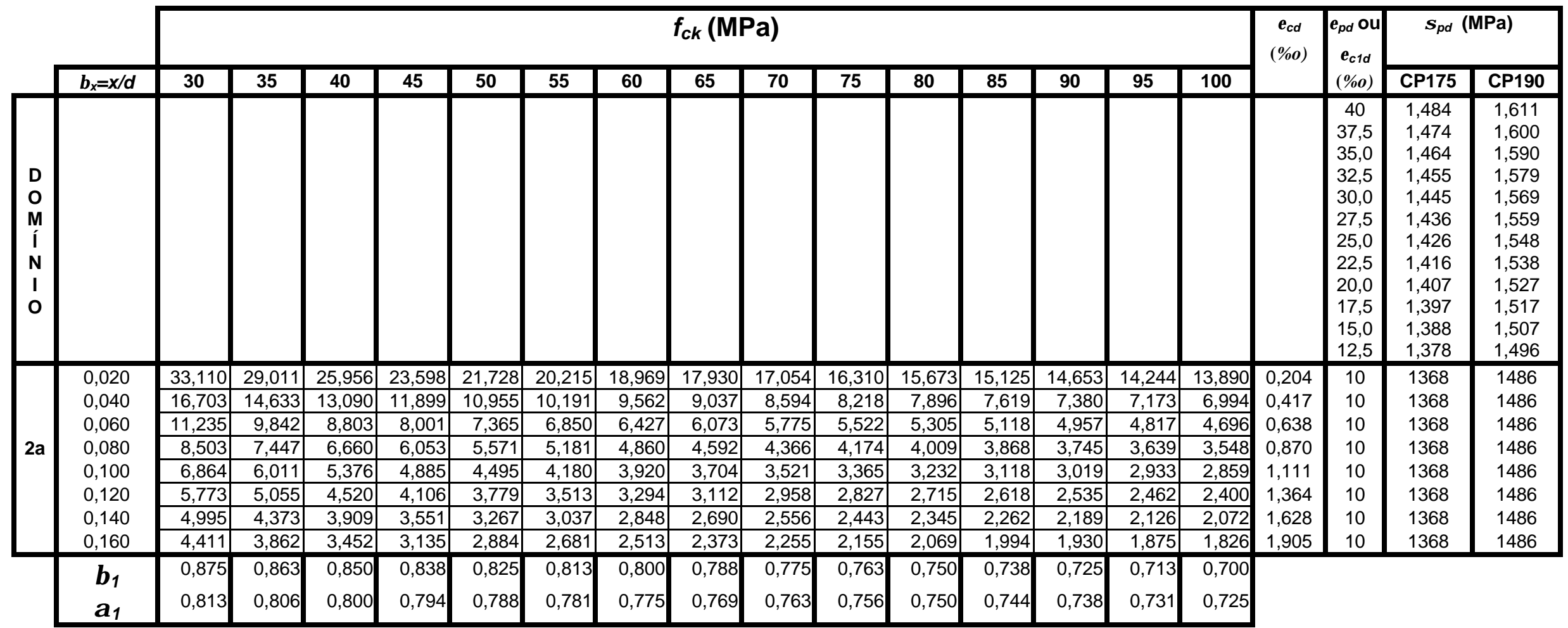


TABELA A1 (CONTINUAÇÃO)

$k_{c}=b d^{2} / M_{d}\left(\mathrm{~cm}^{2} / \mathrm{kN}\right)$

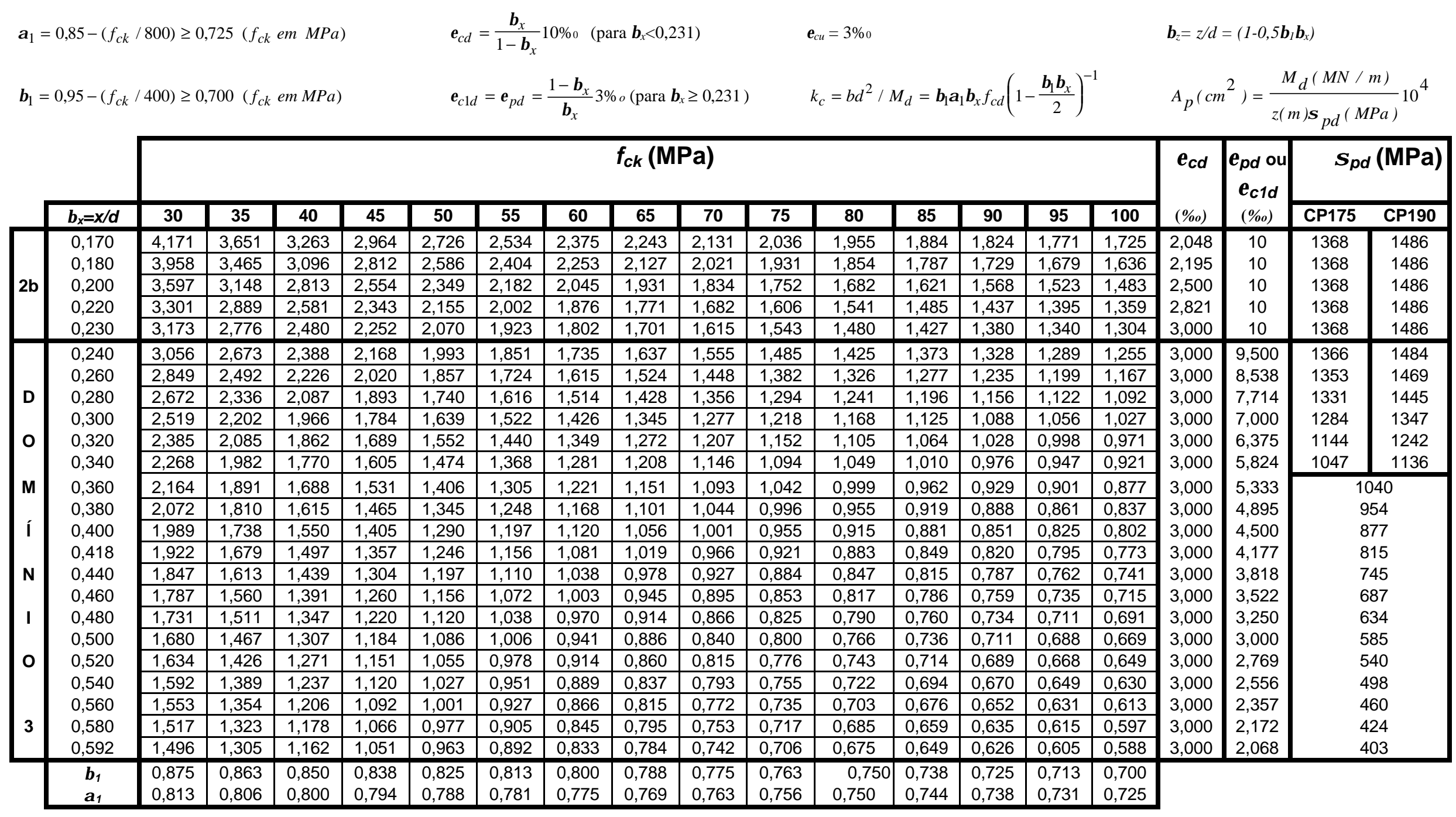


TABELA A1 (CONTINUAÇÃO)

$$
k_{c}=b d^{2} / M_{d}\left(\mathrm{~cm}^{2} / k N\right)
$$

$\alpha_{1}=0,85-\left(f_{c k} / 800\right) \geq 0,725\left(f_{c k}\right.$ em MPa $)$

$\beta_{1}=0,95-\left(f_{c k} / 400\right) \geq 0,700\left(f_{c k}\right.$ em $\left.M P a\right)$ $\varepsilon_{c d}=\frac{\beta_{x}}{1-\beta_{x}} 10 \% \quad\left(\right.$ para $\left.\beta_{x}<0,231\right)$

$\varepsilon_{c 1 d}=\varepsilon_{p d}=\frac{1-\beta_{x}}{\beta_{x}} 3 \% o\left(\right.$ para $\left.\beta_{x} \geq 0,231\right)$ $\varepsilon_{c u}=3 \%$

$k_{c}=b d^{2} / M_{d}=\beta_{1} \alpha_{1} \beta_{x} f_{c d}\left(1-\frac{\beta_{1} \beta_{x}}{2}\right)^{-1}$ $\beta_{z}=z / d=\left(1-0,5 \beta_{1} \beta_{x}\right)$

$A_{p}\left(\mathrm{~cm}^{2}\right)=\frac{M_{d}(M N / m)}{z(m) \sigma_{p d}(M P a)} 10^{4}$

\begin{tabular}{|c|c|c|c|c|c|c|c|c|c|c|c|c|c|c|c|c|c|c|c|}
\hline \multirow[b]{2}{*}{$\beta_{x}=x / d$} & \multicolumn{15}{|c|}{$f_{c k}(\mathrm{MPa})$} & \multirow{2}{*}{$\begin{array}{l}\varepsilon_{c d} \\
(\% o)\end{array}$} & \multirow{2}{*}{$\begin{array}{c}\varepsilon_{p d} \text { ou } \\
\varepsilon_{c 1 d} \\
(\% o)\end{array}$} & \multicolumn{2}{|c|}{$\sigma_{p d}(\mathrm{MPa})$} \\
\hline & 30 & 35 & 40 & 45 & 50 & 55 & 60 & 65 & 70 & 75 & 80 & 85 & 90 & 95 & 100 & & & CP175 & CP190 \\
\hline 0,600 & 1,483 & 1,293 & 1,151 & 1,042 & 0,955 & 0,884 & 0,825 & 0,776 & 0,735 & 0,700 & 0,669 & 0,643 & 0,620 & 0,600 & 0,582 & 3,000 & 2,000 & & 90 \\
\hline 0,620 & 1,453 & 1,266 & 1,127 & 1,020 & 0,934 & 0,865 & 0,807 & 0,759 & 0,718 & 0,684 & 0,654 & 0,628 & 0,605 & 0,586 & 0,568 & 3,000 & 1,839 & & 59 \\
\hline 0,640 & 1,425 & 1,241 & 1,105 & 0,999 & 0,915 & 0,847 & 0,790 & 0,743 & 0,703 & 0,669 & 0,640 & 0,614 & 0,592 & 0,572 & 0,555 & 3,000 & 1,688 & & 29 \\
\hline 0,660 & 1,398 & 1,218 & 1,084 & 0,980 & 0,897 & 0,830 & 0,775 & 0,728 & 0,689 & 0,655 & 0,626 & 0,601 & 0,579 & 0,560 & 0,544 & 3,000 & 1,545 & & 01 \\
\hline 0,680 & 1,374 & 1,197 & 1,065 & 0,962 & 0,881 & 0,815 & 0,760 & 0,715 & 0,676 & 0,643 & 0,614 & 0,589 & 0,568 & 0,549 & 0,532 & 3,000 & 1,412 & & 75 \\
\hline 0,700 & 1,352 & 1,177 & 1,047 & 0,946 & 0,866 & 0,801 & 0,747 & 0,702 & 0,663 & 0,631 & 0,603 & 0,578 & 0,557 & 0,538 & 0,522 & 3,000 & 1,286 & & 51 \\
\hline 0,720 & 1,331 & 1,159 & 1,030 & 0,931 & 0,851 & 0,787 & 0,734 & 0,690 & 0,652 & 0,620 & 0,592 & 0,568 & 0,547 & 0,528 & 0,512 & 3,000 & 1,167 & & 28 \\
\hline 0,740 & 1,312 & 1,142 & 1,015 & 0,916 & 0,838 & 0,775 & 0,722 & 0,678 & 0,641 & 0,609 & 0,582 & 0,558 & 0,537 & 0,519 & 0,503 & 3,000 & 1,054 & & 06 \\
\hline 0,760 & 1,294 & 1,126 & 1,000 & 0,903 & 0,826 & 0,763 & 0,711 & 0,668 & 0,631 & 0,600 & 0,573 & 0,549 & 0,528 & 0,510 & 0,495 & 3,000 & 0,947 & & 85 \\
\hline 0,780 & 1,277 & 1,111 & \begin{tabular}{|l|}
0,987 \\
\end{tabular} & 0,891 & 0,815 & 0,753 & 0,701 & 0,658 & 0,622 & 0,591 & 0,564 & 0,540 & 0,520 & 0,502 & 0,486 & 3,000 & 0,846 & & 65 \\
\hline 0,800 & 1,262 & 1,098 & \begin{tabular}{|l|}
0,975 \\
\end{tabular} & 0,880 & 0,804 & 0,743 & 0,692 & 0,649 & 0,613 & 0,582 & 0,556 & 0,532 & 0,512 & 0,494 & 0,479 & 3,000 & 0,750 & & 46 \\
\hline 0,820 & 1,248 & 1,085 & 0,963 & 0,869 & 0,794 & 0,733 & 0,683 & 0,641 & 0,605 & 0,574 & 0,548 & 0,525 & 0,505 & 0,487 & 0,472 & 3,000 & 0,659 & & 28 \\
\hline 0,840 & 1,235 & 1,074 & 0,953 & 0,859 & 0,785 & 0,725 & 0,675 & 0,633 & 0,597 & 0,567 & 0,541 & 0,518 & 0,498 & 0,481 & 0,465 & 3,000 & 0,571 & & 11 \\
\hline 0,860 & 1,224 & 1,063 & 0,943 & 0,850 & 0,777 & 0,717 & 0,667 & 0,626 & 0,590 & 0,560 & 0,534 & 0,511 & 0,492 & 0,474 & 0,459 & 3,000 & 0,488 & & 95 \\
\hline 0,880 & 1,213 & 1,053 & 0,934 & 0,842 & 0,769 & 0,709 & 0,660 & 0,619 & 0,584 & 0,554 & 0,528 & 0,505 & 0,485 & 0,468 & 0,453 & 3,000 & 0,409 & & 30 \\
\hline 0,900 & 1,203 & 1,045 & 0,926 & 0,835 & 0,762 & 0,702 & 0,653 & 0,612 & 0,577 & 0,548 & 0,522 & 0,499 & 0,480 & 0,463 & 0,447 & 3,000 & 0,333 & & 65 \\
\hline 0,920 & 1,194 & 1,036 & 0,919 & 0,827 & 0,755 & 0,696 & 0,647 & 0,606 & 0,572 & 0,542 & 0,516 & 0,494 & 0,474 & 0,457 & 0,442 & 3,000 & 0,261 & & 51 \\
\hline 0,940 & 1,186 & 1,029 & 0,912 & 0,821 & 0,749 & 0,690 & 0,642 & 0,601 & 0,566 & 0,537 & 0,511 & 0,489 & 0,469 & 0,452 & 0,437 & 3,000 & 0,191 & & 37 \\
\hline 0,960 & 1,179 & 1,022 & 0,906 & 0,815 & 0,743 & 0,685 & 0,636 & 0,596 & 0,561 & 0,532 & 0,506 & 0,484 & 0,465 & 0,448 & 0,433 & 3,000 & 0,125 & & 24 \\
\hline 0,980 & 1,173 & 1,017 & 0,900 & 0,810 & 0,738 & 0,680 & 0,632 & 0,591 & 0,557 & 0,527 & 0,502 & 0,480 & 0,460 & 0,443 & 0,428 & 3,000 & 0,061 & & 12 \\
\hline 1,000 & 1,167 & 1,011 & 0,895 & 0,805 & 0,734 & 0,675 & 0,627 & 0,587 & 0,553 & 0,523 & 0,498 & 0,476 & 0,456 & 0,439 & 0,424 & 3,000 & 0,000 & & 0 \\
\hline $\begin{array}{l}\beta_{1} \\
\alpha_{1}\end{array}$ & $\begin{array}{l}0,875 \\
0,813\end{array}$ & $\begin{array}{l}0,863 \\
0,806\end{array}$ & $\begin{array}{l}0,850 \\
0,800\end{array}$ & $\begin{array}{l}0,838 \\
0,794\end{array}$ & $\begin{array}{l}0,825 \\
0,788\end{array}$ & $\begin{array}{l}0,813 \\
0,781\end{array}$ & $\begin{array}{l}0,800 \\
0,775\end{array}$ & $\begin{array}{l}0,788 \\
0,769\end{array}$ & $\begin{array}{l}0,775 \\
0,763\end{array}$ & $\begin{array}{l}0,763 \\
0,756\end{array}$ & $\begin{array}{l}0,750 \\
0,750\end{array}$ & $\begin{array}{l}0,738 \\
0,744\end{array}$ & $\begin{array}{l}0,725 \\
0,738\end{array}$ & $\begin{array}{l}0,713 \\
0,731\end{array}$ & $\begin{array}{l}0,700 \\
0,725\end{array}$ & & & & \\
\hline
\end{tabular}


TABELA A2 - DIMENSIONAMENTO DE SEÇÕES RETANGULARES DE CONCRETO ARMADO

$$
k_{s}=A_{s} d / M_{d}\left(\mathrm{~cm}^{2} / \mathrm{kN}\right) \text { - CA-50 }
$$

Unidades de entrada: $b, d: c m ; M_{d}: k N . c m$

$\alpha_{1}=0,85-\left(f_{c k} / 800\right) \geq 0,725\left(f_{c k}\right.$ em $\left.M P a\right)$

$\beta_{1}=0,95-\left(f_{c k} / 400\right) \geq 0,700\left(f_{c k}\right.$ em MPa $)$

$$
\varepsilon_{c d}=\frac{\beta_{x}}{1-\beta_{x}} 10 \% 0 \quad\left(\text { para } \beta_{x}<0,231\right)
$$

$\varepsilon_{c 1 d}=\varepsilon_{p d}=\frac{1-\beta_{x}}{\beta_{x}} 3 \% o\left(\right.$ para $\left.\beta_{x} \geq 0,231\right)$ $\varepsilon_{c u}=3 \%$

$k_{c}=b d^{2} / M_{d}=\beta_{1} \alpha_{1} \beta_{x} f_{c d}\left(1-\frac{\beta_{1} \beta_{x}}{2}\right)^{-1}$ $\beta_{z}=z / d=\left(1-0,5 \beta_{I} \beta_{x}\right)$

\begin{tabular}{|c|c|c|c|c|c|c|c|c|c|c|c|c|c|c|c|c|c|c|}
\hline & & \multicolumn{17}{|c|}{$\begin{array}{c}f_{c k} \\
(\mathbf{M P a})\end{array}$} \\
\hline & $\beta_{x}=x / d$ & 20 & 25 & 30 & 35 & 40 & 45 & 50 & 55 & 60 & 65 & 70 & 75 & 80 & 85 & 90 & 95 & 100 \\
\hline D & 020 & 02321 & 02321 & 02320 & 02320 & 0,02320 & 0,02319 & 02319 & 0,02319 & 0,02319 & 0,02318 & 0,02318 & 0,02318 & 0,02317 &, 02317 & 0,02317 & 0,02317 & 0,02316 \\
\hline 0 & 0,040 & 0,02342 & 0,02342 & 0,02341 & 0,02340 & 0,02340 & 0,02339 & 0,02339 & 0,02338 & 0,02337 & 0,02337 & 0,02336 & 0,02336 & 0,02335 & 0,02334 & 0,02334 & 0,02333 & 0,02333 \\
\hline $\mathbf{M}$ & 0,060 & 0,02364 & 0,02363 & 0,02362 & 0,02361 & 0,02360 & 0,02359 & 0,02358 & 0,02357 & 0,02357 & 0,02356 & 0,02355 & 0,02354 & 0,02353 & 0,02352 & 0,02351 & 0,02350 & 0,02349 \\
\hline í & 0,080 & 0,02386 & 0,02385 & 0,02383 & 0,02382 & 0,02381 & 0,02380 & 0,02378 & 0,02377 & 0,02376 & 0,02375 & 0,02374 & 0,02372 & 0,02371 & 0,02370 & 0,02369 & 0,02367 & 0,02366 \\
\hline $\mathbf{N}$ & 0,100 & 0,02408 & 0,02407 & 0,02405 & 0,02404 & 0,02402 & 0,02401 & 0,02399 & \begin{tabular}{|l|}
0,02397 \\
\end{tabular} & 0,02396 & 0,02394 & 0,02393 & \begin{tabular}{|l|}
0,02391 \\
\end{tabular} & \begin{tabular}{|l|}
0,02390 \\
\end{tabular} & 0,02388 & 0,02387 & 0,02385 & $\mid 0,02383$ \\
\hline I & 0,120 & 0,02431 & 0,02429 & 0,02427 & 0,02426 & 0,02424 & 0,02422 & 0,02420 & 0,02418 & 0,02416 & 0,02414 & 0,02412 & 0,02410 & 0,02408 & 0,02406 & 0,02405 & 0,02403 & 0,02401 \\
\hline 0 & 0,140 & 0,02455 & 0,02452 & 0,02450 & 0,02448 & 0,02446 & 0,02443 & 0,02441 & 0,02439 & 0,02436 & 0,02434 & 0,02432 & 0,02430 & 0,02427 & 0,02425 & 0,02423 & 0,02421 & 0,02419 \\
\hline 20 & 0,160 & 0,02478 & 0,02476 & 0,02473 & 0,02470 & 0,02468 & 0,02465 & 0,02463 & 0,02460 & 0,02457 & 0,02455 & 0,02452 & 0,02449 & 0,02447 & 0,02444 & 0,02442 & 0,02439 & 0,02436 \\
\hline \multirow{3}{*}{$2 b$} & 0,180 & 0,02503 & 0,02500 & 0,02497 & 0,02494 & 0,02491 & 0,02487 & 0,02484 & 0,02481 & 0,02478 & 0,02475 & 0,02472 & 0,02469 & 0,02466 & 0,02464 & 0,02461 & 0,02458 & 0,02455 \\
\hline & 0,200 & 0,02527 & 0,02524 & 0,02521 & 0,02517 & 0,02514 & 0,02510 & 0,02507 & 0,02503 & 0,02500 & 0,02497 & 0,02493 & 0,02490 & 0,02486 & 0,02483 & 0,02480 & 0,02476 & 0,02473 \\
\hline & 0,220 & 0,02553 & 0,02549 & 0,02545 & 0,02541 & 0,02537 & 0,02533 & 0,02530 & 0,02526 & 0,02522 & 0,02518 & 0,02514 & 0,02511 & 0,02507 & 0,02503 & 0,02499 & 0,02496 & 0,02492 \\
\hline \multirow{7}{*}{3} & 0,240 & 578 & 0,02574 & 0,02570 & 0,02566 & 0,02561 & 0,02557 & 0,02553 & 0,02548 & 0,02544 & 0,02540 & 0,02536 & 0,02532 & 0,02527 & 0,02523 & 0,02519 & 0,02515 & 0,02511 \\
\hline & 0,260 & 0,02605 & 0,02600 & 0,02595 & 0,02590 & 0,02586 & 0,02581 & 0,02576 & 0,02572 & 0,02567 & 0,02562 & 0,02558 & 0,02553 & 0,02548 & 0,02544 & 0,02539 & 0,02535 & 0,02530 \\
\hline & 0,280 & 0,02632 & 0,02626 & 0,02621 & 0,02616 & 0,02611 & 0,02605 & 0,02600 & 0,02595 & 0,02590 & 0,02585 & 0,02580 & 0,02575 & 0,02570 & 0,02565 & 0,02560 & 0,02555 & 0,02550 \\
\hline & 0,300 & 0,02659 & 0,02653 & 0,02647 & $\mid 0,02642$ & 0,02636 & 0,02630 & 0,02625 & 0,02619 & 0,02614 & 0,02608 & 0,02603 & \begin{tabular}{|l|}
0,02597 \\
\end{tabular} & 0,02592 & 0,02586 & 0,02581 & 0,02575 & 0,02570 \\
\hline & 0,320 & 0,02687 & 0,02681 & 0,02674 & 0,02668 & 0,02662 & 0,02656 & 0,02650 & 0,02644 & 0,02638 & 0,02632 & 0,02626 & 0,02620 & 0,02614 & 0,02608 & 0,02602 & 0,02596 & 0,02590 \\
\hline & 0,340 & 0,02715 & 0,02709 & 0,02702 & 0,02695 & 0,02688 & 0,02682 & 0,02675 & 0,02669 & 0,02662 & 0,02656 & 0,02649 & 0,02643 & 0,02636 & 0,02630 & 0,02623 & 0,02617 & 0,02611 \\
\hline & $\beta_{1}$ & 0,90000 & 0,88750 & 0,87500 & 0,86250 & 0,85000 & 0,83750 & 0,82500 & 0,81250 & 0,80000 & 0,78750 & 0,77500 & 0,76250 & 0,75000 & 0,73750 & 0,72500 & 0,71250 & 0,70000 \\
\hline
\end{tabular}

$A_{p}=M_{d} / z \sigma_{p d}$ 
TABELA A2 (CONTINUAÇ̃̃̃)

$k_{s}=A_{s} d / M_{d}\left(\mathbf{c m}^{2} / \mathbf{k N}\right)$ - CA-50

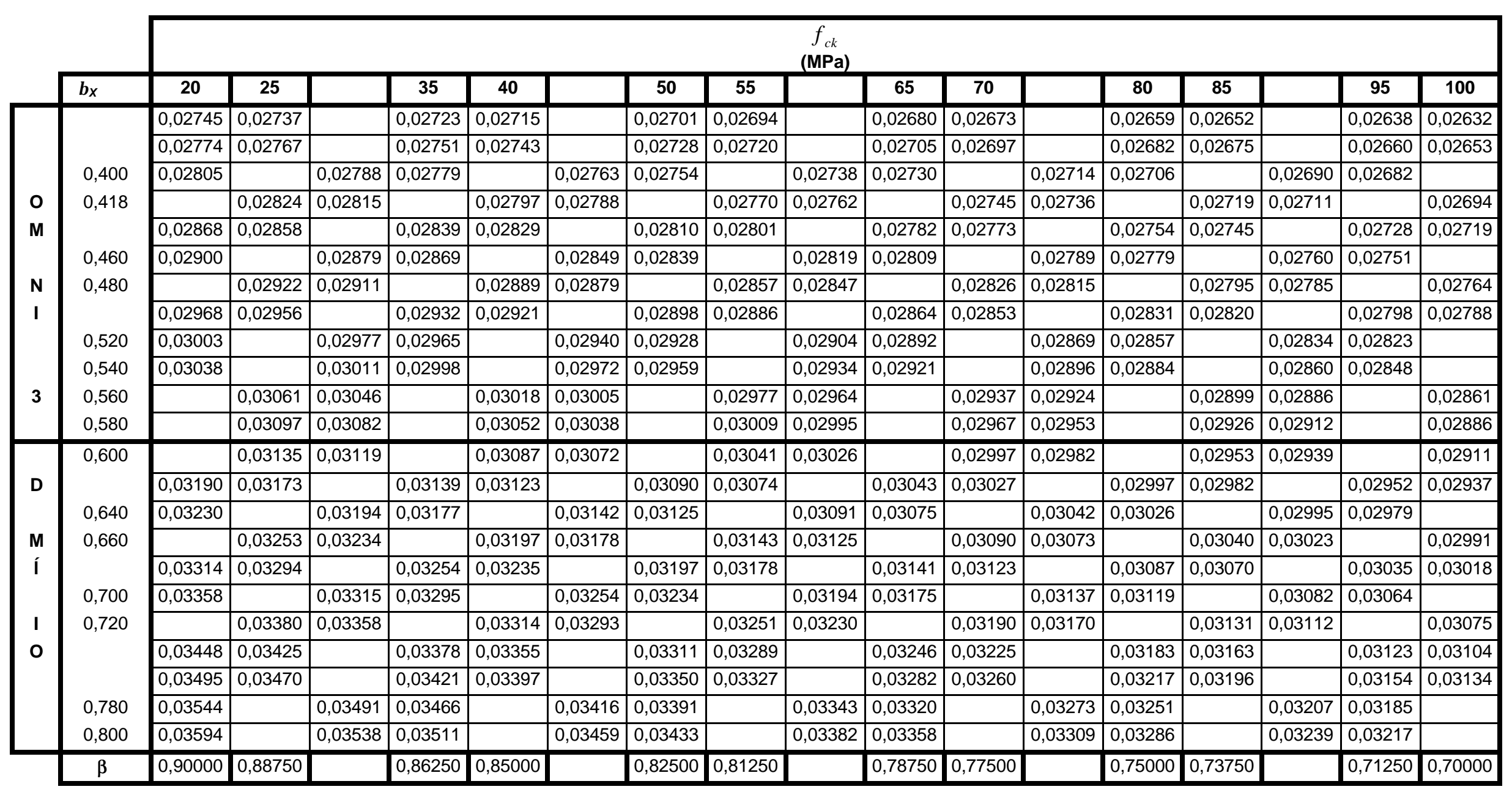




\section{REFERÊNCIAS BIBLIOGRÁFICAS}

ADEBAR, P.; COLLINS, M.P.; MITCHELL, D.; VECCHIO, F.J. (1996). A general shear design method. ACI Structural Journal, v.93, n.1, p.236-245, JanuaryFebruary.

AHMAD, S.H.Y.X.; YU, T.; HINO, S.; CHUNG, W. (1994). Shear ductility of reinforced concrete beams of normal and high-strength concrete. ACI Structural Journal, v.91, n.2, p. 140-149, March-April.

AÏTCIN, P.C.; CHAALlAL, O.; EL HINDY, E.; MIAO, B. (1994). Drying shrinkage of ready-mixed high-performance concrete. ACI Materials Journal, v.91, n. 3, p. 300-305, May-June.

AMERICAN CONCRETE INSTITUTE. Committee 318 (1992). Buiding code requirements of reinforced concrete. Detroit, ACI.

AMERICAN CONCRETE INSTITUTE. Committee 318 (1992). Buiding code requirements of reinforced concrete. Detroit, ACI.

AMERICAN CONCRETE INSTITUTE (1992). Committee 209 (1992). Prediction of creep, shrinkage, and temperature effects in concrete structures. Detroit.

AMERICAN CONCRETE INSTITUTE. Committee 316 (1992). State-of-the-art report on high strength concrete. Detroit.

ASSOCIAÇÃO BRASILEIRA DE NORMAS TÉCNICAS. (1978). NBR 6118 - Projeto e execução de obras de concreto armado. Rio de Janeiro, 76p.

ASSOCIAÇÃO BRASILEIRA DE NORMAS TÉCNICAS. (1989). NBR 7197 - Projeto de estruturas de concreto protendido. Rio de Janeiro. 
ASSOCIAÇÃO BRASILEIRA DE NORMAS TÉCNICAS (1991). NBR-5733 Cimento Portland de alta resistência inicial. Rio de Janeiro.

ASSOCIAÇÃO BRASILEIRA DE NORMAS TÉCNICAS (1991). NBR-5732 Cimento Portland comum. Rio de Janeiro.

ASSOCIAÇÃO BRASILEIRA DE NORMAS TÉCNICAS (1992). EB-903 Cimentos Portland resistentes a sulfatos. Rio de Janeiro.

ATTARD, M.M.; MENDIS, P.A. (1993). Ductility of high-strength concrete columns. Australian Civil Engineering Transactions, v.35, n.4, p.295-306, October .

ATTIOGBE, E.K. (1997). Discussion of "Shrinkage cracking of high-strength concrete". ACI Structural Journal, v.94, n.5, p.444, September-October.

BRANSON, D.E. (1965). Instantaneous and time-dependent deflections on simple and continuous reinforced concrete beams. Alabama Highway Department, Bureau of Public Roads. p. 1-78. August. (HPR Report n. 7, Part 1)

BRANSON, D.E. (1974). The deformation of non-composite and composite prestressed concrete members. Deflection of Concrete Structures, ACI-SP-43, American Concrete Institute, Detroit.

BRITISH STANDARDS INSTITUTION (1985). BS 8110 - Structural use of concrete. Part 1: Code of practice for design and construction. London. BSI.

CANADIAN STANDARD ASSOCIATION (1994). CSA A23.3-94 - Design of concrete structures. Rexdale, Ontario. 199p.

CARRASQUILO, R. L.; NILSON, A. H.; SLATE, F. O. (1982). Properties of High Strength Concrete Subjected to Short-Term Loads" ACI Journal, Proceedings v. 78, n. 3, May-June (1981), p. 171-178 and Discussion, Proceedings v. 79, n. 2, Mar.-Apr. 1982, p. 162-163.

CHARIF, H. (1990). Réduction des déformations des structures en béton grâce à l'utilisation de bétons à hautes performances; etude numérique et expérimentale. Tese (Doutorado) - EPFL, Lausanne, n. 884. 220p. 
CHARIF, H.; FAVRE, R. (1994). Basic model and simplified calculations of deformations according to the CEB-FIP model code 1990. ACI Journal, v. 91, n. 2, p.169-177, March-April.

COLLINS, M.P.; MITCHELL, D. (1991). Prestressed concrete structures. Englewood Cliffs, New Jersey, Prentice Hall. 766p.

COLLINS, M.P.; VECCHIO, F.J. (1986). Modified compression field theory for reinforced concrete elements subjected to shear. ACI Structural Journal, v. 83, n. 2, Mar.-Apr., p. 219-231.

COMITE EURO-INTERNATIONAL DU BETON (1979). Code-modèle CEB-FIP pour les structures au béton. CEB Bulletin d'Information, n.124/125.

COMITÉ EURO-INTERNATIONAL DU BETON (1985). CEB design manual: cracking and deformations. CEB Bulletin d'Information, n. 158E, 230 p.

COMITE EURO-INTERNATIONAL DU BETON (1991). CEB-FIP model code 1990. CEB Bulletin d'Information, n.203-205.

COOK, W.D.; DENIS, M.; YOON, Y.-S. (1996). Minimum shear reinforcement in normal, medium e high-strength concrete beams. ACI Journal, v. 93, n. 5, p.576584, September-October.

COOK, W.D.; KHAN, A.A.; MITCHELL, D. (1997). Creep, shrinkage, and thermal strains in normal, medium, and high-strength concretes during hidratation. ACI 4Structural Journal, v. 94, n. 2, p. 156-163, March-April.

CORLEY, W.G.; MAGURA, D.D.; PFEIFER, D.W.; RUSSEL, H.G. (1971). Time dependent deformations in a 70 story structure. In: DESIGNING for effects of creep, shrinkage, temperature in concrete structures. Detroit. p.159-185. (ACI SP-37)

CORLEY, W.G.; RUSSEL, H.G. (1978). Time-dependent behavior of columns in water tower place. In: DOUGLAS McHenry International Symposium on Concrete and Concrete Structures. Detroit. p.347-373. (ACI SP-55) 
DE LARRARD, F.; LE ROY, R. (1992). The influence of mix-composition on the mechanical properties of silica-fume high-performance concrete. In: INTERNATIONAL ACI-CANMET CONFERENCE ON FLY ASH, SILICA FUME, SLAG AND NATURAL POZZOLANS IN CONCRETE, $4^{\text {th }}$, Instambul.

DURNING, T.A.; REAR, K.B. (1993). Braker Lane Bridge: high strength concrete in prestresses bridge girders. PCI Journal, v. 38, n.3, p.46-51, May-June.

EL-ZANATY, A.H.; NILSON, A.H.; SLATE, F.O. (1986). Shear capacity of prestressed concrete beams using high-strength concrete. ACI Journal, v. 83, n.3, p.359-368, May-June.

EL-ZANATY, A.H.; NILSON, A.H.; SLATE, F.O. (1986). Shear capacity of reinforced concrete beams using high-strength concrete. ACI Journal, v. 83, n. 2, p.290-296, March-April.

EUROCODE 2 (1992). Design of concrete structures. Part 1: General rules and rules for buildings. Brussels, CEN.

FERNANDES, G. B. (1992). Cisalhamento de vigas de concreto de alta resistência. São Paulo. Tese (Doutorado) - Escola Politécnica, Universidade de São Paulo.

FIP-CEB WORKING GROUP (1990). High strength concrete: state of the art report. CEB Bulletin d'Information, n. 197, August.

FREEDMAN, S. (1970). High strength concrete. Modern Concrete, v.34, n.6, p.2936 ; n. 7 , p. $28-32$; n. 8 , p. $21-24$; n. 9 , p. $15-22$; n. 10 , p. $16-23$

FUSCO, P.B. (1981). Estruturas de concreto: solicitações normais. Rio de Janeiro, Guanabara 2. Cap. 1, p.7.

FUSCO, P.B. (1981). Estruturas de concreto: solicitações tangenciais. São Paulo, EPUSP.

GARCIA, D.T.; NILSON, A.H. (1990). A comparative study of eccentrically loaded high strength concrete columns. Ithaca, Department of Civil Engineering, Cornell University. 206p. (Research Report n. 90-2) 
GARDNER, N.J.; ZHAO, J.W. (1993). Creep and shrinkage revisited. ACI Materials Journal, v. 90, n. 3, p. 236-246, May-June.

GHOSH, S.K.; MORENO, J.; SHIN, SUNG-WOO. (1989). Flexural ductility of ultra high-strength concrete members. ACI Structural Journal, v. 86, n. 4, p.394-400, July-Aug.

GILBERT, R.I.; MICKLEBOROUGH, N.C. (1990). Design of Presstressed Concrete. Hampshire, Chapman \& Hall. 504p.

GOMIERO, P. F. (1994). Armadura reduzida para cisalhamento em vigas de concreto de alta resistência. Campinas. Dissertação (Mestrado) - Faculdade de Engenharia Civil, Universidade Estadual de Campinas.

GROB, J.; THÜRLIMANN, B. (1976). Ultimate strength and design of reinforced concrete beams under bending and shear. Zurich, IABSE. p.105-120. (Publication n. 36 - II)

HOVER, K.C.; NILSON, A.H; PAULSON, K.A. (1991). Long-term deflexion of high-strength concrete beams. ACI Structural Journal, v. 88, n. 2, p.197-206, March-April.

IBRAHIM, H.H.H.; MacGREGOR, J.G. (1997). Modification of the ACI rectangular stress block for high-strength concrete. ACI Structural Journal, v. 94, n. 1, p.40-48, January-February.

KAPLAN, M.F. (1959). Flexural and compressive strength of concrete as affected by the properties of the coarse aggregates. ACI Journal, v. 55, n. 11, p.1193-1208, May.

LEONHARDT, F.; WALTHER, R. (1961). The Stuttgart shear tests. London, Cement and Concrete Association (1964). Translation 111, 134 p.

LESLIE, K.E.; RAJAGOPALAN, K.S.; EVERHARD, N.J. (1976). Flexural behavior of high-strength concrete beams. ACI Journal, v. 73, n. 9, p.517-521, September.

LEVI, F.; MARRO, P. (1989). Shear tests up to failure of beams made with normal and high strength concrete. CEB Bulletin d'Information, n.193, p.13-23, December. 
LUEBKEMAN, C.L.; NILSON, A.H.; SLATE, F.O. (1985). Sustained load deflection of high-strength concrete beams. Ithaca, Department of Structural Engineering, Cornell University. 164p. (Report n. 85-2)

MacGREGOR, J.G. (1992). Reinforced concrete: mechanics and design. 2.ed. Englewood Cliffs, N.J., Prentice Hall.

MARTIN, L.D. (1977). A rational method for estimating camber and deflections. PCI Journal, v. 22, n. 1, p. 100-108, January-February.

MALIER, Y., ed. (1994). High performance concrete: from material to structure. London, E \& FN Spon.

MARIKUNTE, S.; SHAH, S.P.; WIEGRINK, K. (1996). Shrinkage cracking of highstrength concrete. ACI Structural Journal, v. 93, n. 5, p.409-415, SeptemberOctober.

McDONALD, D.B.; ROPER, H. (1993). Accuracy of prediction models for shrinkage of concrete. ACI Materials Journal, v. 90, n. 3, p. 265-271, May-June.

MENDIS, P.; PATNAIKUNI, I.; PENDYALA R. (1996). Full-range behavior of high-strength concrete flexural members: comparison of ductility parameters of high and normal strength concrete members. ACI Structural Journal, v.93, n.1, p.30-35, January-February.

MIRZA, W.H.; SAMMAN, T.A.; WAFA, F.F. (1996). Plastic shrinkage cracking of normal and high-strength concrete: a comparative study. ACI Structural Journal, v.93, n.1, p.36-40, January-February.

MÖRSCH, E. (1948). Teoria y práctica del hormigón armado. Barcelona, Gustavo Gili.

MPHONDE, A.G.; FRANTZ, G.C. (1985). Shear test of high and low strength concrete beams with stirrups. In: RUSSEL, H.G, ed. High-strength concrete. Detroit, ACI. p.179-96. (ACI SP-87)

NAAMAN, A.E. (1982). Prestressed Concrete Analysis and Design, vol.1. McGrawHill, Inc.. p. 251-252. 
NAGATAKY, S.; YONEKURA, A. (1978). Studies of the volume changes of high strength concrete with super-plasticizer. Journal of Japan Prestressed Concrete Engineering Association, Tokyo, v. 20, p. 26-33.

NAWY, E.G. (1995). Reinforced concrete: a fundamental approach. 3.ed. PrenticeHall. Chapter 5, p.93.

NGAB, A.S.; NILSON, A.H. ; SLATE, F.O. (1981). Shrinkage and creep of highstrength concrete. ACI Journal, v.78, n. 4, p.255-61, July-August.

NGAB, A.S.; NILSON, A.H.; SLATE, F.O. (1980). Behavior of high-strength concrete under sustained compressive stress. Ithaca, Department of Structural Engineering, Cornell University. 201p. (Research report n. 80-2)

NILSON, A.H. (1985). Design implications of current research on high strength concrete. In: RUSSEL, H.G. High-strength concrete. Detroit, ACI, p.85-118. (SP-87).

NILSON, A.H.; WINTER, G. (1991). Design of concrete structures. 11.ed. New York, McGraw-Hill, 904p.

NORWEGIAN COUNCIL FOR BUILDINGS STANDARDIZATION (1992). NS 3473 E - Concrete structures: design rules. 4.ed. Oslo, NSF.

PARROT, L.J. (1969). The properties of high-strength concrete. Wexham Springs, Cement and Concrete Association. 12p. (Technical Report n. 42.417)

PASTOR, J.A.; NILSON, A.H.; SLATE, F.P. (1984). Behavior of high-strength concrete beams. Ithaca, Department of Structural Engineering, Cornell University. (Research Report n. 84-3)

PAULSON, K.A.; NILSON, A.H.; HOVER, K.C. (1989). Immediate and long-term deflection of high-strength concrete beams. Ithaca, Department of Structural Engineering, Cornell University. 230p. (Research Report n. 89-3)

PAULSON, K.A.; NILSON, A.H.; HOVER, K.C. (1991). Long term deflection of high-strength concrete beams. ACI Materials Journal, v. 88, n. 2, p.197-206, Mar-Apr. 
PFEIL, W. (1984). Concreto protendido - vol. 3: Dimensionamento à flexão. Rio de Janeiro, LTC - Livros Técnicos e Científicos. Cap. 3, p.129.

PFEIL, W. (1988). Concreto protendido - vol. 1: Introdução. 2. ed. rev. Rio de Janeiro, LTC - Livros Técnicos e Científicos. Cap. 1, p.6.

PINTO JR., N.O. (1992). Flexão de vigas de concreto de alta resistência. São Paulo. Tese (Doutorado) - Escola Politécnia, Universidade de São Paulo.

ROLLER, J.J.; RUSSELL, H.G. (1990). Shear strength of high-strength concrete beams. ACI Structural Journal, v. 87, n. 2, p.191-198, Mar-Apr.

SANTOS, L.M. (1983). Cálculo de concreto armado segundo a nova NB-1 e o CEB. 2.ed. São Paulo, Ed. LMS. v.1, cap. E, p.192.

SHAH, S.P. (1994). High performance concretes and applications. London, Edward Arnold. Cap. 7, p.219.

SILVA, I.S.S. (1995). Concreto de alta resistência: composição, propriedades $e$ dimensionamento. São Carlos. Dissertação (Mestrado) - Escola de Engenharia de São Carlos, Universidade de São Paulo.

SWAMY, R.N.; ANAND, K.L. (1973) Shrinkage and creep of high strength concrete. Civil Engineering and Public Works Review, London, v.68, n.807, p.859-865, 867-868.

SWARTZ, S.E.; NIKAEEN, A.; NARAYAN BABU, H.D.; PERIYAKARUPPAN, N.; REFAI, T.M.E. (1985). Structural bending properties of high strength concrete. In: RUSSEL, H.G, ed. High-strength concrete. Detroit, ACI. p.147-178. (ACI SP-87)

TELLENBACH, A. (1985). Deformation à long terme des dalles em béton à l'etat fissuré. Lausanne. Tese (doutorado). n. 544. EPFL. 256p.

VASCONCELOS, A.C. (1980). Manual prático para a correta utilização dos aços no concreto protendido em obediência às normas atualizadas. Rio de Janeiro, Livros Técnicos e Científicos. 64p. 
ZHAO, J-W. (1991). Early-Age Mechanical Properties of Concrete. MASc thesis, Department of Civil Engineering, University of Ottawa. 